\title{
Climate change and tourism: Impacts and vulnerability in coastal Europe
}

Citation for published version (APA):

Moreno, A. (2010). Climate change and tourism: Impacts and vulnerability in coastal Europe. [Doctoral Thesis, Maastricht University]. Datawyse / Universitaire Pers Maastricht.

https://doi.org/10.26481/dis.20100319am

Document status and date:

Published: 01/01/2010

DOI:

10.26481/dis.20100319am

Document Version:

Publisher's PDF, also known as Version of record

\section{Please check the document version of this publication:}

- A submitted manuscript is the version of the article upon submission and before peer-review. There can be important differences between the submitted version and the official published version of record.

People interested in the research are advised to contact the author for the final version of the publication, or visit the DOI to the publisher's website.

- The final author version and the galley proof are versions of the publication after peer review.

- The final published version features the final layout of the paper including the volume, issue and page numbers.

Link to publication

\footnotetext{
General rights rights.

- You may freely distribute the URL identifying the publication in the public portal. please follow below link for the End User Agreement:

www.umlib.nl/taverne-license

Take down policy

If you believe that this document breaches copyright please contact us at:

repository@maastrichtuniversity.nl

providing details and we will investigate your claim.
}

Copyright and moral rights for the publications made accessible in the public portal are retained by the authors and/or other copyright owners and it is a condition of accessing publications that users recognise and abide by the legal requirements associated with these

- Users may download and print one copy of any publication from the public portal for the purpose of private study or research.

- You may not further distribute the material or use it for any profit-making activity or commercial gain

If the publication is distributed under the terms of Article $25 \mathrm{fa}$ of the Dutch Copyright Act, indicated by the "Taverne" license above, 


\section{Climate Change and Tourism}

Impacts and Vulnerability in Coastal Europe

Álvaro Moreno 
Cover picture: (CÁlvaro Moreno

(C) Copyright: Álvaro Moreno, Maastricht 2010

Datawyse | Universitaire Pers Maastricht

ISBN 978-90-5278-920-0 


\title{
Climate Change and Tourism
}

\author{
Impacts and Vulnerability in Coastal Europe
}

\begin{abstract}
DISSERTATION
to obtain the degree of Doctor at the Maastricht University, on the authority of the Rector Magnificus, Prof. dr. G.P.M.F. Mols, in accordance with the decision of the Board of Deans, to be defended in public on Friday March $19^{\text {th }} 2010$ at 12:00 hours
\end{abstract} by

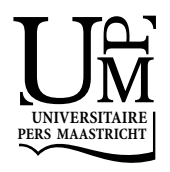




\section{Promotor}

Prof. dr. Pim Martens

\section{Copromotor}

Dr. Bas Amelung

\section{Assessment Committee}

Prof. dr. Jan Stel (chair)

Prof. dr. Jeroen van den Bergh, Universitat Autònoma de Barcelona

Prof. dr. Peter Burns, University of Brighton

Prof. dr. Marjan Peeters

This Ph.D. research was funded by the Vulnerability, Adaptation and Mitigation Programme (VAM) of the Nederlandse Organisatie voor Wetenschappelijk Onderzoek (Netherlands Organization for Scientific Research, NWO), grant number 454-04-005. 
Para mis padres 



\section{Table of Contents}

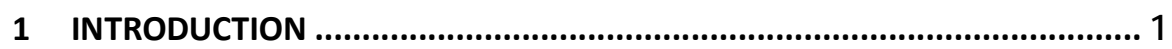

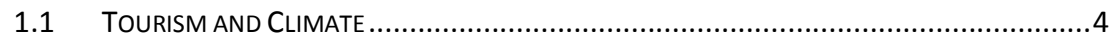

1.2 The Challenge of Climate Change for Tourism ................................................

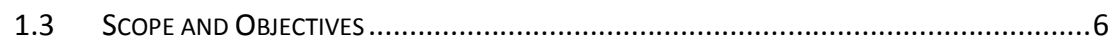

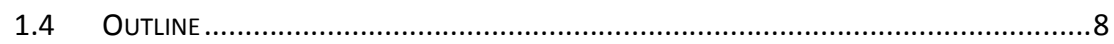

2 CONCEPTUAL AND METHODOLOGICAL FRAMEWORKS ........................ 11

2.1 THE TOURISM AND CLIMATE SYSTEMS: ISSUES OF COMPLEXITY AND THE ROLE OF

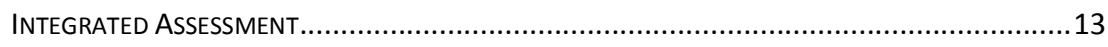

2.1.1 Complexity and the tourism and climate relationship .....................13

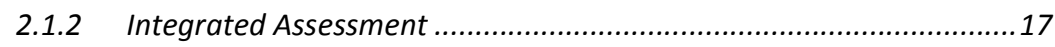

2.2 TheORETICAL FrameWork \& RESEARCH APPROACH ........................................ 18

3 THE ROLE OF TOURISM IN THE IPCC FOURTH ASSESSMENT REPORT:

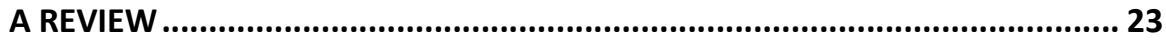

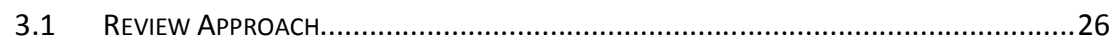

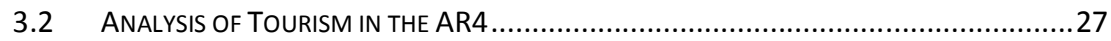

3.2.1 Implications of a changed climate and climate-induced

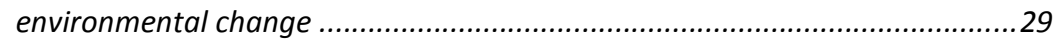

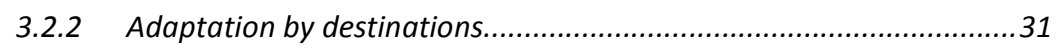

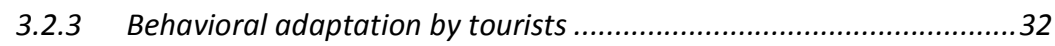

3.2.4 Climate change mitigation ...........................................................3

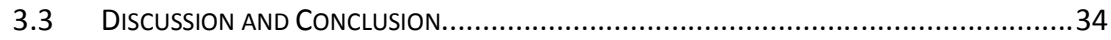

4 CLIMATE CHANGE AND COASTAL \& MARINE TOURISM: REVIEW

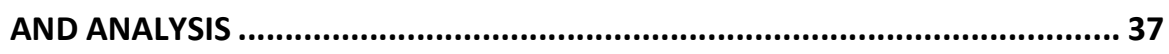

4.1 VARIETY AND IMPORTANCE OF COASTAL \& MARINE TOURISM ................................40

4.2 Climate Change Impacts on Coastal \& Marine EnVIRONMENTS .........................4

4.3 Climate Change And Coastal \& Marine Tourism ...........................................42 
4.3.1 Implications of climate change on coastal \& marine tourism .............42

4.3.2 Coastal \& marine tourism GHG emissions ......................................47

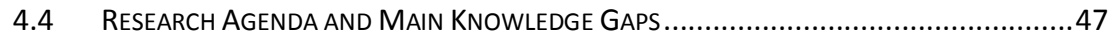

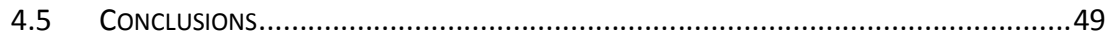

5 MEDITERRANEAN TOURISM AND CLIMATE (CHANGE): A SURVEY-

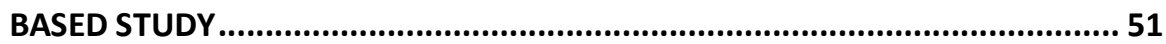

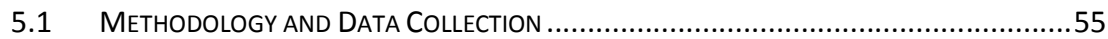

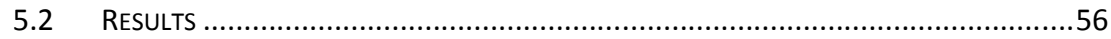

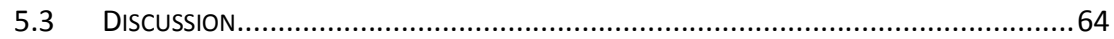

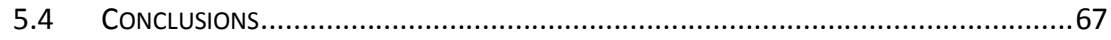

\section{LINKING BEACH RECREATION TO WEATHER CONDITIONS: TWO} CASE STUDIES FROM THE NETHERLANDS AND SPAIN ................................69

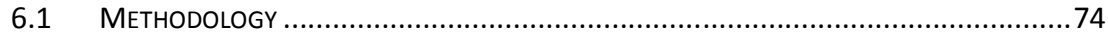

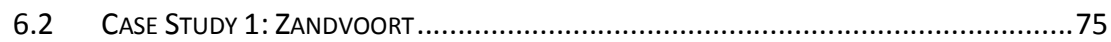

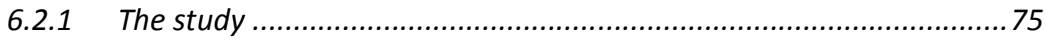

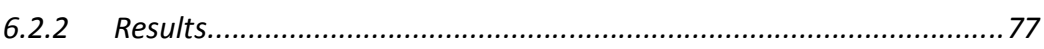

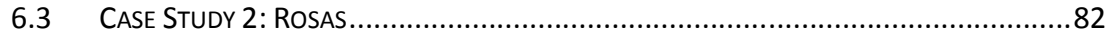

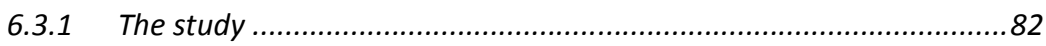

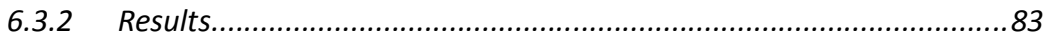

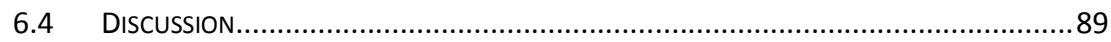

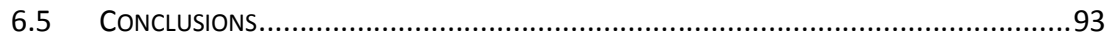

\section{CLIMATE CHANGE AND TOURIST COMFORT ON EUROPE'S BEACHES}

IN SUMMER: A REASSESSMENT ............................................................. 95

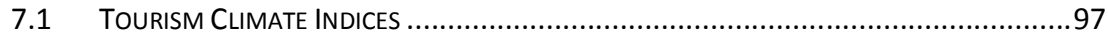

7.1.1 Beach tourism climate index..........................................................99

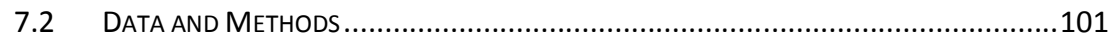

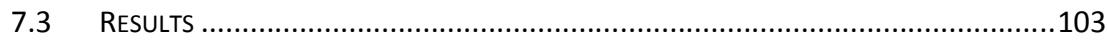

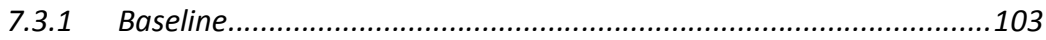


7.3.2 Projected change and future state ..............................................103

7.3.3 Agreement and disagreement between scenario results .................106

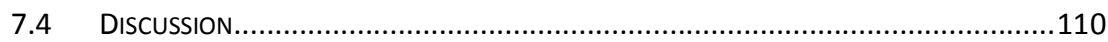

7.4.1 Implications for research and management................................110

7.4.2 Methodological limitations.......................................................111

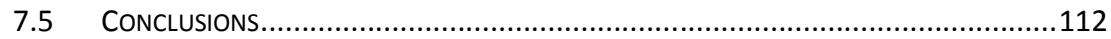

\section{A CLIMATE CHANGE VULNERABILITY ASSESSMENT METHODOLOGY} FOR COASTAL TOURISM.................................................................... 115

8.1 DeVEloping a Methodology for Tourism Vulnerability ASSESSMENTS ..............118

8.1.1 Background on vulnerability ....................................................118

8.1.2 A methodology for assessing tourism's vulnerability .....................120

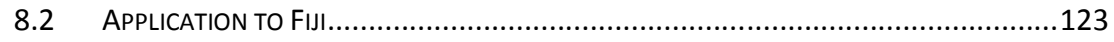

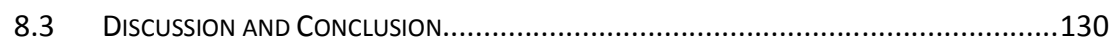

\section{IMPACT OF CLIMATE CHANGE ON ISLAND TOURISM - THE} BALEARIC ISLANDS: IMPACTS, VULNERABILITY AND CRITICAL

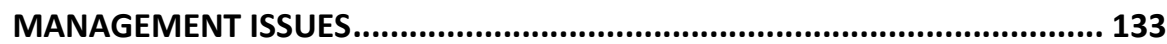

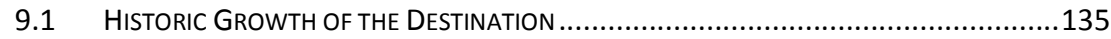

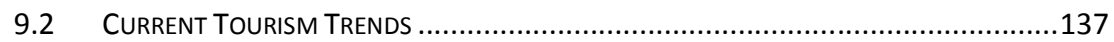

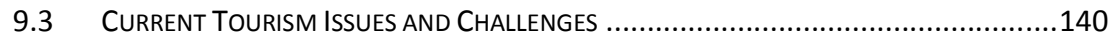

9.4 Existing and Perceived Climate Change Impacts ........................................142

9.5 AN INTRODUCtion to THE VULNERABILITY OF THE BALEARIC TOURISM SECTOR TO

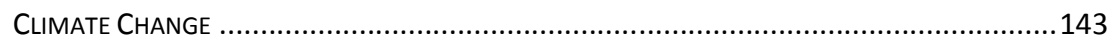

9.6 OVerview of Current Management And Policy Strategies.............................146

9.7 SUMMARY AND CONCLUSION OF CRITICAL ISSUES ..........................................149

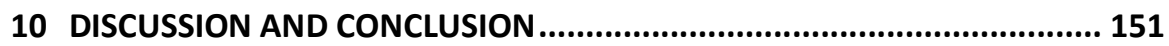

10.1 Climate Change \& Tourism: KNOWLedge AND IMPlications for CoAStal \&

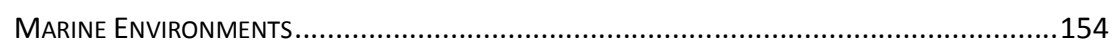

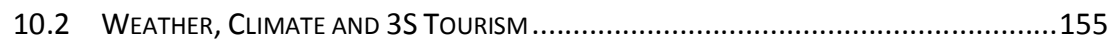




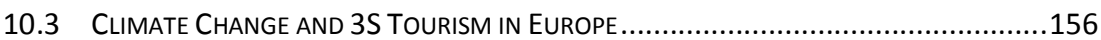

10.4 TOURISM VUlNERABILITY to CLIMATE ChangE: A FrameWork ............................158

10.5 Climate ChANGe AND COASTAL \& MARINE TOURISM: GUIDELINES FOR FUtURE RESEARCH.

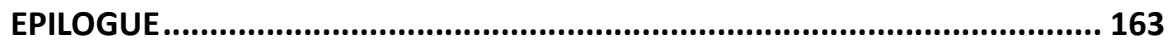

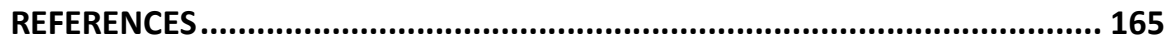

LIST OF ACRONYMS AND ABBREVIATIONS......................................... 181

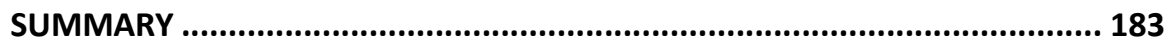

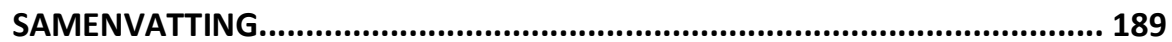

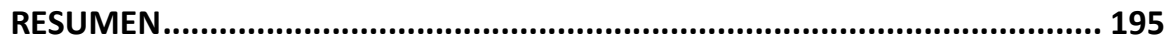

ACKNOWLEDGEMENTS / AGRADECIMIENTOS ......................................... 201

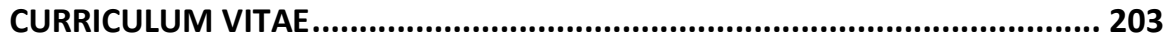

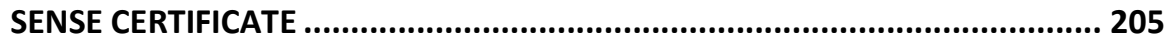


Chapter 1

\section{INTRODUCTION}





\section{INTRODUCTION}

Traveling for tourism and recreation is not a new phenomenon. From ancient Greece to the European Grand Tour in the $20^{\text {th }}$ century and the development of the first coastal resorts in Europe and America, people have been traveling for recreation, culture, religion or health. These first phases of the tourism sector were, however, very limited in scale and distribution, and only accessible to a limited number of aristocrats. The current magnitude and expansion of tourism as a global activity is relatively recent. Since the 1950 s tourism has experienced a tremendous growth, driven by socioeconomic changes such as the increase in free time and wealth, as well as by other factors such as improved and more accessible means of transport.

Tourism is now one of the largest economic sectors worldwide. The 922 million tourists registered in 2008 generated 642 billion $€$ (or US\$ 944 billion) in tourism receipts. If international passenger transport (i.e. visitor exports) is included, then this number reaches US\$ 1.1 trillion, or over US\$ 3 billion a day (UNWTO, 2009). According to the projections of the United Nations World Tourism Organization, the number of international arrivals is expected to reach 1.6 billion by 2020 (UNWTO, 2001). In other words, assuming international tourism only started in the 1950s, projections of future growth in the sector suggest that international tourism will experience the same growth in tourist arrivals in 15 years as it had during the last 55 years (the 800 million benchmark was reached in 2005) ${ }^{1}$.

International tourist flows are unevenly distributed between the different world regions. Europe is currently the world's leading destination, with a total of 487.9 million international arrivals (a market share of 53\%) in 2008. The popularity of the Mediterranean is a predominant factor in Europe's leading position. Accounting for 179 million international arrivals in 2008, it is the single most important regional destination in the world, outnumbering entire world regions such as the Americas (UNWTO, 2009).

Most of the international arrivals in the Mediterranean originate from Europe itself, in particular from northern Europe. Although recently there has been a diversification in the spaces developed for tourism, coastal zones still play a crucial role as tourism destinations. The European Union estimates that about $60 \%$ of trips within Europe with at least four overnight stays take place at the seaside; closeness to the sea

\footnotetext{
${ }^{1}$ For this thesis, the UNWTO definition of 'tourism' will be used: "tourism is defined as the activities of persons travelling to and staying in places outside their usual environment for not more than one consecutive year for leisure, business and other purposes not related to the exercise of an activity remunerated from within the place visited. The use of this broad concept makes it possible to identify tourism between countries as well as tourism within a country. 'Tourism' refers to all activities of visitors, including both 'tourists (overnight visitors)' and 'same-day visitors'".
} 
remains as a major selection criteria despite the common opinion of a growing importance of cultural and nature-based tourism (Leidner, 2004). Multiple elements can explain the North to South flow of tourists that characterizes the European tourism industry, including the accessibility, infrastructures, availability of attractions and the cultural and historical assets in the southern countries. The number one factor, however, for choosing a southern European holiday destination is the search for warm weather and sunshine by the seaside (Bramwell, 2004; Leidner, 2004; Mather et al., 2005).

\subsection{Tourism and Climate}

Weather and climate ${ }^{2}$ are very important for tourism and outdoor activities, and the interrelation is especially significant for coastal recreation. Climate influences the temporal distribution of tourists through the year, and determines the environmental context (e.g. flora, fauna, resources such as rivers or glaciers, etc.) in which tourism activities develop. In many cases this environmental context is the tourist attraction itself, e.g. coastal glaciers such as the Ilulissat Icefjord in Greenland (UNESCO, 2007). For some destinations, certain climatic characteristics are marketed as an attraction on its own and they are the main reason for the tourists to travel to the regions. This is the case for example of Tarifa (south coast of Spain), a destination that specializes in the windsurf tourism segment due to the year-around strong winds (Gómez Martín, 2005). At the destinations, weather has an effect on the timing of certain activities and it influences participation rates as for many activities a minimum value for certain weather parameters is required (e.g. warm and sunny weather for swimming and sunbathing). Personal safety and comfort are also affected by weather, for example in the case of extreme events such as hurricanes, flash-floods or heat waves. In this sense, and with few exceptions, regions where climatic disasters are frequent are in general incompatible with mainstream tourism. Visitors satisfaction is also influenced by experienced versus expected weather conditions. As a consequence of this interdependency between weather and recreation, the profitability of climate-dependent segments of the tourism sector -such as coastal and marine recreation- is also at risk (Gómez Martín, 2005).

Scholarly interest in the relationship between weather and climate on the one hand and recreation and tourism on the other started around the 1950s (see Scott et al., 2006 for a review). Until relatively recently, however, the relationship between

\footnotetext{
${ }^{2}$ Weather can be defined as the state of the atmosphere (temperature, humidity, etc.) at a specific moment. Climate makes reference to the averaged prevailing weather conditions that characterize a specific location or region.
} 
climate and tourism was not a major area for research. Climate was considered a more or less stable property of destinations (Abegg et al., 1997), which could not account for any long-term trends in tourism demand. This position is gradually being abandoned because of the increasing evidence that the global climate is changing.

\subsection{The Challenge of Climate Change for Tourism}

The recognition of the role that climate and weather play in tourism and recreation acquired a new dimension over the last few years with the identification of climate change as a powerful factor shaping tourism activities (Matzarakis et al., 2004; UNWTO et al., 2008). According to the Intergovernmental Panel on Climate Change (IPCC, 2007d), the global mean temperature is likely to increase by 1.1 to 6.4 degrees Celsius (best estimate: between 1.8 and 4 degrees) over the course of this century. Global average sea level is projected to rise by 18 to $59 \mathrm{~cm}$ or more in the same period.

These projections have led to a renewed interest in the relationship between the weather and tourism, and the impacts that a changing climate could have on the tourism sector (see UNWTO et al., 2008 for an overview). In recent years, a range of impact assessments have been produced. Some of these studies are global in nature (Agnew \& Viner, 2001; Amelung et al., 2007; Hamilton et al., 2005), whereas others focus on specific countries of origin (Hamilton, 2003; Maddison, 2001), or destination types, such as ski areas (Elsasser \& Bürki, 2002; Scott et al., 2003; Scott et al., 2001), parks (Jones \& Scott, 2006a; Jones \& Scott, 2006b), and coastal zones (Amelung \& Viner, 2006; Perry, 2005, 2006).

Reflecting this increasing interest and acknowledging the potential magnitude of the impacts climate change would pose on tourism, the United Nations World Tourism Organization (UNWTO), jointly with the United Nations Environment Programme (UNEP) and the World Meteorological Organization (WMO) convened in 2007 the Second International Conference on Climate Change and Tourism, in Davos (Switzerland). More than 450 participants from over 80 countries participated in this event that gathered together scientists, business managers, tourism planners, NGOs and international organizations from around the world. One of the most significant outcomes of the Davos meeting was the publication of the report "Climate change and tourism Responding to global challenges" (UNWTO et al., 2008). The report extensively analyzes the relationship between climate change and tourism, identifying the main impacts in regions and activities and issues of adaptation and mitigation. The report identified as the main impacts on destinations: (i) direct effects through changes in precipitation patterns, extreme events and increasing temperatures, (ii) indirect consequences due to the environmental change originated by climate change such as loss of biodiversity, reduced landscape aesthetic and sea-level rise, (iii) repercussion of miti- 
gation policies with negative impacts on tourism mobility and (iv) indirect societal effects on the economy and political stability of some nations.

Another outcome of the meeting in Davos was the 'Davos declaration' which states:

climate is a key resource for tourism and the sector is highly sensitive to the impacts of climate change and global warming, many elements of which are already being felt. It is estimated to contribute some $5 \%$ of global $\mathrm{CO}_{2}$ emissions.

This statement has two important implications. First, the allusion to impacts that are already being felt emphasizes the need for actions to be taken. This is relevant as there are some indications that certain stakeholders may be overestimating their capacity to adapt to the changes brought about by climate change (Simpson et al., 2008). The second relevant component is that it reflects the other side of the coin that characterizes the pervasive relationship between climate change and tourism: the recognition that tourism not only is impacted by climate change, but at the same time is a powerful driving force of it. The Davos Declaration also appealed to the research community for 'targeted, multi-disciplinary research on impacts of climate change in order to address regional gaps in current knowledge' and 'develop tools for risk assessment' (UNWTO et al., 2008).

\subsection{Scope and Objectives}

Despite the increasing attention for the tourism and climate change relationship since the 1990s, the field is still relatively unexplored. In fact, it has been noted that tourism is lagging a decade behind other sectors with regard to impact assessments and more significantly adaptation and mitigation (Ceron \& Scott, 2007). The important role of human behavior and preferences make tourism a complex research field as compared to other, more physical, studies such as agriculture. Although the tourism sector is showing an increasing interest in climate change and is likely to be prepared now to incorporate climate change considerations into its operations, basic information about the influence that weather conditions have on key tourism stakeholders -from tourists to governments- is still missing. Therefore, consistent, structured and integrated approaches to assess the vulnerability to climate change of tourism and its key stakeholders lack a solid ground.

All tourism activities are to a certain extent influenced by weather conditions, but outdoor recreation in coastal environments is probably among the most weather sen- 
sitive ones. Coastal areas seem particularly vulnerable to climate change impacts as they are exposed to both extreme climate events and sea-level rise (IPCC, 2007a). This vulnerability is exacerbated by the accumulation of multiple stressors and increasing manmade pressures such as rising population and development (Nicholls et al., 2007).

The high vulnerability of coastal zones means that all sectors based in these areas are also likely to be affected by climate change. This is even more the case for those sectors that depend on weather for their existence, such as the European coastal tourism segment. As a matter of fact, the UNWTO (UNWTO et al., 2008) identified coastal zones among the most vulnerable tourist destinations and the Mediterranean coast as one of the main vulnerability hotspots. Several reasons contribute to this high vulnerability. European coastal zones are highly sensitive and exposed to climate change and will, therefore, be significantly impacted by it. Socially, European coasts are key settings for recreation and tourism and are likely to retain this role in the future, especially in relation to sun, sea and sand tourism ( 35 tourism, i.e. light activities such as sunbathing). Finally, from a political and economic point of view, tourism in coastal areas is an important source of employment and regional development; many European governments are still using tourism as a tool for economic dynamization. Due to the high sensitivity of coastal and marine recreation to weather conditions, the high level of exposure of coastal regions to climate change and the limited capacity to adapt of many tourism coastal destinations, climate change has the potential to jeopardize the economic, social and environmental sustainability of many destinations across Europe. For these reasons, vulnerability assessments to climate change have become a vital research field and a major political and social need ${ }^{3}$.

Based on this, the central question this thesis aims to answer is:

In what different ways might climate change affect Europe's tourism in coastal \& marine environments and how can we assess the vulnerability of the sector?

This question is split up into the next sub-questions:

1. What is the state-of-the-art knowledge on climate (change) and tourism, and what are the main knowledge gaps in relation to coastal and marine recreation?

2. What are the weather determinants of sun, sea and sand tourism (3S tourism)?

\footnotetext{
${ }^{3}$ This political, social and scientific need is reflected with the creation by the Nederlandse Organisatie voor Wetenschappelijk Onderzoek (Netherlands Organisation for Scientific Research - NWO) of the Vulnerability, Adaptation and Mitigation (VAM) programme to which this research belongs.
} 
3. What consequences will climate change have for the destinations' climate suitability for 35 tourism?

4. How can the vulnerability of destinations be assessed?

In the context of this thesis the terms 'tourism', 'recreation' and 'activities' have been used interchangeably. Any reference to 'coastal and marine' tourism refers to all activities that take place in a coastal or marine setting, from sunbathing to diving (see Chapter 4 for an analysis of this issue). Finally, 'sun, sea and sand' recreation, also designated as ' $3 S^{\prime}$ ' tourism, has been used interchangeably with the term 'beach' recreation to designate light activities commonly associated with sunbathing by the seashore (therefore implying a high direct exposure of the body to the weather elements).

\subsection{Outline}

The concept of vulnerability is at the core of this thesis. A deep understanding of the tourism system and its relationship with weather and climate is necessary before a methodology to address the vulnerability can be presented. Figure 1.1 represents a simplified conceptual map created in this project to characterize the tourism-climate change relationship and guide the input from the different chapters to answer the central research question presented in the previous section.

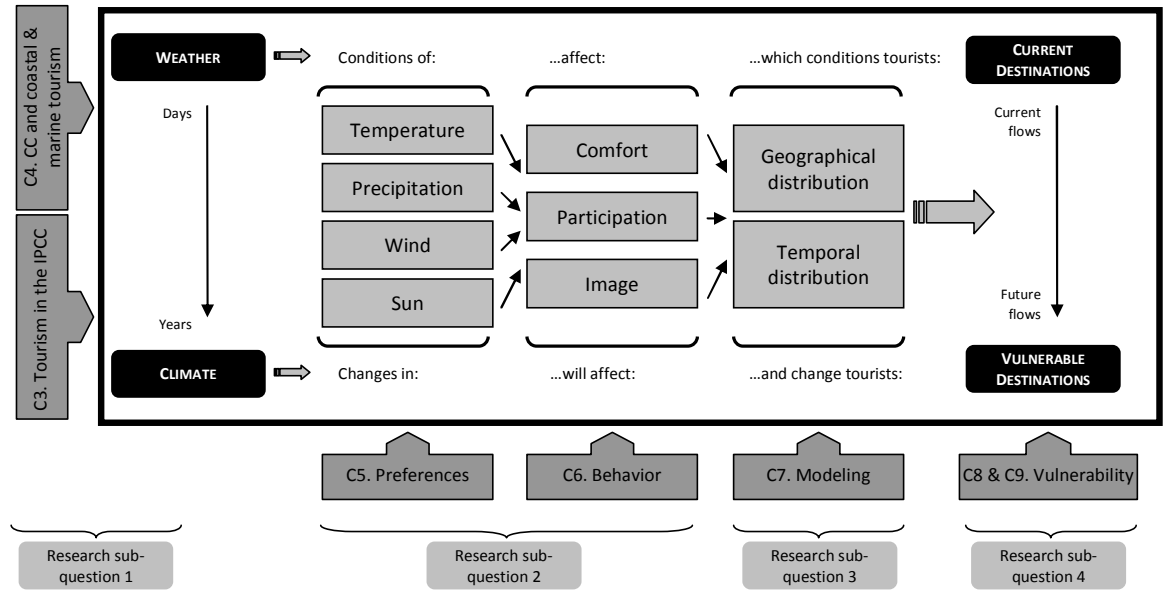

Figure 1.1 Concept map guiding the elaboration of Chapters 3 to 9

Chapter 2 outlines the issue of complexity in relation to the tourism and climate change relationship and how Integrated Assessment, the overarching research phi- 
losophy used in this thesis, has been utilized to frame the conceptual approach and methodologies of the remaining chapters. The subsequent two chapters are based on literature review and provide the background information on tourism and climate change. Chapter 3 reports on the way tourism has been incorporated into the Fourth Assessment Report (AR4) of the Intergovernmental Panel on Climate Change (IPCC). Published in 2007, the report represents the current state of knowledge about the causes and impacts of climate change as well as possible options for adaptation and mitigation. The chapter analyses the evolution of the attention for tourism by the IPCC and points out the issues that demand further attention in the coming years. While this chapter provides information about all major areas of climate change and tourism (impacts on different environments, adaptation, emissions and mitigation), Chapter 4 focuses on coastal and marine recreation. The chapter analyzes the importance of coastal and marine environments for recreation and the relationship of these activities with weather. Current knowledge on the impacts of climate change is also presented, as well as the role of coastal and marine tourism as a source of GHG emissions. The aim of the chapter is to provide an updated knowledge base for understanding climate change relationship with tourism in coastal and marine environments. A number of knowledge gaps are also identified and discussed in this chapter.

Once the scientific background has been presented, Chapters 5, 6 and 7 focus on issues related to $3 \mathrm{~S}$ recreation, presumably the most important form of coastal recreation in Europe. Beach tourism is arguably the most weather-sensitive form of coastal tourism, although the exact way in which it is influenced by weather parameters is not fully understood. Chapter 5 explores the views of tourists on the roles of weather and climate change in the context of their beach holidays. The chapter provides insight into (i) the role of climate in destination choice, (ii) the factors that constitute favorable and unfavorable weather conditions for beach recreation, (iii) the relative importance of a range of potential climate change impacts and (iv) the expected implications of climate change for destination choice. Weather attributes such as temperature, precipitation and wind are key determinants of people's involvement in beach activities. Chapter 6 investigates beach users' participation in 35 recreation in relation to these weather attributes. The information of these two chapters suggest that previous assessments about the tourism climatic suitability of Europe need to be fine-tuned and adapted if they are to reflect the specific weather requirements of beach recreation. Chapter 7 addresses this need and presents a reassessment of the impacts of climate change for European beach tourism during the summer season, looking exclusively at issues of climatic suitability and comfort. Different scenarios of climate change for the 2060s are compared to current conditions in order to assess the potential shifts across Europe and the management implications. 
A methodology for an integrated vulnerability assessment to climate change of coastal tourism destinations is proposed in Chapter 8. The framework, which relies heavily both on scientific information and on stakeholder input, aims at providing decision makers and other stakeholders with a tool to facilitate the systematic, structured and coherent evaluation of the vulnerability of their destination. The chapter includes an example of how the methodology might be applied to Fiji. A second case study is presented in Chapter 9, paying special attention to the past, present and future implications of some of the issues discussed throughout the thesis for the Balearic Islands (Spain).

Chapter 10 recapitulates the main conclusions of the thesis. An epilogue follows, offering some final remarks regarding the present and future of coastal tourism in an era of global climate change. 
Chapter 2

CONCEPTUAL AND

METHODOLOGICAL FRAMEWORKS 



\section{CONCEPTUAL AND METHODOLOGICAL FRAMEWORKS}

Tourism is a phenomenon in which different stakeholders -tourists, transnational tour operators, local populations at destinations- interact with each other and with their environment at different temporal and spatial scales, from local to global. Tourists, tourism providers, receiving communities and the environment are closely linked and dependent on each other in such a way that small changes in one of the components may have important consequences for the rest of elements. For example, the decision of a tour operator to include or exclude a particular destination into their portfolio operations will have important consequences for the economic, social and environmental situation of the destination region. Inter-dependencies make tourism operations difficult to predict, where fluxes of tourists are to a certain extent conditioned by the sector's operations and particularly influenced by social and environmental factors sometimes difficult to foresee. Weather and climate are an important element in the decision making process of tourists and in this aspect, they also play a role in the tourism system. The interdependency between the different tourism components and climate and the uncertainty that surround tourism operations support the idea that tourism should be treated as a complex system (Farrell \& Twining-Ward, 2004; Holden, 2000; McKercher, 1999). In contrast to traditional linear approaches, chaos-complexity theory provides an alternative framework to structure the analysis of the tourism and climate change relationship. This chapter explores the issue of complexity in the tourism-climate change relationship and the way in which Integrated Assessment (IA) provides the tools to study the linkages between both. The chapter concludes with the theoretical framework and research approach used in this thesis.

\subsection{The Tourism and Climate Systems: Issues of Complexity and the Role of Integrated Assessment}

\subsubsection{Complexity and the tourism and climate relationship}

All natural and social systems can be characterized as being complex and adaptive (Farrell \& Twining-Ward, 2004). In the case of the tourism system, it is complex because it is the outcome of an amalgam of components which are interlinked in a nonlinear and unpredictable manner. It is adaptive, because it has the chance of learning, evolving and adjusting itself to new conditions or market forces. This complexity and capacity to adapt has brought some authors to advocate that the tourism system is an 'ecosystem' (Farrell \& Twining-Ward, 2005). This recognition implies that tourism interacts with other natural and social systems at a larger scale than the destination where tourists spend their holidays. 
Tourism has been traditionally approached from individual disciplines; geography, economy and anthropology are fields that have focused on tourism issues in the past (Holden, 2000). Few scholars now question the need to approach tourism as a system. Thinking about tourism as a system provides a holistic view and a better understanding of the functioning of the sector as it moves from the traditional mono-disciplinary, reductionist approach towards a trans-disciplinary perspective. For example, according to Gössling \& Hall (2006) one of the weaknesses of tourism models in predicting travel flows is the unrealistic assumption of linearity of change in tourists' behavior. Chaoscomplexity theory provides an alternative approach to this deterministic view and this approach is gaining importance in tourism research. As compared with the Cartesian/Newtonian paradigm, chaos/complexity theory is based on biological models of living systems, which tend to be unstable. In these complex systems, non-linear relationships are more prevalent and externalities and individual differences are seen as the driving force for variety, adaptation and complexity (Russell \& Faulkner, 1999).

The other attribute that characterizes natural and social systems is the ability to learn and to adapt to shocks and changing situations. This means that the actors that make up the tourism system have the capacity to position themselves in a permanent creative process in which new connections and structures are created leading to a different complex order (Farrell \& Twining-Ward, 2004; McKercher, 1999; Russell \& Faulkner, 1999). Not all destinations have been able to take advantage of this capacity. Due to the 'lock-in effect' (i.e. the idea that certain historical events or initiatives taken by individual entrepreneurs can initiate a strong network of mutually reinforcing relationships that continue long after the initiating event has been outdated by new developments (Russell \& Faulkner, 1999)), many traditional destinations for example across the Mediterranean have built a standardized tourism product based on sun, sea and sand which limited diversity and therefore increased their vulnerability to changes in the market or other external conditions. As in the case of monoculture (i.e. the agricultural practice of growing a single crop over a large area), these destinations have based their survival on a single product and have managed their destination to reach and maintain an idealized state of growth. Some of these destinations have witnessed in the last few years a stagnation or reduction in the numbers of tourists, which has forced them to rethink their management and future development. Many other destinations have faced this same need to recover, usually as a response to crises or shocks. In both cases, managerial intervention has typically been reactive and has attempted to recover the previous state, instead of trying to anticipate potential changes and build a stronger, more resilient, tourism industry. Nevertheless, a tourism industry that anticipates potential changes is more likely to be less affected by these changes (less vulnerable), has more possibilities to recover from external and internal shocks (more resilient) and has more possibilities to take advantage of the new conditions. Destinations that explore the future and do 'management of resilience rather than equilib- 
rium' (Farrell \& Twining-Ward, 2005, p. 115) are more likely to be successful in the era of rapid change in which we are at the moment.

Climate -a complex system itself (Rind, 1999)- is closely interrelated with the tourism system. Figure 2.1 depicts a schematic representation of the interactions between these two systems, the connections between the sub-systems that compose them, and the influences of other external systems which affect them. The tourism system influences the climate system mainly by the emission of greenhouse gases, both directly as a consequence of for example transport and indirectly through electricity uses ${ }^{1}$. Elements in the tourism system that can affect the climate system include changes in tourists' demand for certain activities or destinations: for example, more or less demand for holidays using planes as the means of transport significantly affect the carbon footprint of tourism. Changes in the offer can also have an impact on the climate system as destinations might choose to promote activities with greater or lesser energy use than others. Finally, providers such as tour operators can influence demand, promoting short or long-haul destinations, whereas transport providers can invest in energy efficiency to reduce emissions related with the movement of tourists. The climate system also influences the tourism system as it is a key attribute of many destinations, affecting attractiveness in many cases and the seasonal distribution of arrivals (e.g. the tourism low season in Seville -Andalucia, south Spain- coincides with the hottest months of the year). The climate system determines the offer as certain activities can only be performed if certain weather conditions are met (e.g. availability of snow for skiing). Finally, tourism providers are influenced as they will promote one or another destination based on its attributes, including its climate. To this, already complex relationship, it is necessary to add other elements that influence both the tourism and the climate system, such as policies directly or indirectly influencing tourism (e.g. increased taxation of flights), changes in popularity and the effect of media.

\footnotetext{
${ }^{1}$ Tourism can also affect the climate system by other means, such as land-use change, deforestation or habitat preservation. In this discussion the effects of tourism on climate are analyzed in relation to the emission of greenhouse gases, which have a direct effect on climate change.
} 


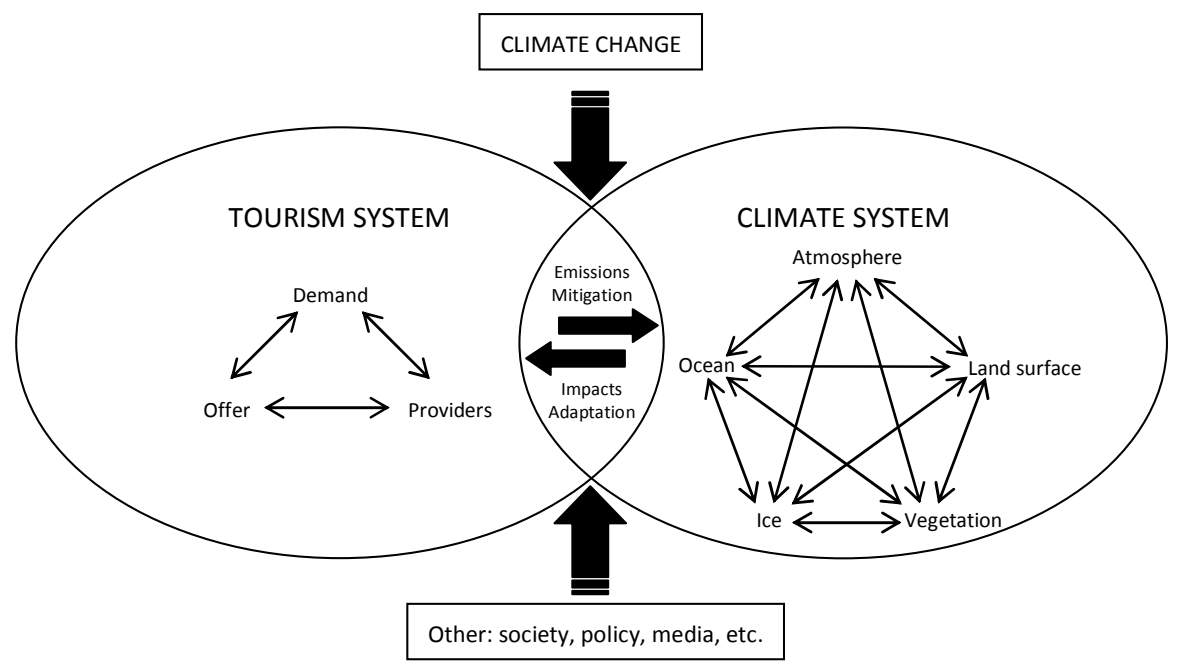

Figure 2.1 A system approach to the tourism-climate relationship

Changes in the climate system will therefore be a new and important element shaping tourism. Using chaos-complexity theory to analyze climate change impacts on coastal destinations has two important implications. First, climate change has the potential to significantly disrupt coastal tourism destinations. Due to the 'butterfly effect', small changes in the climate system might significantly affect the tourism system, both through direct impacts on the physical resources (e.g. disappearing beaches due to sea level rise) and indirect consequences such as problems with water availability. Second, the scale of tourism in many coastal destinations is so great (e.g. mass tourism destinations in the Mediterranean) that, due to the 'lock-in effect', the size of the industry may remain as under current circumstances even when climate change impacts become apparent (on a report about the attitudes of Europeans towards tourism it was shown that as much as $54 \%$ of Europeans prefer to spend their holidays in conventional, well-known tourist destinations, and indication of how important the lock-in effect might be in the future (EC, 2009)). Nevertheless, this possibility will be greatly conditioned by the magnitude of the climate change impacts and the development of other political, social, economic and environmental issues; complexity and uncertainty are at the core of the climate change and tourism relationship.

The recognition of the complex relationship between tourism and climate change demands the use of new approaches towards its analysis. Complexity theory helps understanding this relationship as the result of multiple elements interacting at different spatial and temporal scales. Analyzing the impacts of climate change on tourism 
requires the use of methodologies to deal with this complexity and uncertainty: Integrated Assessment provides the tools to address this need.

\subsubsection{Integrated Assessment}

The relationship between tourism and climate (change) is both complex and surrounded by uncertainties (in e.g. the development of tourism supply, demand and providers; external factors such as economic conditions and political stability; and the climate system, etc.). Whereas traditional reductionists approaches might be able to provide information about some of the connections between components, new approaches are needed that address issues of complexity. Integrated Assessment (IA) offers a holistic methodology to frame and analyze complex problems. The recognition by society of the interconnectedness and increasingly complex nature of the humanclimate linkages has extended the use of the method in the field of climate change (Dowlatabadi \& Morgan, 1993; Morgan \& Dowlatabadi, 1996; Weyant et al., 1995).

The Integrated Assessment Society (TIAS) defines IA as "the scientific "metadiscipline" that integrates knowledge about a problem domain and makes it available for societal learning and decision making processes" (TIAS, 2009). Although several authors have defined the field of IA in slightly different terms, there are a number of features that characterize the methodology and differentiate it from other approaches (Gough et al., 1998; Jakeman \& Letcher, 2003). First of all, the nature of the problems analyzed by IA requires inter- and trans-disciplinary approaches to be used. The intertwined character of current human and environmental problems necessitates the joint contribution of several disciplines including economics, sociology, ecology and physics. This integration of knowledge sources and disciplines goes hand in hand with an integration of actors that bring with them different perspectives on a particular issue. The integration of different perceptions and social actors has the added advantage of increasing the credibility and legitimacy of the policies emerging form the process. In this sense, IA aims at supporting decision and policy-making and building societal learning.

The attempt to address problems deriving from the interaction between complex systems makes uncertainty one of the biggest challenges of IA. However, the presence of uncertainty is not necessarily a drawback as it allows for inclusion of different views on the functioning of the complex systems under assessment while still providing policy-relevant answers and improving societal learning; uncertainty legitimizes different perspectives and therefore plays an important role in IA (Gough et al., 1998).

The methods and tools that are used in IA are commonly grouped into analytical and participatory methods. The set of analytical methods has its origin in the natural science and includes model-analysis, scenario analysis and risk analysis. The participatory tools available to IA are less well defined and are rooted in the social sciences. 
They include a variety of methods that share the aim of involving non-scientists in the process (for a detailed discussion on IA methods see Harris, 2002; Rotmans, 1998; van Asselt \& Rijkens-Klomp, 2002).

The aim of this research is to analyze the connections between climate change and tourism -including relevant social and natural developments that may influence this relationship- and assess the possible impacts. IA provides the tools to analyze this complex problem; "its strength and potential lie in making the intertwined relation between social and natural systems explicit and adopting a flexible attitude to the interaction with these complex systems" (Gough et al., 1998, p. 21). In this thesis, the principles of IA have been incorporated by combining knowledge from different disciplines and research methods ranging from social to natural sciences. The way this has been done is presented in the next section.

\subsection{Theoretical Framework \& Research Approach}

It is widely recognized that the relationship between climate change and tourism is bidirectional and occurs at different spatiotemporal scales. Since the 1990s this relationship has received increasing attention although the complexity of the system, with its multiple interactions at different levels both with other societal developments and with the environment, has made it a difficult sector to analyze (Higham \& Hall, 2005). In order to address the holistic, trans-disciplinary aspects of the climate-tourism relationship, it is first necessary to acquire disciplinary, in-depth knowledge on specific issues of this relationship.

Previous assessments of the impacts of climate change on tourism have primarily focused on two distinctive methodological approaches. A number of studies is available that have attempted to incorporate climate into tourism demand models to study the effects of climate change (Hamilton, 2003; Lise \& Tol, 2002; Maddison, 2001). The limited implementation of climate (only temperature) and the temporal and spatial resolution (years and countries respectively) constitute the main drawbacks of these approaches, as they are very coarse given tourism's marked seasonality and spatial concentration.

Another strand of climate change research (Amelung et al., 2007; Amelung \& Viner, 2006; Scott et al., 2004) uses more elaborate tourism climate indices. These climate indices, which usually incorporate several weather parameters such as temperature, precipitation and wind, attempt to reflect destinations' climate suitability for tourism, using greater temporal and spatial detail. The main disadvantages of these approaches are the limited empirical validation against actual tourist behavior and their limited application to other forms of tourism besides sightseeing. This thesis aims to fill the 
gap between these two methodological approaches, by linking an elaborate representation of climate (latter approach) to observed tourist behavior (former approach). The research methods and scales used for the elaboration of this thesis are summarized in Table 2.1.

Table 2.1 Methods, data sources, types of tourism and spatial and temporal scales used in this thesis

\begin{tabular}{|c|c|c|c|c|c|}
\hline Chapter & Method & $\begin{array}{c}\text { Source of } \\
\text { data }\end{array}$ & $\begin{array}{l}\text { Type of } \\
\text { tourism }\end{array}$ & Spatial scale & Temporal scale \\
\hline 3 & $\begin{array}{l}\text { Literature } \\
\text { review }\end{array}$ & IPCC 4AR & General & Global & $\begin{array}{l}\text { Past, present and } \\
\text { future }\end{array}$ \\
\hline 4 & $\begin{array}{l}\text { Literature } \\
\text { review }\end{array}$ & $\begin{array}{l}\text { Scientific } \\
\text { literature }\end{array}$ & $\begin{array}{l}\text { Coastal \& } \\
\text { Marine }\end{array}$ & Global & $\begin{array}{l}\text { Past, present and } \\
\text { future }\end{array}$ \\
\hline 5 & $\begin{array}{l}\text { Questionnaire } \\
\text { surveys }\end{array}$ & Tourists & $3 S$ & $\begin{array}{l}\text { Respondents origin: } \\
\text { Belgium and Nether- } \\
\text { lands; Destination: } \\
\text { multiple beach } \\
\text { destinations }\end{array}$ & $\begin{array}{l}\text { Current prefer- } \\
\text { ences and explo- } \\
\text { ration of future } \\
\text { behavior }\end{array}$ \\
\hline 6 & Observation & Beach users & $3 S$ & $\begin{array}{l}\text { Local ( } 2 \text { destina- } \\
\text { tions: one in Nether- } \\
\text { lands and one in } \\
\text { Spain) }\end{array}$ & Present behavior \\
\hline 7 & $\begin{array}{l}\text { Modeling and } \\
\text { scenario } \\
\text { analysis }\end{array}$ & $\begin{array}{l}\text { Morgan et } \\
\text { al. (2000) } \\
\text { and climate } \\
\text { data }\end{array}$ & 35 & $\begin{array}{l}\text { All European coasts } \\
\text { (except for some } \\
\text { island territories) }\end{array}$ & $\begin{array}{l}\text { Comparison } \\
\text { present and 2060s } \\
\text { conditions }\end{array}$ \\
\hline 8 & $\begin{array}{l}\text { Framework } \\
\text { development }\end{array}$ & $\begin{array}{l}\text { Previous } \\
\text { chapters- } \\
\text { Vulnerabil- } \\
\text { ity litera- } \\
\text { ture }\end{array}$ & $\begin{array}{l}\text { Coastal \& } \\
\text { Marine- } \\
\text { General }\end{array}$ & General & Present and future \\
\hline 9 & Case study & Literature & $\begin{array}{l}\text { 3S-Coastal \& } \\
\text { Marine }\end{array}$ & Balearic Islands & $\begin{array}{l}\text { Present conditions } \\
\text { and future pros- } \\
\text { pects }\end{array}$ \\
\hline
\end{tabular}

The publication of the First Assessment Report by the IPCC in 1990 constituted a milestone and provided the basis for a systematic analysis of climate change impacts on different aspects of human activities, societies and natural environments. Since then, the research field of tourism and climate change has increased its presence in all types of publications, ranging from scientific journal to governmental documents and Non-Governmental Organization (NGO) reports. The first chapters in this thesis are therefore dedicated to providing an overview of current developments in the tourismclimate change field of study. The IPCC possesses a dominant role as the major institution in the science, impacts, adaptation and mitigation to climate change. For this, the 
IPCC Fourth Assessment Report (4AR) has been critically reviewed and analyzed to explore the way tourism has been incorporated both in terms of impacts and adaptation, and from an emission-mitigation point of view. This review is necessarily broad and provides the reader with an overview of the main impacts of climate change in different environments. Given the focus of this thesis on coastal and marine environments, a separate chapter is dedicated to an in-depth literature review on the existing knowledge about climate change impacts on coastal and marine recreation and the identification of the main knowledge gaps.

Different weather elements are relevant to tourists' perceptions of comfort. For beach tourism, temperature, precipitation, wind and sun (or presence of clouds) have been identified as the most important ones. The two methodological approaches available in the literature and described previously present several drawbacks in relation to the relevance of weather parameters for tourism. Whereas demand models (former approach) are based on the assumption that temperature is the most important component shaping tourist movements, methodologies based on climate indices (later approach) use a number of weather variables but assign rates and weights to each of them based on expert judgment. Despite these acknowledged limitations, the results of these studies constitute the foundation of our current knowledge of the impacts of climate change on Europe's tourism. Using quantitative techniques of data gathering, this thesis attempts to overcome some of these limitations in order to finetune the available impact assessments. Questionnaire surveys have been used to obtain data on tourists' perceptions about climate, and the importance assigned to the different weather parameters in reference to $3 \mathrm{~S}$ recreation. With this same technique, the validity of the major assumptions regarding the temporal and spatial shifts in tourist flows related to $3 \mathrm{~S}$ recreation in Europe is tested.

Different people experience the same weather in different ways. To associate ideal weather conditions with specific values of temperature, wind or precipitation is therefore a complex task. Moreover, there may be differences between stated and real behavior. Observational methods have been applied to obtain statistically relevant data about the observed behavior of beach users in relation to weather conditions at two different destinations: Zandvoort (The Netherlands) and Rosas (Spain). Over a period of 6 weeks, images reflecting beach densities were taken hourly and for every day, and then compared to the specific weather conditions from a nearby weather station to assess the relationship between atmospheric conditions and beach visitation.

The implications of these two approaches support the need of a reassessment of the potential impacts of climate change on European 35 tourism. The analyses previously described look into the influence of weather variables taken in isolation. The way humans experience weather is more complex; the way we perceive a specific value of 
temperature will depend on other factors such as the humidity or wind speed. Therefore, a composite index adjusted to $3 \mathrm{~S}$ tourism requirements is required for the reassessment of impacts. Based on the questionnaire information compiled by Morgan et al. (2000) about beach tourists' preferences for weather parameters, a model has been created and combined with high resolution gridded climate data, with each grid representing a surface of $16 \mathrm{~km} \times 16 \mathrm{~km}$ approximately (10'x10'). Geo-information systems have been used to generate graphical information and a new assessment of tourism climatic comfort adapted to 35 recreation both for the current, baseline conditions (1961-1990 or '1970s'), and for the conditions in 50 years (2051-2080 or '2060s') according to different models of climate change. The selected scenario is the SRES A1FI high emissions scenario (Nakicenovic et al., 2000). To account for the model uncertainty, two models have been used: one from the Met Office Hadley Centre for Climate Change (HadCM3 model) and one from the Commonwealth Scientific and Industrial Research Organisation (CSIRO).

Building on the overview of past and current developments in the climate change and tourism field and the reassessment of the potential impacts on climatic comfort for 35 tourism, a climate change vulnerability assessment methodology for coastal tourism is proposed. Deeply rooted in the ideas of complexity, trans-disciplinarity and integrated assessment, the methodology incorporates elements of scenario analysis, modeling and it has a very strong emphasis on participatory methods and stakeholder involvement. Two desktop case studies are presented in which the methodology is applied. Elaborated in the context of this research for coastal destinations, the framework is a tool that can be applied for the integrated assessment of vulnerability to climate change of any destination. The proposed methodology is intended to help destination managers and other stakeholders assess in a systematic and structured way the vulnerability of their destination to climate change, and to identify feasible adaptation options. 



\section{Chapter 3}

\section{THE PLACE OF TOURISM IN THE IPCC FOURTH ASSESSMENT REPORT: A REVIEW}

Based on:

- Amelung, B., Moreno, A., \& SCOtT, D. (2008). The place of tourism in the IPCC Fourth Assessment Report: A review. Tourism Review International, 12, 5-12. 



\section{THE ROLE OF TOURISM IN THE IPCC FOURTH ASSESSMENT REPORT: A REVIEW}

Climate change has the potential to alter the environment and our societies in a fundamental way, and on a global scale. This was already acknowledged by the United Nations Framework Convention on Climate Change (UNFCCC), produced in 1992 during the Earth Summit in Rio de Janeiro: "The ultimate objective of this Convention . . . is to achieve ... stabilization of greenhouse gas concentrations in the atmosphere at a level that would prevent dangerous anthropogenic interference with the climate system" (1992). The Intergovernmental Panel on Climate Change (IPCC) was established in 1988 by the United Nations Environmental Programme and the World Meteorological Organization to inform society and policy makers about the current state of knowledge about the causes and impacts of climate change as well as possible options for adaptation and mitigation. As part of its mandate, the IPCC periodically produces assessment reports that are based in the latest peer-reviewed scientific literature, undergo extensive expert and government reviewing, and involve thousands of scientists worldwide, making them very authoritative and a key reference for decision makers in the international community. The first of these reports appeared in 1990 and the fourth and last one to date was published in 2007.

Wall (1998) reported on the discussion of tourism in the IPCC Second Assessment Report (SAR) that was published in 1995. He noted that tourism was not even mentioned in the IPCC First Assessment Report (FAR) in 1990 and proceeded to concisely document the extent to which tourism was incorporated into the SAR. At that time, Wall concluded that, "while it is encouraging that tourism is receiving greater attention in IPCC reports, it is also apparent that the likely consequences of climate change for tourism and recreation are not well understood" (p. 68).

Much has changed in the interceding 12 years with regard to the scientific understanding of anthropogenic climate change and its potential implications for natural and human systems around the world. Even the vocabulary used to assess the potential implications of climate change has changed over this time frame, with adaptation and vulnerability now much more prominent terms than in the SAR. The purpose of this chapter is to identify the extent of progress in our understanding of the interactions of climate change and tourism by examining the place of tourism in the Fourth Assessment Report (AR4) published in 2007. The chapter briefly describes the AR4 process and the methodological approach used in this review. The subsequent section identifies the chapters of the AR4 documents where tourism is found and briefly summarizes the tourism-relevant discussion. Finally, the chapter also discusses well-known uncer- 
tainties that are acknowledged in the IPCC reports or the original scientific literature and key knowledge gaps ${ }^{1}$.

\subsection{Review Approach}

The Fourth Assessment Report in 2007 is the result of 6 years of work by more than 2,500 scientific expert contributors and reviewers. The AR4 is composed of four volumes: three working group reports and a synthesis report. The first volume "The Physical Science Basis" (IPCC, 2007d) by Working Group I discusses the science of climate change from its origins to the most recent knowledge on the global climate system and its interactions with other Earth systems. The second volume "Impacts, Adaptation and Vulnerability" (IPCC, 2007a) by Working Group II focuses on different ecosystems and regions, examining observed and potential ecological, economic, and social vulnerabilities. Volume three "Mitigation of Climate Change" (IPCC, 2007b) by Working Group III describes short-, medium-, and long-term mitigation options (both carbon sequestration and decarbonization of the global economy) in various economic sectors and geographic regions. It also presents cross-sectoral synergies and tradeoffs, macroeconomic effects, interactions between mitigation policies and sustainable development goals, and policy instruments to reduce greenhouse gas (GHG) emissions. The fourth report draws on the previous three to succinctly answer key policy-relevant scientific questions posed to the IPCC by the international community.

Although it has been attempted to make this analysis comparable with Wall's (1998) review, the methodological approach is slightly different out of necessity. Wall's discussion relied heavily on direct quotations and paraphrases of sections of the SAR. Because the volume of material related to tourism or recreation has increased substantially in the AR4, it has not been possible to follow this same approach. Instead an electronic word search was performed on the three AR4 volumes for the following terms: tourism, tourist, recreation, leisure, holiday, vacation, sports. The initial results were checked for unrelated or less relevant items (e.g., the casual mentioning of "tourism" in a long list of examples). In this review, the statements in AR4 are not substantiated or critically examined; for references to the original sources, the reader is referred to the full IPCC assessment reports. Chapter and section numbers from the AR4 reports are provided for easy navigation-except where specifically mentioned, all chapter or section references are to the report of Working Group II.

\footnotetext{
${ }^{1}$ Authorship teams in the IPCC assessments struggle with severe space limitations in their reports and often the limitations of individual studies are not adequately reflected in the IPCC reports as a result.
} 


\subsection{Analysis of Tourism in the AR4}

The word search revealed that tourism was discussed in two volumes of the AR4, that of Working Group II, which focuses on the impacts, adaptation and vulnerability of natural and human systems to climatic change (328 references), and, more briefly ( 8 references), in the volume of Working Group III, which focuses on the contribution of various economic sectors and geographic regions to anthropogenic climate change and possible mitigation strategies. Table 3.1 summarizes the specific chapters that tourism appeared in and the number of word search occurrences that were documented.

Table 3.1 Word search results by IPCC AR4 chapters

\section{Chapter}

Working Group II: Impacts, Adaptation and Vulnerability

1 Assessment of observed changes and responses in natural and managed systems

2 New assessment methods and the characterization of future conditions

3 Fresh water resources and their management

4 Ecosystems, their properties, goods and services

5 Food, fibre, and forest products

6 Coastal systems and low-lying areas

7 Industry, settlements and society

8 Human health

9 Africa

10 Asia

11 Australia and New Zealand

13 Latin America

14 North America

15 Polar regions (Arctic and Antarctic)

16 Small islands

17 Assessment of adaptation practices, options, constraints and capacity

18 Inter-relationships between adaptation and mitigation

19 Assessing key vulnerabilities and the risk from climate change

Working Group III: Mitigation of Climate Change 
Considerable diversity turns out to exist in how prominently tourism is treated in the various regional chapters, and important geographic gaps in the research literature are revealed. Chapter 16 on Small Islands pays much attention to tourism, both in terms of possible impacts and adaptation options, which is perhaps not a surprise given the importance of tourism for many of these islands. The sector is also treated in some detail in the Europe, North America, and Australia chapters, with references to multiple studies. Remarkably, the number of word occurrences in these chapters is not much higher than in the chapter on Africa. The critical message found there, however, is that while the impacts of climate change on tourism are anticipated to be very important, there are almost no tourism specific studies available on this continent. Tourism-specific studies are also absent from the Asia, Latin America, and the Polar Region chapters, and the gap in knowledge related to this economically important sector is not explicitly identified in these chapters. Tourism receives extensive treatment in Chapter 7 on Industry, Settlement and Society, is amply discussed in Chapter 6 on Coastal Systems, and is casually mentioned as a user of ecosystem amenities in Chapter 4 on Ecosystems. Mountain tourism features in Chapter 1 on observed biophysical and socioeconomic changes observed in the late $20^{\text {th }}$ century. Tourism is all but absent in some of the other chapters by Working Group II, where some discussion could be expected. This is particularly striking for the chapters on human health (e.g. effect of heat waves on tourism) and freshwater resources (e.g. competition for water between tourism and other sectors). The treatment of tourism is also very limited in the chapters on sustainability and on the interrelationships between adaptation and mitigation.

Tourism receives minimal attention in the report by Working Group III, where the word search yielded just 8 occurrences in 5 separate chapters. The prominence of tourism in overall transport emissions and the implications of mitigation for tourist mobility might have been expected to be acknowledged more explicitly.

The remainder of this chapter is structured around the four main areas of tourism discussion found within the AR4:

- Impact of a changed climate and future climate-induced environmental change on vulnerable regions.

- Adaptation by destinations.

- Behavioral adaptation by tourists.

- Climate change mitigation. 


\subsubsection{Implications of a changed climate and climate-induced environmental change}

Climate itself is an important resource for tourism, as it co-determines the suitability of locations for a wide range of tourist activities and the seasonality of demand (Amelung et al., 2007). Regional differences in natural resources for tourism may be magnified, and existing assets (e.g., biodiversity, water, snow, climatic comfort) are likely to be reduced at some destinations (Chapters 9, 11, 12, 14). Mountains and coastal regions are prominent in the AR4 as far as tourism-related physical impacts of climate change are concerned, as much of the available research has focused on these areas. They host much of the world's tourism activity and are considered highly sensitive to climatic change. Nevertheless, the focus on these regions in past research does not imply that there may not be other vulnerable areas.

\section{Mountains, Snow, and Ice}

Negative impacts of climate change on mountain tourism are mainly related to the observed (1.3.1) and projected reduction of the cryosphere. Skiing is the main international tourist activity that is affected. Global warming causes glaciers to retreat (Chapter 17) and changes the temporal and spatial distribution of requisite natural snow cover. As glaciers retreat and the snow line moves up and/or retreats to higher latitudes, many ski areas are projected to face a decrease of the skiing season. Reductions in snow and ice-related sports are projected for mountain ranges in several regions: Alps of Switzerland and Austria, eastern and western US and Canada, Australia, and South America (Chapters 7, 10, 11, 14).

It is likely that some of the projected impacts of climate change on winter sports tourism in mountain regions is overestimated because widespread climate adaptations that are in use currently, such as snowmaking, are not incorporated in the large majority of these impact studies (Scott \& McBoyle, 2007). Different adaptation measures are being put into place or suggested to offset the negative impacts of climate change on snow-dependent mountain activities. Snowmaking technologies are widely used in North America, Australia, Japan, and parts of Europe (Austria, France, Germany) and are capable of considerably reducing the climate change vulnerability of ski resorts in most locations (Chapters 12,14), although there are technological and economic limitations as machine-made snow can only be produced with sufficiently cold temperatures and the increased costs may be prohibitive to some operators. Snowmaking technologies may also be environmentally problematic in some locations because of its intensive use of water or chemical additives. Where feasible, ski resorts may also propose to extend their terrain higher up in search of more reliable natural snow conditions and entirely new ski areas may be developed at higher elevation (Chapters 12, 14). However, government policies or public opposition may pose a significant barrier 
to such an adaptation strategy in many locations (Scott \& McBoyle, 2007). Snowmobiling, a US\$10 billion industry in North America (Chapter 14), is identified to be even more vulnerable to a reduction on the snow cover than skiing due to its complete reliance on natural snowfall.

Diversification into activities not based on snow and ice is put forward as an adaptation strategy for tourism operators (Table 17.1, Chapters 10,12). Opportunities for these types of mountain tourism activities, ranging from spa and health tourism to outdoor nature-based tourism and ecotourism, are projected to increase even with only moderate climate change (Chapter 14). In Canada and the northern areas of the US, where visitation to parks is limited by winter conditions, longer and climatically more suitable warm-weather tourism seasons are projected to result in higher visitation levels as early as the 2020s (14.4.7). Thus, a climate-induced increase in visitation would have positive economic implications, but could exacerbate visitor use pressures such as crowding and ecological impacts in some park areas. Interviews with visitors of mountain areas in North America suggest that the large majority of these visitors will not alter their intention to visit these mountain parks or the frequency of their visits because of climate-induced environmental change through to at least the latter decades of this century (Chapter 17). There are expected to be destination-specific exceptions, where changes in high-profile tourist attractions are likely to impact visitation levels sooner. For example, glacial retreat is thought to cause striking changes in mountain landscapes, with possible, but as yet speculative, implications for local tourism in many areas around the world (Chapters 1,9).

\section{Coastal Areas and Islands}

With very high confidence, which in the IPCC AR4 reports translates into a more than $90 \%$ chance of being correct, the AR4 concludes that climate change vulnerabilities are greater in "certain high-risk locations, particularly coastal and riverine areas, and areas whose economies are closely linked with climate-sensitive resources, such as agricultural and forest product industries, water demands and tourism" (IPCC, 2007a, p. 359, Chapter 7). Coastal tourism, a climate-sensitive activity in a high-risk area, can therefore be considered highly vulnerable to climate change. The attractiveness of the coast has resulted in disproportionately rapid expansion of economic activity, including tourism (Chapter 6). Tourism based on the attractions of sun, sea, and sand makes up a large share of tourism in the world. The Mediterranean alone accounts for an estimated $16 \%$ of international tourist arrivals (6.4.2.6) and in many small island states tourism is a major contributor to GDP and employment (16.4.6).

According to AR4, the "more significant impacts" of climate change on tourism in coastal areas will result from temperature change, extreme events, floods, erosion, and biological effects (Chapter 6), while the impacts from rising water tables and salt 
water intrusion are considered negligible or have not been established. Overall, temperature increase is deemed more important to coastal tourism than sea-level rise, except where factors such as sea-level rise promote beach degradation, and viable adaptation options to sustain the beach (via nourishment or erosion control structures) are not available (6.4.2.6). The temperature ranges required for coastal tourism are uncertain, however, and our understanding of how tourists respond to increases in mean and extreme temperatures remains limited (Amelung \& Scott, 2007). In high-risk coasts, such as hurricane-prone coastlines, insurance costs for tourism could increase substantially or may no longer be available, exacerbating the impacts of extreme events or restricting new tourism development (Chapter 14).

Small islands face all the impacts of climate change related to coastal zones and several others, often in an intensified form. For small islands, climate change is considered a major threat to sustainable development (Executive Summary). In many cases, small islands are very sensitive to climate change (e.g., low lying), have high exposure (e.g., hurricane prone), and they have a low adaptive capacity (e.g., relatively poor, with less diversified economies). As a result, sea-level rise, beach erosion, and the effects of extreme events are likely to cause very significant problems for many of these islands. These phenomena can affect tourist infrastructures, such as hotels and transportation networks (16.4.7). Hurricane Ivan, which struck Grenada in September 2004, for example, damaged the island so severely that the socioeconomic development was set back by at least a decade (16.4.6). Ninety percent of guest rooms were damaged or destroyed, equivalent to approximately $29 \%$ of GDP. In some locations, the availability of fresh water sources may be affected by changes in precipitation patterns and salinization through sea-level rise (16.4.1), increasing competition for water between tourism and other sectors, such as agriculture (16.4.3), and potentially limiting further tourism development or jeopardizing existing tourism operations.

In some coastal areas, coral reefs are an important resource for tourism (e.g., the Great Barrier Reef). Coral reefs ecosystems are broadly covered by the IPCC report due to their high sensitivity to slight changes in parameters affected by climate change, such as water temperature and ocean acidity. As a result of climate change, thermal thresholds could be exceeded, resulting in bleaching and high mortality in many of these ecosystems around the world (Box 4.4; Executive Summary, Chapter 6; 9.2.1; 9.4.5; $11.4 .9 ; 16.4 .4 ; 16.4 .6)$. The deterioration of these environmental assets may cause a decrease in the number of visitors to nearby coastal or island regions (Chapter 16, Executive Summary).

\subsubsection{Adaptation by destinations}

According to Chapter 7, "there are three categories of adaptation processes: technological, managerial, and behavioral." With respect to tourism operators and destina- 
tions, most attention in AR4 is on technological and managerial adaptation to climate change. AR4 mentions a range of examples of technological adaptation in the tourism sector, including snowmaking to combat the shortening of the ski season, desalination plants to overcome periods of water scarcity, air-conditioning for visitor comfort, and infrastructure protection against sea-level rise and flooding (Chapters 12, 14, 16). Options for managerial adaptation that are mentioned include: the promotion of new forms of tourism (such as cultural tourism) to offset losses of climate-sensitive tourism, putting greater emphasis on human-made rather than natural attractions, and diversification of revenues by tourism businesses (e.g., new leisure industries such as health spas, conference centers, grass-skiing, hiking, or ecotourism for ski resorts) (Chapters $10,12)$. Adaptive capacities and strategies are likely to vary substantially among tourism stakeholders (Chapter 7). Large tour operators, who do not own the infrastructure and can influence demand through marketing, for example, are in a better position to adapt to changes in tourist destinations than local tourism operators (e.g., ski area or accommodations owners), who are tied to a specific location because of high capital investment in infrastructure and facilities.

\subsubsection{Behavioral adaptation by tourists}

The AR4 also recognizes that climate plays an important role in tourism demand, while acknowledging that there is only very limited knowledge on the complex interactions between tourism, climate, and other environmental and socioeconomic systems (Chapter 1). Without denying the important influence of non-climatic factors, climate is identified as being a highly relevant factor in the tourist destination choice (Chapter $1,7)$. A changed climate is anticipated to make some regions more attractive for tourism (e.g. the Baltic in summer) and others less attractive (e.g. the Mediterranean in summer). Consequently, it is anticipated that tourist demand will shift, through spatial and seasonal redistribution (Chapters 6, 9, 12, 14). Very broadly, climate change is projected to lead to a poleward shift of tourist activity patterns (Chapters 12,14) and a shift from lowland to highland tourism (Chapter 12, 9.4.7). Under a scenario of gradual warming, it is anticipated at least some tourists would spend their holidays in different places than they currently do, but the available research does not suggest reduced competitiveness of the sun, sea, and sand destinations. Furthermore, the very limited knowledge about cross-cultural climate preferences of tourists, and climatic preferences for different tourist environments currently restricts our capacity to project potential redistribution of tourists with much certainty (Amelung \& Scott, 2007). At a global scale, changes in total international tourist numbers induced by climate change are generally projected to be much smaller than those resulting from population and economic growth (Chapter 6). 
Behavioral changes may not only result from changing physical circumstances, but can also be triggered by institutional developments. One indirect factor of considerable importance is energy prices, which affect both the cost of providing comfort in tourist areas and the cost of travelling to them (Chapter 7). The price of air transport, now the means of transport of $42 \%$ of all international tourists (Gössling \& Hall, 2006), is expected to rise as the international community attempts to reduce greenhouse gas emissions (Chapter 7). The potential increase in travel costs resulting from greenhouse gas emission reduction policies could alter mobility patterns and thus require adaptation in terms of leisure lifestyles, such as the substitution of long-distance travel by vacationing locally or regionally (Chapter 7). This effect could be especially significant for national or regional economies that are highly dependent on long-haul tourism (e.g. New Zealand and several Small Island nations-Chapter 7).

\subsubsection{Climate change mitigation}

Leisure styles are identified as important determinants of long-term emission profiles (WGIII-3.1.5), but the third volume of AR4 pays very little attention to tourism and recreation. Tourism is thought to be responsible for a significant and rapidly growing share of radiative forcing (Gössling, 2002; Peeters et al., 2006), in particular through transport, but it is not given explicit attention in the sections dedicated to transport. Tourism is more frequently mentioned as a sector that could be potentially affected by climate change mitigation policies, rather than as an industry contributing to the alteration of the global climate system. When describing the mitigation option of reducing deforestation, for example, the benefits for tourism and recreation are repeatedly mentioned as important side effects (e.g., WGIII-Chapter 12). However, there is no empirical evidence to indicate where this may directly (through new recreation opportunities) or indirectly (though improved habitat to support biodiversity) benefit the tourism industry. In the context of destination management, mitigation options are mentioned in connection with adaptation. Adaptation options, including airconditioning, improved building structures, replanting of trees, and mangroves, can have direct and indirect impacts on energy consumption and GHG emissions (WGIIIChapter 2). There is a potential for exploiting synergies between adaptation and mitigation in the tourism sector. Energy efficiency policies, for example, induce cost savings that can be attractive from an economic and adaptation perspective, in addition to the mitigation perspective, making such initiative appealing even for countries that do not have mitigation as a main priority (WGIII-Chapter 2). 


\subsection{Discussion and Conclusion}

Tourism has clearly received more attention in the IPCC Fourth Assessment Report (AR4) than in the Second Assessment Report (SAR). In particular, the impacts of climate change on the climatic and natural resources of destinations have been studied in more detail. The possible consequences for mountain areas, coastal zones, and small island states are more fully understood, although the net effect of climate change for any specific destination has yet to be ascertained. The effects of climate change and climate-induced economic or environmental change on tourist demand are receiving increasing attention, but large uncertainties remain. In part, these uncertainties result from fundamental knowledge gaps regarding tourist climate preferences and the role of climate in destination choice, and tourist perceptions of and behavioral response to environmental change (now and decades into future). In terms of geographical coverage, the research on tourism and climate is also unbalanced. Whereas there are substantial sections dedicated to tourism in the chapters on Africa, Australia, Europe, and North America, there is hardly any consideration of tourism in the chapters on Asia and Latin America. Even among the regions with dedicated sections on tourism, the available research varies substantially. Given the regional distribution of global tourism receipts and relative importance of tourism to the economies to some nations in the Caribbean and Southeast Asia, these regional gaps need to be redressed in the future.

The focus of climate change impact on the tourism sector is slowly moving away from purely physical impacts to incorporate socioeconomic impacts, but there are some large unexplored research areas that are in need of urgent attention in the coming years. It is not known, for example, how significant the discrepancies are between actual and perceived climate change, which is important for anticipating changes in tourist behavior. The same holds for the relative importance of gradual climate changes vs. extreme weather events when explaining tourist behavior. The AR4 also reveals that adaptation by destinations and tourism operators is poorly accounted for. Ceron \& Scott (2007) believe tourism is a decade behind some other sectors with regard to adaptation research. In economic cost-benefit analyses and climate change costing analyses, tourism has been underrepresented relative to its contribution to global GDP. In the AR4 there are fewer references to studies estimating economic impacts on tourism sectors than in the SAR, which may be related to the crudeness and low confidence of these earlier estimates (e.g., the estimated US\$1.7 billion impact of climate change on the US ski industry cited in the SAR (p. 259) even though not a single impact assessment on the US ski industry had been conducted). Climate change-induced reductions of global GDP (e.g. Stern, 2006) may have implications for tourism spending, but this subject has also hardly been explored to date. 
There are many relationships between the climate system, the environment, overall society, and tourism. These relationships involve billions of tourists and other stakeholders, and take place at many different spatial and temporal scales. As the bibliography of Scott et al. (2006) revealed, the volume of research dedicated to exploring these complex relationships has increased substantially since the SAR in 1995. New methodological approaches have emerged in this increasingly multidisciplinary field and in some instances revealed important limitations of earlier work. The body of research referred to in the AR4 has clearly advanced our knowledge of the many interlinkages of climate change and tourism, but it has also revealed more complexity and fundamental knowledge gaps, so that the conclusion from this review remains very similar to Wall's (1998). While tourism has received greater attention in the AR4 (attention more consistent with the contribution of tourism to the global economy and society), our understanding of the potential consequences of climate change for tourism remains highly limited. However, with the number of new researchers contributing to this field, the increasing organization of the climate change and tourism research community and the better involvement of the tourism research community and tourism stakeholders, there are very positive prospects for substantially improving this situation over the next 10 years. 



\section{Chapter 4}

\section{CLIMATE CHANGE AND COASTAL \& MARINE TOURISM: REVIEW AND ANALYSIS}

Based on:

- Moreno, A., \& Amelung, B. (2009a). Climate change and coastal \& marine tourism: review and analysis. Journal of Coastal Research, SI56, 1140-1144. 



\section{Climate Change and Coastal \& Marine Tourism: REVIEW AND ANALYSIS}

For many centuries the coast has been a salient environment for human settlement. The richness in resources from food to materials and its importance as communication and origin of trade routes made certain coastal areas major centers of human activities. Coastal zones are also key centers of recreation and tourism. Stimulated by its milder climate as compared to the inland regions, the marine environment possesses an attractiveness that brings millions of tourists every year, and the intensity and diversity of activities seem to be continuously growing (Hall, 2001; Kenchington, 1993; Miller, 1993; Orams, 1999, 2007). Many countries are now aware of the potential of coastal and marine environments and are developing policies to stimulate these activities. For example, Denmark's national tourism policy strategy 2006-2009 has coastal tourism as one of the three main strategic areas and Mexico's Ministry of Tourism is applying fast track mechanisms to approve licenses for foreign investments in coastal zones (OECD, 2008).

Coastal and marine environments have been identified as being highly vulnerable and "likely to be especially affected" by climate change (IPCC, 2007c), with important implications for the tourism activities that take place in them. Despite this high vulnerability and the great importance for tourism and recreation, researchers that have traditionally explored issues of coastal and marine tourism have commonly omitted the problem of climate change, whereas scholars exploring issues of climate change impacts on tourism, have typically focused on few activities, mainly related to $3 \mathrm{~S}$ recreation (e.g. tourists preferences for weather factors; impacts on tourists' comfort; or physical impacts on destinations). Other activities related to the coastal or marine realm such as sailing or marine wildlife watching have received little if any attention. The aim of this chapter is to present the key impacts climate change will have on coastal and marine tourism based on current knowledge and scientific literature. Tourism's role as a source of greenhouse gases (GHG) is also considered, with especial attention to studies that focus on coastal and marine recreation. The chapter is organized as follows. The importance of tourism and recreation activities in coastal and marine environments is explored in section 4.1. Section 4.2 describes the main observed and projected impacts of climate change on these environments. Section 4.3 elaborates on the complex relationship between climate change, marine environments and tourism, introducing the state-of-the-art knowledge in terms of impacts and emissions. The main knowledge gaps that should guide future research are identified in section 4.4. Section 4.5 concludes. 


\subsection{Variety and Importance of Coastal \& Marine Tourism}

According to Hall (2001),

coastal tourism embraces the full range of tourism, leisure, and recreationally oriented activities that take place in the coastal zone and the offshore coastal waters. These include coastal tourism development (accommodation, restaurants, food industry, and second homes) and the infrastructure supporting coastal development (e.g. retail businesses, marinas, and activity suppliers) (...) Marine tourism (...) includes ocean-based tourism such as deep-sea fishing and yacht cruising. (p. 602)

This definition of coastal and marine tourism is important as it acknowledges the multiple elements involved in the tourism sector, from demand to offer, using the coastal and marine environment as the contextual background for the tourism activities.

The diversity of coastal and marine recreation goes well beyond the typical beach (sun, sand \& sea) tourism. Shore-based leisure includes activities as varied as sunbathing, collecting objects (e.g. dead shells, fragments of corals), nature appreciation or land-based wildlife watching. Diving and underwater photography, recreational fishing and cruising are only a few examples of off-shore recreation; some other forms are less common, such as solo around the world yacht trips. For many communities, countries and regions around the world, marine tourism constitutes the main economic sector and source of employment. For example in Calvià, a coastal town in the island of Majorca (Spain), 95\% of the jobs in 2002 were related to tourism (UNEP \& UNWTO, 2005).

The great diversity of activities and the expansion the sector is experiencing are related to socioeconomic factors and coastal population growth. Most importantly, development of, and easier and cheaper access to advanced technology have dispersed coastal and marine recreation to virtually every corner of the world, from the poles to the tropics (Hall, 2001; Orams, 1999).

For most of coastal and marine activities there is no data about participation and revenues at the global level. However, some studies about specific sectors and regions can give an idea about the relevance of the sector. According to the report "Current participation patterns in marine recreation" prepared by the U.S. National Oceanic and Atmospheric Administration (NOAA), 89 million Americans (over $40 \%$ of the population 16 years and older) participated in at least one marine outdoor activity in 1999-2000 (Leeworthy \& Wiley, 2001). One sector that has experienced rapid development in the last years is the cruise industry; the worldwide average growth rate is $7.4 \%$ per annum; 
the segment of 2 to 5-day cruises in the North American market has even grown by 1011\% between 1980 and 2007 (CLIA, 2008), which corresponds to 9\% per annum. Finally, whale-watching is another activity which has seen an spectacular increase, taking place in 12 countries in 1983 but expanding to 65 countries by 1995 (Hoyt, 1996; cited in Orams, 2000). Before looking into the relationship between the coastal and marine tourism industry and climate change, it is necessary to understand what kind of impacts the latter will pose on these environments.

\subsection{Climate Change Impacts on Coastal \& Marine Environments}

Scientific evidence indicates that the climate is changing, and that it is all but certain that human activities play a crucial role in these changes, affecting the rate and speed at which this process is happening. Research in the field of climate change has identified coastal zones as highly vulnerable to its effects. The Intergovernmental Panel on Climate Change (IPCC) is the main body in the field of climate change science, impacts, adaptation and mitigation. In 2007 the IPCC published the 4th Assessment Report (AR4) which states there is a very high confidence that coasts will be increasingly exposed to climate change risks, including coastal erosion and sea-level rise (IPCC, 2007a). The report comprehensively compiles the available evidence, including observed climate related changes and projections of future impacts in all kinds of natural and human environments. The AR4 contains a wealth of relevant material for tourism, although the implications for this sector are not always explicitly addressed (Chapter 3 of this thesis). The next list presents some of the most important impacts of climate change in coastal areas which are or could be potentially relevant for tourism, indicating in each case the level of confidence of the statement and the page where it can be found in the IPCC report (IPCC, 2007a):

- Sea-level rise: losses of coastal wetlands and mangroves, and increasing damage from coastal flooding in many areas (very high confidence, p. 9 \& 12); deterioration of coastal conditions, for example through erosion of beaches reducing the value of these destinations for tourism (high confidence, p. 15); damage to vital infrastructure, settlements and facilities that support livelihood in small communities (very high confidence, p. 15)

- Changes in the water cycle: drought-affected areas will likely grow in extent. Heavy precipitation events, which are very likely to increase in frequency, will augment flood risk (high confidence, p. 11).

- Increase in global average temperature: major changes in ecosystem structure and function, species' ecological interactions, and species geographical ranges, with pre- 
dominantly negative consequences for biodiversity and ecosystem goods and services (high confidence, p. 11); more frequent coral bleaching events (high confidence, p. 12); detrimental effects on many organisms including migratory birds, mammals and higher predators in polar regions (high confidence, p. 15).

- Progressive acidification: with negative impacts on corals (medium confidence, $p$. 11).

- Extreme weather events: some weather events and extremes will become more frequent, more widespread and/or more intense (p. 17).

Among the most vulnerable industries the report identifies those located in coastal plains and whose economies are closely linked with climate sensitive resources (IPCC, 2007a), which is clearly the case for the coastal and marine tourism industry.

\subsection{Climate Change and Coastal \& Marine Tourism}

Climate change and tourism are related in a circular manner (Patterson et al., 2006). Climate has a direct impact on (i) the physical, environmental and social resources available for tourism and (ii) the comfort, perceptions and safety of participants. At the same time, tourism contributes significantly to anthropogenic global climate change through the emission of greenhouse gases (GHG) related to accommodation, activities and most importantly, transport. Climate change and tourism studies have commonly focused on either one of the two aspects. As knowledge in both fields has grown, and interlinkages have become apparent, aspects of both adaptation and mitigation are now integral part of climate change and tourism assessments. This section is structured following the two traditional subfields.

\subsubsection{Implications of climate change on coastal \& marine tourism}

The extent to which the variety of coastal and marine activities is related to and dependent on weather conditions and climate changes differs. While for some of the activities the relationship is direct and easy to observe (for example sunbathing requires a minimum temperature, bright skies, and no precipitation), in other cases this connection is less obvious (e.g. the weather requirements of wildlife viewing, or climate change impacts on animal populations). This is one of the reasons why researchers are only starting to understand the possible threats and opportunities that climate change might pose to certain tourism activities. As a consequence, existing research on climate change and tourism is highly unbalanced, with most of the attention so far focused on those activities more directly dependent to weather conditions. 


\section{Activities for which Research is Commonly Available}

Of all the activities that take place in coastal environments, beach tourism has received most research attention. As they have sunbathing and swimming as their main activities, beach tourists are very sensitive to weather variables such as precipitation, temperature and wind. Climate-related studies of beach tourism have typically focused on (i) establishing preferences for certain weather conditions, and establishing the climate suitability (i.e. tourism comfort) of coastal destinations, based on tourist preferences, and (ii) assessing the impacts of climate change on climate suitabilities.

Research on weather requirements for outdoor and more specifically beach recreation started in the 1970s and 1980s (e.g. Besancenot et al., 1978; Mieczkowski, 1985), and it has intensified significantly since the 1990s (Becker, 1998; de Freitas, 1990; de Freitas et al., 2008; Morgan et al., 2000; and Chapters 5 \& 6 of this thesis). Building on biometeorological information, observation and questionnaires, this research attempts to better understand tourist comfort, behavior, and preferences for weather conditions, usually reducing these into the individual weather components, such as temperature, wind, and precipitation. From raw data for the relevant weather variables, composite indices are constructed that reflect the climate suitability of destinations for beach recreation.

These studies form the basis of research exploring the impacts of climate change on beach tourism and in most cases, destinations. For example, Amelung \& Viner (2006) documented the potential impacts of climate change on Mediterranean tourism using Mieczkowski's Tourism Climate Index (Mieczkowski, 1985). The index categorizes destinations according to their climate suitability for comfortable outdoor recreation. As it was designed for sightseeing activities, the findings cannot be extrapolated to beach recreation due to its different weather requirements (a detailed description of the $\mathrm{TCl}$ is available in Chapters 5 \& 7).

The increasing availability of information about potential impacts of climate change on coastal zones has opened up new research avenues. One of these focuses on tourists' appreciation of the physical characteristics of beach destinations, and explores how climate change could affect this appreciation. Braun et al. (1999) proposed a series of scenarios for future tourism at the German North Sea and Baltic Sea coasts, to facilitate the assessment of their potential desirability and acceptability. Uyarra et al. (2005) examined the importance of environmental attributes for the selection of holiday destinations, and for tourists' enjoyment of two Caribbean islands. One of these islands had a strong focus on marine biodiversity and diving activities, while the other one featured beach (i.e. sunbathing) activities. The study suggested that climate change would have a significant negative effect on visitation to both islands: in the first case through coral bleaching and reduced marine biodiversity as a result of higher sea 
temperatures; in the second case through reduced beach area as a result of sea level rise.

Finally, coastal destinations and small island states have been at the centre of attention of climate change research, due to their high vulnerability to sea level rise, extreme events and coastal erosion. Added to this in many cases, is their high dependency on tourism as an economic activity (e.g. Becken, 2004; Raksakulthai, 2003).

\section{Emerging Research}

Climate change impact studies for most tourism activities are in short supply, although their number is currently on the increase. In many cases, the impact on tourism is a second-order effect, the first-order effect being the impact on the resource or ecosystem that forms the basis of the tourism activity. Meaningful impact assessments for tourism therefore need sufficient prior knowledge about the physical impacts of climate change. Two examples represent this well. The first one relates to diving tourism, mainly in connection with reefs. An initial phase of studies focused on issues such as coral monitoring and bleaching (Donner et al., 2005; IPCC, 2007c; Walther et al., 2002), while a second phase analyzed the socioeconomic impacts for tourism destinations that rely on this type of tourism and the effects of these physical impacts on tourists (Andersson, 2007; Cesar, 2000; Ngazy et al., 2001).

The second example relates to certain types of wildlife watching, for which habitat deterioration, and impacts on the phenology of species are relevant. Phenology studies the times when recurring natural phenomena occur, including flowering of plants and first flights of butterflies. There is increasing evidence that climate change is having an impact not only on species' habitats, but also on their migratory patterns, breeding timings, and overall distribution (Peñuelas \& Filella, 2001). As some of these phenomena are important tourist attractions, climate change will indirectly also affect the tourists that travel to certain areas to observe them. Probably the most significant and representative example is that of climate change impacts on polar bears. Many authors have reported on the deterioration in the habitat and population of the species due to climate change (e.g. Derocher et al., 2004; Learmonth et al., 2006; Stirling \& Parkinson, 2006; Tynan \& DeMaster, 1997). Only recently, however, has a first assessment been made of the consequences for tourist perceptions, and for the economies of destinations that depend on polar bear viewing (Dawson et al., 2007). For other types of wildlife watching, such as whale-watching, the impact of climate change is largely unknown, despite the growth of the activity, and the economic importance it has for many communities (Curtin, 2003).

For certain tourism activities, there is a body of literature on the first-order effects on the ecosystem, but the second phase of research linking these effects to tourism has not occurred yet. The studies on impacts of climate change on deltas and coastal 
wetlands many of which are important for tourism (commonly connected to wildlife and bird-watching) constitute an example. Physical impact assessments have been performed for wetlands, but not in direct relation to the implications of those impacts to tourism activities (El-Raey, 1998; Nicholls et al., 1999). Other examples include climate change impacts on coastal glaciers such as the Ilulissat Icefjord, in Greenland, and impacts on historical monuments and coastal cities like Venice, in Italy (UNESCO, 2007).

\section{Non-researched Activities}

For the coastal and marine recreation activities that have not been addressed above (e.g. windsurf, kitesurf, sailing and cruising, recreational fishing, marine archaeology), climate change impacts are largely unknown and research on the topic virtually nonexistent. Despite this, certain media reports of supposedly climate change related events suggest that the impacts may be substantial. Examples of this are the sinking of the tourist cruise ship Explorer in Antarctica after hitting an iceberg, and the injuries to tourists onboard the Alexey Maryshev due to a glacier rupture in the Arctic, both in 2007 (Cormier, 2007; Williams, 2007).

Table 4.1 provides an overview of the main effects of climate change and the potential consequences on a number of selected coastal and marine activities. 


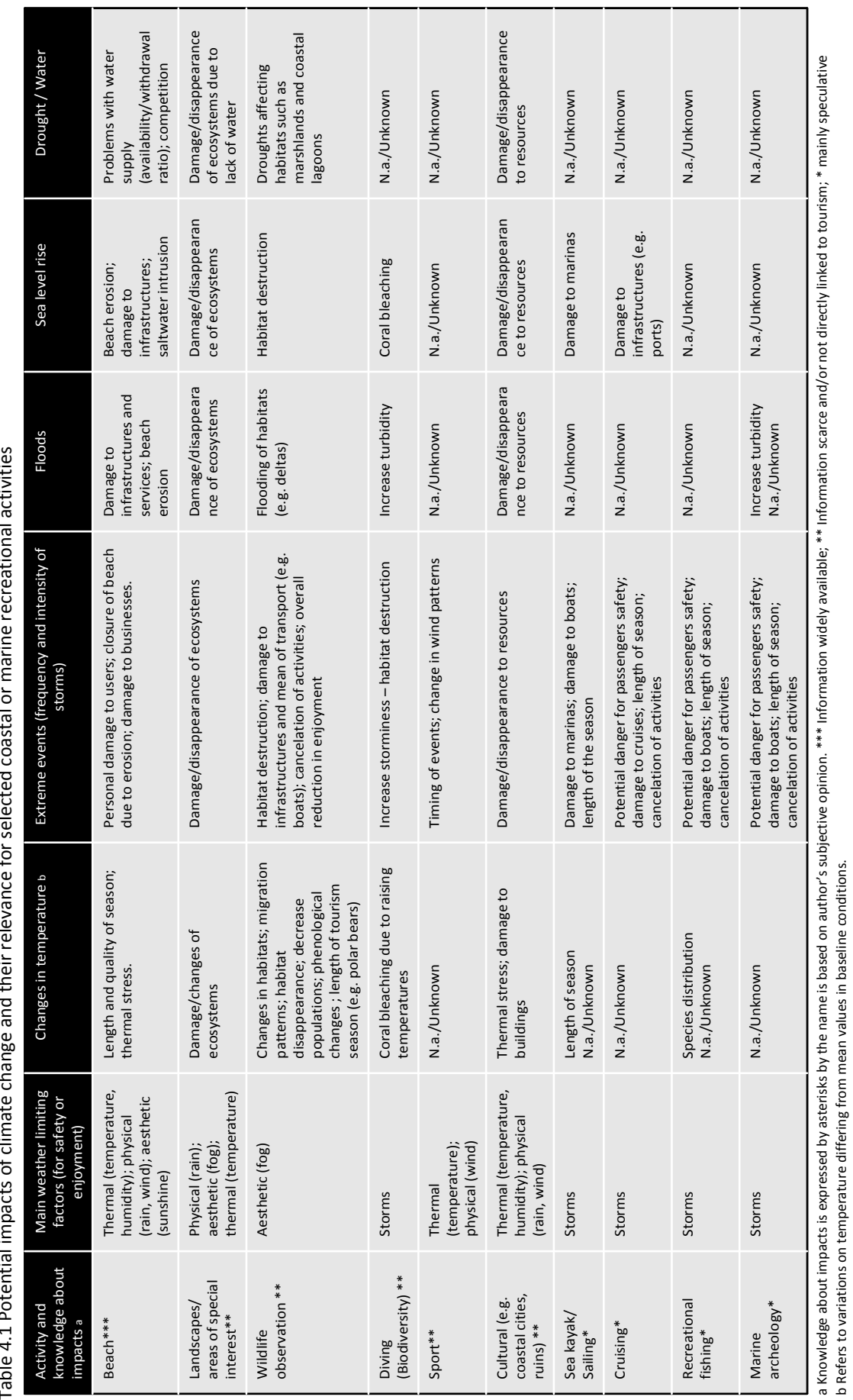




\subsubsection{Coastal \& marine tourism GHG emissions}

Tourism related greenhouse gas emissions have become one of the most important issues in the climate change and tourism debate. The most recent studies indicate that tourism emissions from transport, accommodation and activities represent approximately $5 \%$ of global emissions, and $75 \%$ of this is related to transport (UNWTO et al., 2008). Although important advances are occurring at calculating tourism GHG emissions at the global and regional level (e.g. Becken, 2002; Peeters et al., 2007), activity specific studies are still uncommon. Few, but remarkable exceptions exist. Becken \& Simmons (2002) estimated the energy consumption for different categories of tourism activities in New Zealand. Their study showed that out of the 11 activities analyzed, 'motorized water activities' were second in energy use per tourist after 'air activities'. Amelung \& Lamers (2007) calculated that tourism GHG emissions related to Antarctic tourism are about 15 tons $\mathrm{CO}_{2}-\mathrm{e}^{1}$ per tourist, and UNWTO et al. (2008) estimated that a diving holiday could emit as much as 6.8 tons $\mathrm{CO}_{2}-$ e. Finally, Byrnes \& Warnken (2004) established the emissions of the boat tourism industry in Australia at 70000 tons $\mathrm{CO}_{2}-\mathrm{e}$, adding an extra 27 to $61 \mathrm{~kg} \mathrm{CO}_{2}$-e per tourist if their holiday trip included a boat tour.

\subsection{Research Agenda and Main Knowledge Gaps}

Climate change and tourism are both complex systems which interact in multiple ways. With the exception of few activities (e.g. beach recreation), studies on climate change impacts on tourism have focused mainly on destinations (e.g. Mediterranean) or on specific ecosystems (e.g. mountains, coasts), with little attention paid to the diversity of recreation activities that take place in these environments and their distinct weather requirements. This chapter has presented an overview of the existing knowledge about and potential impacts of climate change on selected coastal and marine tourism activities. Despite the increasing attention many of these activities have received during the last years, a large number of information gaps still exist. Future research should be oriented towards:

- Baseline research on weather and tourism/recreation including tourist preferences. Recreation requirements for weather are still poorly understood, and climate change adds another layer of complexity. For this reason more research should be carried out

\footnotetext{
${ }^{1} \mathrm{CO}_{2}$-e stands for 'equivalent carbon dioxide (CO2) emission' and is defined as "the amount of carbon dioxide emission that would cause the same integrated radiative forcing, over a given time horizon, as an emitted amount of a well mixed greenhouse gas or a mixture of well mixed greenhouse gases [...] Equivalent carbon dioxide emission is a standard and useful metric for comparing emissions of different greenhouse gases" (IPCC, 2007d, p. 945)
} 
to understand the key mechanisms of weather affecting the different types of activities. Research should focus not only on impacts on the resource or tourist attraction but also on tourists' weather preferences; satisfaction and expectations should be analyzed in order to project potential shifts in tourism demand more accurately (UNWTO et al., 2008). For example, research carried out by the Cooperative Research Centre for the Great Barrier Reef (CRC Reef) on tourist satisfaction reported that bad weather conditions were mentioned as the worst experience after visiting the reef and caused a significant drop in overall satisfaction (Coghlan \& Prideaux, 2007).

- Development of vulnerability assessments. In order to analyze the extent of the impacts of climate change on tourism in a detailed and structured manner, vulnerability assessments should be carried out at destinations. This type of analyses would facilitate the identification of key hazards and activities susceptible of being damaged by climate change, while identifying adaptation strategies to minimize negative impacts. Methodologies that facilitate this type of analyses are now available and should be implemented (see Chapter 8 of this thesis).

- Development of indicators and monitoring programs. Indicators have proven to be important tools to describe and measure changes in the state of tourism systems (Miller \& Twining-Ward, 2005; UNWTO, 2004). Destinations and research projects need to develop sets of indicators to assess changes in relevant variables. While indicators can provide valuable information they also have to be adapted to the specific circumstances of the situation in question; i.e. some of these indicators would be applicable to every destination and activity (e.g. tourism arrivals and tourists' satisfaction) while others should be specific for each tourism activity (e.g. rates of coral bleaching; frequency of bleaching events).

- Improvement of tourism data. Despite the numerous efforts of the United Nations World Tourism Organization in compiling up-to-date tourism data, there is an important gap for activity-specific figures. Numerous regions and countries are doing substantial efforts to compile this kind of data but global figures are still missing. Calculations of greenhouse gas emissions are also very limited due to the lack of activity specific tourism data and energy consumption values.

- Improvement of interdisciplinary communication. Global environmental change and specifically climate change have received increasing attention in the last years. It has been noted in the previous section that for some tourism activities specific research on climate change impacts is not available. However, the field of climate change and tourism will greatly benefit from the input of different disciplines such as climate change impacts on wildlife, deltas and estuaries, ecology, phenology, etc. 
- Use of analogues. Despite the potential use of analogues (observed weather events that are similar to future climate projections) for projecting impacts, they are still uncommon in the tourism and climate change field (UNWTO et al., 2008).

- Include feedbacks. Certain tourism activities and destinations might benefit from climate change, resulting for example in higher visitation. Tourism management plans must incorporate this type of industry response to make sure that ecological and carrying capacity limits are not surpassed. It has been noted for example that warmer temperatures would mean a longer ice-free period in the Hudson Bay area and therefore an extended season for bear-watching tours. This would imply that the extra pressure from increasing tourist numbers should be added to the stress exerted by changing climate conditions in the bears environment and food availability, with uncertain consequences for the species (Dyck \& Baydack, 2004).

- Promote adaptation and proactive crisis management. Natural hazards and extreme events are an important cause of crisis in many destinations (Meheux \& Parker, 2006). More research should be oriented toward the reduction of the impacts of such events facilitated by the use of indicators and promoting proactive adaptation management and sustainable tourism development plans (de Sausmarez, 2007).

- Raise awareness. An important and usually underestimated mission of research should be directed towards public communication to tourism stakeholders, including tourists, companies and governments. This would facilitate collaboration between different parties, as well as impact reduction, as some stakeholders might overestimate their capacity to adapt (UNWTO et al., 2008). Tourists are also likely to benefit from this awareness raising as it has been noted they are informed about climate change impacts in destinations but are still not aware of their own role, or are unwilling to reduce their own carbon footprint generated during their trip (Dawson et al., 2007).

- Incorporate climate change in tourism related policies. As in the case of Denmark and Mexico presented in the introduction, many countries around the world are developing tourism policies that include the coast as a key strategic area (OECD, 2008). Any policy or tourism plan should assess the negative impacts and opportunities brought about by climate change, and consider the potential for adaptation and mitigation.

\subsection{Conclusions}

Coastal and marine environments are among the most important areas for tourism and recreation. Increasing knowledge about and interest in the coasts and oceans have caused an enormous growth in the activities that take place in these environments. 
This growth has been facilitated by new and cheaper technology (e.g. diving equipment), making coastal and marine environments increasingly accessible to more people. In many aspects, the involvement, enjoyment and safety of participants is shaped by weather conditions (e.g. wind and waves are needed for windsurfing, and absence of fog is required for wildlife watching). Climate change will affect these weather conditions, as well as many of the other resources on which tourism activities are based, such as beaches and coral reefs. The physical impacts include sea-level rise, beach erosion, increased frequency and intensity of extreme events, droughts, floods and changes in ecosystems' structures and biodiversity.

Climate change will have both positive and negative consequences for recreation depending on the activity and the destination. Despite the increasing interest from scientists, policy makers and tourism managers on the issue, many impacts and activities remain virtually unexplored. This chapter gives an overview of the existing knowledge on the impacts of climate change on coastal and marine tourism activities, as well as the GHG emissions these activities generate. A number of knowledge gaps have been identified, providing the base for future research in the topic. More research into specific activities, interdisciplinary communication, stakeholder dialogue and policies that incorporate climate into tourism planning and management are necessary steps to minimize the potential impacts of climate change, while taking advantage of the possible benefits it might bring about. 


\section{Chapter 5}

\section{MEDITERRANEAN TOURISM AND CLIMATE (CHANGE): A SURVEY-BASED STUDY}

Based on:

- Moreno, A. (2009). Mediterranean tourism and climate (change): a survey-based study. Paper presented at the $7^{\text {th }}$ International Symposium on Tourism and Sustainability, Eastbourne. 



\section{Mediterranean Tourism AND Climate (Change): A SURVEY-BASED STUDY}

The Mediterranean region is one of the most popular destinations for tourism. In 2008, Southern and Mediterranean European countries received 179 million international tourists, $19.4 \%$ of the world total (UNWTO, 2009). This is almost as much as the total international arrivals to Asia and the Pacific (20.4\%). It also exceeds any other region in the world. Coastal regions are major tourist destinations in Europe and more specifically in the Mediterranean. The European Union estimates that some $60 \%$ of the trips within Europe with at least four overnight stays take place at the seaside. Despite the common opinion of a growing importance of cultural and nature-based tourism, closeness to the sea remains as a major selection criteria. Climate and scenery are the predominant motives for choosing the holiday destination (Leidner, 2004).

The IPCC has identified the Mediterranean as a region highly vulnerable to climate change (Alcamo et al., 2007). At the same time, the UN World Tourism Organization has also pointed to tourism in the Mediterranean region as a major vulnerability hotspot (UNWTO et al., 2008). Assessments of climate change impacts on tourism have commonly concluded that the increase of temperatures is one of the major threats to Mediterranean tourism (Perry, 2005, 2006; UNWTO et al., 2008).

Research on climate change and tourism has commonly made use of comfortbased tourism indices. Several of these indices exist (e.g. Hatch, 1988) but probably the most commonly used is the Tourism Climatic Index - $\mathrm{TCl}$ - developed by Mieczkowski (1985). This index represents climatic suitability of destinations for tourism. It assigns different weights to various climatic parameters that are rated according to the ideal conditions for the practice of sightseeing activities. As not all the tourism activities have the same weather requirements, to be able to apply the $\mathrm{TCl}$ to other tourism activities, such as beach tourism, Mieczkowski suggested that the idex should be adjusted.

Different studies have used this index to assess changes in climatic suitability for tourism in different regions of the world due to climate change. Most relevant to this work are the studies by Amelung \& Viner (2006) that explored the impact of climate change on Mediterranean tourism, Amelung et al. (2007) studying the global impacts on seasonality and Nicholls \& Amelung (2008) who focused their analysis to northwestern Europe. The results from these and similar studies depict a Mediterranean region with deteriorating climatic conditions during the summer, resulting in decreasing attractiveness for tourism. The same increasing temperatures that would make the Mediterranean too hot for tourism would in contrast favor conditions in northern Europe as a developing tourism destination. The consequence of this would be more northern European tourists spending their holidays in higher latitudes instead of trav- 
eling to the Mediterranean (Amelung et al., 2007; Amelung \& Viner, 2006; Nicholls, 2006). The results might be a consequence of the rating and weighting of the different sub-indices it includes. Of the five sub-indices that compose the $\mathrm{TCl}$, the thermal aspect has the highest weight of all (40\% for daytime temperature plus an additional $10 \%$ for daily temperature). The thermal aspect is then rated according to its value following an inversed U-shape curve, with optimal temperatures ranging between 21 and 27 degrees Celsius $\left({ }^{\circ} \mathrm{C}\right)$. The other sub-indices included on the $\mathrm{TCl}$ formula are precipitation and hours of sunshine, with $20 \%$ of the weight, and wind speed with $10 \%$ of the weight. While this might be the case for sightseeing, there are few studies that explore the distinctive weather requirements for beach tourism, one of the most weathersensitive recreation activity and a crucial segment in Mediterranean tourism.

Some authors have criticized the validity and broad application of the $\mathrm{TCl}$ across destinations. Arguments for this criticism are its subjectivity -rates and weights assigned based on lab experiences and experts' judgment- and its lack of specificity for different activities (de Freitas et al., 2008). Besides, a number of studies suggest that the preferences for weather parameters -i.e. the weight for each component- are different between nationalities due to the existence of cultural differences (Morgan et al., 2000; Scott et al., 2008). Finally, recent findings on tourism climatology point out to the existence of overriding weather elements, a possibility not fully covered by the TCI. The elucidation of these limitations is crucial for the assessment of climate change impacts on tourism. The comparative relevance of the different weather components for the tourism experience determines the 'construction' of these indices and the magnitude of the impacts. For beach tourism, this is even more important due to the high exposure of the body to the atmospheric elements.

In recent years new research approaches based on surveys and questionnaires have been developed in order to overcome these limitations. A number of studies stand out for their contribution to this field (Table 5.1). From the information presented in this table it can be seen that different nationalities seem to perceive differently the importance of weather components. It is also noted that temperature is not always given the highest weight.

Taking a similar approach to that of the studies presented in Table 5.1, the present chapter explores by means of a questionnaire the relationship between weather and tourism and the implications for climate change research. Specific objectives of the study are:

- To determine the relative importance of climate in contributing to the overall attractiveness of Mediterranean destinations; 
- To examine the relative weight of different climate parameters for beach tourism and tourists definition of 'unfavorable' and 'ideal' weather for beach recreation, paying special attention to the role of temperature;

- To explore two major assumptions existing in the literature about climate change impacts on Mediterranean tourism: (i) the dominant role of heat waves as compared to other climate change impacts and (ii) the possibility that north European tourists will stay at their home country or neighboring regions.

Table 5.1 Overview of some recent studies on priorities for climatic parameters for beach tourism

\begin{tabular}{|c|c|c|c|c|c|c|c|c|}
\hline \multirow[t]{2}{*}{ Authors } & \multicolumn{2}{|c|}{ Respondents } & \multirow{2}{*}{$\begin{array}{l}\text { Type of } \\
\text { tourism }\end{array}$} & \multirow[t]{2}{*}{ Sample } & \multicolumn{4}{|c|}{ Ranking of weather parameters } \\
\hline & Number & Country & & & Precip. & Temp. & Wind & Sun. \\
\hline $\begin{array}{l}\text { de Freitas et } \\
\text { al, } 2008\end{array}$ & 331 & Canada & $3 S$ & Students & 2 & 1 & 3 & 1 \\
\hline \multirow{3}{*}{$\begin{array}{l}\text { Scott et al, } \\
2008\end{array}$} & 333 & Canada & $3 S$ & Students & 3 & 2 & 4 & 1 \\
\hline & 207 & New Zealand & 35 & Students & 1 & 2 & 4 & 3 \\
\hline & 291 & Sweden & $3 S$ & Students & 3 & 2 & 4 & 1 \\
\hline $\begin{array}{l}\text { Morgan et } \\
\text { al, } 2000\end{array}$ & 1354 & North Europe & $3 S$ & Tourists & 1 & 4 & 3 & 2 \\
\hline $\begin{array}{l}\text { Mieczkowski } \\
, 1985\end{array}$ & $\begin{array}{l}\text { Based on } \\
\text { literature }\end{array}$ & n.a. & $\begin{array}{l}\text { Sight- } \\
\text { seeing }\end{array}$ & n.a. & 2 & 1 & 3 & 2 \\
\hline
\end{tabular}

The chapter is organized as follows. The details on the data collection are presented in section 5.1. The results of the study are detailed in section 5.2 and its implications are discussed on section 5.3. Section 5.4 concludes.

\subsection{Methodology and Data Collection}

A questionnaire was designed with the aim of addressing Belgian and Dutch tourists traveling to the Mediterranean ${ }^{1}$. Tourists were interviewed in the departure hall of different airports. The requisites for the airports to be considered were: (i) frequent daily flights to the Mediterranean and; (ii) proximity to researchers working place. After checking with the different management departments of several airports, per-

\footnotetext{
${ }^{1}$ Some respondents were traveling to the Algarve region in the South of Portugal. Although geographically not in the Mediterranean Sea, this region shares, however, a similar climate and attracts the same type of tourists (mainly $3 \mathrm{~S}$ tourists) as most destinations in the Mediterranean do.
} 
mission was obtained from Maastricht-Aachen airport and Rotterdam airport (both in The Netherlands) and Brussels airport (Belgium).

The self-completed questionnaire was elaborated in three languages (Dutch, French and English) and a pre-test was carried out at Maastricht-Aachen airport to test wording, layout and completion time. After this, the survey was adjusted accordingly and it was eventually carried out during three days in May and June 2007 in the checkin areas of the Rotterdam and Brussels airports. Limited resources and time only allowed for the given sampling days and locations, determining the number of completed questionnaires.

The questionnaire was handed in to tourists departing to a Mediterranean destination, regardless of what that destination would be. It was structured in four main sections: a first section focused on the role of climate in general as a destination attribute and the other three addressing specifically issues of the relationship between weatherbeach tourism and climate change impacts. The same questionnaire was used in the two airports, although the questionnaire done in Brussels had two additional questions as compared to the one of Rotterdam (these additional questions are analyzed on the results epigraph 'Ideal weather' and improving conditions in northern Europe destinations').

To avoid any potential influence on the respondents about the matter of the survey, the objective of the questionnaire was not mentioned in the introductory notes given to the respondents.

\subsection{Results}

A total of 118 questionnaires were distributed and returned. Three of them were only partially answered and therefore not included in the analysis. To facilitate the analysis, the results are presented for each of the four main sections covered on the questionnaire. Table 5.2 summarizes the results for the socio-demographic questions. 


\begin{tabular}{|c|c|c|}
\hline & Frequency & Percent \\
\hline \multicolumn{3}{|c|}{ Country of origin $(N=113)$} \\
\hline Belgium & 63 & 55.7 \\
\hline Netherlands & 50 & 44.3 \\
\hline \multicolumn{3}{|l|}{ Gender $(N=113)$} \\
\hline Female & 63 & 55.8 \\
\hline Male & 50 & 44.2 \\
\hline \multicolumn{3}{|c|}{ Traveling with $(N=114)$} \\
\hline Partner & 55 & 48.2 \\
\hline Friends & 24 & 21.1 \\
\hline Family & 23 & 20.2 \\
\hline Alone & 12 & 10.5 \\
\hline \multicolumn{3}{|c|}{ Holiday organization $(N=112)$} \\
\hline Travel agents & 43 & 38.4 \\
\hline Independent & 41 & 36.6 \\
\hline Holiday package & 25 & 22.3 \\
\hline Other & 3 & 2.7 \\
\hline \multicolumn{3}{|l|}{ Age (years, $N=114$ ) } \\
\hline $20-24$ & 16 & 14.0 \\
\hline $25-29$ & 14 & 12.3 \\
\hline $30-34$ & 13 & 11.4 \\
\hline $35-39$ & 15 & 13.2 \\
\hline $40-44$ & 9 & 7.9 \\
\hline $45-49$ & 10 & 8.8 \\
\hline $50-54$ & 12 & 10.5 \\
\hline $55-59$ & 9 & 7.9 \\
\hline $60-64$ & 12 & 10.5 \\
\hline+65 & 4 & 3.5 \\
\hline \multicolumn{3}{|l|}{ Destination $(N=114)$} \\
\hline Turkey & 56 & 48.7 \\
\hline Spain & 21 & 18.3 \\
\hline Greece & 17 & 14.8 \\
\hline France (Nice) & 10 & 8.7 \\
\hline Portugal & 9 & 7.8 \\
\hline Other & 1 & 0.9 \\
\hline
\end{tabular}


The role of climate as a key pull attribute to the Mediterranean

From all the activities tourists planned to carry out at their destination (multiple choices possible), beach tourism was selected by 76 of the respondents (66.7\%), more than double the second activity, cultural tourism, which was selected 37 times (32.5\%). The attractiveness of the destination was measured based on 14 attributes, using a Likert scale from unimportant (1) to very important (5). Table 5.3 shows that 'climate' is the attribute that contributed the most to the attractiveness of the destinations (mean 4.56) for the overall sample $(\mathrm{N}=115)$, but even if the analysis is limited to the respondents that will not be involved in beach tourism (38 did not choose this activity), 'climate' still obtains the highest score (mean 4.50). Cultural influences might affect the preferences of different nationalities for weather and climate (Scott et al., 2008). To test if this is the case with the available sample, a T-Test was performed. From the list of attributes in Table 5.3, the ones that were found to be significantly different between the two nationalities are indicated by an asterisk.

Table 5.3 Descriptive statistics of destination attributes (asterisk indicates significant difference between nationalities)

\begin{tabular}{|l|c|c|c|}
\hline Attributes & Mean & Std. Deviation & N \\
\hline Climate & 4.56 & .580 & 115 \\
\hline Security & 4.15 & .858 & 113 \\
\hline Cuisine* & 4.08 & .951 & 114 \\
\hline Price of accommodation* & 3.94 & .820 & 112 \\
\hline Nature/Landscape & 3.85 & .774 & 112 \\
\hline Price of transport to destination & 3.79 & .881 & 113 \\
\hline Characteristics of bathing zones* & 3.52 & 1.063 & 115 \\
\hline Local price levels & 3.52 & .865 & 114 \\
\hline Travel distance/time* & 3.34 & 1.063 & 114 \\
\hline Shopping opportunities* & 3.27 & 1.041 & 114 \\
\hline Cultural and historical attractions & 3.25 & 1.054 & 114 \\
\hline Uniqueness of local people's way of life & 3.13 & .941 & 115 \\
\hline Sports and recreational opportunities & 3.03 & 1.085 & 114 \\
\hline Festivals, special events* & 2.38 & .999 & 114 \\
\hline
\end{tabular}

a 1 = unimportant; 5 = very important

To assess the influence of age on the importance assigned to the attributes of the destination, three different age groups were created: 'young' for ages lower than 30 , 
'adult' for ages between 30 and 54, and 'senior' for 55 or older. The ANOVA test showed to be significant for the attributes 'price of accommodation', 'cultural and historical attractions' and 'uniqueness of local people's way of life'. In the three cases, the 'young' segment gave the lowest score to the attributes (and therefore lowest importance) and the 'senior' segment the highest.

To address more specifically the role of climate, respondents were asked to choose the first and second most important attributes of their destination from the 14 provided: $61 \%$ selected 'climate' as the first most important, a very high percentage considering that the second attribute that obtained more votes in this question was 'landscape' with $10 \%$. From those that did not select 'climate' as the first most important, $50 \%$ selected as the second most important. This means that from the 100 respondents that answered this question, 78 chose 'climate' as the first or second most important attribute making attractive this destination. Table 5.4 presents the results of the cross-tabulation between first most important attribute and the country of origin and country of destination ${ }^{2}$.

\begin{tabular}{|c|c|c|c|c|c|c|c|c|c|}
\hline \multirow{2}{*}{$\begin{array}{l}\text { Attributes } \\
\text { Single most impor- } \\
\text { tant attribute }\end{array}$} & \multicolumn{3}{|c|}{ Nationality } & \multicolumn{6}{|c|}{ Destination } \\
\hline & Dutch & Belgian & Total & Turkey & Spain & Greece & France & Portugal & Total \\
\hline Climate & 27 & 34 & 61 & 31 & 12 & 7 & 6 & 5 & 61 \\
\hline Landscape & 4 & 6 & 10 & 4 & 0 & 2 & 1 & 3 & 10 \\
\hline Security & 5 & 4 & 9 & 5 & 2 & 1 & 1 & 0 & 9 \\
\hline Cuisine & 1 & 7 & 8 & 6 & 1 & 1 & 0 & 0 & 8 \\
\hline $\begin{array}{l}\text { Price of accom- } \\
\text { modation }\end{array}$ & 5 & 0 & 5 & 0 & 3 & 2 & 0 & 0 & 5 \\
\hline $\begin{array}{l}\text { Cultural and his- } \\
\text { torical attrac- } \\
\text { tions }\end{array}$ & 2 & 1 & 3 & 1 & 0 & 1 & 1 & 0 & 3 \\
\hline $\begin{array}{l}\text { Uniqueness of } \\
\text { the local peo- } \\
\text { ple's way of life }\end{array}$ & 0 & 2 & 2 & 2 & 0 & 0 & 0 & 0 & 2 \\
\hline $\begin{array}{l}\text { Sports and rec- } \\
\text { reational oppor- } \\
\text { tunities }\end{array}$ & 0 & 1 & 1 & 0 & 0 & 1 & 0 & 0 & 1 \\
\hline $\begin{array}{l}\text { Travel distance } \\
\text { time }\end{array}$ & 0 & 1 & 1 & 1 & 0 & 0 & 0 & 0 & 1 \\
\hline
\end{tabular}

\footnotetext{
${ }^{2}$ The respondent that chose 'other' destination has not been included in this analysis
} 
Role of (high) temperature and other weather parameters and definition of 'unfavorable' weather for beach tourism

The next set of questions aimed at investigating in depth the relevance of weather specifically for beach tourism. First, respondents were asked to grade how important a set of weather variables were, again using a Likert scale from not important to extremely important. 'Absence of rain' was the aspect seen as most important (mean 4.28), followed by 'comfortable temperature' (mean 4.22), with no significant difference between respondents that chose beach as their main activity and respondents that did not choose this option (Table 5.5; asterisk indicates significance difference between nationalities).

Table 5.5 Importance of weather parameters for beach tourism

\begin{tabular}{|l|c|c|c|}
\hline & Mean $_{\mathrm{a}}$ & Std. Deviation & $\mathrm{N}$ \\
\hline Absence of rain & 4.28 & 1.105 & 115 \\
\hline Comfortable temperature & 4.22 & .761 & 114 \\
\hline Hours of sunlight & 4.12 & .857 & 113 \\
\hline Water temperature* & 3.73 & .976 & 115 \\
\hline Absence of clouds & 3.51 & 1.079 & 115 \\
\hline Absence of strong wind & 3.26 & 1.236 & 115 \\
\hline
\end{tabular}

a 1 = unimportant; 5 = very important

The questionnaire then addressed whether high temperatures were considered a negative factor for beach tourism. In the opinion of the respondents, the climatic conditions that characterize a day of 'unfavorable weather' in relation to beach tourism are mainly related to the 'presence of precipitation' (87 respondents or $75.7 \%$ ) and 'strong wind' ( 66 respondents or $57.4 \%$ ). 'High temperatures' ranked in the fifth position ( 23 respondents or $20.0 \%$ ), only followed by 'high humidity' and 'low humidity' (Table 5.6).

Based on this notion of what 'unfavorable conditions' are for the different respondents, they were asked how they would react if, before booking their holiday package, they would know they would find these bad conditions during at least half of the time of their holidays (Figure 5.1). 'Choose a different destination' was selected by $38.9 \%$ of respondents whereas $37.2 \%$ would 'not change destination'. The other $23.9 \%$ would 'choose the same destination but different dates' $(\mathrm{N}=113)$. When asked if these 'unfa- 
vorable weather' would influence negatively in the possibility of returning to the same destination, $72.2 \%$ answered positively ( $\mathrm{N}=115)$.

Table 5.6 Conditions that characterize a day of 'unfavorable weather' for beach tourism (percentages do not add to $100 \%$ as several responses were possible) $(\mathrm{N}=115)$

\begin{tabular}{|l|c|c|}
\hline & Sum & Percentage \\
\hline Precipitation & 87 & 75.7 \\
\hline Strong wind & 66 & 57.4 \\
\hline Low temperatures & 51 & 44.3 \\
\hline Cloudy sky & 30 & 26.1 \\
\hline High temperatures & 23 & 20.0 \\
\hline High humidity & 19 & 16.5 \\
\hline Low humidity & 6 & 5.2 \\
\hline
\end{tabular}

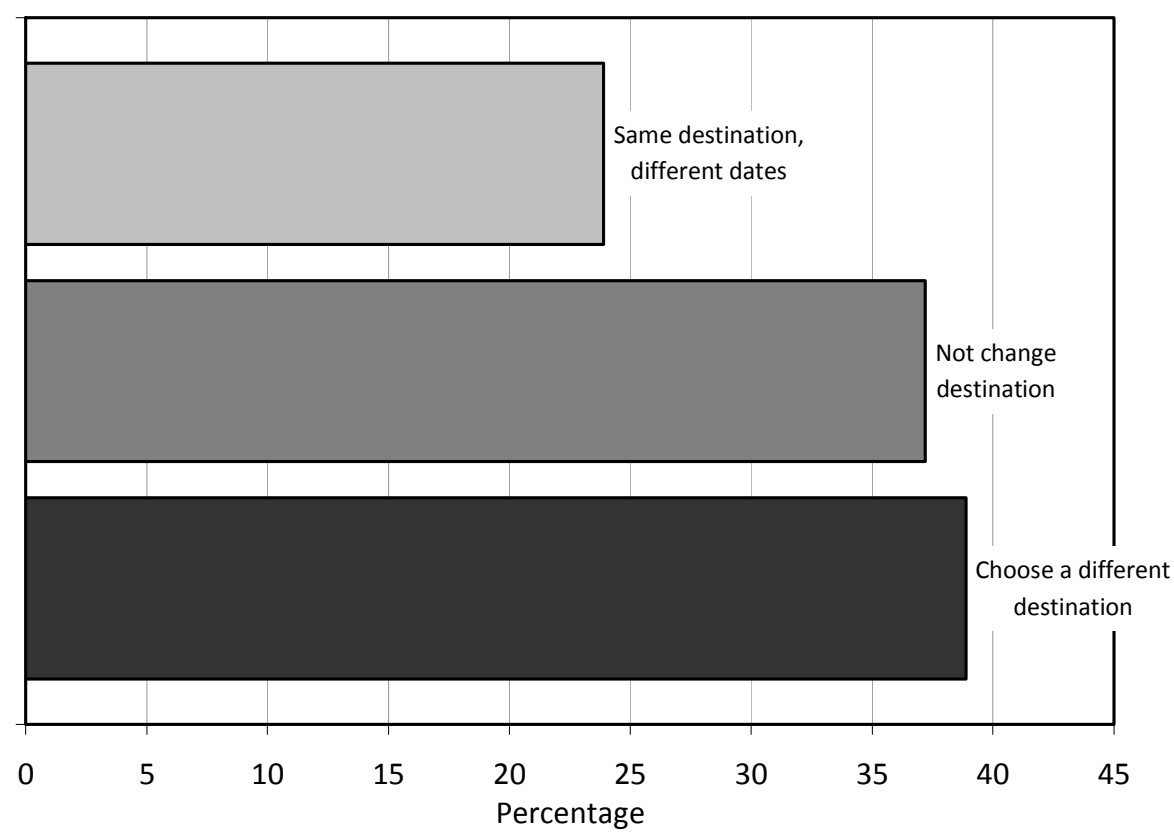

Figure 5.1 Behavioral response to 'unfavorable weather' at destination during half of the time of the holidays $(\mathrm{N}=113)$ 


\section{Perceptions about climate change impacts in the Mediterranean destination}

Finally, the last question explored the effect on tourists' satisfaction of five different potential impacts of climate change in the Mediterranean identified in the literature. The five impacts had to be rated from no influence (1) to very negative influence (4). The impact considered more negatively was the 'risk of diseases', while 'heat waves' was ranked as the least negative of all of them (Table 5.7). Table 5.8 shows the responses both nationalities gave for the specific case of heat waves.

Table 5.7 Perceived importance of different climate change impacts on destinations (asterisk indicates significant difference between nationalities)

\begin{tabular}{|l|c|c|c|c|}
\hline & Mean $_{\mathrm{a}}$ & Mode & Std. Deviation & $\mathrm{N}$ \\
\hline Risk of diseases & 3.32 & 4 (very negatively) & .820 & 111 \\
\hline Forest fires & 2.99 & 3 (negatively) & .837 & 111 \\
\hline Water restrictions in hotel* & 2.79 & 3 (negatively) & .935 & 111 \\
\hline Reduced beach extension* & 2.34 & 3 (negatively) & .860 & 110 \\
\hline Heat wave* & 1.94 & 2 (not too negatively) & .897 & 111 \\
\hline
\end{tabular}

a 1 = unimportant; 5 = very important

Table 5.8 Frequency distribution of the influence of heat waves at a Mediterranean destination

\begin{tabular}{|l|c|c|c|c|}
\hline \multirow{2}{*}{} & \multicolumn{3}{|c|}{ Dutch } & \multicolumn{2}{c|}{ Belgian } \\
\cline { 2 - 5 } & Frequency & Percent & Frequency & Percent \\
\hline No influence & 24 & 48.0 & 17 & 28.8 \\
\hline Not too negatively & 20 & 40.0 & 23 & 39.0 \\
\hline Negatively & 4 & 8.0 & 15 & 25.4 \\
\hline Very negatively & 2 & 4.0 & 4 & 6.8 \\
\hline
\end{tabular}

\section{'Ideal weather' and improving conditions in northern Europe destinations}

After the first round of questionnaires in Rotterdam airport, two new questions were added to the survey to explore the concept of 'ideal weather conditions' for beach tourism and how they would affect northern Europeans tourists' behavior in case they could be found in their country of origin. Before this, it was necessary to explore in which way respondents define 'ideal weather conditions' for beach tourism. , A day with 'ideal weather conditions' for beach tourism turned out to have an average temperature of $28.3^{\circ} \mathrm{C}$, with a 'light breeze' (wind speed of $1-9 \mathrm{~km} / \mathrm{h}$ ), ' 8 to 10 hours' of sun and a clear blue sky (\% cloud cover) (Table 5.9 and Figure 5.2). 
Table 5.9 Results of 'ideal temperature' for beach tourism $\left({ }^{\circ} \mathrm{C}\right)(\mathrm{N}=60)$

\begin{tabular}{|l|c|}
\hline & 'Ideal temperature' \\
\hline Mean & 28.3 \\
\hline Mode & 30.0 \\
\hline Std. Deviation & 2.38 \\
\hline Minimum & 22.0 \\
\hline Maximum & 35.0 \\
\hline
\end{tabular}

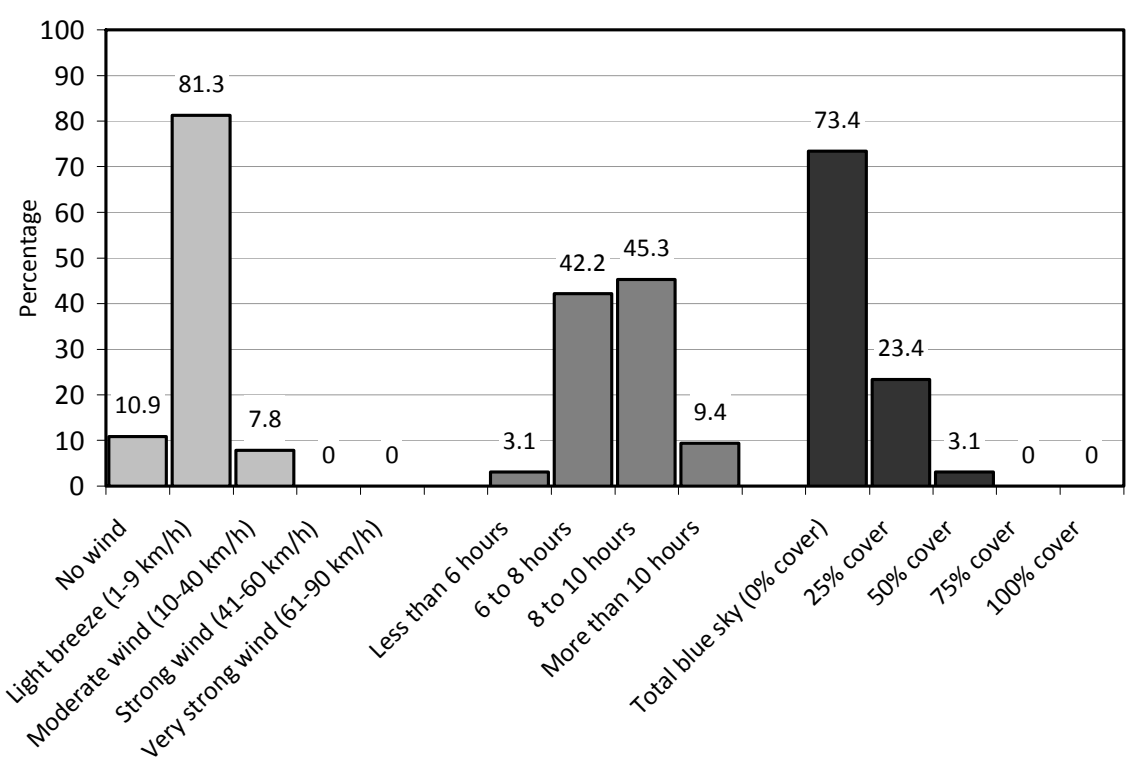

Figure 5.2 Results of ideal 'wind', 'hours of sun' and 'cloud cover' ( $N=63)$

By age groups, the mean 'ideal temperature' for the 'young', 'adult' and 'senior' segments is $29.9,28.2$ and $27.1^{\circ} \mathrm{C}$ respectively, although this difference was not significant.

If the 'ideal conditions' defined by the respondent were to be found on northern Europe, $\mathbf{7 2 . 4 \%}$ would still travel to the Mediterranean on their next beach holidays (Figure 5.3). 


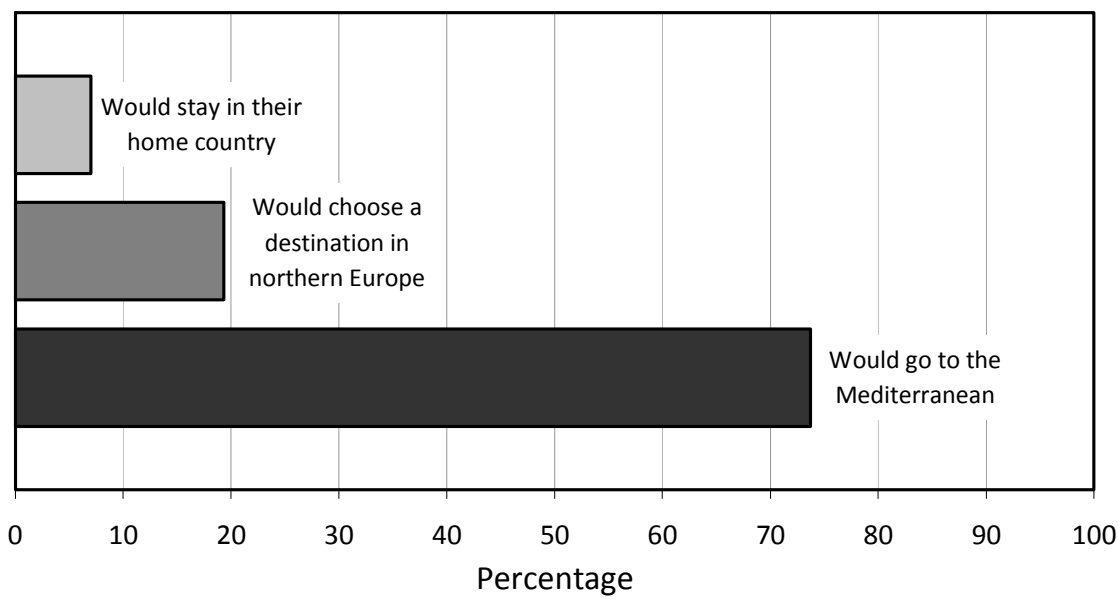

Figure 5.3 Behavioral response to 'ideal conditions' for beach holidays in northern Europe $(\mathrm{N}=57)$

\subsection{Discussion}

The field of climate change and tourism has paid significant attention to the impacts on the Mediterranean, one of the most successful tourism destinations mainly in relation to beach activities. Most of the research until now has focused on index-based analyses measuring the climatic suitability of the destination for tourism. There are, however, a relatively small number of studies that surveyed tourists' weather preferences. Even less empirical evidences exist about the relatively importance of climate change impacts on tourists comfort vs. the impacts on other destination attributes.

Climate plays a very important role as a pull factor for tourists visiting the Mediterranean even when they are not involved in beach activities. Existing tourists' comfort studies predict a negative future for this region due to their focus on the relevance of temperature and heat stress (Amelung \& Viner, 2006; UNWTO et al., 2008). Besides, these studies hypothesize about the potential that northern European tourists will stay at their home countries or neighboring areas if climate change brings more suitable conditions in these latitudes. This study approaches these complex but relevant issues.

The results support previous studies about the key role of climate as a pull attribute attracting tourists to the Mediterranean (Hamilton \& Lau, 2005; Kozak, 2002; Morgan et al., 2000). Not only climate achieved the highest ranking of the 14 attributes provided, it was also selected by 78 respondents as the first or second most important attribute of their destination, independently of the main activity they would do during their holidays and the destination country. 
The ranking of the weather parameters for beach tourism is in agreement with the findings of other empirical studies indicating that temperature does not occupy the first place as the most important (de Freitas et al., 2008; Morgan et al., 2000). The presence of rain is seen as the most negative factor, at least within a "broad range of moderate or 'non-extreme' thermal conditions" (de Freitas et al., 2008, p. 405). When the results of the ranking are compared to those of the studies presented in Table 5.1, it can be seen that the sample of Dutch and Belgian tourists used in this research match only with the sample of New Zealanders. This result would sustain the idea that cultural differences between nationalities exist. However, it is important to note the different nature of the sample used by these studies -'young adult' segment represented by university students- as compared to tourists of different age groups in this study. Another conclusion is the difficulty of using a single universal index to measure climate suitability and climate change impacts as already suggested by Scott et al. (2008).

In relation to the role of temperature, whereas it is seen as an important aspect, high temperatures are hardly considered as an 'unfavorable weather' element for beach tourism (Table 5.6). Of all parameters provided to respondents to characterize these 'unfavorable weather', only low and high humidity are considered as more irrelevant than high temperatures, probably due to the difficulty to determine the effect of these two elements in isolation. The relatively less weight of temperature as compared to other weather elements has important implications for future assessments of climate change impacts on beach destinations in general and on the Mediterranean specifically, and suggests past assessments to be revised (see Chapter 7 for a reassessment of impacts). This result is even more significant when statements about an 'over-heated' Mediterranean are compared to other climate change impacts. From the impacts projected for the Mediterranean by the IPCC 4th Assessment Report (Alcamo et al., 2007) the next ones have been included on the questionnaire: increase frequency of forest fires; water availability restrictions affecting hotels; heat waves at destination; risk of diseases and; reduce extension of the beach area. In this case, heat waves would have 'no influence' or affect 'not too negatively' tourists' satisfaction for $88 \%$ of Dutch and $68 \%$ of Belgian surveyed tourists, and only a $4 \%$ of Dutch and a $6.8 \%$ of Belgian would be 'very negatively affected' by these events of extreme high temperature.

The ideal weather conditions respondents associated to beach tourism are a mean temperature of $28.3^{\circ} \mathrm{C}$, a light breeze (1-9 km/h), between 6 and 10 hours of sun and with no clouds. These results can be compared to those found by Scott et al. (2008) for beach environments (Table 5.10). Belgian citizens (this question was not included in the Dutch version) seem to prefer the same weather conditions as Swedish in all the assessed aspects. 
Table 5.10 Comparison of results for ideal beach conditions for different nationalities

\begin{tabular}{|l|c|c|c|c|}
\hline & This study & & \multicolumn{3}{|c|}{ Scott et al., 2008 } \\
\hline Country & Belgium & Canada & New Zealand & Sweden \\
\hline Temperature $\left({ }^{\circ} \mathrm{C}\right)$ & 28.3 & 26.8 & 24.9 & 28.5 \\
\hline Cloud cover & $0 \%$ of sky & $25 \%$ & - & $0 \%$ \\
\hline Wind & Light breeze & Light breeze & Light breeze & Light breeze \\
\hline
\end{tabular}

The studies that suggest the Mediterranean will be 'too hot' for tourism are based on our current knowledge on what ideal conditions might be, and not on what temperature suppose a threshold that once surpassed motivates the people to abandon the beach or to choose a different beach destination (see for example UNWTO et al., 2008 Box 17). Analyzing climate thresholds is also difficult as different people have different thresholds and even a same person might react differently to a stimulus in different times of his/her lifetime (Meze-Hausken, 2008). Studies based on observed tourists' behavior suggest that whereas minimum temperatures are important in determining tourists' presence on the beach, maximum temperatures above which tourists would leave the beach are a lot more difficult to determine (Martínez Ibarra, 2006 and Chapter 6 of this thesis).

Different studies on climate change impacts on tourism have suggested that as climatic conditions deteriorate in the Mediterranean due to increasing temperatures, northern European tourists might stay at their home country or neighboring areas (Amelung et al., 2007; Nicholls \& Amelung, 2008). The results presented here indicate that as much as $72 \%$ of the respondents would still travel to the Mediterranean even if the 'ideal weather conditions' they assigned to beach tourism would occur in northern Europe. Although this a big majority of the respondents, it must be acknowledged that it leaves room for a potential decrease in visits of as much as $28 \%$, which could have important implications for the tourism sector in many destinations. The restricted number of questionnaires does not allow for generalizations to be made, but these results could be a starting point into this aspect of climate change and tourism that has not been explored so far. It is remarkable that being weather the single most important attribute of the destination according to respondents, they will still travel if they find this attribute closer to their home. This factor indicates that besides weather, other features also play an important role attracting tourists.

Research by Braun et al. (1999) found that a scenario of improved weather in the north coast of Germany could result on tourists less eager to travel to the area than under current climate conditions. According to the authors this would be related to a 
potential overloading of tourists facilities due to better weather. Because tourists visiting north European destinations would seek an environment related to relaxation, an overdevelopment of the tourism industry could have a 'boomerang effect' and generate a decrease in numbers of tourists (Braun et al., 1999). The findings of the present study and those of Braun and colleagues would complement each other and reaffirm the importance of expectations and tourism experience in the field of climate change and tourism, aspect that has not received sufficient attention from the research community.

There are a number of limitations associated to the use of questionnaires. A specific problem for this research is that the optimality of weather conditions may be difficult to assess as the way a person experiences climate comfort depends on many factors such as age, gender and country of origin. Questionnaires might also be affected by the way in which respondents interpret the questions and the possible answers provided (closed questions). The way these drawbacks have been addressed in this research is by the use of triangulation (the application of other research techniques to obtain answers about the same phenomenon). This has been done by direct observation of tourists' behavior and its statistical association to weather conditions as it will be explained in the next chapter.

\subsection{Conclusions}

The Mediterranean, a world leading tourism destination, has been identified as a major vulnerable hotspot to climate change impacts. Increasing temperatures have been identified as a key hazard, leading to tourists' heat stress and therefore a potential decrease in the attractiveness of the region. Improvements in weather conditions in tourists' home countries and neighboring areas has also been suggested as a potential threat to Mediterranean tourists, as progressively more of these tourists would stay in their home country rather than traveling to the (over-)heated Mediterranean. The findings of this chapter are notably important as they have shown that the role of temperatures might not be as dominant as initially expected and that other weather components are considered more relevant. Specifically, high temperatures are not necessarily associated with 'unfavorable weather' for beach tourism. Even when the term 'heat wave' is used, tourists still perceive it as not affecting their satisfaction very negatively. Tourists' are also unlikely to stay at home even if they have good weather conditions in their own country.

These results have both theoretical and practical implications. From the theoretical point of view, the results invite to review previous studies that analyze climate change impacts on Mediterranean tourism. Studies that used general indices to measure climate suitability might be overestimating the capacity of these tools to project climate 
change impacts due to the cultural differences that seem to exist and their lack of adjustment to different activities. The high relevance some of these indices (e.g. Tourism Climate Index) give to temperatures does not seem to match the stated preferences of tourists in this and other studies. From the practical standpoint, the results suggest that future research and management interventions should pay more attention to other climate change impacts such as health issues and forest fires.

This chapter has broadened the limited knowledge on some of the assumptions in relation to tourists' perceptions and possible responses to climate change. The results indicate that this area has the potential to bring new insights and therefore deserves more attention from the research community. Using this study as starting point, future research could make possible the generalization of the results to all north Europeans by expanding the sample and including other nationalities representing the main source markets to the Mediterranean. The role of weather in respondents' country could be another aspect to include, as it might explain the differences found between nationalities. Other research techniques, such as conjoint analysis, could be used to check for the combined effect of different aspects, e.g. good weather in northern Europe and heat wave periods in southern Europe. The survey period could also be extended to cover at least the summer, to test if better weather conditions in the country of origin in the period of departure would have some effect on the respondents' answers. Depending on the results, autumn and winter could also be considered. 


\section{Chapter 6}

\section{LINKING BEACH RECREATION TO WEATHER CONDITIONS: TWO CASE STUDIES FROM THE NETHERLANDS AND SPAIN}

Based on:

- Moreno, A. (2007). The role of weather in beach recreation - a case study using webcam images. In Matzarakis, A., De Freitas, C.R. \& Scott, D. (Eds.), Developments in tourism climatology. Freiburg: Commission on climate, tourism and recreation - International Society of Biometeorology.

- Moreno, A., Amelung, B., \& Santamarta, L. (2008). Linking beach recreation to weather conditions. A case study in Zandvoort, Netherlands. Tourism in Marine Environments, 5(2-3), 111-119. 



\section{LINKING BEACH RECREATION TO WEATHER CONDITIONS: TWO CASE STUDIES FROM THE NETHERLANDS AND SPAIN}

It is common knowledge that beach visitation is strongly related to weather conditions. Sunshine and higher temperatures are correlated with more crowded beaches, whereas cold, rain and wind cause low levels of beach use. Remarkably, there is relatively little scientific knowledge about the exact relationship between weather factors and beach visitation, or about the relative importance of the weather when compared to other factors, such as the hour of the day. Until recently, this knowledge gap went largely unnoticed. Although the weather has always been highly variable, the climate was considered relatively stable, and the tourist sector was generally well adapted to it. The position of the climate as a stable factor is being undermined by climate change. All around the world, climate change is projected to lead to structural shifts in the spatial and temporal patterns of climatological suitability for tourism purposes (Amelung et al., 2007; Mather et al., 2005).

Various methods have been used to assess the influence of weather and climate on recreation and tourism, including index-based and survey-based approaches. The purpose of the index-based approaches is to describe the climatic suitability of a region for tourism purposes based on its weather and climate patterns as summarized in an index (see Chapter 7).

The purpose of the survey-based approaches is to establish empirical relationships on a local scale between weather variables and tourist satisfaction or visitation. This line of research is primarily aimed at eliciting respondents' stated preferences by means of questionnaires. With this technique, de Freitas (1990) analyzed the perception of weather elements by beach users in Australia to define overriding climate factors and threshold values for beach activities. Morgan et al. (2000) surveyed more than a thousand beach tourists from northern Europe to quantify their weather preferences for 'sun \& sea' recreation. Scott et al. (2008) explored weather preferences for three environments -beach, city and mountain- with a sample of students from different countries and more recently Rutty \& Scott (2009) used also a sample of students to elucidate ideal temperature and thresholds for beach and urban tourism in Europe. This method has also been used in Chapter 5 of this thesis. A main drawback of these survey-based approaches lies in the potential different interpretations respondents give to both the questions and the answers provided (Suchman \& Jordan, 1990). Moreover, stated preferences may be only loosely connected to revealed preferences, i.e. to actual behavior. 
The role and existence of thresholds and optimal weather conditions for beach recreation is poorly understood. Various studies suggest temperatures of around $27^{\circ} \mathrm{C}$ to be the optimal for the practice of sun and beach activities (Besancenot, 1990; Gómez Martín, 2006; Martínez Ibarra, 2006). Some authors like Perry (2005) suggest that heat waves and high temperature, which could become more frequent due to climate change, may put at risk the continuation of tourism in the Mediterranean. However, there is certain disagreement about the effect high temperatures have on the presence of tourists on the beach. Martínez Ibarra (2006) analyzed the relationship between weather and the number of beach users in Alicante (Spain) by direct observation. His study, which included the heat wave of 2003, suggests that higher temperatures might indeed stimulate people's participation in beach recreation. To obtain a comprehensive understanding of the influence of weather and climate on beach tourism and to estimate the magnitude of the impact of climate change on these activities, more knowledge about the current influence of the weather on tourists' behavior is indispensable.

The new technology of webcams, in combination with the availability of real-time weather data, provides an innovative approach to the study of the relationship between weather and beach use. It allows for the exploration of real behavior in relation to on-site weather conditions. Webcams are stationary cameras that are used to capture and transmit still and live images commonly using Internet as a platform for their diffusion. Their ease of use, as well as the increasing access to high-speed internet have proliferated the use of webcams in many fields. This has not gone unnoticed by the tourism sector, which has been using them as marketing tools for destinations and diverse tourism attractions (Timothy \& Groves, 2001). Despite the extensive use of webcams by tourism offices and businesses, and the sometimes large numbers of people consulting them ${ }^{1}$, researchers have hardly used this technology for tourism studies.

Timothy \& Groves (2001) were the first to explore the multiple uses that webcam images provide for tourism research. Their analysis of 300 webcams on the internet identified weather conditions, crowd density, existence and changes in tourism facilities and infrastructures, and car registration numbers as the main four types of data that could be obtained and used for tourism research. One of the main benefits of using this technology is that real behavior can be studied. Another important characteristic is the possibility of analyzing different locations at the same time, allowing for the compilation of a relatively large dataset.

\footnotetext{
${ }^{1}$ (Princess Cruises reported that one of their cruise webcams was visited by some 77,000 viewers a day in 1999, cited in Timothy \& Groves, 2001)
} 
Examples of the use of webcam images in beach tourism research are given by Kammler \& Schernewski (2004) and Martínez Ibarra (2006), and applied to recreation planning in Jiménez et al. (2007) as part of the ARGUS program. Kammler \& Schernewski focused on temporal and spatial patterns of visitors at the beach in Warnemünde (Germany), installing their own webcam to obtain information about the density of visitors. The results of their work show an important relationship between weather conditions and visitation. Unfortunately, the study contains little methodological detail; for example the term 'very good weather' was not specified. The study by Martínez Ibarra aimed at identifying the thresholds and optimal weather conditions for different aspects of beach recreation (sunbathing and swimming) along the coast of Alicante (Spain), using weather information and data on density of use of the beach obtained from webcam images. From August 2002 until December 2003, one image per day was recorded at $12 \mathrm{pm}$. These images were assessed in terms of density of users and classified into one of four categories numbered 0 to 3 , with 0 representing an empty beach, and 3 denoting maximum concentration of visitors. More case studies on weather and beach use are needed to verify the results obtained by previous studies, to test new hypotheses, and to allow for comparison of case study results.

The primary aim of this chapter is to explore the relationship between weather conditions and beach recreation by looking into real tourists' behavior and making use of the resources available on the internet. The influence of different weather variables will be assessed in relation to the presence of users on the beach. The study will also evaluate the relevance of other elements such as the day of the week and the hour of the day. To do this, webcam images and on-site weather data were compiled during the summer of 2006 for two sites: Zandvoort (The Netherlands) and Rosas (Spain). In this research the terms 'visitor' and 'user' are applied interchangeably to refer to people who are present on the beach with the intention of sunbathing or swimming, excluding other uses from the analysis.

The chapter is organized as follows. Section 6.1 describes the layout of the study, and its methodological setup. The next two sections are focused on the two different case studies and include a short description of the study areas and an analysis of the main results of each. A discussion of the main findings follows in section 6.4 and in the last section some conclusions are presented. 


\subsection{Methodology}

Two coastal towns were chosen for this study: Zandvoort (The Netherlands) and Rosas (Spain). These two locations fulfilled the following basic criteria: (1) the webcam images were of high enough quality to extract information about density of use, while being coarse enough to avoid moral and legal issues associated with identifying individuals; (2) the image was refreshed (updated) every five minutes, allowing almost continuous observations; (3) weather data for the same time intervals from a nearby location was readily available on internet; (4) they provided information for two different types of resorts with a good spatial distribution: one in northern Europe and the other one in Mediterranean Europe.

The original plan was to save webcam images and weather data on an hourly basis between 9 am and 9 pm between July 1 and August 16, 2006 for both locations. As the retrieval of images was done manually, however, their number varied widely, leaving some parts of the day (in particular the evening and early morning) structurally underrepresented. After this period, several hundreds images and weather data had been collected and were ready for analysis. The first operation done with the set of 'raw' data was to filter out unusable images, followed by the classification of the remaining images. Various techniques for doing this were reviewed. The technique used by Kammler \& Schernewski (2004) and Jiménez et al. (2007), which entails a softwarebased analysis of pixels to extract information about beach use, was initially considered very promising but proved to be technically unfeasible. The more qualitative approach proposed by Martínez Ibarra (2006) was used instead, albeit in a slightly adjusted form. This approach consists of establishing a number of density classes, identifying the most representative image for each of these classes, and subsequently sorting all remaining images to the different density classes based on their similarity to the archetypical images. Instead of the four classes used by Martínez Ibarra (2006), three were used in this study, labeled 'low', 'intermediate' and 'high'. 'Low' refers to situations of no or low use of the beach; 'intermediate' represents situations of medium densities; 'high' refers to situations in which the beach is crowded.

The classification of the images (i.e. the decision of whether an image represents 'low', 'intermediate' or 'high' density) is based on the subjective assessment by the researcher; doing a head count of the tourists on the beach was not possible. To improve the robustness of the results two different members of the research team carried out the classification of images independently. The two classifications were subsequently compared and the inter-rate of reliability or inter-observer level of agree-

\footnotetext{
${ }^{2}$ This section presents the methodological notes that apply to both cases. More specific information can be found on the section describing each case study.
} 
ment (Cohen's kappa statistic) was calculated. The resulting value of 0.84 for Cohen's kappa indicated that the strength of agreement between the observers was 'very good'.

The analysis of the data was performed in two steps. Step 1 tested the existence of climate overriding factors. Based on the literature two possible variables were identified and defined: precipitation and high wind speeds (de Freitas, 1990). Precipitation was implemented as a dummy variable that assumed the value of 1 for any observation done on a day with precipitation. For wind, different thresholds were found in the literature. De Freitas et al. (2004) propose a wind speed of $6 \mathrm{~m} / \mathrm{s}$ as a threshold for ideal conditions while Gómez Martín (2004) and Martínez Ibarra (2006) used 8 m/s. The analysis tested the existence of any threshold, comparing it to the values indicated in the literature. If these events were indeed found to be overriding, the cases in which these events occurred would be eliminated from the dataset used in step 2 .

The second step analyzed the influence of individual variables on the presence of users. Differences between the three density groups with respect to a specific variable were explored using different statistics. Variables considered included both weather related (heat index, temperature and wind) and other variables like the day of the week and the hour of the day. To carry out these analyses, the statistical software SPSS 15.0 was used.

\subsection{Case Study 1: Zandvoort}

\subsubsection{The study}

The Dutch coastal town of Zandvoort is located around $30 \mathrm{~km}$ west of Amsterdam. With a sandy beach that stretches for $9 \mathrm{~km}$, and having an average width of 100 meters, Zandvoort is one of the most famous coastal resorts of the country, receiving annually around 4.5 million visitors. Its short distance to some of the major cities of the country and its accessibility make it a common place for recreation, the beach being its main attraction.

The webcam images of Zandvoort are available from the internet site www.zandvoort.com. From the various webcam views that the website offers, two were systematically recorded for this study: the 'Central Beach Northwest' and 'Central Beach Southwest'. The former view was the primary source for the analysis of the density of visitors; the Southwest images were used to check for major differences in visitor densities between the two views that could indicate special circumstances or irregularities. The images cover an estimated section of around 300-400 meters of beach and are updated every 5 minutes (Figure 6.1). 


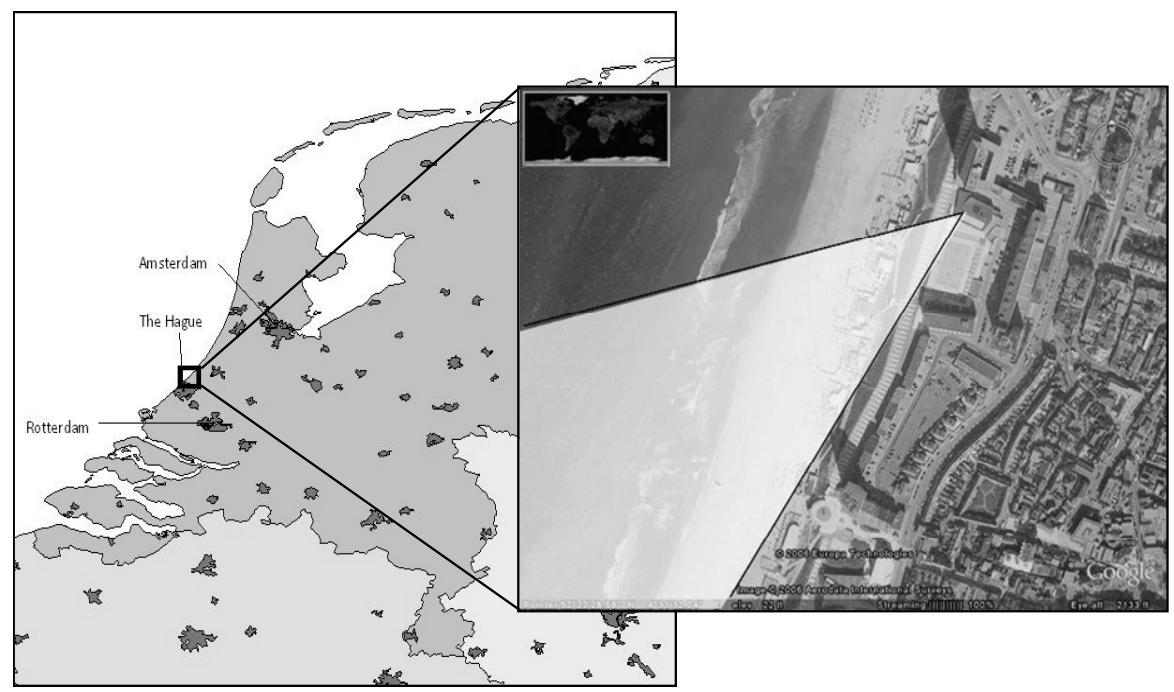

Figure 6.1 Location of Zandvoort and orientation of the webcam (Central beach Northwest)

At the time this research project began (July 2006), the Zandvoort website did not yet provide weather data. Therefore, the weather data was obtained from www.haarlemweer.nl, which displays information from a weather station in the nearby town of Haarlem. The approximate distance between the weather station and the beach is around seven kilometers. Of the different weather parameters provided by the meteorological station of Haarlem, the following variables are considered in this study: daily precipitation, heat index (a composite indicator that assesses the combined effect of temperature and humidity on the human thermal sensation), and wind speed.

All in all, a total of 246 images of the coast and weather data were saved. To prepare for the analysis, this set of 246 'raw' data points were pre-processed to filter out unusable images; two of the images were taken on foggy days and therefore removed from the set (Table 6.1). The remaining 244 images were subsequently sorted into density classes as explained previously on the methodology section. Figure 6.2 represent the archetypical representatives of each category group. 

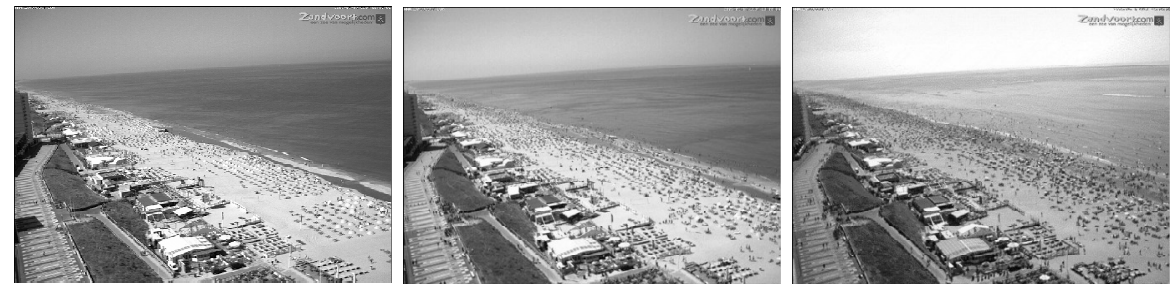

Figure 6.2 Archetypical images representing 'low', 'intermediate' and 'high' densities

\subsubsection{Results}

\section{Testing the existence of overriding factors}

Precipitation. July 2006 was one of the driest months on record in many parts of The Netherlands. The country's average precipitation during this month was $25 \mathrm{~mm}$, well below the normal $70 \mathrm{~mm}$ (KNMI, 2006b). August 2006, in contrast, was the wettest August in 100 years (KNMI, 2006a). The weather station in Haarlem registered only four days of precipitation in July, and in two of these cases the amount was less than $1 \mathrm{~mm}$, whereas in August, 12 out of 16 days analyzed were rainy days. Each and every observation made on rainy days fell in the category of 'low density'. This was the case even when the precipitation happened during the morning only and temperatures as high as 30 degrees were recorded during the afternoon. This result was considered sufficient evidence of the overriding nature of precipitation.

Hour Of The Day. The initial screening of the images revealed that all images taken in the morning (before $12 \mathrm{pm}$ ) and evening (after $6 \mathrm{pm}$ ) depicted 'low use' situations, regardless of weather conditions. Therefore from the initial set of 246 images, 87 were eventually used for the next step of the analysis: 72 from July and 15 from August (only those images taken between 12 and $6 \mathrm{pm}$ from days without rain) (Table 6.1). From these 87 images, 37 belonged to the 'low' ' '29' to the intermediate and 21 to the 'high' density group (Figure 6.3).

Wind. The analysis to test the overriding role of wind failed because there were no occurrences of wind speeds in excess of $6 \mathrm{~m} / \mathrm{s}(21.6 \mathrm{~km} / \mathrm{h})$. An analysis of all the values of wind was performed to check whether it was possible to find some correlation between the available data and the presence of users. However, this analysis showed no significant relationship between both elements. 
Table 6.1 Number of images recorded

\begin{tabular}{|l|c|c|c|c|}
\hline & $\leq 11 \mathrm{am}$ & $12 \mathrm{pm}-6 \mathrm{pm}$ & $\geq 7 \mathrm{pm}$ & Fog \\
\hline Month & & & & \\
\hline July & 27 & 72 & 13 & 2 \\
\hline August & 28 & 99 & 5 & \\
\hline $\begin{array}{l}\text { Density (days without rain) } \\
\text { Low }\end{array}$ & 55 & 37 & 18 \\
\hline Intermediate & - & 29 & - \\
\hline High & - & 21 & - \\
\hline
\end{tabular}

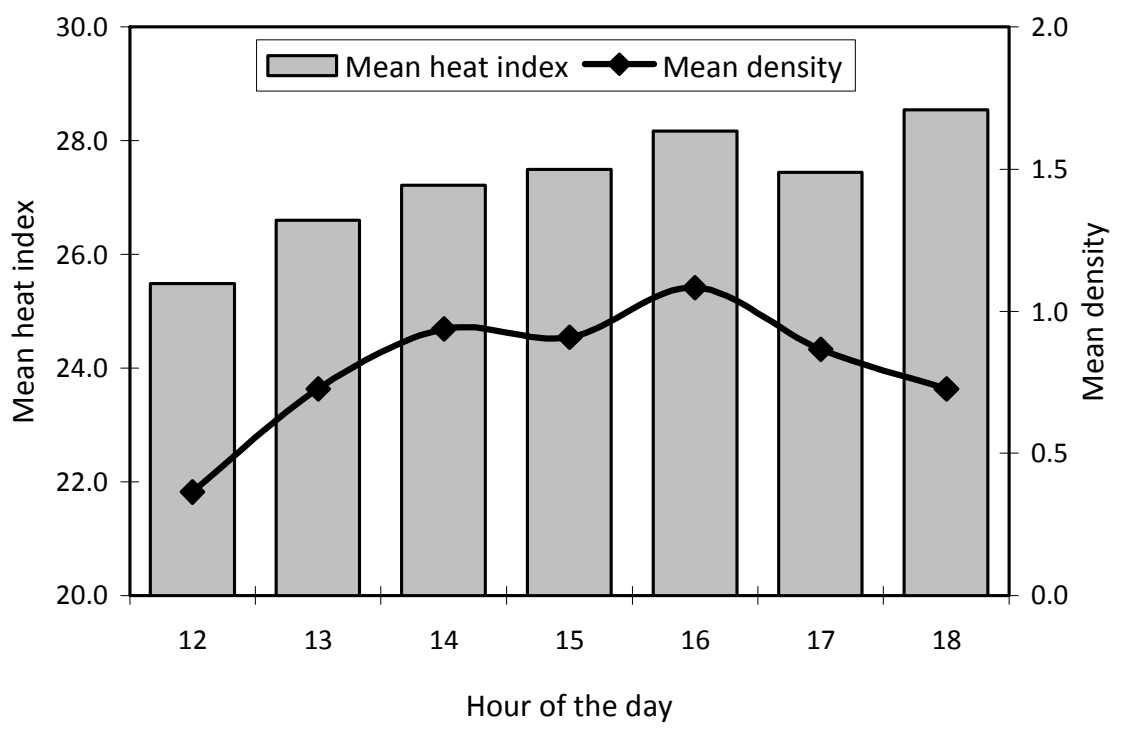

Figure 6.3 Distribution of mean temperatures and mean densities along the day during the whole recorded period (87 images)

\section{Analyzing predictive variables}

Heat Index. Heat Index is a composite measure that combines temperature and humidity and represents the thermal sensation of the human body. The index is based on work from Steadman (1979) and is commonly used in meteorology (e.g. by the National Oceanic and Atmospheric Administration - NOAA) as it represents the thermal body-environment relationship more closely than temperature only. 
Examination of the relationship between heat index and density of users of the beach showed important differences for the three categories, with low densities associated in general with lower scores and vice versa (Table 6.2 and Figure 6.4).

Table 6.2 Descriptive statistics of Heat Index per density group

\begin{tabular}{|l|c|c|c|c|c|}
\hline Density of visitors & $\mathbf{N}$ & $\begin{array}{c}\text { Mean Heat } \\
\text { Index }\left({ }^{\circ} \mathrm{C}\right)\end{array}$ & Std. Deviation & Minimum & Maximum \\
\hline Low & 37 & 23.7 & 2.6114 & 16.6 & 29.1 \\
\hline Intermediate & 29 & 28.9 & 2.2129 & 22.2 & 32.3 \\
\hline High & 21 & 31.4 & 2.2120 & 25.6 & 35.3 \\
\hline
\end{tabular}

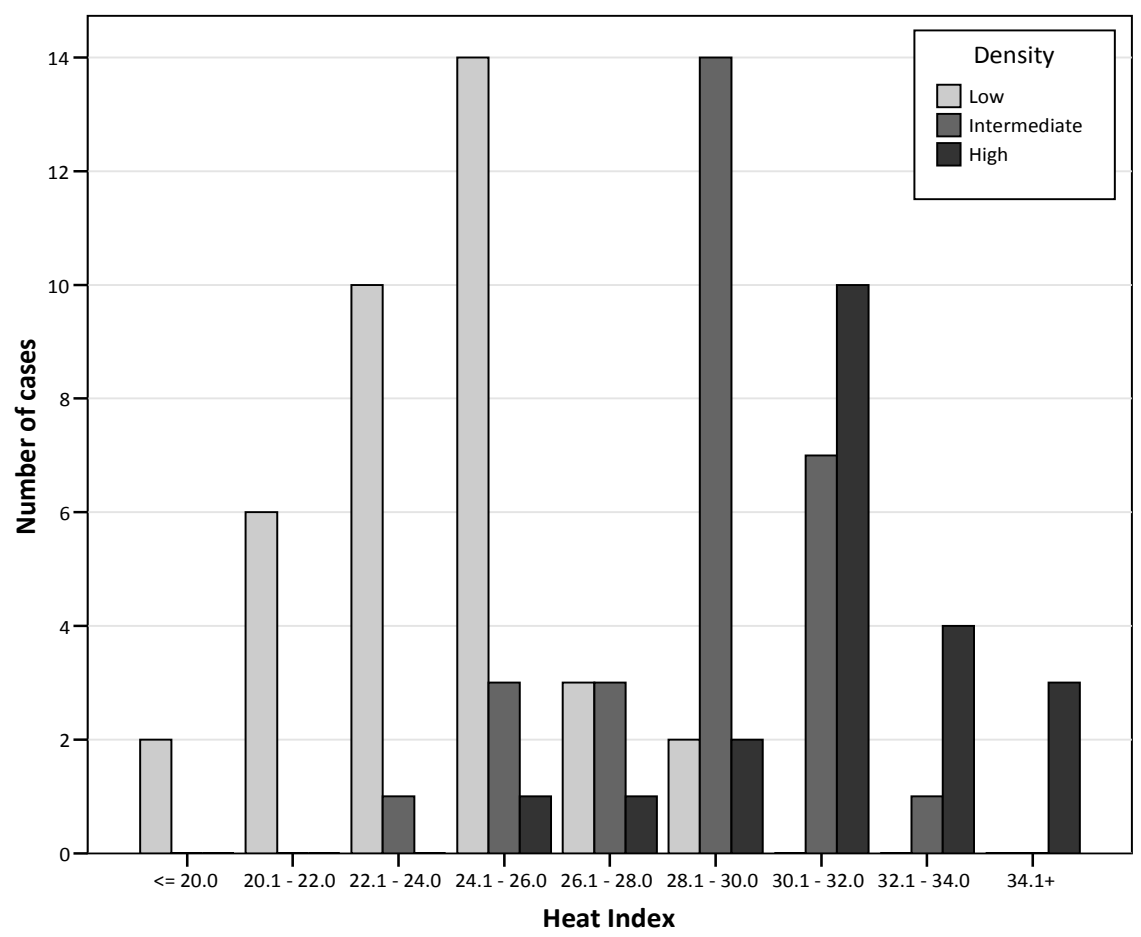

Figure 6.4 Number of images of each density category for different ranges of heat index (between 12 and 6 $\mathrm{pm}$ for days without rain)

To test differences between group means a one-way ANOVA was performed. The result shows a statistically significant difference between the three mean temperatures, $F(2,84)=79.723, p<0.001$. The linear correlation coefficient was 0.828 (Spear- 
man Rho). That is, $83 \%$ of the variance in the density groups of beach users can be accounted for (not explained, as this suggests causality) by the variance in heat index.

Day Of The Week. To test the potential influence of the day of the week (working day vs. weekend) on the density of users the variable was recoded into a dummy $(0=$ working day; 1 = weekend). The relationship between week day/weekend and density was not significant at the 5 per cent level $\left(\chi^{2}=0.532, D F=2\right)$.

\section{Predictive Discriminant Analysis (PDA)}

A final statistical analysis was carried out with the dataset of Zandvoort. This step analyzed the data obtained from the classification of images using the statistical technique of Discriminant Analysis. There are two basic variants of this method: the Descriptive Discriminant Analysis (DDA), aimed at describing differences between groups and the Predictive Discriminant Analysis (PDA), used to predict group membership (Huberty \& Hussein, 2003; Huberty \& Olejnik, 2006). While in DDA the response variables (weather in this case) are considered an outcome, in PDA the response variables have the role of predictors for assessing group membership (Huberty \& Hussein, 2003). In this study PDA was used to assess the potential use of weather parameters as predictors of density of beach users. For a detailed description of this technique the reader is referred to Huberty \& Olejnik (2006).

For the PDA, predictor variables were selected based on available data, analysis of it and expert judgment. Precipitation was not considered due to its overriding effect, while day of the week and hour of the day were eliminated from the list of variables since they were not significant in the test of equality of group means. Wind speed may be a useful variable but there were insufficient data points in this study to test its significance in the PDA.

Thus, only the variable Heat Index was eventually used as a predictor. The test of equality of group means was found to be significant at the 0.05 significance level, $F(2,84)=79.723, p<0.001$. The other requisite of Discriminant Analysis is the equality of the covariance matrices. The two tests carried out showed no evidence to conclude that they were different. The Box's $M$ test results were $F(2,13954)=0.562, p=0.570$, and the logarithms of the three covariance matrix determinants were 1.92, 1.59 and 1.59. This information supports the use of a linear classification function (LCF).

The 87 data points that were used in the previous section were also used for the PDA. The group sizes were $\mathrm{N}=37$ for 'low', $\mathrm{N}=29$ for 'intermediate' and N=21 for 'high' densities and therefore the prior probabilities were assigned by group size. 
To improve the robustness of the estimations a cross validation or leave-one-out rule was used. In this classification analysis each case is classified by the functions derived from all cases other than that case. This LCF is subsequently used to predict the group membership of the excluded unit (Huberty \& Olejnik, 2006).

The obtained linear classification function is:

SCORE $=(0.418 \cdot$ Heat_Index $)-11.412$

Where the score is the density group and heat index the predictor variable in degrees Celsius. Using this function, the results of the normal and cross-validated classification are presented in Table 6.3.

\begin{tabular}{|c|c|c|c|c|c|c|}
\hline & & & \multicolumn{3}{|c|}{ Predicted Group Membership } & \multirow[b]{2}{*}{ Total } \\
\hline & & Density & Low & Intermediate & High & \\
\hline \multirow[t]{6}{*}{ Original } & Count & Low & 33 & 4 & 0 & 37 \\
\hline & & Intermediate & 5 & 20 & 4 & 29 \\
\hline & & High & 1 & 4 & 16 & 21 \\
\hline & $\%$ & Low & 89.2 & 10.8 & .0 & 100.0 \\
\hline & & Intermediate & 17.2 & 69.0 & 13.8 & 100.0 \\
\hline & & High & 4.8 & 19.0 & 76.2 & 100.0 \\
\hline \multirow{6}{*}{$\begin{array}{l}\text { Cross- } \\
\text { validated }\end{array}$} & Count & Low & 33 & 4 & 0 & 37 \\
\hline & & Intermediate & 6 & 19 & 4 & 29 \\
\hline & & High & 1 & 5 & 15 & 21 \\
\hline & $\%$ & Low & 89.2 & 10.8 & .0 & 100.0 \\
\hline & & Intermediate & 20.7 & 65.5 & 13.8 & 100.0 \\
\hline & & High & 4.8 & 23.8 & 71.4 & 100.0 \\
\hline
\end{tabular}

There were $79.3 \%$ of original and $77.0 \%$ of cross-validated grouped cases correctly classified using the predictor Heat Index. Due to the difference in group sizes, if a unit (i.e. a day of week and hour) was to be related to one of the three density groups just using chance, there would be a $42.5 \%, 33.3 \%$ and $24.1 \%$ chance that the unit is correctly associated to the 'low', 'intermediate' or 'high' group respectively. However, if heat index is used as predictor, the accuracy is significantly higher $(89.2 \%, 69.0 \%$ and $76.2 \%$ respectively), an evidence of the suitability and relevance of the predictor. 


\subsection{Case Study 2: Rosas}

\subsubsection{The study}

Rosas is located in Catalonia (Northeast Spain), in the north section of what is known as Costa Brava. Its position, less than $30 \mathrm{~km}$ from the French border and $160 \mathrm{~km}$ from Barcelona, makes of it an important town for both international and Spanish tourists (Figure 6.5).

Two webcam views were systematically recorded, one for analysis and one for verification purposes (available at www.roses.net). The images cover a section of several hundred meters of the beach and are updated every 5 minutes. Weather data was obtained from the automatic station that the Meteorological Service of Catalonia has on this locality (available at www.meteocat.com), which provides data in 30 minutes intervals. The weather variables included in this study are: daily precipitation, wind speed and temperature.

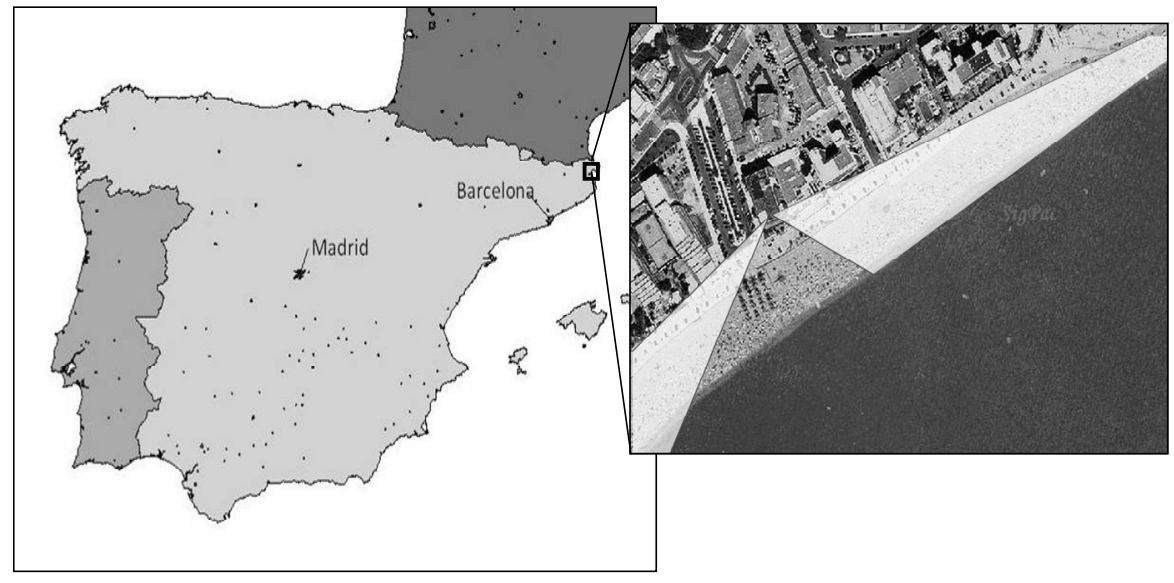

Figure 6.5 Location of Rosas and orientation of the webcams looking out on the beach

A total of 215 images of the coast and weather data were saved every hour between 9 am and 9 pm (July and August 2006). The images were subsequently sorted into density classes as explained previously on the methodology section. The images on Figure 6.6 represent the archetypical representatives of each category group. 

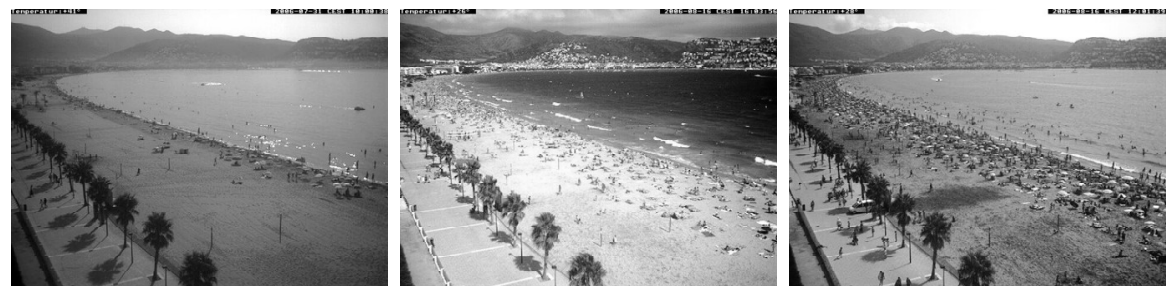

Figure 6.6 Archetypical images representing 'low', 'intermediate' and 'high' densities

\subsubsection{Results}

\section{Testing the existence of overriding factors}

Precipitation. The overriding effect of precipitation was assessed by transforming the variable into a dummy. In this way, when there was precipitation during one day, all those units taken after the rain happened were coded as 1 , while those units without precipitation were coded as 0 . The data from Roses showed only two days with precipitation during the period of study. During those days the beach was invariably empty, even if the rain occurred before $1 \mathrm{pm}$. This was considered sufficient evidence of the overriding nature of precipitation and therefore the 17 data points with precipitation were eliminated from the analysis.

Hour Of The Day. The initial analysis of the images revealed a strong bimodal distribution on the density of users depending on the hour of the day. Images taken at 9 and 10 am and 8 and $9 \mathrm{pm}$ felt invariable on the 'low' use category group regardless of weather conditions. After $10 \mathrm{am}$, the density of users increased to reach a peak at 12 pm. Between 12 and $3 \mathrm{pm}$ there was a marked decreased on the number of users, and after $3 \mathrm{pm}$ densities increased again to reach a second peak at $5 \mathrm{pm}$, followed by a progressive decrease after that hour (Table 6.4 and Figure 6.7).

Table 6.4 Number of images recorded

\begin{tabular}{|l|c|c|c|c|c|}
\hline & $\leq 11 \mathrm{am}$ & $12 \mathrm{pm}$ & 1 to $4 \mathrm{pm}$ & $5 \mathrm{pm}$ & $\geq 6 \mathrm{pm}$ \\
\hline Month & & & & & \\
\hline July & 20 & 9 & 33 & 8 & 19 \\
\hline August & 23 & 13 & 50 & 10 & 30 \\
\hline Density & 24 & & & & \\
\hline Low & 16 & 2 & 20 & 1 & 13 \\
\hline Intermediate & 3 & 2 & 50 & 2 & 10 \\
\hline High & 18 & 13 & 15 & 26 \\
\hline
\end{tabular}




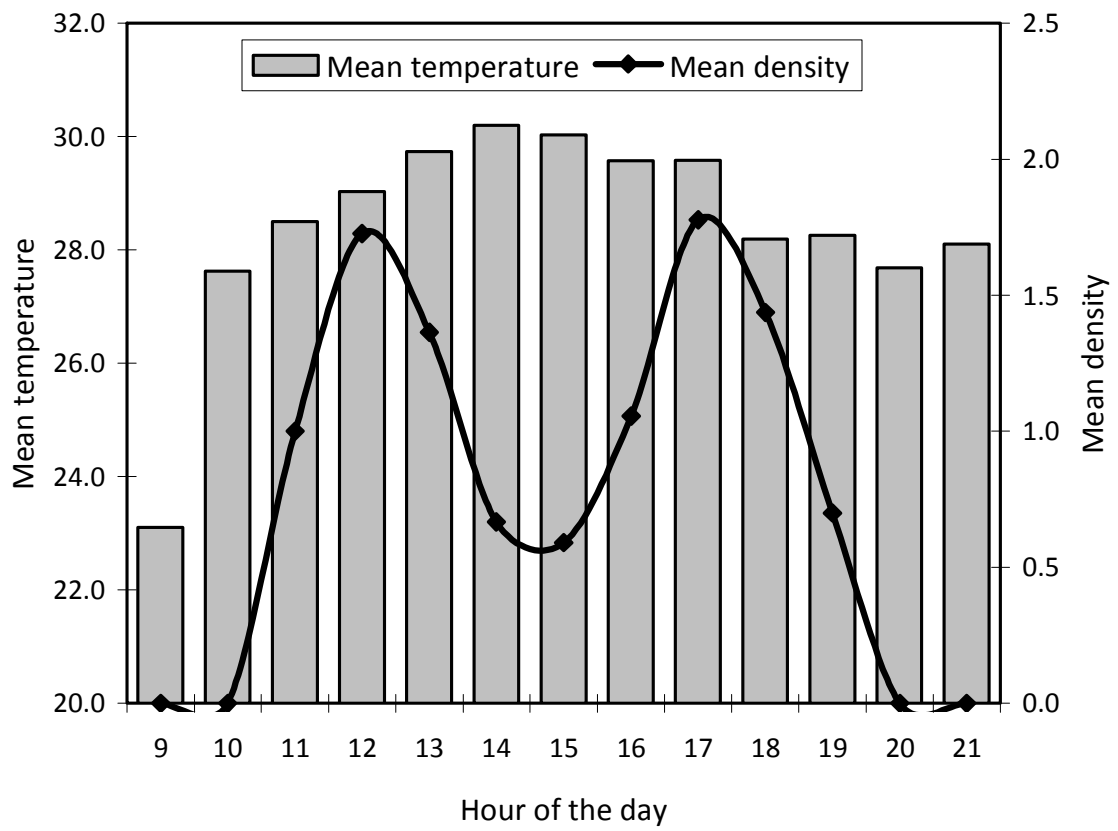

Figure 6.7 Distribution of mean temperatures and mean densities along the day during the whole recorded period

Wind. In general, high densities of users are linked to wind speeds above $2 \mathrm{~m} / \mathrm{s}$ (7.2 $\mathrm{km} / \mathrm{h}$ ), with a distribution of values having the shape of a reversed $U$, with a steep decrease in the number of cases above $6 \mathrm{~m} / \mathrm{s}(21.6 \mathrm{~km} / \mathrm{h})$. From the whole dataset, only 3 cases had 'high' densities with wind speeds above $7 \mathrm{~m} / \mathrm{s}(25.2 \mathrm{~km} / \mathrm{h})$ and only 1 case above $8 \mathrm{~m} / \mathrm{s}$ (28.8 km/h) (Figure 6.8). It is difficult to obtain definitive conclusions about the role of wind, however, since other elements such as the hour of day may have an overriding role. 


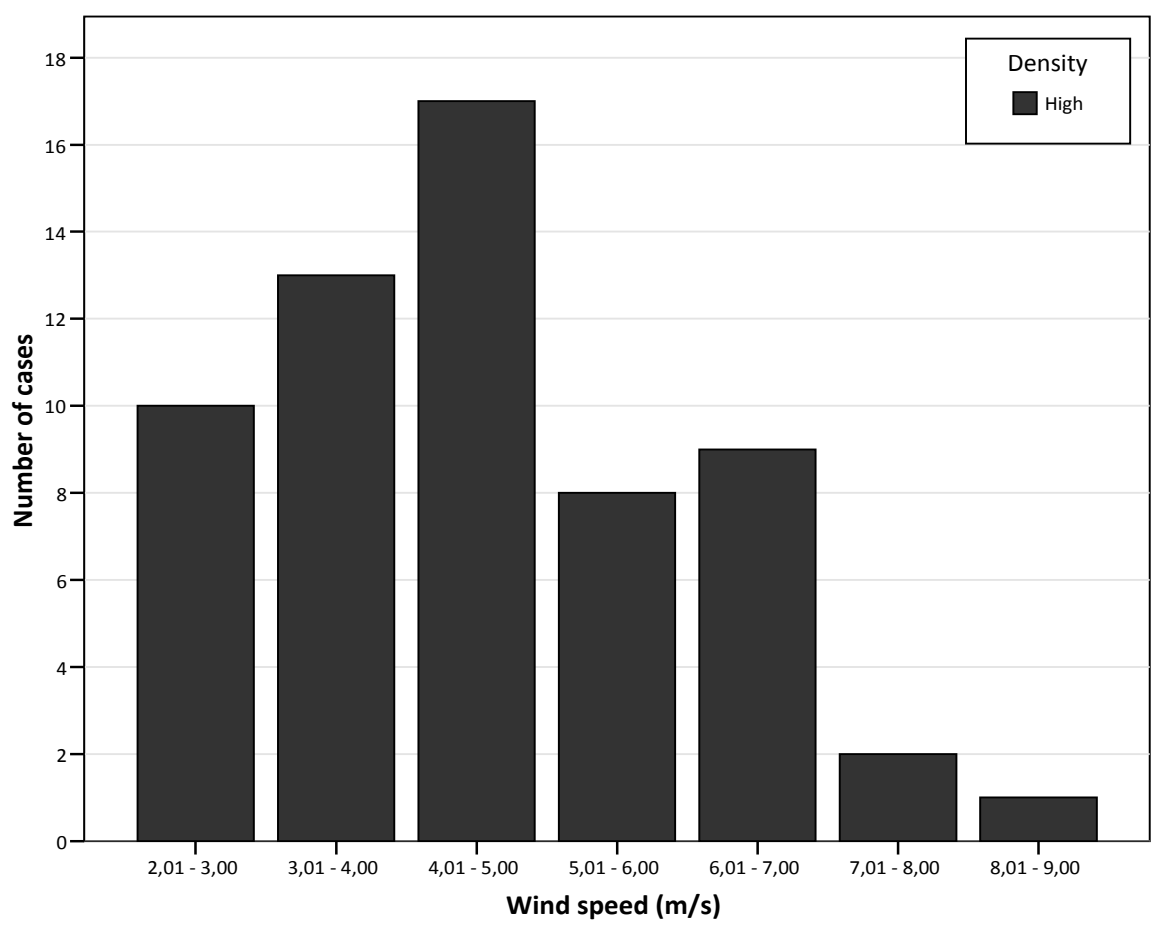

Figure 6.8 Distribution of 'high' density situations for different wind speeds

The analysis of the influence of wind speed is based on the idea that there is range of values for ideal wind conditions and a threshold above which high winds cause disturbance, blowing sand and tourists belongings. As Table 6.7 shows, the analysis of the 'low' densities during hours of the day when high densities could be expected (at 12 and $5 \mathrm{pm})$ suggested that wind speeds above $7 \mathrm{~m} / \mathrm{s}(25.2 \mathrm{~km} / \mathrm{h})$ could be the cause of such low densities. The statistical analysis supports this theory as the T-Test shows a significant difference between mean densities of users for values of wind below and above $7 \mathrm{~m} / \mathrm{s}(25.2 \mathrm{~km} / \mathrm{h})(\mathrm{t}=-2.6, \mathrm{p}=0.033)$.

Temperature. Before the analysis of temperatures was carried out, the dataset was reduced eliminating those units in which there was precipitation and those before at 9 and 10 am and 8 and $9 \mathrm{pm}$ (due to the inconclusive character of the analysis of thresholds for wind speed, no units were eliminated due to this element). The analysis of the relationship between temperature and presence of users at the beach for the remaining data units (171) is represented in Table 6.5 and Figure 6.9. A first look to the figure suggests that there is a certain threshold after which densities start to decrease. That 
would explain why the peak of 'high' density occurs at a temperature lower than the peak of the 'intermediate' density class.

Table 6.5 Descriptive statistics of temperature per density group and whole sample

\begin{tabular}{|l|c|c|c|c|c|}
\hline Density of visitors & $\mathbf{N}$ & $\begin{array}{c}\text { Mean Tem- } \\
\text { perature }\end{array}$ & Std. Deviation & Minimum & Maximum \\
\hline Low & 33 & 28.4 & 3.8794 & 23.1 & 34.7 \\
\hline Intermediate & 78 & 30.0 & 3.1160 & 22.4 & 35.6 \\
\hline High & 60 & 28.9 & 3.1371 & 22.4 & 34.9 \\
\hline
\end{tabular}

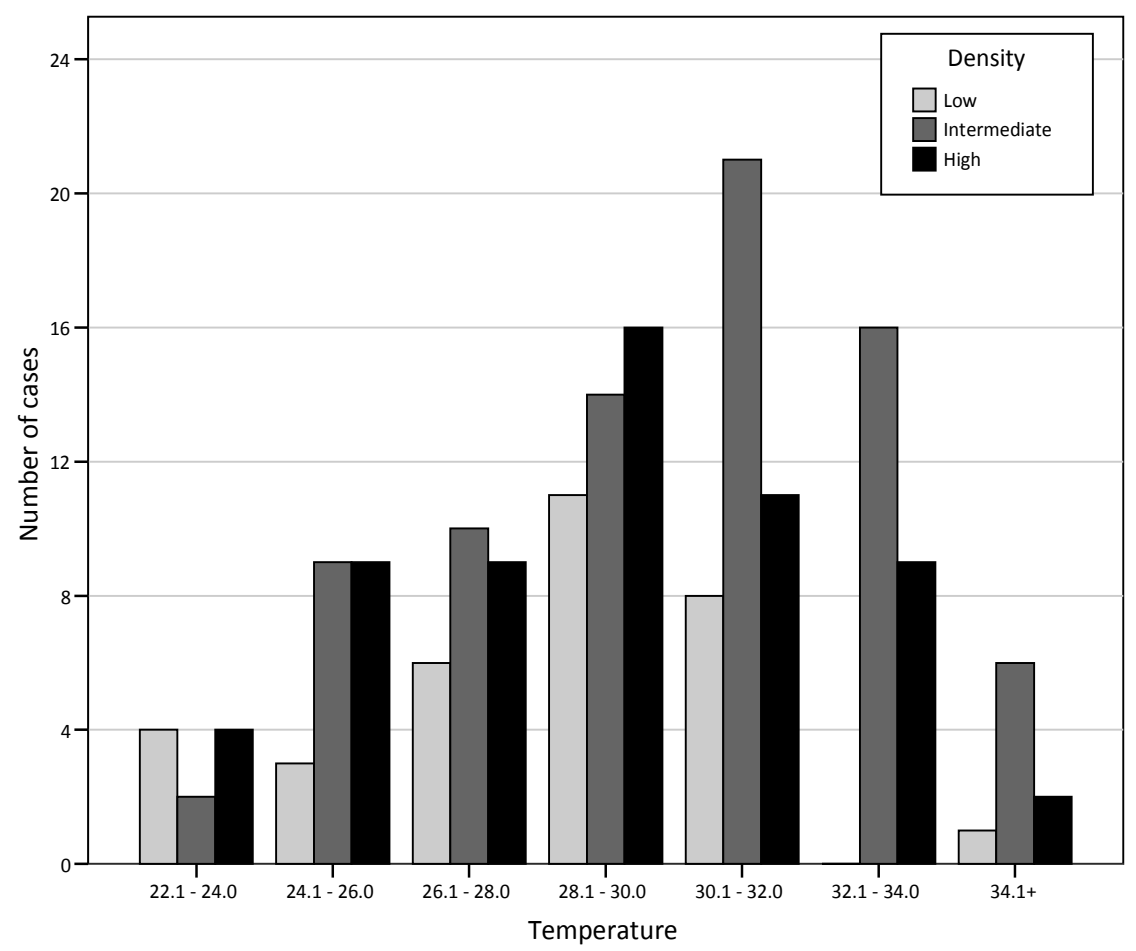

Figure 6.9 Distribution of density groups (171)

Figure 6.10, however, which is exclusively based on the cases at 12 and $5 \mathrm{pm}$ when the greatest concentration of 'high' densities can be found, reveals that the peak for this category is in fact much higher, between 28 and $34^{\circ} \mathrm{C}$. The implication could be that users are at the beach independently of the temperature, or at least that they are not deterred by high temperatures (see Table 6.6). 
Table 6.6 Descriptive statistics of temperature per density group at 12 and $5 \mathrm{pm}$

\begin{tabular}{|l|c|c|c|c|c|}
\hline & N & Mean & Std. Deviation & Minimum & Maximum \\
\hline Low & 3 & 26.533 & 2.7319 & 23.5 & 28.8 \\
\hline Intermediate & 4 & 29.800 & 1.0677 & 28.5 & 30.9 \\
\hline High & 33 & 29.470 & 3.4015 & 22.4 & 34.9 \\
\hline
\end{tabular}

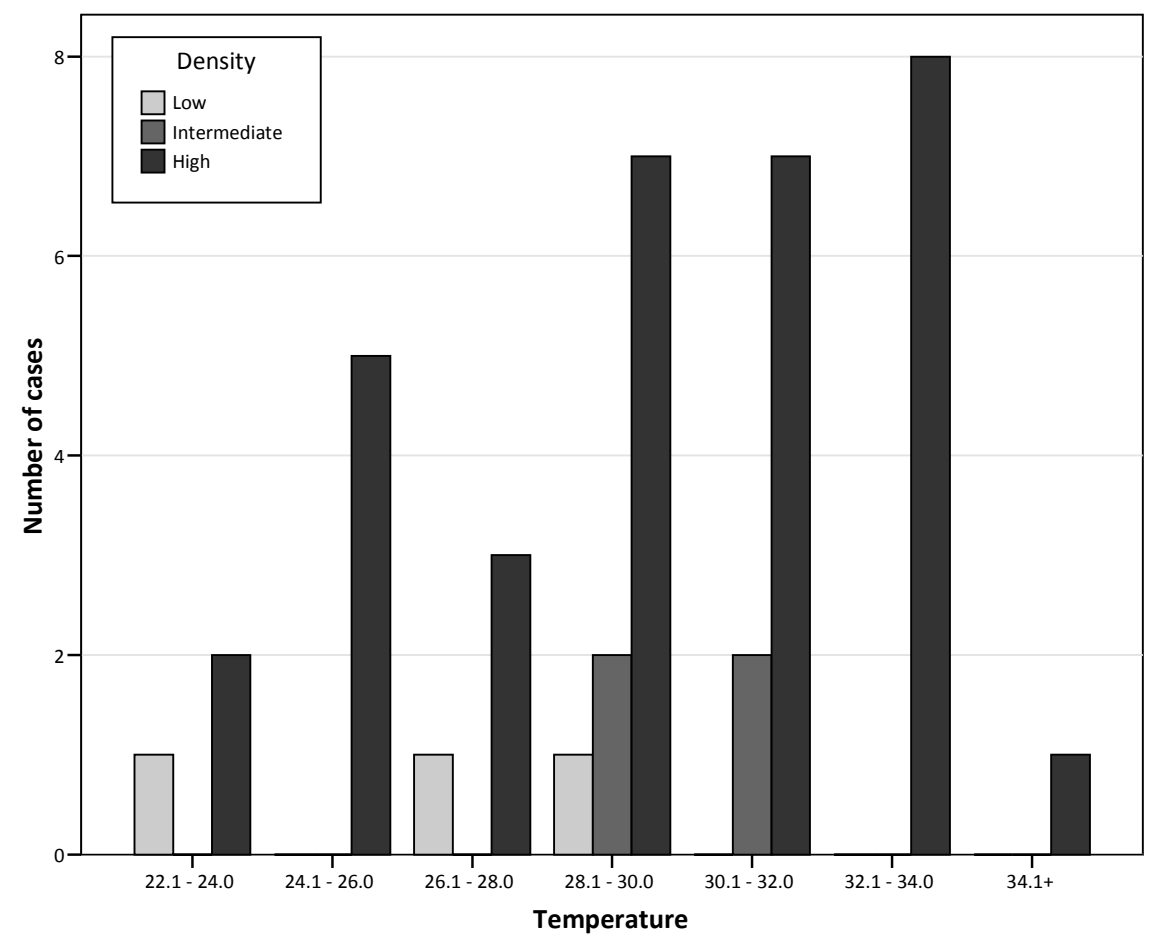

Figure 6.10 Distribution of density groups for at 12 and $5 \mathrm{pm}$

Another possibility is to analyze the cases at 12 and $5 \mathrm{pm}$ that had 'low' and 'intermediate' densities in order to obtain some information about the reason that could have caused the low densities during those typically crowded hours. Three cases exist for 'low' and 4 for 'intermediate' densities (Table 6.7). From the data on the table it seems that in at least 5 of the 7 cases the low and intermediate densities could be related to high wind speeds, whereas 1 case could be associated to low temperatures. For the other case (08/08), no apparent explanation seems to exist in relation to tem- 
perature and wind. Perhaps cloudiness played a role (aesthetic component), or the prospect of rain, as around $2 \mathrm{pm}$, the first rains were registered.

Table 6.7 Analysis of 'low' and 'intermediate' density cases at 12 and 5 pm

\begin{tabular}{|c|c|c|c|c|}
\hline Date & Day of the week & Hour & Temperature $\left({ }^{\circ} \mathrm{C}\right)$ & Wind \\
\hline Low & & & & \\
\hline $04 / 08$ & Friday & $12 \mathrm{pm}$ & 27.3 & $\mathbf{9 . 2}$ \\
\hline $08 / 08$ & Tuesday & $5 \mathrm{pm}$ & 28.8 & $\mathbf{7 . 7}$ \\
\hline $12 / 08$ & Saturday & $12 \mathrm{pm}$ & $\mathbf{2 3 . 5}$ & 1.6 \\
\hline Intermediate & & & & \\
\hline $19-07$ & Wednesday & $5 \mathrm{pm}$ & $\mathbf{7 . 6 0}$ \\
\hline $20-07$ & Thursday & $5 \mathrm{pm}$ & 28.5 & $\mathbf{7 . 0 0}$ \\
\hline $07-08$ & Monday & $12 \mathrm{pm}$ & 30.9 & $\mathbf{7 . 8 0}$ \\
\hline $08-08$ & Tuesday & $12 \mathrm{pm}$ & 29.4 & 3.50 \\
\hline
\end{tabular}

Regarding low temperatures, only on rainy days minimum temperatures dropped below the $21^{\circ} \mathrm{C}$ and as mentioned before on days with rain (especially during the morning hours) densities were invariably low. In the whole dataset there are four occurrences of times of the day with 'high' density and temperature between 22 and $24^{\circ} \mathrm{C}$ (Table 6.8). In all the cases these high densities were registered around the peak hour of 12 , supporting the idea that variables like the hour of the day may play a more important role, provided that certain minimum weather conditions are met.

Table 6.8 High density occurrences with temperature below $24^{\circ} \mathrm{C}$

\begin{tabular}{|l|c|c|c|c|}
\hline Date & Day of the week & Hour & Temperature $\left({ }^{\circ} \mathrm{C}\right)$ & Wind \\
\hline $13-08$ & Sunday & 13 & 23.3 & 3.50 \\
\hline $14-08$ & Monday & 12 & 22.4 & 4.80 \\
\hline $14-08$ & Monday & 13 & 23.3 & 3.30 \\
\hline $16-08$ & Wednesday & 11 & 23.9 & 2.80 \\
\hline
\end{tabular}

Day Of The Week. The influence of the day of the week (week day vs. weekend) on the density of users was done by recoding this variable into a dummy $(0=$ working day; 1 = weekend). The relationship between week day/weekend and density was not significant at the 5 per cent level $\left(\chi^{2}=0.733, d f=2\right)$. 


\subsection{Discussion}

This study has used webcam images to explore the relationship between weather and the presence of visitors in the beach at the coastal resorts of Zandvoort (The Netherlands) and Rosas (Spain). The discussion is structured around the main findings for both cases.

Precipitation. The scientific literature identifies primarily two weather elements with potentially overriding qualities in the context of beach related activities: wind and precipitation.

The discussion about the quantity or duration of precipitation that constitutes a threshold for the practice of the beach activities has been largely theoretical. This research supports the idea that rain may be overriding the influence of other weather variables (de Freitas, 1990; de Freitas et al., 2004). The analysis of both case studies shows that more important than the duration or quantity, the mere threat of rain might constitute a limiting factor, as Besancenot (1990) already suggested. Even very low quantities of rain during the morning hours seem to discourage people from going to the beach that day.

Hour of the day. The hour of the day is a key determinant of beach use. The two cases present very distinct average hourly density curves through the day. In Zandvoort, the density of users as measured by the three category groups exhibited an inversed- $U$ shape, with the central hours of the day presenting the highest average densities and the morning and evening (before $12 \mathrm{pm}$ and after $6 \mathrm{pm}$ ) showing invariably 'low' densities. In Rosas, the early morning and late afternoon had a similar behavior as in Zandvoort with low densities. However, the curve had a bimodal distribution with two peak density hours at 12 and $5 \mathrm{pm}$, with an important decrease in the presence of users in between. Similar distributions were found by van Herwerden et al. (1989) and Sinclair-Hannocks (1994) in relation to urban beaches in South Africa.

Different reasons might explain this difference between both destinations. First, it is possible that in Rosas high temperatures incite people to leave the beach during the central and warmest hours of the day. As it will be explained below, however, this is unlikely as similar temperatures were registered during 'peak' and 'low' hours (12 and $3 \mathrm{pm}$ respectively). Second, cultural differences between both case studies may play an important role as the lunch break is a well established cultural and social component in Spanish customs and therefore explaining why the density of users in Rosas beach is lower between 12 and 5 pm.

The third and perhaps least obvious reason to explain this difference could be that the type of visitors and the destinations themselves cause the difference. In Smith (1993) scheme, Zandvoort is a 'weather-sensitive' destination, whereas Rosas is a 'cli- 
mate-dependent' destination. 'Weather-sensitive' tourist destinations are those in which climate is not a tourist attraction itself, but in which weather conditions limit or might affect to a certain extent the involvement of visitors for certain activities. In this type of destinations flexibility to adapt plans and opportunism to take advantage of good weather are key concepts when the visitor plans outdoor activities. On the other hand, 'climate-dependent' destinations are those where climate is an important pull factor and tourist resource by itself and contributes to attract visitors who expect a "guaranteed summer sun" during their holiday at this destination (Smith, 1993, p. 401). All Mediterranean sun \& sea tourist resorts, including Rosas, would qualify as 'climate-dependent' destinations. According to this distinction, visitors in 'weathersensitive' areas (Zandvoort) would plan their activities based on daily weather conditions. On days with good weather, they would spend as much time as possible on the beach, uncertain as they are about the next opportunity for beach recreation. Users of Zandvoort beach could be categorized as 'day-trippers', i.e. visitors that reside relatively close to the coast, who engage in sun \& sea recreation for a day when the weather is nice. In a climate-dependent destination (Rosas), visitors usually spend longer periods of time and the good weather is 'taken for granted', i.e. they might feel there is some kind of security that good weather will continue during the rest of their holiday. This might stimulate people to behave differently, leaving the beach during the central hours of the day to come back in the afternoon. In the case of Rosas, the type of users are likely to fit the profile of 'holiday-makers' or the more traditional definition of tourists, i.e. people that travel to a region different to where they live and stay there for more than a day.

Wind. In the case of Zandvoort and with the available data it has not been possible to reach conclusions about the overriding effect of wind.

The case of Rosas, however, provided more information about this component. The analysis of the influence of wind speed seems to confirm previous research based on stated preferences where 'high' densities of users are primarily found to be associated with intermediate values of wind speed (de Freitas, 1990) resulting in a reversed Ushaped relationship between wind speed and tourist comfort. Regarding the existence of thresholds, different values were found in the literature. De Freitas et al. (2004) propose a wind speed of $6 \mathrm{~m} / \mathrm{s}$ as a threshold for ideal conditions while Gómez Martín (2004) and Martínez Ibarra (2006) used $8 \mathrm{~m} / \mathrm{s}$. In this study, the analysis of those cases with 'low' and 'intermediate' densities at 'peak' hours have revealed that in 5 out of 7 cases the relatively low number of users is very likely to be associated with wind speeds above $7 \mathrm{~m} / \mathrm{s}$.

Temperature. In Zandvoort, the analysis of the effect of the heat index on beach recreation identified a significant difference in the means of the three groups of densities, with high visitation levels associated with higher values of the index $\left(31.4^{\circ} \mathrm{C}\right)$. It is 
remarkable to notice that the image which was identified as presenting the highest density of people on the beach was also the image that had the highest associated temperature in the dataset (July 19th at $4 \mathrm{pm}$ with an air temperature of $36^{\circ} \mathrm{C}$, equivalent to a heat index of $35.3^{\circ} \mathrm{C}$ ).

In Rosas, it has not been possible to identify the existence of thresholds of minimum or maximum temperature. In the case of minimum temperature this is because, once the units affected by rain had been eliminated from the analysis, the minimum temperature registered was $21.7^{\circ} \mathrm{C}$ at $10 \mathrm{am}$, with a low density of users probably more related to the hour than to the temperature. Concerning maximum temperature, both at $12 \mathrm{pm}$ and at $3 \mathrm{pm}$, hours of maximum and minimum densities respectively, the maximum temperatures reached similar values, around $34^{\circ} \mathrm{C}$. Therefore, the decrease in the number of people that can be observed during the central and hottest hours of the day (between 1 and $4 \mathrm{pm}$ ) does not seem to be related to temperatures, but perhaps to cultural factors (between 1 and 4 is in general the lunch hour in Spain).

To eliminate the influence of the hours of the day and explore differences between groups in terms of temperature, the analysis was carried out on all those cases collected at $12 \mathrm{pm}$ and $5 \mathrm{pm}$. The results showed that 'low' densities at these hours are associated with mean temperatures of around $26^{\circ} \mathrm{C}$, while the intermediate and high densities are correlated with mean temperatures of approximately $29.5^{\circ} \mathrm{C}$, although the difference between the 'intermediate' and 'high' groups is not significant. It was also shown that the 'low' and 'intermediate' densities are likely to be related to the effect of wind rather than temperature at these hours.

Studies such as the one by Perry (2005) on the impact of climate change on Mediterranean tourism suggested that this region might become too hot to attract tourism due to rising temperatures, and therefore might lose part of its appeal. This study has not found any indication of a threshold or maximum temperature that might cause a decrease of the number of people present at the beach. The study from Martínez Ibarra (2006), which focused on one location in the Mediterranean and included data from the summer heat wave of 2003, had similar results. Both studies suggest that higher temperatures might not be as restrictive as was previously assumed for sun and sea tourism. This hypothesis requires more research since it could have important implications for the analysis of the impacts of climate change on tourism in many regions.

Day of the week. No significant correlation was found between the day of the week and the presence of visitors in any of the two study areas. This may be a result of the study period, which fell completely within the holiday period. A similar result was found by Sinclair-Hannocks (1994) when analyzing 3 consecutive summers, although she found a difference between weekdays and weekends when the four seasons were 
considered. A study covering more months of the year would be valuable as it could be expected that this variable does matter in seasons outside the summer holiday period.

Predictive Discriminant Analysis. In the case of Zandvoort, a Predictive Discriminant Analysis has been used to analyze the capacity of the variable heat index to predict density of users. The good classification results indicate a potential use of the method for predicting visitation densities at Zandvoort based upon this variable. According to the classification results obtained with the available sample a new unit could be correctly classified with a probability of almost $80 \%$. The classification could as well be combined with weather forecast or applied to new locations in order to test its validity and predictive capacity.

In the case of Rosas this type of analysis could not be tested since temperature and density does not show a linear correlation. This is supported by the fact that temperature is not significant in the test of equality of group means and therefore is not a suitable variable for this type of analysis.

\section{Limitations and recommendations for future research}

It is important to note that the results presented here are based on a study with a limited dataset and therefore the statistical results must be handled with care. The conclusion that there is a clear link between temperature and visitation levels should be tested more thoroughly by follow-up research projects.

Although very promising to analyze real behavior, this method does not provide information about the way people actually experience their environment, e.g. the fact that visitors decide to stay on the beach with a temperature of for example $40^{\circ} \mathrm{C}$ does not say whether the person is actually experiencing comfort or discomfort. Future research could combine observations with on-site questionnaires addressing this issue.

The method used to classify the different images into one of the three density categories is based on the authors' perception of visitor densities and therefore subjective. However, classifications performed by different people were shown to produce highly similar results. Ideally, future research should use an objective technique of determining densities.

Finally, the source of the climate data in the case of Zandvoort does not come from an official source (e.g. Dutch Meteorological Service - KNMI) and the station is not located at the beach. Some elements such as temperature and wind are affected by the distance to the shoreline (Jehn \& Jehn, 1979). Future research should address this issue by obtaining weather data from the exact location where the images are taken as in the case of Rosas. 


\subsection{Conclusions}

This chapter has explored the relationship between beach recreation and weather conditions in the coastal towns of Zandvoort (The Netherlands) and Rosas (Spain). Webcam images available from the Internet have been used to obtain information relating to the presence of users on the beach and to correlate this with relevant variables like weather parameters and the hour of the day. The statistical analysis has shown that the presence of rain has an overriding effect over other weather variables, while the effect of wind has not been conclusive. However, in the dataset from Rosas it has been observed that on times of the day and with temperatures where high densities of users could be expected, values of wind above $7 \mathrm{~m} / \mathrm{s}$ cause in general low densities of beach use. The statistical analysis of mean densities was significant for wind speeds below and above $7 \mathrm{~m} / \mathrm{s}$.

Temperature has a strong influence on the density of visitors at the beach, with a trend towards higher numbers as the temperature rises. This study has produced no evidence for a threshold value of maximum temperature causing enough discomfort for people to leave the beach. This finding could have important implications for the field of climate change impacts on tourism. Previous studies stating that higher temperatures due to climate change might cause fewer tourists to travel to these regions (Perry, 2005, 2006) might be overstated. Even if such a threshold exists, the bimodal pattern observed in the density distribution along the day in Rosas could also suggest that tourists may be able to adapt to this conditions for example by leaving the beach at the hours of maximum heat as this research shows.

The hour of the day is to a certain degree an important element: during the morning and evening low number of users were found on the beach independently of weather elements, whereas between 12 and $6 \mathrm{pm}$ the influence of the hour is not significant and weather is the most important element. No statistical relation has been found between the day of the week and the density of users.

This work suggests the importance of precipitation and temperature for beach recreation, and the potential use of webcams for the study of the interactions between tourism/recreation and weather/climate. This type of research can produce new knowledge about the links between weather and beach recreation, such as the role and effect of high temperatures on beach activities. This information could then be applied to explore the possible consequences of climate change on this kind of tourism activities. Future work with webcam images should also attempt to include other elements in the analysis; de Freitas (1990) identified three groups of elements as determinant factors in the tourism and climate relationship: the thermal, physical and aesthetical. This study has only considered the thermal (heat index) and physical (rain and wind). The aesthetical component (e.g. sky conditions) has not been considered. 
The study also attempts to complement those studies which are based on interviewing tourists about their preferences such as the one presented in Chapter 5. However, the observed behavior does not necessarily relate to the way tourists perceive their environment and therefore the first type of studies are indispensable to know about how tourists experience and come into contact with the different weather elements. Only with studies combining both methodologies it will be possible to improve our understanding of the multiple relationships between weather/climate and tourism and the consequences climate change might have for the tourism sector. 


\section{Chapter 7}

\section{CLIMATE CHANGE AND TOURIST COMFORT ON EUROPE'S BEACHES IN SUMMER: A REASSESSMENT}





\section{Climate Change And Tourist COMfort ON EUROPE'S BEACHES IN SUMMER: A REASSESSMENT}

It is commonly agreed that the relationship between weather and recreation is highly dependent on the kind of activity that is assessed, with beach recreation, city visits or hiking requiring different weather conditions (de Freitas et al., 2008; Mieczkowski, 1985). This feature has been ignored in many previous assessments, which may have led to over and under-estimations of the impact of climate change for specific tourism segments. In this vein, Chapter 6 claims that tourism in the Mediterranean may not suffer as much from climate change as has been suggested by previous studies, because of the relatively high temperatures preferred by beach tourists (Rutty \& Scott, 2009).

Based on the work by Mieczkowski (1985), Morgan et al. (2000) developed a userbased climate index to assess the climate suitability of coastal destinations specific for beach recreation. They used a large number of empirical observations to improve and fine-tune the original index to beach activities. This chapter follows up on Morgan et al.'s work, exploring the climate suitability for beach tourism of all coastal zones in Europe, both at present and in a future scenario of climate change. In addition, it discusses the important implications that this suitability assessment shows. The results can assist long-term destination planning in coastal zones, reducing the vulnerability to impacts, and facilitating adaptation.

The chapter is organized as follows. Section 7.1 provides a general introduction to climate indices for tourism, including a more detailed discussion of Morgan et al.'s beach climate index $(\mathrm{BCl})$. Section 7.2 details the methodology and data used in this study. Section 7.3 presents the results. Section 7.4 compares these to outcomes from previous studies and puts them in a wider context, discussing their management implications and limitations. Finally section 7.5 concludes.

\subsection{Tourism Climate Indices}

Establishing the influence of climate and weather conditions on tourism is a complex matter. According to de Freitas (1990) there are three distinct aspects of climate that are relevant to tourism: thermal, physical and aesthetic aspects. The thermal component is primarily physiological in nature and determines the comfort of tourists. The physical component refers to climate features, such as rain and wind, which may cause physical annoyance. Finally, the aesthetic component represents climate features (e.g. sunshine) that may influence the tourist's appreciation of a view or landscape. Ideally, 
climate suitability assessments for tourism should take account of each of these three components.

Thermal indices, such as Physiologically Equivalent Temperature (PET) were originally developed to assess human comfort in general (Matzarakis et al., 1999), and later applied to tourism by Cegnar \& Matzarakis (2004), Morabito et al. (2004) and others. An advantage of thermal indices is that they are rooted in the long tradition of physiological research; a major drawback is that they disregard important non-thermal aspects of weather and climate. For a proper assessment of the suitability of climate and weather conditions for tourism purposes, the use of composite measures is to be preferred.

Several composite indices have been proposed, and employed in a number of studies. The Tourism Climate Index (TCl), developed by Mieczkowski (1985), is arguably one of the most sophisticated and commonly used ones. The index incorporates thermal components as well as physical and aesthetic features. It was developed with the 'typical' tourist in mind, who engages in light physical activities, such as sight-seeing, shopping and relaxing.

While being widely used (Amelung et al., 2007; Amelung \& Viner, 2006; Nicholls \& Amelung, 2008; Scott et al., 2004), the TCl presents a number of limitations, some of which apply to all climate indices. First of all, the $\mathrm{TCl}$ has been considered too coarse an indicator, as it is insensitive to the large variety of weather requirements that are posed by tourist activities. Mieczkowski (1985) explicitly mentioned the possibility to tailor the rating and weighting system to specific activities, but this flexibility has hardly been used so far. A second point of criticism is that the empirical validation of the index is relatively weak. In particular, there is very little known about the influence on tourism of the physical and aesthetic components of the climate. To a large extent, Mieczkowski's rating and weighting scheme is based on his personal views, expert opinion and existing biometeorological literature, the accuracy of which has so far not been tested extensively. Other, more subtle points of criticism are that the $\mathrm{TCl}$ does not take potential overriding effects of e.g. rain into account, and that it does not correct for potential inter-cultural and geographical differences in climate preferences as suggested by de Freitas et al. (2008).

Progress has been made in addressing these issues and improving the climate indices for tourism. De Freitas et al. (2008) proposed a new index that accounts for the overriding properties of some weather aspects and acknowledges the existence of inter-cultural differences in climate preferences. Morgan et al. (2000) developed a tailor-made climate index for beach tourism, based on Mieczkowski's TCl, but finetuned with empirical information. Morgan's framework is at the basis of this study, and is introduced in more detail in the following section. 


\subsubsection{Beach tourism climate index}

Morgan et al. (2000) devised a specific climate index for beach tourism that contained the same elements as Mieczkowski's (1985) TCl except for the daily (24-hour average) thermal component (i.e. thermal sensation, precipitation, sunshine and wind). The main difference between the two indices is in the rating and weighting schemes. While Mieczkowski based his schemes heavily on expert judgment, Morgan et al. based theirs on the stated preferences of actual beach users. These preferences were elicited from questionnaires, filled out by a total of 1354 north European beach users while spending their holidays in Wales, Malta and Turkey in 1994 and 1995.

Similar to Mieczkowski's TCl, Morgan et al.'s beach climate index (BCI) is made up of smaller components (sub-indices) that, after weighting, add up to a maximum score of 100 (ideal conditions). The weights are based on the importance that the beach users attached to each of the four components. Beach users expressed the importance values on a Likert scale between 1 (not important) and 9 (very important). The Likert scores for each component were added, and these aggregated scores were subsequently scaled so that they added up to 1 .

As Table 7.1 shows, this procedure results in weights that differ substantially from those proposed by Mieczkowski, with precipitation, wind and sunshine becoming more relevant at the expense of thermal comfort.

Table 7.1 Weightings (in \% of total maximum score) for the different components used by Morgan et al. and Mieczkowski

Climate Index (Morgan et al.)

\section{TCI (Mieczkowski)}

\begin{tabular}{|l|c|c|}
\hline Thermal sensation & $18_{\mathrm{a}}$ & $50_{\mathrm{b}}$ \\
\hline Precipitation & 29 & 20 \\
\hline Wind & 26 & 10 \\
\hline Sunshine & 27 & 20 \\
\hline
\end{tabular}

a Skin temperature (see thermal sensation below); b Effective temperature (40\% of the weight corresponds to Daytime Thermal Comfort Index and $10 \%$ to Daily Thermal Comfort Index)

The resulting equation is as follows:

(1) $\mathrm{BCl}=0.18 \cdot \mathrm{TS}+0.29 \cdot P+0.26 \cdot \mathrm{W}+0.27 \cdot \mathrm{S}$

In which $\mathrm{BCl}$ is the beach climate index, TS, P, W and $\mathrm{S}$ are the components of thermal sensation, precipitation, wind, and sunshine respectively. Each of the four 
components is itself represented by an index, with values ranging from 0 to 100 . These values are the beach users' evaluation of the underlying weather conditions.

To assess beach users' preferred thermal sensation, Morgan et al. (2000) adopted an approach proposed by de Freitas (1990), who found that descriptors of subjective thermal sensation ('very hot', 'cool', etc.) are strongly correlated to skin temperature. Skin temperature in turn is a function of the effective air temperature, proportion of sunshine, and wind speed, in addition to several individual characteristics (Green, 1967; cited by Morgan et al., 2000), which were set to representative values for North Europeans. Respondents were asked to rank 6 thermal descriptors in order of preference: three, two and one points were allotted to the first, second and third most preferred thermal sensation respectively. For each of the descriptors, scores were then aggregated and subsequently scaled, setting the value for the highest-scoring descriptor to 100 (Table 7.2).

Table 7.2 Relationship between thermal sensation, skin temperature (Ts) and the scoring systems (adapted from Morgan et al., 2000). Temperatures below 21.0 and above $36.5^{\circ} \mathrm{C}$ were allotted 0 points reflecting very cold and extremely hot conditions

\begin{tabular}{|c|c|c|}
\hline Thermal sensation & Ts & Index \\
\hline Cold & $21.0-25.9$ & 2 \\
\hline Cool & $26.0-28.9$ & 21 \\
\hline Neither cold nor warm & $29.0-32.4$ & 39 \\
\hline Warm & $32.5-34.4$ & 100 \\
\hline Hot & $34.5-35.4$ & 77 \\
\hline Very hot & $35.5-36.4$ & 24 \\
\hline
\end{tabular}

Morgan et al. (2000) adopted Mieckowski's rating scheme for precipitation. The maximum index value of 100 was assigned to instances of less than $15 \mathrm{~mm} / \mathrm{month}$, decreasing in linear fashion by 10 points for each additional $15 \mathrm{~mm}$ of precipitation. Amounts of precipitation exceeding $150 \mathrm{~mm} /$ month were given an index value of 0 .

Morgan et al.'s (2000) scheme for wind contains three categories. Wind speeds of less than $4 \mathrm{~m} / \mathrm{s}$ receive the maximum index value of 100 , whereas wind speeds greater than $6 \mathrm{~m} / \mathrm{s}$ correspond to an index value of 0 . A value of 50 is allotted to wind speeds of between 4 and $6 \mathrm{~m} / \mathrm{s}$. In Morgan et al.'s scheme for sunshine, continuous sunshine was allocated the maximum index value of 100 , falling in linear fashion to 0 for a situation of complete absence of sunshine.

The final Beach Climate Index $(\mathrm{BCl})$ can attain values ranging from 0 to 100 . Morgan et al. (2000) divides this range as suggested by Mieczkowski (1985), with values below 
40 seen as unfavourable, the range between 40 and 60 as acceptable, values from 60 to 70 as good, between 70 and 80 as very good, and scores above 80 as excellent for beach tourism.

\subsection{Data and Methods}

Morgan et al.'s (2000) beach climate index is applied without any changes in the original calculation schemes. Different from Morgan et al., who took their data from weather stations, the input data are taken from grid-based sets of observed and projected climate data. The CRU TS 1.2 dataset (New et al., 2002) is used to represent observed climate conditions. It contains mean monthly values for five climate variables (temperature, diurnal temperature range, precipitation, cloud cover and vapour pressure) for the $20^{\text {th }}$ century (1901-2000). The dataset has a spatial resolution of 10 arcmin longitude-latitude, which in Europe corresponds to approximately $16 \mathrm{~km} \times 16$ $\mathrm{km}$.

Projected climate data are taken from the TYN SC 1.0 dataset (Mitchell et al., 2004), which is based on outputs from transient coupled atmosphere-ocean General Circulation Models (GCMs). It contains all relevant climate variables at the same temporal and spatial resolutions as the CRU TS 1.2 dataset, except for wind speed. The TYN SC 1.0 dataset covers most of the $21^{\text {st }}$ century (2001-2080) for 16 climate change scenarios representing all possible combinations of four Intergovernmental Panel on Climate Change (IPCC) emissions scenarios described in the Special Report on Emissions Scenarios (SRES (Nakicenovic et al., 2000)), and four GCMs. Together, these 16 scenarios cover $93 \%$ of the range of uncertainty in global warming in the $21^{\text {st }}$ century as established by the IPCC (Mitchell et al., 2004).

It is generally advocated to use a wide range of scenario-GCM combinations to express uncertainty in future projections (IPCC-TGICA, 2007; Viner, 2002).To get an idea of the maximum impact of climate change on beach tourism, this chapter sets out to explore the implications for tourist well-being of scenarios in which the room for tourism growth is largest, and increases in emissions are highest. The SRES A1FI scenario meets these two criteria. It assumes rapid growth of global GDP and ongoing globalization with increased mobility, both of which contribute to tourism growth (Amelung, 2006); and it results in the highest emissions of all SRES scenario families. It is also the scenario that resembles the actual path of emissions most closely. In fact, the latest evidence suggests that "the emissions growth rate since 2000 was greater than for the most fossil-fuel intensive of the Intergovernmental Panel on Climate Change emissions scenarios" (Raupach et al., 2007). 
Climate models differ in their assumptions about the sensitivity of the climate system to changes in greenhouse gas concentrations. At the top-end of the spectrum is the $\mathrm{HadCM} 3$ model, which projects an increase in summer temperature of $5.4^{\circ} \mathrm{C}$, and a decrease in summer precipitation of $17.9 \%$ in Europe at the end of the century under the A1FI scenario. At the bottom-end of the spectrum is the CSIRO Mk2 model $\left(+3.1^{\circ} \mathrm{C}\right.$, $-0.1 \%$ precipitation under the same scenario). Together, the HadCM3-A1FI and CSIROA1Fl integrations cover a large share of the spectrum of climate projections for Europe (see Figure 7.1).
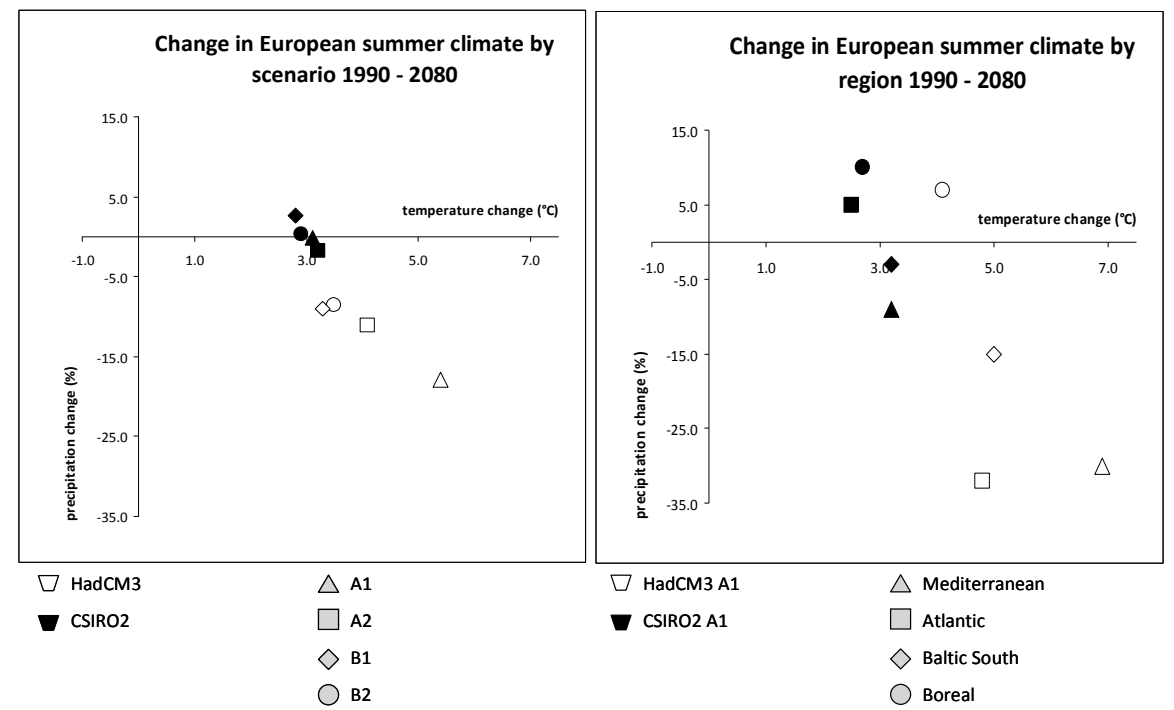

Figure 7.1 Changes in average summer temperature and precipitation in Europe between the baseline and the 2060s, according to the integrations of two climate models (HadCM3, CSIRO2) and: four scenarios (SRES $\mathrm{A} 1 \mathrm{FI}, \mathrm{A2}, \mathrm{B} 1, \mathrm{~B} 2$ ) (left) and for four different European regions (right)

Except for wind, all variables required for the calculations were either directly available from the climate models or could be inferred with some straightforward data transformations. Skin temperature (thermal component) was calculated based on effective temperature $\left({ }^{\circ} \mathrm{C}\right)$ and humidity (\%) using the formula proposed by Green (1967; cited in Morgan et al., 2000). The effective temperature was established with a nomogram as mentioned in the previous section. Humidity values were calculated from vapour pressure data as proposed by Bloutsos (1976; cited in Balafoutis et al., 2004), and sunshine values were inferred from cloud cover data. As wind speed is not a variable in the projected climate datasets, it was kept constant at the baseline value. 
Baseline conditions are represented by the 1961-1990 ('1970s') timeslice of the CRU TS 1.2 dataset. The 2051-2080 ('2060's) timeslice of the TYN SC 1.0 dataset is used to represent climate conditions in 50 years from now. The analysis is seasonally limited to changes in summer conditions, i.e. conditions in June, July and August, as this is by far the dominant season for beach tourism in Europe. Spatially, the analysis is limited to Europe's coastal zone, which is defined as the area within $100 \mathrm{~km}$ from the shoreline.

\subsection{Results}

Results are presented in three main subsections. In the first subsection (7.3.1), the baseline case is depicted. The second subsection (7.3.2) explores the effects of climate change on the distribution of climate suitability some 50 years from now ('2060s'). Finally, 7.3.3 explores the differences between the baseline case and projected future conditions, to address issues of uncertainty and thresholds of change.

\subsubsection{Baseline}

Figure 7.2 depicts the climatic conditions for beach tourism in the summer season of the baseline period. Very good and excellent conditions $(\mathrm{BCl} \geq 70)$ can be found along the Mediterranean coasts, from Spain in the West to Turkey in the East. Good conditions $(\mathrm{BCl} \geq 60)$ are found in the North of Spain and the Southwest of France, while the rest of the European coasts attain acceptable scores at best (index values below 60).

\subsubsection{Projected change and future state}

Under the A1FI scenario of the HadCM3 model (Figure 7.3 left), parts of the Mediterranean, including most of the Spanish southern coast, are projected to suffer a significant decrease in their suitability for beach tourism. Other highly popular destinations in the same region, including Italy and Greece, and the Mediterranean islands, however, are projected to maintain their high climate ratings. Another salient implication of this scenario is the notable improvement in climatic conditions around the Baltic Sea and along the Atlantic coast of Europe. In particular the northern coast of Spain and the western coast of France are projected to attain very good conditions by the second half of the century.

In the more moderate scenario CSIRO-A1FI the Mediterranean remains an excellent destination in terms of climate for sun and beach tourism (Figure 7.3 right). Some regions, such as the south coast of Spain (Guadalquivir Valley), could see their climate resources for beach tourism deteriorate, but in general the ratings remain very good or 
better. In the rest of Europe, only the Northwest of the Iberian Peninsula, and the Southwest (Pays de la Loire, Poitou-Charentes, Aquitaine) and Southeast (Côte d'Azur, Languedoc-Roussillon) of France reach very good ratings. Good ratings are projected only for parts of the Northwest of France and for isolated areas along the southern and south-eastern shoreline of the Baltic Sea (Poland, Lithuania, Latvia). The conditions in the Southeast of the UK, the North Sea region, and the northern shoreline of the Baltic remain unchanged. 


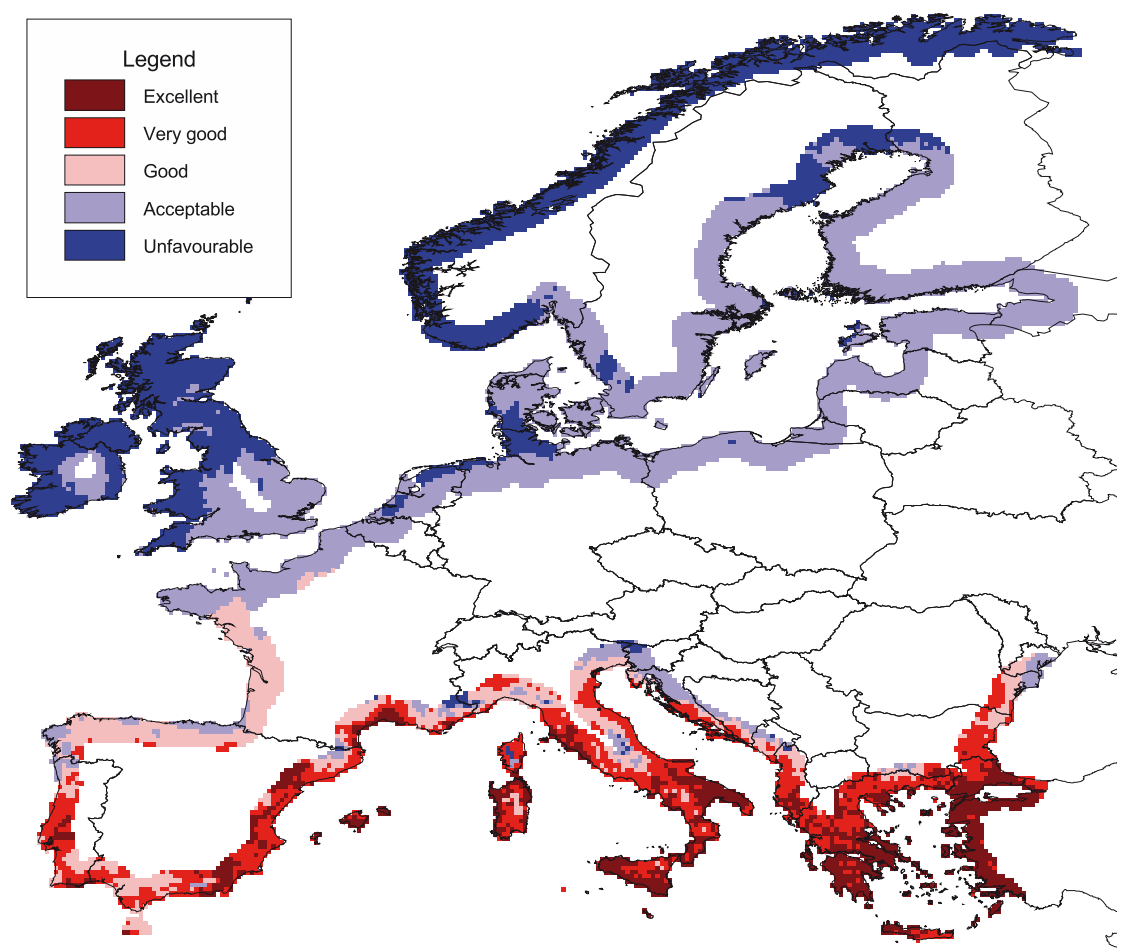

Figure 7.2 Beach tourism climate index for current summer conditions
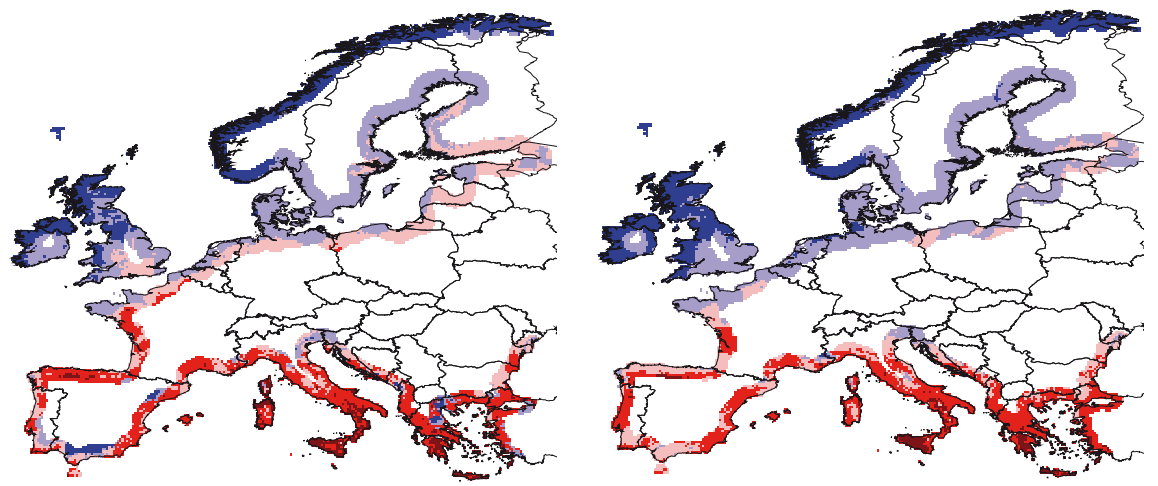

Figure 7.3 Beach tourism climate index during summer in the 2060's according to the HadCM3-A1FI model (left) and to the CSIRO2-A1FI model (right) (legend as in Figure 7.2) 


\subsubsection{Agreement and disagreement between scenario results}

To explore the potential range of change with respect to current conditions, the level of agreement between the maps for the current and the two future states is assessed. $\mathrm{A} \mathrm{BCl}$ of 70 is used as the cut-off score for pleasant beach conditions. In general, the two models produce very similar maps projecting what areas will attain scores above 70 in the 2060s and what areas will not. In a relatively limited number of cases, they disagree (see Figure 7.4 left). A possible explanation may be that the relatively 'cooler' parts of the Mediterranean warm up just fast enough to become too hot for comfort according to the HadCM3 model, but not according to the CSIRO model. More towards the North, some of the relatively 'warmer' regions warm up too slowly for comfort according to the CSIRO model, whereas they just exceed the minimum values in the HadCM3 model. The rest of the section focuses on the cases for which the two models are in agreement.

A first category of interest is made up by coastal regions that enjoy very good conditions $(\mathrm{BCl} \geq 70)$ at present and continue to do so in both scenarios considered. Most of the Mediterranean area falls into this category. A second category includes those coastal regions that at present have values of $\mathrm{BCl}$ below 70 and that will also not attain very good conditions during this century. This category encompasses all coasts in the northern half of the continent as well as some isolated areas in the Mediterranean (see Figure 7.4 right).
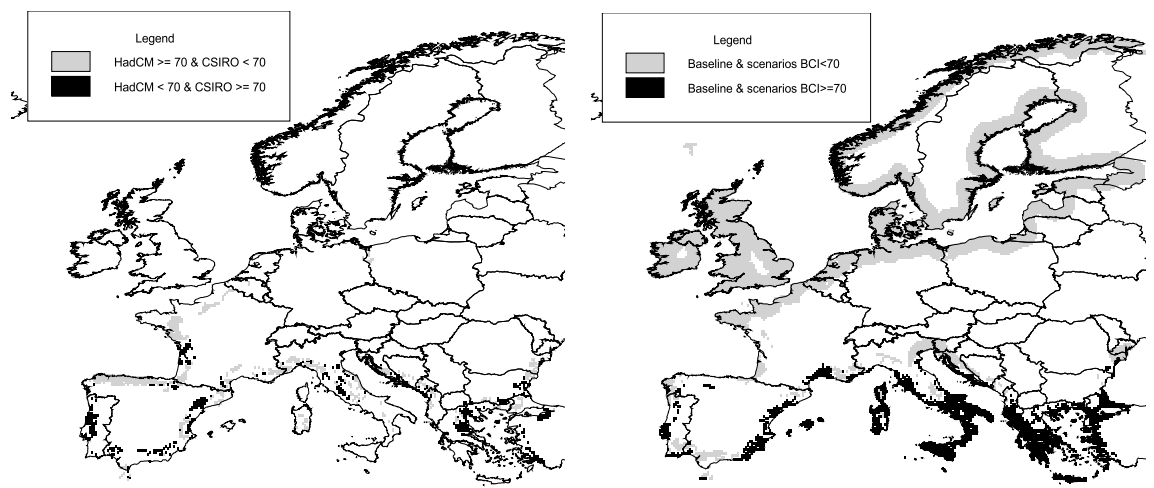

Figure 7.4 Beach tourism climate index disagreement between climate change scenarios (left) and agreement between baseline and the two climate change scenarios (right)

A third important category is formed by the regions that currently have a $\mathrm{BCl}$ lower than 70 , but that will attain scores in excess of 70 in both scenarios considered, i.e. even if the moderate CSIRO2-A1FI scenario materializes ('winners'). The Northwest of 
the Iberian Peninsula and the French regions of Poitou-Charentes and Aquitaine are in this category (see Figure 7.5).

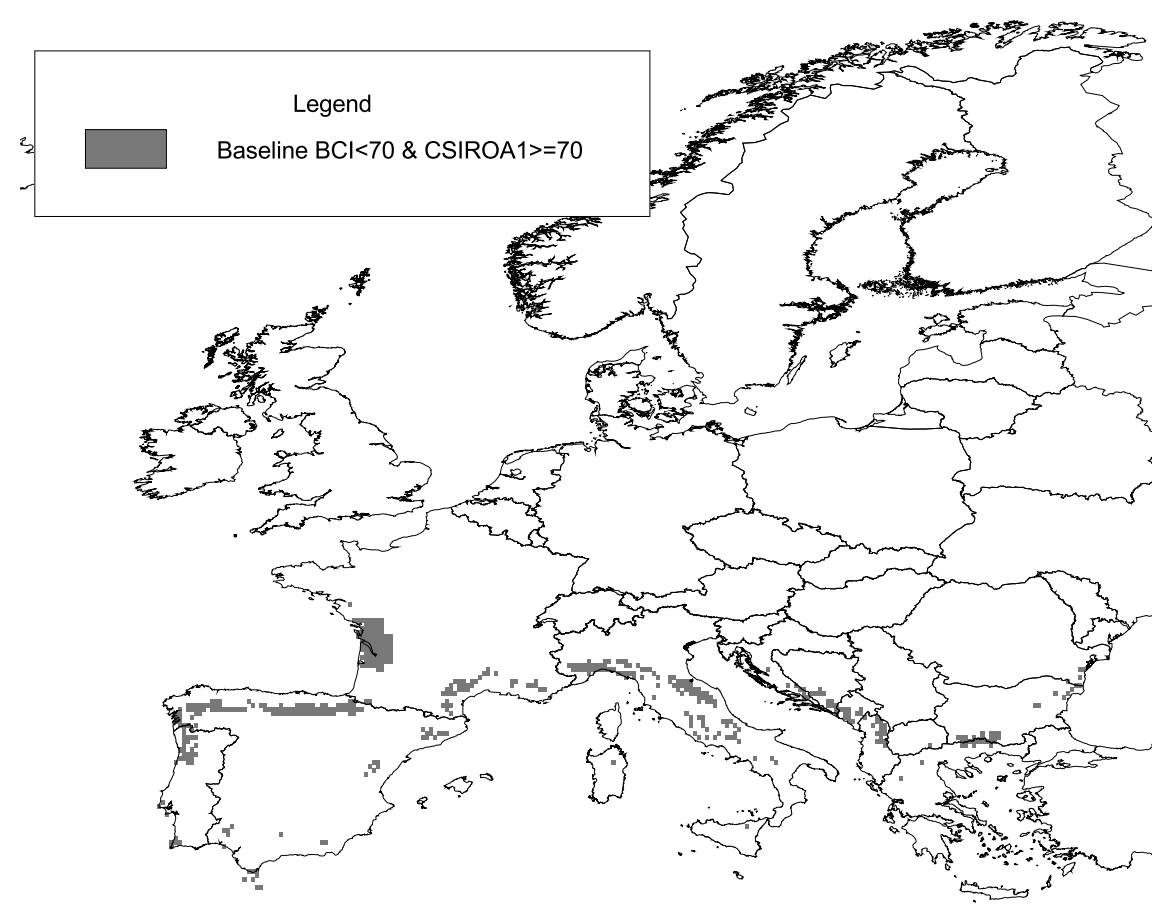

Figure 7.5 Areas with $\mathrm{BCl}$ below 70 in the baseline case and above 70 even with the moderate emission scenario (CSIRO2-A1FI) ('winners')

The fourth category considered is the group of areas that currently enjoy very good or better conditions, but that will see their climate resources deteriorate to levels under 70 even if the moderate CSIRO2-A1FI scenario materializes ('losers'). Various regions in the South of the Iberian Peninsula (Algarve, Andalucía, Valencia) as well as a few other areas in the Mediterranean basin belong to this category (see Figure 7.6). 


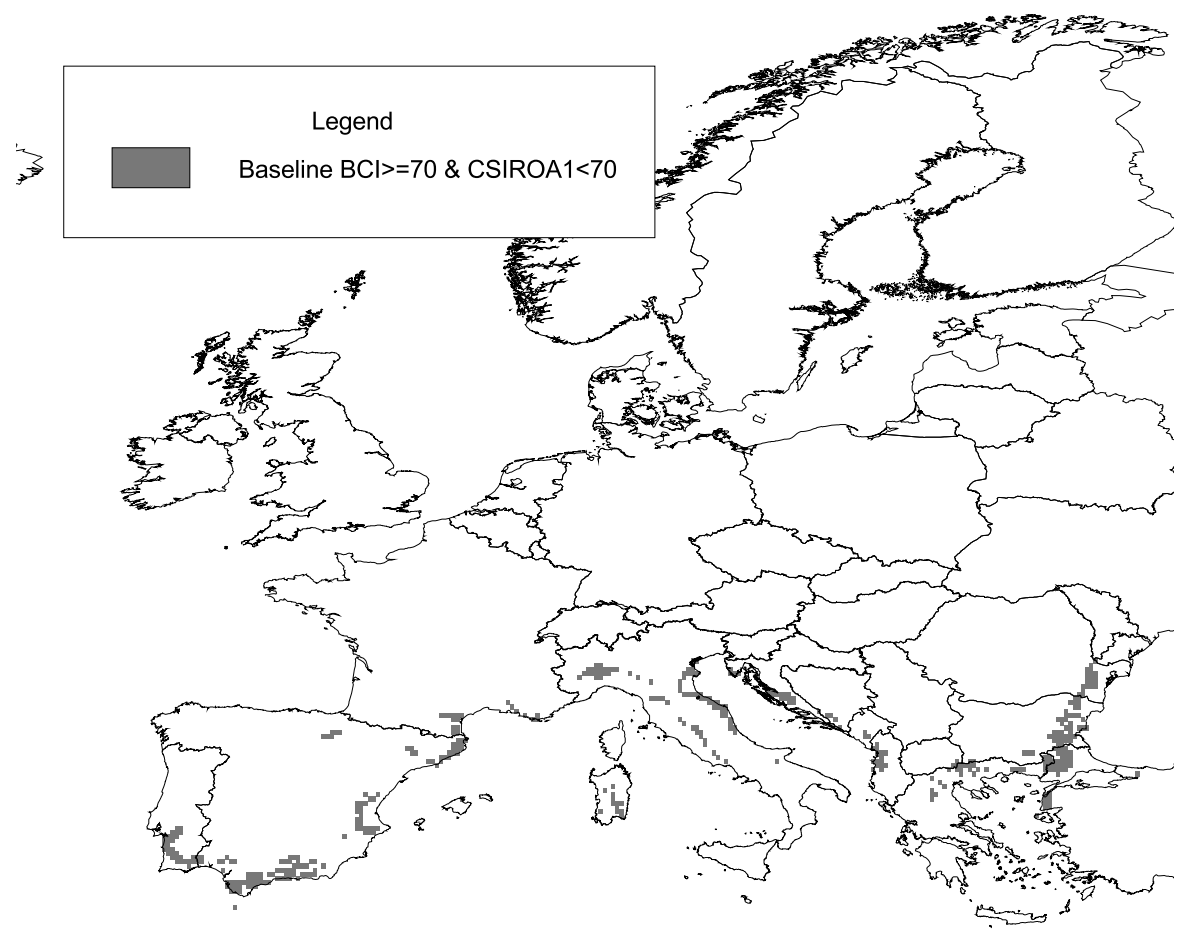

Figure 7.6 Areas with $\mathrm{BCl}$ above 70 in the baseline case and below 70 even with the moderate emission scenario (CSIRO2-A1FI) ('losers')

Finally, Figure 7.7 presents a summary of the findings for five aggregated coastal segments in Europe: Atlantic North, Atlantic South, Baltic South, Mediterranean, and Scandinavia. These segments together encompass all NUTS 2 regions included in the study. All of the listed countries' coastal NUTS 2 regions are included, unless specified otherwise (as is the case for France, Germany and Spain).

- Atlantic North: Belgium, Denmark, France (Basse-Normandie, Bretagne, HauteNormandie, Nord - Pas-de-Calais), Germany (Lüneburg, Schleswig-Holstein, WeserEms), Ireland, Netherlands, United Kingdom

- Atlantic South: France (Aquitaine, Poitou-Charentes, Pays de la Loire), Portugal, Spain (Cantabria, Galicia, País Vasco, Principado de Asturias)

- Baltic South: Estonia, Germany (Mecklenburg-Vorpommern), Latvia, Lithuania, Poland, Russia

- Mediterranean: Albania, Bosnia \& Herzegovina, Bulgaria, Croatia, France (Languedoc-Roussillon, Provence-Alpes-Côte d'Azur), Greece, Italy, Romania, Serbia, Slovenia, 
Spain (Andalucía, Cataluña, Comunidad Valenciana, Illes Balears, Región de Murcia), Turkey

- Scandinavia: Finland, Norway, Sweden

The aggregated losses in climate suitability in the Mediterranean are relatively modest, and smaller than the gains in the other regions, in particular the Atlantic North and Scandinavia. The Atlantic South region is projected to attain values similar to those found in the Mediterranean with climate change.

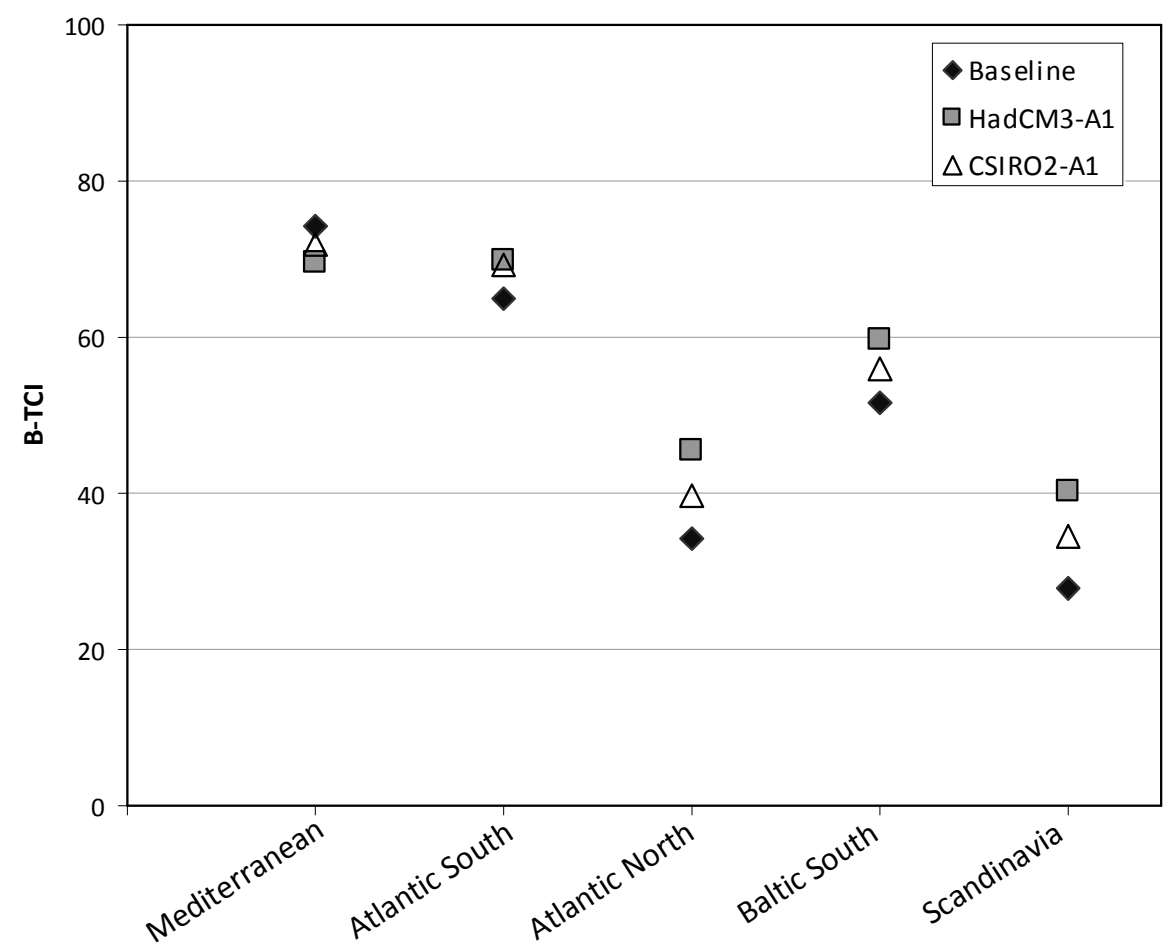

Figure 7.7 Change in $\mathrm{BCl}$ in different European coastal regions (including only the first $100 \mathrm{~km}$ inland from the shoreline) 


\subsection{Discussion}

\subsubsection{Implications for research and management}

The analyses presented above map the spatial patterns of climatic suitability for beach tourism purposes now and in the future. Based on observed climate data, the most suitable summer destinations are situated along the Mediterranean coast. In the course of the century, the band of prime conditions expands to the North, in particular into northern Spain and southern France. The speed at which this happens varies according to the model used: the HadCM3 model projects much higher rates of change than the CSIRO2 model. The exploration of thresholds in Figure 7.4 has shown that even when the high impact scenario materializes (HadCM3-A1FI), most of the Mediterranean will retain $\mathrm{BCl}$ scores above 70 (very good conditions). Similarly, this scenario does not show a remarkable improvement of conditions in most of northern Europe.

A crucial finding is that the rate of change in climatic suitability is much lower than the rates found in earlier studies. Several of these studies have used Mieczkowski's Tourism Climate Index to explore the implications of climate change for tourism in Europe (Amelung et al., 2007; Amelung \& Viner, 2006; Nicholls \& Amelung, 2008). They indicated a marked improvement of conditions in northern Europe and a sharp deterioration of climatic suitability in the Mediterranean in the second half of the century. These results are not confirmed in the present study that focuses specifically on beach tourism. As beach tourism is a major market segment for Mediterranean tourism, claims that the Mediterranean will lose its attractiveness for tourism (Amelung \& Viner, 2006; Perry, 2005, 2006) appear overstated. There is also little chance that specific areas of northern Europe will be able to compete with the Mediterranean in the market segment of beach tourism before the end of the century. However, the new areas attaining good $\mathrm{BCl}$ values (e.g. North of Spain and Southwest of France) might compete with the traditional destinations in the Mediterranean area.

In this context, it should be noted that the $\mathrm{BCl}$ was intended as a tool to aid in the identification of climatically optimal destinations for beach vacations, rather than as a predictor of inbound travel. Even though appropriate climate conditions are a condicio sine qua non for beach tourism, a high score on the $\mathrm{BCl}$ does not necessarily translate into a high level of visitation. Successful destinations must exhibit a range of qualities, including adequate transportation links and infrastructure, appropriate numbers and kinds of accommodations and attractions, and a safe and pleasant environment, in addition to offering an appealing climate.

Climate change impacts on many of these qualities. Assessing the vulnerability of tourism destinations and individual tourism enterprises to not only the impacts of climate change on tourist comfort, but also to the indirect impacts of climate change is 
therefore of paramount importance. The implications of water shortages, sea level rise and environmental changes for tourism have to date hardly been investigated. In particular for the coastal destinations in the Mediterranean, these issues should be high on the research and policy agendas for the coming years. It is recommendable for tourism and coastal managers to actively work together in the elaboration of policies and development plans that address these issues.

Coastal and tourism managers in the non-Mediterranean parts of Europe will also need to take into account the biophysical transformations climate change will bring about. Climate change may not turn these regions into perfect destinations for beach tourism, but their climatic conditions are projected to improve very significantly. Two main trends are a longer season with suitable weather for general tourism, and an increase in the average number of days per year with suitable weather for beach tourism. Management strategies can be developed for coastal regions to capitalise on these trends. Beach towns, for example, may try to benefit more fully from the increased potential for beach tourism by disseminating tourism-specific weather information through new technologies such as webcams. Target groups may be short and medium-distance visitors, who can respond quickly when good weather conditions occur. The development of seasonal climate predictions (see e.g. UNWTO et al., 2008) may broaden the scope of such strategies to include longer-distance visitors. Market differentiation is another possible strategy managers could consider, specializing and marketing tourist products according to the climate of the region (e.g. kite-surfing in windy destinations).

\subsubsection{Methodological limitations}

When evaluating the results, a number of limitations and uncertainties associated with the methodology employed in the study must be recognized. First of all, the calculations in this study were based on the climate preferences of Northern European tourists, as recorded by Morgan et al. (2000). The generalization of these results may be limited as a result of possible intercultural differences in climate preferences (see e.g. de Freitas et al., 2008), a point that is also stressed by Morgan et al. Climate preferences may also change in time, e.g. through acclimatization to a warmer climate.

Secondly, results may be sensitive to the evaluation of precipitation. Whereas Morgan et al. assume that low scores on precipitation can be compensated by high scores on other variables, others (e.g. de Freitas, 1990; de Freitas et al., 2008) have suggested that it has overriding properties: precipitation renders the other factors irrelevant. The implications of this latter conviction could not be tested with the monthly normals that were used. 
Thirdly, a limited set of two contrasting climate models and one emissions scenario were used to explore climate uncertainties. This was deemed adequate in this study, as its emphasis was on investigating the effects of a maximum ('worst case') scenario. Nevertheless, in future studies it could be worthwhile to consider more scenarios, and a wider range of models in order to increase the robustness of the outcomes.

Fourthly, the analysis was limited to the summer season, and shifts in the seasonal distribution of tourist comfort were therefore not explored. However, large seasonal shifts in tourist flows as a result of strong improvements of the relative conditions in the shoulder seasons (Amelung \& Viner, 2006) are considered unlikely for beach tourism, as our analysis revealed significant dips in future summer conditions for only few areas in Europe.

Finally, calculations in this study are based on monthly climate normals and they do not allow identification of possible increases in the frequency and/or intensity of extreme weather events, such as heat waves and floods. Though hard to predict, these extreme events may nevertheless be highly relevant for tourism activity, perhaps even more important than the changes in mean conditions projected by climate models. This is because people experience actual weather conditions rather than climate ("average weather"), and as a result they are more likely to react to sudden, extreme events that severely impact the physical environment and can cause substantial damage to tourism infrastructure.

\subsection{Conclusions}

This chapter presents an analysis of the potential impacts of climate change on beach tourism in Europe during the summer season, based on projected shifts in climatic attractiveness over the coming 50 years. The results suggest that non-Mediterranean coastal zones will likely benefit from climate change, although the improvements will not be enough to attain the climatic suitability of the Mediterranean. Coastal managers in these regions may still benefit from improving suitability, and promote coastal and marine recreation in accordance with the new climate conditions. For Mediterranean beach tourism, the impacts of climate change on tourist comfort may be less severe than previously anticipated, even in the SRES A1FI scenario of rapid change. For some of the more active types of tourism, the Mediterranean may become 'too hot for comfort' in the course of the century, but our findings suggest that this is not the case for beach tourism. Given the prominence of beach tourism on the Mediterranean coasts, this has important policy implications. Coastal and tourism managers and researchers may do well to shift some of the attention away from the impacts on tourist comfort towards other impacts of climate change, such as sea-level rise, water availability, and biodiversity, a suggestion also supported by the findings of Chapter 5 . 
Nevertheless, additional research on tourist comfort is also urgently needed. So far, there is very little known about tourists' likely behavioral reactions to the projected climatic changes, a topic that can be addressed using a qualitative or traditional survey-based approach. New studies should take into account recent trends indicating that tourists expect the traditional formula of 'sun, sea and sand' to be complemented by other elements such as diversity in activities and environmental quality (EC, 2000). For other tourism segments requiring higher levels of physical activity (e.g. adventure tourism), new impact assessment studies are necessary to reflect the specific climate requirements. A better integration of suitability assessments and tourism demand models is also warranted, to increase the economic relevance of the results. 



\section{Chapter 8}

\section{A CLIMATE CHANGE VULNERABILITY ASSESSMENT METHODOLOGY FOR COASTAL TOURISM}

Based on:

- Moreno, A., \& BECKEN, S. (2009). A climate change vulnerability assessment methodology for coastal tourism. Journal of Sustainable Tourism, 17(4), 473-488. 



\title{
8 A Climate Change Vulnerability Assessment METHODOLOGY FOR COASTAL TOURISM
}

In the past, weather events have generally been associated with natural cycles (e.g. seasons) or local variability against the background of a constant climate (Abegg et al., 1997). More recently, with increasing scientific agreement about human influences on the global climate, some weather events are seen as indicators of a changing climate (e.g. Emanuel, 2005). Coastal areas seem particularly vulnerable to climate change impacts as they are exposed to both extreme climate events and sea-level rise (IPCC, 2007a). This vulnerability is exacerbated by the accumulation of multiple stressors and increasing manmade pressures such as rising population and development (Nicholls et al., 2007). Coastal and marine environments are also very important tourist destinations, with hundreds of millions of people visiting coasts and participating in some kind of marine activity (Orams, 1999). According to Hall (2001, p. 602),

\begin{abstract}
. . . coastal tourism embraces the full range of tourism, leisure, and recreationally oriented activities that take place in the coastal zone and the offshore coastal waters. These include coastal tourism development (accommodation, restaurants, food industry, and second homes) and the infrastructure supporting coastal development (e.g. retail businesses, marinas, and activity suppliers).
\end{abstract}

Most of the recreational activities in coastal and marine environments are dependent on weather and climate conditions. In some cases, weather even determines or limits tourists' involvement on certain activities (e.g. cancellation of trips due to bad weather conditions), as it impacts directly on comfort or safety of participants. In other cases, climatic events could affect the natural resources that are essential for tourist activities, resulting in a decrease of attractiveness and therefore visitor numbers (Uyarra et al., 2005). For example, during the 3 months after hurricane Gilbert hit Cancun in 1988 approximately US\$87 million were lost in income from tourism (Aguirre, 1991), and even after the event tourists were reluctant to return, thus exacerbating the negative effects (Davenport \& Davenport, 2006). With a few exceptions (Becken, 2005; Raksakulthai, 2003), however, the consequences of climate change on coastal tourism have not been explored in detail so far.

Climate change might trigger the occurrence of a tourism industry crisis in many destinations (e.g. decrease in tourism numbers, environmental degradation, social disruption), and it is of crucial importance for the sustainability of the tourism sector and the destination as a whole to develop mechanisms to anticipate and minimize the 
impacts of such crises (de Sausmarez, 2007; Meheux \& Parker, 2006). Tourism managers are now likely to be aware that climate change might affect their business and there is an increasing need to discuss and implement adaptation measures. However, there are very few, if any, detailed assessments or tools that allow decision-makers and managers to address climate change proactively and develop the necessary adaptation to the potential changes (e.g. "early warning systems"; "beach nourishment"). This chapter, therefore, provides a methodology for assessing the vulnerability of tourism in coastal areas. More specifically, the proposed methodology assists stakeholders in the identification of key vulnerability components (sensitivity, exposure and adaptation measures) and it also provides an opportunity for a systematic comparison of vulnerability across different situations and destinations to ensure a sustainable tourism development.

The chapter is organized as follows. Section 8.1 introduces the concept of vulnerability in the context of this research and describes the components of the vulnerability assessment methodology. The application of the methodology is illustrated in Section 8.2, using coastal tourism in the Mamanuca Islands (Fiji) as a case study. Section 8.3 discusses the results and validity issues of the proposed methodology and section 8.4 draws overall conclusions and explores next steps.

\subsection{Developing a Methodology for Tourism Vulnerability Assessments}

\subsubsection{Background on vulnerability}

The concept of vulnerability was originally applied in geography and risk-hazard studies (Füssel, 2007; Kasperson et al., 2003; Turner et al., 2003), but its use has been extended to fields such as ecology, health or food systems (Füssel, 2007). The vulnerability concept is now also widely used in climate change science (Adger, 2006). The IPCC defined it as

... the degree to which a system is susceptible to, or unable to cope with, adverse effects of climate change, including climate variability and extremes. Vulnerability is a function of the character, magnitude, and rate of climate variation to which a system is exposed, its sensitivity, and its adaptive capacity. (McCarthy et al., 2001, Glossary) 
It has been noted by Luers et al. (2003) that some vulnerability assessments in the past (e.g. Ribot, 1995) were quite narrow in focus (i.e. isolated impacts on the natural and biophysical elements in a system), but more recent advances recognized the need to consider the combined effect in so-called coupled human-environment systems (Füssel, 2007; Polsky et al., 2007; Schröter et al., 2005; Turner et al., 2003). Such vulnerability assessments are often place-based (Cutter, 1996), although Luers et al. (2003) argued that the key focus of vulnerability assessments should be on selected variables of concern and specific sets of stressors rather than particular locations per se. Schröter et al. (2005) suggested that vulnerability assessments should (1) be derived from multiple disciplines and stakeholder participation, (2) be place-specific, (3) consider multiple interacting stresses, (4) take into account differential adaptive capacity and (5) be prospective as well as historical. To assist implementation of such assessments, the authors proposed an eight-step method; informing stakeholders about adaptation options is an integral component in each step.

Building on the above eight-step methodology, Polsky et al. (2007) developed the Vulnerability Scoping Diagram (VSD) as a tool for visualization and comparison between different vulnerability assessments. The diagram is composed of three layers: the innermost layer relates to the dimensions of vulnerability, namely exposure, sensitivity and adaptive capacity. The next layer specifies the components of each vulnerability dimensions, i.e. the "abstract characteristics" that typify the dimensions (Polsky et al., 2007, p. 478). These depend on the particular vulnerability situation in question. Finally, the outermost layer shows the indicators that are used to measure the components.

In an attempt to summarize the various conceptualizations and terminologies of vulnerability to climate change, Füssel (2007) concludes that the concept of "vulnerability" should usefully be applied in reference to particular vulnerable situations. The following six dimensions are central to describe such a situation:

- the system of analysis, e.g. the tourism sector, a tourism destination;

- the attribute of concern, e.g. tourism infrastructures, coral reef;

- the hazard or potential event that might damage or affect the system of analysis and the particular attribute of concern, e.g. sea-level rise or extreme events;

- the temporal reference, either the point of time or time period of interest (current vs. future vs. dynamic);

- the sphere, which distinguishes internal (i.e. from within the system of analysis), external (i.e. outside the system in question, but impacting upon the system) or crossscale (both internal and external) vulnerability factors and; 
- the knowledge domain, which includes socio-economic, biophysical or integrated factors.

This section provided an overview of vulnerability research for the purpose of this specific research on coastal tourism. Extensive reviews on the history, interpretations, methods and application of the concept can be found in Adger (2006), Füssel \& Klein (2006), Nicholls (1995) and O'Brien et al. (2004) among others. Adger (1999) concluded that the challenge of vulnerability assessment consists in the development of credible measures that allow for the inclusion of different perceptions of risk and vulnerability, dynamics of the systems, aspects of governance and the wider political economy that take into consideration the multiple scales that are relevant for climate change impacts.

\subsubsection{A methodology for assessing tourism's vulnerability}

Tourism systems have been identified as complex systems (Chapter 2, Miller \& Twining-Ward, 2005), and the interaction between tourism and the climate systems adds another layer of complexity (Becken \& Hay, 2007). A tourist destination comprises a variety of stakeholders or agents, including tourism businesses, public sector organizations, community groups and non-governmental organizations (NGOs). Moreover, the destination is characterized by different settings, both natural and cultural, a broad range of infrastructure and the kinds of activities that different types of tourists might engage in. Tourist destinations are excellent examples of human-environment coupled systems (Füssel, 2007; Polsky et al., 2007; Schröter et al., 2005; Turner et al., 2003).

The quantification of vulnerability to climate change requires consistent and structured methodologies (Adger, 2006). This thesis develops a five-step methodology to address this requirement for assessing coastal tourism's vulnerability to climate change (Figure 8.1). The proposed steps are sequential in principle but circular if appropriate. All steps rely on the input of both quantitative data and qualitative (expert and stakeholder) input. 


\section{Step 1. System analysis}

- Economic, environmental and social context of destination

- Identification and characterization of tourism activities

- Prioritization according to their importance

\section{Step 2. Climate}

- Characterization of climate conditions and identification of key hazards

- Creation of activity-hazard sub-systems

- Selection of sub-systems for the analysis

\section{Step 3. Vulnerability}

- Identification of vulnerability components and indicators

- Fine-tuning of components and indicators (with the help of VSD)

- Operationalization of vulnerability

- Validation of Steps 1-3

\section{Step 4. Integration of individual vulnerability assessment}

- Scenario construction

- Analysis of non-linearities, interdependencies and feedback loops

- Discussion of results and overall vulnerability assessment

- Validity, scenarios and uncertainties assessed

\section{Step 5. Communication of results}

- Communication to broader audience (e.g. use of visualization tools like VSD)

Figure 8.1 Overview of the five-step tourism vulnerability assessment methodology

Step 1 is concerned with the coastal tourism system in question. Given the complexity of tourist destinations, it is paramount to understand the system as thoroughly as possible and describe its key features, including relationships between its components and feedback loops, and other dynamics. In this step, the geographic, social and institutional scope of the study area is clearly defined, main stakeholders are identified and involved in the process (Schröter et al., 2005) and relevant tourism activities are described and prioritized according to their relevance. Following Füssel's line of thought it is not only important to understand the system, but also the attributes of concern. In a tourism context, attributes could be the ongoing sustainability of key tourism activities, such as diving or water sports. Step 1 also includes an analysis of 
existing management plans and relevant policies, such as environmental impact assessments (Ramjeawon \& Beedassy, 2004), as well as other institutional arrangements for environmental management.

Step 2 analyses potential climate hazards and makes an explicit link between tourism activities and hazards. This requires a tailoring of existing climate information (e.g. outputs from climate models) to the specific needs of tourism stakeholders. To this end, the tourist destination will be disaggregated into a number of coupled activityhazard sub-systems or, in Füssel's language, vulnerability situations. An example of an activity-hazard sub-system is coastal ecotourism's (activity) dependence on biodiversity that might be influenced by changing temperatures (hazard). The sub-system would then be referred to as ecotourism-temperature. The different sub-systems might operate at different scales. In this step, a selection of the sub-systems to be analyzed is undertaken in collaboration with stakeholders.

Step 3 builds on the earlier two steps as it involves identification of key vulnerability components and quantitative indicators to measure them. Different tools could be used to facilitate the identification and visualization of vulnerability components. The Vulnerability Scoping Diagram developed by Polsky et al. (2007) is useful to organize the multiple components and indicators for each activity-hazard sub-system, check them for completeness and validate them in consultation with stakeholders.

Indicators will assist decision-makers to assess vulnerable components each within exposure, sensitivity and adaptive capacity. Importantly, these indicators are also used to monitor these components over time, assess their stability and susceptibility to disturbance and eventually track changes in vulnerability (de Sausmarez, 2007; Miller \& Twining-Ward, 2005). Indicators are typically of a quantitative nature and they may involve intensive data gathering. While the practice of measurement through indicators seeks to be as objective as possible, the interpretation of the indicators could be highly subjective and depend on the values and perceptions of those involved in the assessment process (Adger, 2006; de la Vega-Leinert et al., 2008). For example, it will be necessary to determine a "threshold of risk, danger or harm" (Adger, 2006, p. 276) associated with some indicators and/or the system as a whole. A common practice in many impact and vulnerability assessments is the use of semi-quantitative approaches. These often involve scoring methods, where each indicator is divided into categories (e.g. low, medium and high) and a numerical score is assigned to each of these categories, a process which is usually carried out with inputs from stakeholders (Brooks et al., 2005; de la Vega-Leinert et al., 2008; IFRC, 2007; Yamada et al., 1995).

Step 4 assesses the overall climate change impact on the destination. Scenario analysis could be employed in order to project potential future vulnerabilities, address relevant variables and development patterns and to explore different adaptation op- 
tions and possible unexpected shocks affecting the system. This is, in fact, not a linear process, but a dynamic step in which stakeholders define development patterns and other elements that might determine or influence future vulnerability (e.g. different adaptation options). To this end, stakeholders will have to discuss the totality of individual assessments and weigh them against specified criteria. This decision-making process is subjective in nature and depends on the assessment of the stakeholders involved, their attitudes to risk and the goals they attach to tourism, e.g. employment generation, economic development, foreign exchange contribution, nature conservation or social equity. A multi-criteria analysis tool in which actors assess different measures based on their personal perspectives and values can contribute in the consensus-building process between different stakeholders (Belle \& Bramwell, 2005; Brown et al., 2001). In this process, it is also important to take into account system attributes, such as non-linearity (e.g. the potential for surprises), interdependencies and feedback loops. Engaging stakeholders also allows for validation of the methodology and the derived sets of vulnerability components and indicators (visualized for example in the VSDs).

Step 5 involves the communication of the results to stakeholders beyond those who were involved in the decision-making process. Involving stakeholders during the assessment as well as afterwards ensures the credibility and acceptability by the different stakeholders (Schröter et al., 2005; Vogel et al., 2007). The aim is to improve the methodology and also facilitate its application to other contexts and regions and as a result maximize the learning for each specific assessment.

\subsection{Application to Fiji}

Fiji is the largest tourist destination in the South Pacific. Tourism has typically been linked to marine environments (beach and diving) with more than $60 \%$ of tourists engaging in swimming and snorkeling and 12\% participating in scuba diving (Becken, 2004). The Mamanuca Islands are an important tourist destination in the Fijian archipelago (Figure 8.2). Yet, they are likely to be highly vulnerable to climate change. In the following, the vulnerability assessment methodology presented in the previous section is applied to the situation of the Mamanuca Islands. The desktop assessment is based on the authors' previous work in Fiji, which included interviews with key stakeholders from the public sector and NGOs (undertaken in two different projects in 2004 and 2006), a survey among tourists $\left(N=373\right.$ ) and a survey of accommodation providers ${ }^{1}(N$

\footnotetext{
${ }^{1}$ The example presented here focuses on accommodation providers to illustrate the principle; however, in reality the mix of stakeholders is more diverse and complex, including a wide range of representatives from the public and private sectors and civil society.
} 
= 25) (Becken, 2004; Fiji Ministry of Tourism, 2006). During this process, stakeholder engagement was not difficult as they had a strong interest in the issue; the process was set up as a participatory one and the key was to ensure that the different voices were represented and heard. This related to various levels of government, industry, communities and NGOs. A combination of personal and group meetings was found to be fruitful. The earlier work provided sufficient information and knowledge about the local conditions and stakeholders' views on climate change to test the proposed methodology.

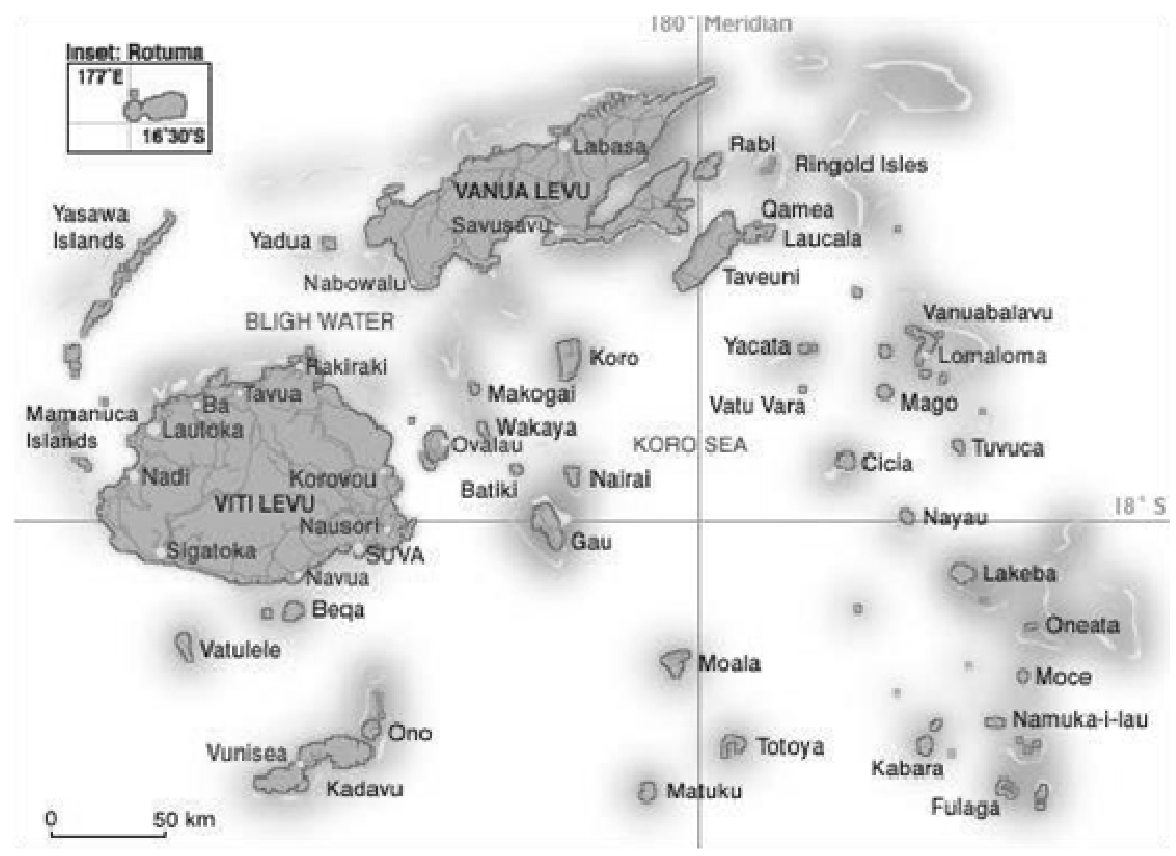

Figure 8.2 Map of Fiji showing the Mamanuca Islands to the West of Viti Levu (the islands of Ono-i-Lau and Vatoa from the Southern Lau group are not represented in this map) (Source: by kind permission of Fiji Visitor Bureau, 2004)

Step 1: The Mamanuca Islands lie west of Viti Levu (main island). The island group counted about 88,341 visitor nights in 2005 (17.3\% of all nights in Fiji) and tourism is an extremely important income and job generator (GRM International, 2007). The Mamanuca Islands offer 808 guest rooms in 23, mostly up-market, accommodation properties. As for the rest of Fiji, key activities undertaken by tourists are relaxing on the beach, swimming, snorkeling and diving. Increasingly, tourists participate in ecotourism and cultural village tours. Relevant management plans and policies should be 
explored in this step although they are not presented here, as the purpose is to develop the methodology and illustrate the principles.

Step 2: Fiji's climate is oceanic tropical, with a dry season from May to October and a wet season from November to April. The wet season - which includes the holiday peak season around Christmas - is also the cyclone season. Rainfall patterns are determined by the southeastern trade winds, resulting in a wet east and dry west (including the Mamanucas). The El Niño Southern Oscillation affects Fiji as it influences the position of the Southern Pacific Convection Zone. During El Niño events (about every 7 years), the weather conditions in Fiji are drier and hotter than average (Hay et al., 2003).

The Mamanuca Islands are highly exposed to cyclones, droughts and increasing sea temperatures, which will have an impact on coastal erosion, water shortages and coral bleaching among others (Fiji Meteorological Service, 2006). In 2000, a massive coral bleaching event led to the damage of substantial parts of the coral reefs due to high water temperatures (Cumming et al., 2002). The Mamanuca Islands are low-lying atoll islands, and as such are vulnerable to sea-level rise. According to a survey among accommodation operators, tourist resorts face problems with beach erosion and water quality (Becken, 2004). The same group of stakeholders identified cyclones as the most important impacts from climate change to their (often uninsured) businesses. Cyclones also pose a hazard to the local communities and tourists and they destroy natural resources, including beaches and coral reefs. As such cyclones affect the very existence of tourism in this destination and the activity-hazard system of "beach-cyclone" is identified as the most critical one. The risk of coral bleaching and the fact that snorkeling is a major activity, makes "diving/snorkeling- coral bleaching" the second subsystem of analysis. Other activity-hazard systems of interest would be "hotel-water supply" and "ecotourism-biodiversity changes", although they have not been included in this assessment. The particular circumstances for each vulnerability situation depend on the particular island in question.

Step 3: The identified vulnerability components of both sub-systems in the Mamanuca Islands are shown in Figures 8.3 and 8.4. The VSD (Polsky et al., 2007) is used here for visualization purposes. For the "beach-cyclone" sub-system, components describing the exposure include, for example, the "statistical risk of cyclones" and the "tourist population" and "infrastructure" that might be affected by a cyclone. Potential measures for exposure to cyclones could relate to the "intensity" of the storms or the return periods, based on historic data and trend analyzes (Fiji Meteorological Service, 2006). Tourist population could be measured as the number of tourists on an island for each night during the cyclone season. The exposure of tourist infrastructure could be estimated in the form of capital "value" and/or "location" (e.g. distance from the hightide mark). 
Sensitivity is described through the following components: the particular "characteristics of the beach and shoreline", the "perception of tourists", and the "condition of the infrastructure". The sensitivity of the beach/shoreline to cyclones can be measured by "current erosion rates" (e.g. in millimeters per year), a parameter that is highly dependent on the geomorphologic coastal characteristics (i.e. different coastal types because of variables such as hard/soft rocks or beach materials and profiles - possess different sensitivity to erosion) (EC, 2004). Other parameters could be useful as well, such as topography and bathymetry or integrity of vegetation. Tourists' perceptions could be captured in surveys, for example the proportion of tourists that are concerned about being caught in a cyclone. The condition of the infrastructure could be measured as the proportion of "cyclone-proof buildings". In addition, an indicator could measure insured capital versus uninsured.

Finally, adaptive response is captured by components such as "management capacity", "access to financing" and "institutional support". Indicators to assess these components include, for example, the number of islands/resorts that are part of an early "warning system" or the dollars invested into adaptation measures and technology, such as the use of hard and soft structures for protection. Management strategies like "diversification" of activities and "marketing" campaigns could contribute to a reduction in the dependency on beach tourism and therefore less vulnerability in case of beach damage. 


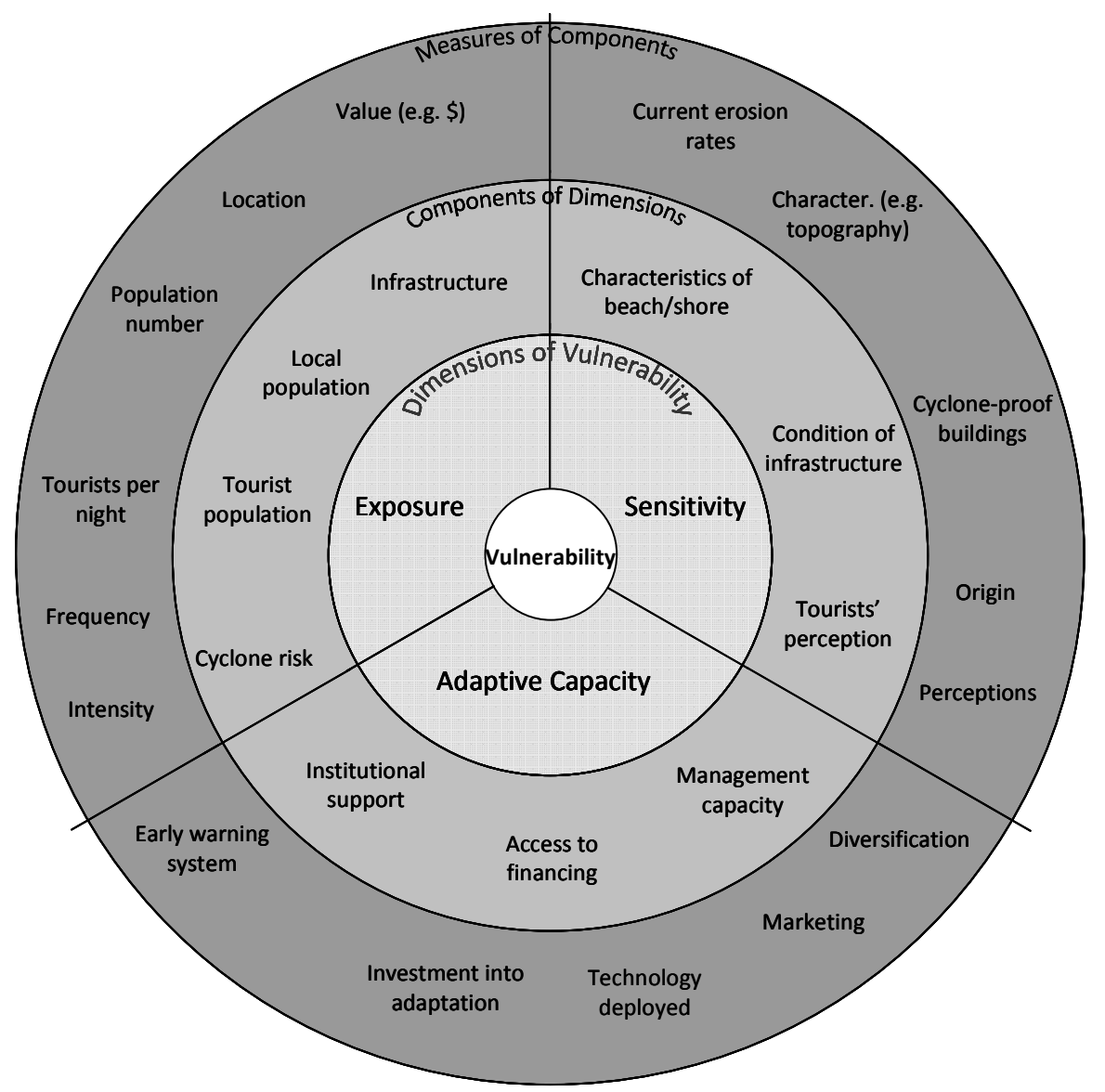

Figure 8.3 Vulnerability Scoping Diagram for the "beach-cyclone" sub-system (adapted from Polsky et al., 2007)

Similarly, the vulnerability components for the "snorkeling-coral bleaching" can be described briefly. Main determinants of the exposure include the "reef location", "ocean conditions" and "storminess" as key drivers of coral bleaching. Reef characteristics, such as "number of species present" or "diversity", influence the extent to which the reef is sensitive to the changing conditions. "Tourists preferences and knowledge" about the reef and their pressure are also part of the sensitivity dimension. Finally, the capacity to adapt is described, for example, by "managerial", "technological" and "institutional" components like the possibilities of creating "artificial reefs" and protection measures through "visitors management" and establishment of "marine protected areas" to improve the resilience of the reef system. 


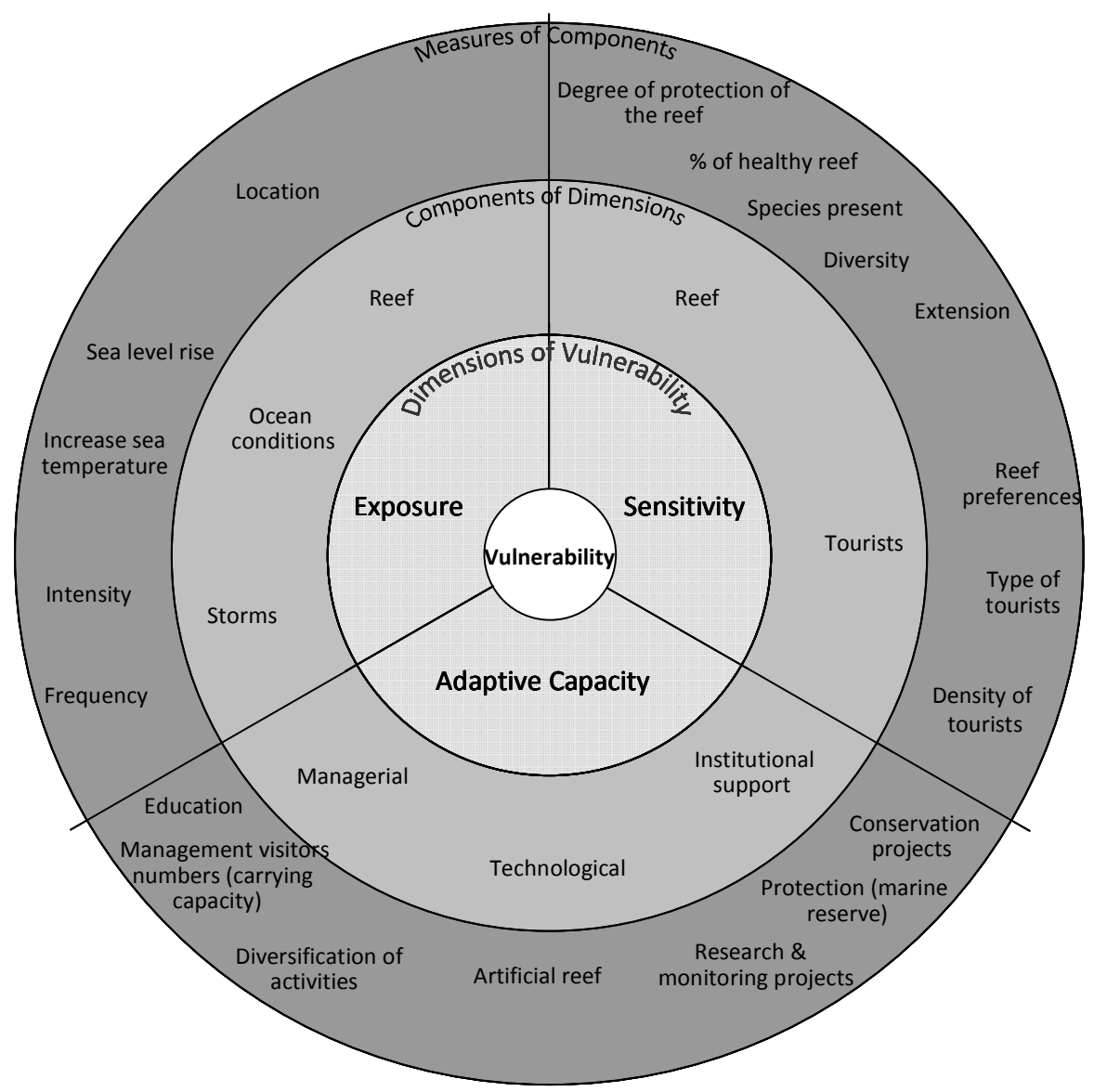

Figure 8.4 Vulnerability Scoping Diagram for the "snorkeling-coral bleaching" sub-system (adapted from Polsky et al., 2007)

For the assessment of the indicators that measure the different vulnerability components, a scoring system should be developed in collaboration with stakeholders, and building on existing knowledge and data. For the Mamanuca example, and based on expert knowledge and existing literature, the result of such scoring would provide an assessment of the degree of vulnerability for each sub-system as reflected in Table 8.1. The overall vulnerability is not the mean of the three components as different weights can be applied to each of them (i.e. adaptive capacity plays a fundamental role in defining the final vulnerability as it determines to a great extent the magnitude of the impacts). This assessment is speculative at this stage and has not been derived with stakeholder input. 
Table 8.1 Summary of vulnerability components of the two activity-hazard sub-systems analyzed in Mamanuca Islands

\begin{tabular}{|c|c|c|c|c|}
\hline Activity-hazard & Exposure & Sensitivity & $\begin{array}{l}\text { Adaptive } \\
\text { Capacity }\end{array}$ & $\begin{array}{l}\text { Overall Vulner- } \\
\text { ability }\end{array}$ \\
\hline 1. Beach-cyclones & High & Very High & Moderate & Moderate \\
\hline 2. Snorkelling-coral bleaching & High & High & Low & High \\
\hline
\end{tabular}

A key component of any vulnerability assessment is the identification of potential adaptation options that are both feasible and practical (Smit \& Wandel, 2006). These adaptation strategies should not only aim at the reduction of impacts but also explore new possibilities brought about by climate change taking into consideration the triplebottom line of economic, social and environmental aspects. Communities have been dealing with adaptation to coastal change for decades. In the case of Fiji, protection of the shoreline, mainly by seawalls, started after 1960 as a reaction to population pressure and coastal erosion. These and other structures were created mainly based on available materials and not guided by any expertise, making the maintenance of such structures expensive and complicated for the communities (Mimura \& Nunn, 1997). This provides a good example of how sustainable tourism planning strategies, supported by tools like the vulnerability methodology presented here, are needed and could assist tourism stakeholders to proactively adapt to climate change impacts.

Steps 4 and 5: The analysis of each activity-hazard sub-system provides an identification of the main components of vulnerability as reflected in the above VSDs, as well as a measure of the degree and severity of the vulnerability. This allows identification of the dimensions that contribute most to vulnerability, i.e. a high exposure, high sensitivity or lack of adaptive capacity for each sub-system. When making an overall assessment, stakeholders would explore a number of scenarios and assess how future developments and unexpected shocks could influence the sub-systems' vulnerabilities. Non-linearities and feedback mechanisms between the different sub-systems should also be included. For example, an increase of coral bleaching due to warmer water temperatures and storm impacts will lead to a reduction in the coastal protection and therefore a magnification of the effect of cyclones in beach erosion (Pacific Islands Climate Change Assistance Programme, 2005). Stakeholders involved in the analysis would therefore prioritize vulnerabilities and the actions that should be taken. Stakeholders in the Mamanuca Islands could include the resort owners and/or managers, community representatives, local or national NGOs (e.g. the Mamanuca Environmental Society), regional bodies (e.g. SOPAC or WWF South Pacific), local councils (Lautoka Council) and national bodies such as the Ministry of Tourism and Environment. The 
results of the study could then be distributed to interested parties within Fiji or other island destinations.

\subsection{Discussion and Conclusion}

There is a substantial research body on vulnerability to climate change. The IPCC technical guidelines for assessing climate change impacts and adaptations (Carter et al., 1994) have been widely used and are the basis for several national climate change vulnerability assessments. Based on this, the United Nations Environment Programme (UNEP) handbook on methods for climate change impact assessment and adaptation strategies (Feenstra et al., 1998) was designed to provide guidance at system or sector level. However, none of the two methodologies addressed the specific requirements of the tourism sector. Recent advances in vulnerability research identified the need of focusing on coupled human-environment systems. Tourism with its high dependency on the natural environment and the involvement of numerous human actors is a very good example of such a system.

This chapter developed a five-step methodology for assessing the vulnerability to climate change of a coastal tourism destination. The framework recognizes that a tourism destination is a complex system that consists of many different vulnerability situations. Each of these situations are characterized by different attributes of concern, hazards, stakeholders involved, timeframes considered and adaptive capacities. Also, these vulnerability situations, or activity-hazard sub-systems, are not all equally important for the sustainability and well being of the destination as a whole. Some of the sub-systems will be integral parts of what makes the particular destination, while others are possibly more dispensable. The sub-systems are not independent from each other, but are likely to be interlinked.

The vulnerability assessment methodology for coastal tourism presented in this chapter has several advantages. The analysis of vulnerability by disaggregating the systems into multiple activity-hazard sub-systems reduces complexity, making it easier for stakeholders to be involved in the process. This process allows identifying key areas of vulnerability and taking specific actions to improve adaptation. The framework captures the dynamic nature of tourism and can easily be used to explore both current and future states in the system, such as new activities that could be favor by new climate conditions.

This chapter argues that the framework provides a useful "scaffold", but it also acknowledges that detailed assessment analyses have to be undertaken across case studies. Some difficulties, and potentially disagreement amongst stakeholders, might arise, for example, when determining which vulnerability components and measures 
are to be included in the analysis and which dimensions they belong to. In the present example of the Mamanuca Islands, the existence of "early warning systems" was understood as an element that improved the capacity to adapt. However, it could also be seen in the context of sensitivity, where an established and functioning warning system decreases the sensitivity of a particular sub-system. As Polsky et al. (2007) pointed out, exposure, sensitivity and adaptive capacity are not perfectly separable and need to be negotiated depending on the context of analysis.

Two different approaches exist in the application of sustainable development to tourism: those who advocate sustaining tourism in a destination in the long term, and those who advocate tourism as a vehicle for achieving sustainable development, an approach which encompasses much wider goals and priorities (Holden, 2000). Independent of the approach, climate change will threaten destinations putting at risk the continuation of tourism activities and therefore jeopardizing the development of those regions which might find in tourism not only a key driving force for their economy, but also an important incentive for social and environmental conservation. The presented methodology addresses the sustainability of the tourism sector, increasing its preparedness for future potential crises triggered by climate change impacts and stimulating the adaptation of destinations and their development in a sustainable way. 



\section{Chapter 9}

\section{THE BALEARIC ISLANDS: IMPACTS, VULNERABILITY AND CRITICAL MANAGEMENT ISSUES}

Based on:

- Moreno, A. (in press). Impact of climate change on island tourism - The Balearic Islands: impacts, vulnerability and critical management issues. In Jones, A. \& Phillips, M. (Eds.), Disappearing Destinations: CABI. 



\section{IMPACT OF Climate CHANGE ON IsLAND TOURISM - THE BALEARIC ISLANDS: IMPACTS, VULNERABILITY AND CRITICAL MANAGEMENT ISSUES}

The Balearic Islands are one of the best known coastal destinations in the Mediterranean. Tourism growth started in the 1950s and 1960s focusing on a relatively unmanaged and uncontrolled development of the coast and with a single product as key attraction: beach tourism. The shift from a traditional lifestyle to a tourism based economy meant not only an important increase in the wealth of the inhabitants, but also impacted significantly its society and environment. Today, tourism is the single most important source of revenue and employment in the islands.

The Balearic Islands are increasingly facing new challenges that jeopardize the economic sustainability of the tourism industry. One of the most challenging issues for the islands is climate change. Impacts associated with increasing temperatures, changing precipitation patterns and sea level rise will very likely have important consequences for the tourism industry. Environmental degradation -which is already an important issue due to the unplanned growth in the initial development stages of the destination- and problems associated with water availability, are likely to be aggravated by climate change.

This chapter presents the development of the Balearic Islands as a destination, explores the main challenges climate change pose on the tourism industry and describes the main policies being developed in the area of climate change which are relevant to tourism.

\subsection{Historic Growth of the Destination}

The Balearic Islands autonomous community is situated off the east coast of mainland Spain, in the Mediterranean Sea. The capital of the region, Palma, is located on the biggest island -Mallorca- about $130 \mathrm{~km}$ east of Valencia. There are another two major islands called Menorca and Ibiza and three smaller ones -Formentera, Cabrera y Dragonera (Figure 9.1). 


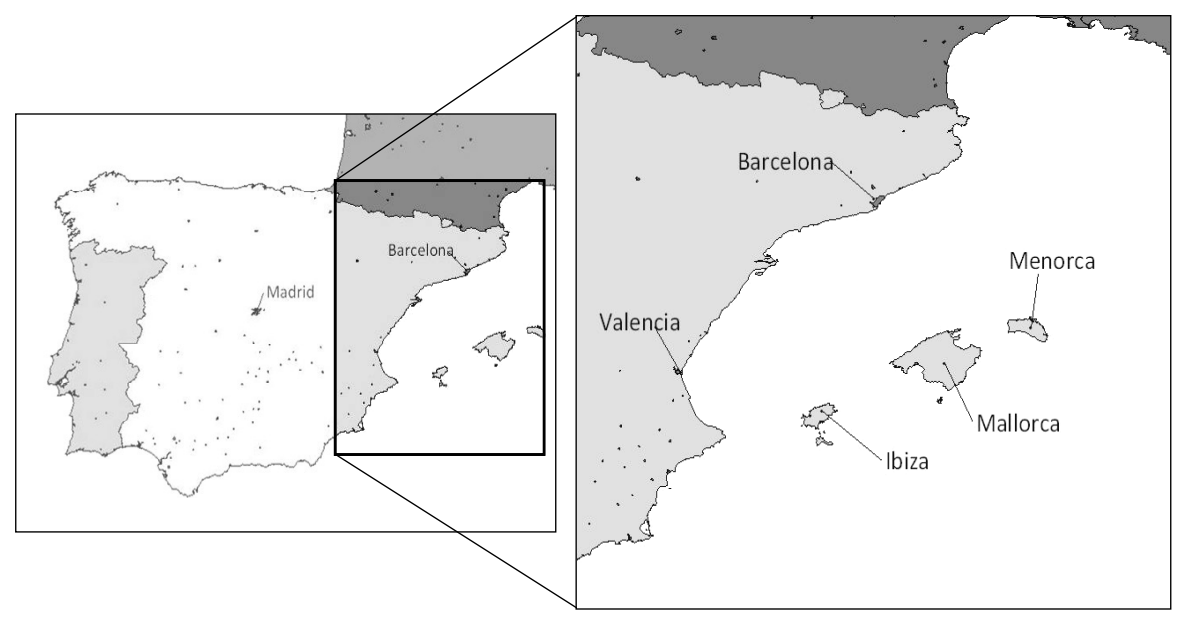

Figure 9.1 Location of the Balearic Islands

The history of the Balearic Islands as a tourist destination goes back more than 100 years (Bayón Marine et al., 1999). In 1905 the Fomento de Turismo de Mallorca is created, first institution of its kind that aimed at attracting and entertaining the visitors to the islands. It is during the first 30 years of the $20^{\text {th }}$ century that the first hotels are built and tourism activities start to have relevance, especially in Mallorca between 1925 and 1930. In 1935, Mallorca received more than 40,000 tourists, mainly upperclass visitors from other Spanish regions. This tourism evolution was interrupted by the occurrence of the two World Wars and the Spanish Civil War. It is not until the 1950s that the Balearics start their race to become one of the major tourism destinations in Europe. Several reasons explain the growth that started in the 1950s. At the global scale, the improvement of workers rights, including the introduction of paid holidays, together with technological development and improvements in the means of transport made the islands more accessible than ever to the main international source markets. The decision of the United Nations to remove the economic restrictions on Spain (put in place as a mean of pressure to the dictatorship of General Franco) and the policies and infrastructure development during these years opened the borders to international tourism.

The rapid growth during the 1950s, 1960s and 1970s coincided with the emergence of package holidays from western and northern European markets and the development of mass tourism. In this period the islands, and especially Mallorca, experienced a process of homogenization, uncontrolled development with lack of planning and poor quality construction, a phenomenon that has received the name of balearization and a concept that explains some of the challenges the tourism industry faces today (Bramwell, 2004; Robledo \& Batle, 2002). To give an idea of the exponential growth of 
arrivals the Balearic experienced during this period, it is worth mentioning that the milestone of one million arrivals per year was reached in 1965; in just 15 years the ratio changed from 1 tourist per 5 inhabitants to 2 tourists per inhabitant: a tenfold increase (Bayón Marine et al., 1999). In 1980s, problems associated with this unrestrained growth became apparent, with environmental degradation becoming a serious issue and the whole destination receiving lower income visitors and an image of downmarket and poor standards (Essex et al., 2004). Following the terminology coined by Butler (1980), the destination was entering the 'stagnation' and 'decline' phases and required management intervention if its 'rejuvenation' was to be ensured. This intervention of the local authorities and industry started in the 1990s in an effort to control tourism development, and improve standards and the overall quality of the sector, focusing on product diversification and the attraction of higher-income tourists. The consequences of this intervention have been diverse and are discussed in some more detail below.

\subsection{Current Tourism Trends}

The most recent and complete overview of the state of tourism in the Balearic Islands is published every year by the Conselleria de Turisme (Balearic Tourism Ministry). The evolution of arrivals by air shows a clear increase of approximately 57\% between 1994 and 2008 (Figure 9.2). The positive trend in arrivals halted in 2000, when a negative tendency started that lasted until 2003, mainly due to the economic crisis in Germany (Aguiló et al., 2005). Since then, and with the exception of 2008, arrivals have increased yearly. According to the latest report available from the Conselleria de Turisme (2009), the Balearics received in 2008 a total of 13.1 million tourists arrivals, of which $96 \%$ arrived by air and $4 \%$ by sea. Foreign visitors outnumber domestic tourists $76 \%$ against $24 \%$ respectively-, and the international markets are dominated by Germany (32\%) and the UK (27\%). In 2008, as compared to 2007 , there has been a drop of $1 \%$ in the total number of arrivals: while the number of foreign visitors increased by $0.9 \%$, the number of Spanish tourists decreased by $6.5 \%$. A trend towards shorter stays has also been observed: from 11.1 days on average in 2005 to 9.9 days on 2008. The economic significance of the sector can be easily envisaged. In the Balearic, tourism is responsible for $44.2 \%$ of the GDP and employs directly and indirectly $30.8 \%$ of the active population. Tourism is also a major source of revenues for the regional government, generating $42.5 \%$ of the total earnings by means of taxes (Conselleria de Turisme, 2008). 


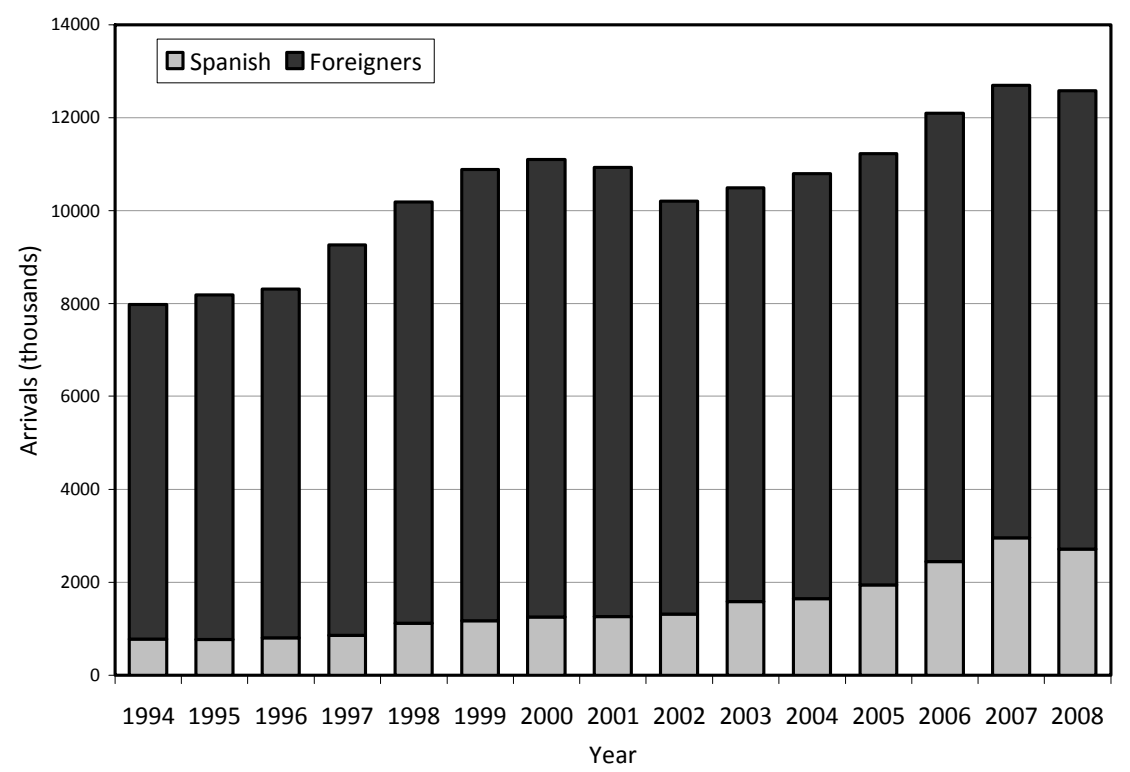

Figure 9.2 Evolution of tourists arrivals by air 1994-2008 (Conselleria de Turisme, 2009)

Seasonally, the distribution of arrivals is characterized by a clear summer peak: $46.9 \%$ of the tourists visit the islands in the months of July, August and September, and $79 \%$ if the period includes the months of May, June and October (Figure 9.3). Two elements explain this seasonal concentration: the profile of the tourists and their motivations for choosing this destination. Roughly $40 \%$ of the visitors to the islands are between 25 and 44 years old; $92 \%$ of them come with their families for leisure (Conselleria de Turisme, 2009). This implies that, to a great extent, these tourists are limited in their choice of the holiday period by the school and work holidays. Senior citizens (age above 64), the market often associated with higher flexibility in choosing their vacation time, represent only $13.2 \%$ of total arrivals and the smallest group of all recorded. 


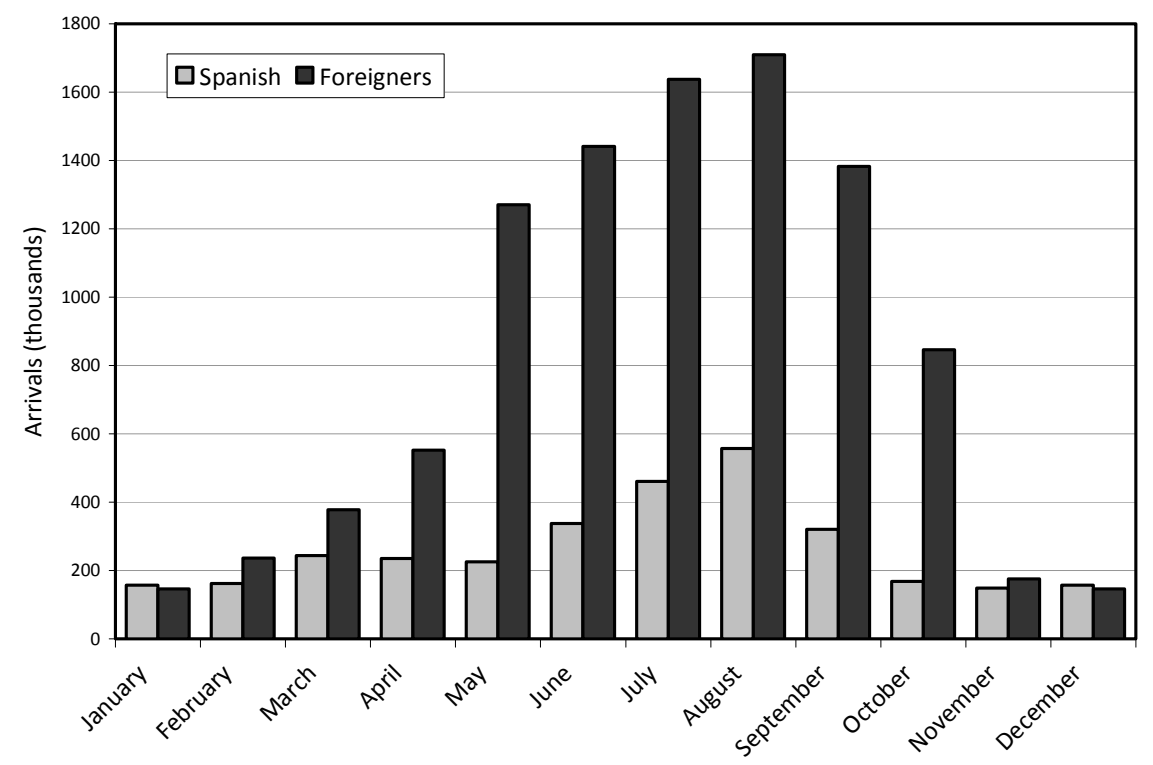

Figure 9.3 Monthly tourists arrivals in Balearic Islands in 2008 (Conselleria de Turisme, 2009)

The motivations of tourists to choose the Balearic Islands are a second and very important factor explaining the marked seasonality. Research by Kozak (2002) among German and British tourists found out that weather is the most powerful destination attribute for a summer vacation on the Balearic Islands. Similar results were also presented by Lohmann \& Kaim (1999) and Aguiló et al. (2005). This preference for climatic attributes is therefore another factor determining the summer concentration of tourists. Based on the data presented before, and according to Aguiló et al. (2005), it can be argued that 'sun and sea' is the main tourist product attracting tourists to the islands. However, and due to the intervention of the Balearic government and businesses to curve the declining arrivals during the 1980s, there has been an important effort to diversify the activities offered to tourists besides the typical beach tourism. The evolution in recent years of nautical, cruise and golf tourism is summarized in Figure 9.4. 

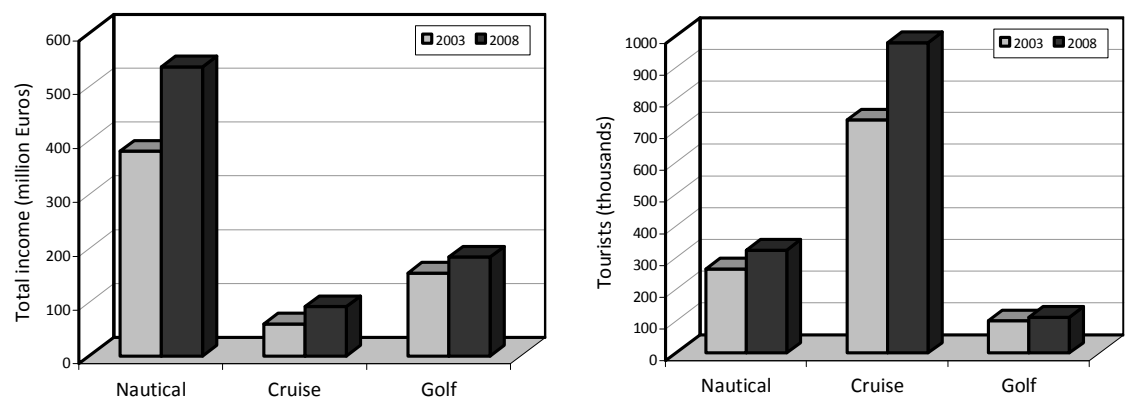

Figure 9.4 Evolution of nautical, cruise and golf tourism 2003-2008 (Conselleria de Turisme, 2009)

Motivations, together with the activities tourists carry out during their stay, play a major role in understanding the potential climate change impacts on tourism; when motivations and activities are heavily dependent on the weather of the destination, climate change impacts can be expected to be greater (see Chapter 8). The combination of weather driven pull factors and highly sensitive tourism products -beach tourism-imply the Balearics will be very vulnerable to the impacts of climate change.

\subsection{Current Tourism Issues and Challenges}

Some of the major management issues and challenges the Balearic Islands are facing at the moment are rooted in the mass tourism model the islands experienced during the 1950s and 1960s. Overdevelopment of infrastructures and residential areas (unplanned to a great extent), deterioration and disappearance of environmental attributes and dependence on northern European tour operators and markets are some of the major weaknesses of this clearly unsustainable model. The decline in arrivals during some periods and the negative tendency of other variables such as the declining expenditure per tourist, made some authors suggest that any rejuvenation strategy of these mass market resorts was condemned to fail (Knowles \& Curtis, 1999). On the other hand, Aguiló et al. (2005) suggests that the market reality does not support this view as recent trends indicate that there is still ample demand for 'sun and sand' tourism in the Balearics. In addition, there has been a profound restructuring process based on quality-based measures and the application of sustainable development guiding principles. Current tourism plans are precisely focused on this commitment to rejuvenation strategies and environmental protection to halt the decreasing arrivals. Sustainable development principles have become a fundamental component in the 
new tourism planning. The district of Calvià -once a major tourist area that experienced severe degradation due to unplanned tourism development- is a good example of successful rejuvenation related to the implementation of the Agenda 21 for sustainable tourism (EC, 2000). However, not all measures have obtained the expected support and results. A good example of this is the case of the 'ecotax', which was agreed upon by the parliament in 2001 as a response to the increasing environmental degradation related to tourism. The 'ecotax' was contentious from the beginning and found a strong opposition both from hoteliers (who were supposed to collect the tax from tourists) as well as from tour operators. Introduced in May 2002, the polemic tax was abolished on November 2003 (Essex et al., 2004; Palmer \& Riera, 2003).

Some major challenges remain for the islands, with resource availability, especially water, needing special attention as it is already a major issue and is likely to be significantly affected by climate change, threatening the short and long term sustainability of the Balearic tourism industry. Several elements play a role in determining the pressure of tourism on water resources including the volume of tourists, the type of activities offered and their geographical and temporal concentration. Water consumption by tourists is known to be higher than that of the resident population and the type of amenities developed for tourists are in many cases water intensive (Essex et al., 2004). In addition, temporal concentration of visitors during the drier months of the year (almost 50\% of arrivals occur between July and September) adds extra pressure over the water resources of the Balearics. During the 1980s and 1990s, the continuous growth in the housing and tourist sector (more than 100,000 beds between 1995 and 2000 only in Mallorca (Consell de Mallorca, 2004)) and the efforts made to revitalize and diversify the sector were associated with important increases in water demand. In 1999, the gross average consumption in Mallorca was 367 litres per day (Essex et al., 2004; Garcia \& Servera, 2003). These elements, combined with the use of irrigation in farmlands ( $62 \%$ of total water demand), the natural seasonal and annual variability and the geophysical characteristics of the islands have had important consequences on the water resources. Between 1973 and 1994, the water table of the main aquifer in Mallorca had been lowered by $110 \mathrm{~m}$ and salt water contamination of the aquifers due to saline intrusion (rendering them useless for irrigation or human consumption) has become a major problem for the water supply of the island and consequently for the tourism sector (Essex et al., 2004). In Mallorca, three quarters of water requirements are covered by groundwater, a major source of vulnerability given the fact that already in 1998 eight of the twenty one hydrological units were over-exploited, six of them suffering problems of saline intrusion (Kent et al., 2002). 


\subsection{Existing and Perceived Climate Change Impacts}

The Mediterranean region has been identified as being highly vulnerable to the impacts of climate change. In the Balearic Islands, the historical climate records for temperature (1976-2006) and precipitation (1951-2006) available provide information of the observed changes during the last decades. An increase of the maximum temperatures has been recorded at a rate of $4.83^{\circ} \mathrm{C}$ per 100 years, much higher than the global average increase. As a matter of fact, the mean warming in Europe in the past has been approximately twice as rapid as the global average, a trend that can also be observed on the Balearics. As for rainfall, the average annual precipitation has shown a negative linear trend of $-170 \mathrm{~mm} / 100$ years (30\% reduction per 100 years compared to the $550 \mathrm{~mm}$ reference value) (Conselleria de Medi Ambient, 2008). These trends constitute a remarkable example that supports the projections of a warmer and drier Mediterranean projected by the IPCC (Alcamo et al., 2007).

According to the study by Moreno et al. (2005) for the Spanish Environmental Ministry, the potential climate change impacts in Spain and in the Balearic Islands specifically are:

- Mean temperatures: increases in mean temperature in the Balearics during the $21^{\text {st }}$ century of $3-4^{\circ} \mathrm{C}$ in winter and up to $5^{\circ} \mathrm{C}$ in the summer (A2 scenario).

- Accumulated precipitation: overall, a greater variability in the temporal and spatial distribution of precipitation can be expected, with a generalized trend to less annual precipitation during the summer months and without appreciable changes in the rest of the year (A2 scenario)

- Sea level rise: for the Balearics a realistic scenario point towards a rise of $50 \mathrm{~cm}$. In the face of this rise, beaches (especially those that are confined by human infrastructures) are expected to be the most vulnerable to processes of inundation and erosion. Combined with the increasing extraction of water for human consumption and the reduction of precipitation, sea level rise may lead to processes of salt-water intrusion into aquifers and their deterioration and unsuitability for human and ecosystem services.

- Impacts on biodiversity and ecosystems: severe impacts on wetlands and animal and plant communities (both terrestrial and marine), favoring the expansion of invading species and plagues, the frequency of forest fires, processes of land degradation and desertification and the loss of fertility.

- Interannual variability of monthly values: increase in the range $(+20 \%)$ and frequency of monthly thermal anomalies (i.e. in the anomalous hottest months in the future climate, the temperature increases will be around $20 \%$ higher than the projected values for average warming). 
- Frequency of extreme events: the occurrence of flash floods, droughts and heat waves are not new in the Balearic. Although climate models provide very limited information about the trend of these phenomena, it can be assumed that any increase in the frequency or intensity will have severe implications for the tourism industry.

The way tourism in the Balearic Islands will be affected by these climate change impacts has not been systematically assessed, although several studies exist that explore the implications of some of these impacts for tourism in the Mediterranean as a whole (Amelung \& Viner, 2006; Perry, 2006; UNWTO et al., 2008). The decreasing climate suitability for summer tourism in the Mediterranean due to heat stress associated with high temperatures is recurrent in these studies. Overall, the tourist season is projected to extend over the spring and autumn, while the summer loses part of its attractiveness due to excessive heat. However most of these studies are based either on qualitative hypothetical descriptions (Amelung \& Viner, 2006; Perry, 2005, 2006) or on models that were not specifically designed for sun and sea tourism and therefore of limited application to the case of the Balearic Islands. In fact, the assumption of the Mediterranean becoming 'too hot' for tourism is being challenged recently by the results of new studies like this thesis (Chapter 7) or the research by Rutty \& Scott (2009). Little is known about the existence of thresholds -especially related to temperature- affecting the perception of comfort or safety of beach users and beyond which tourists might not be willing to stay at a destination. Although some studies exist about the stated preferred temperature for beach tourism, they must be considered with caution as they have not been validated with on-site data or compared to real behavior (e.g. Scott et al., 2008; UNWTO et al., 2008). Other studies have attempted to observe behavior and compare it to weather conditions and no upper threshold could be found, suggesting that previous studies might have overstated the impact of heat events on beach tourism (Martínez Ibarra, 2006; Chapter 6). Regardless the lack of certainty about exact temperature thresholds, it is possible that the increase of several degrees during the summer season as projected by climate models will have important consequences on tourists' comfort.

\subsection{An Introduction to the Vulnerability of the Balearic Tourism Sector to Climate Change}

Chapter 8 presented a methodology to facilitate the assessment of tourism vulnerability to climate change. The methodology is rooted in stakeholder participation and comprises five steps: (step 1) description of the economic, environmental and social context of the destination and key tourism activities; (step 2) characterization of the climate and identification of key hazards and selection of tourism component-climate 
hazard sub-systems (human-environment systems); (step 3) operationalization of vulnerability by identifying the components and indicators to define the exposure, sensitivity and adaptive capacity of each tourism-hazard sub-system; (step 4) integration of individual assessments from step 3 and analysis of non-linearities, interdependencies, future scenarios and overall vulnerability of the tourism destination; and (step 5) communication of results. Derived from the information presented on Chapter 8 and the previous section, three key tourism-hazard sub-systems of the Balearic Islands (step 2) could be proposed ${ }^{1}$ :

- tourists' comfort- temperatures changes leading to heat stress. As explained previously, it is possible that an increase in temperatures may lead to increasing tourists' discomfort ${ }^{2}$. Although not formulated for beach tourism, analysis of the climatic suitability for tourism in the Balearic by means of the Tourism Climatic Index (Mieczkowski, 1985) shows that by 2080s summer months could reduce their attractiveness due to heat stress (Amelung \& Viner, 2006).

- water availability for tourism-precipitation patterns. The technical report prepared by Bates et al. (2008) for the IPCC on water and climate change projects that, annual runoff in southern Europe may be up to $23 \%$ lower in the 2020 s, and $36 \%$ lower in the 2070s according to the different model calculations. The same report also predicts an increasing drought risk: in parts of Spain, today's 100-year droughts are projected to return every 10 years (or fewer) on average by the 2070s (Bates et al., 2008). Groundwater exploitation and sea level rise are likely to intensify the contamination of freshwater resources, reducing even further the water availability for human uses and ecosystem services (Kent et al., 2002).

- beach conditions-change on coastal dynamics. The unplanned urban development and modification of the coast has led to degradation processes over the beach-dune system and the implementation of renourishment plans, although the result seems to be an acceleration of the beach erosion processes (Garcia \& Servera, 2003). 'Urban beaches' -surrounded by architectural elements, disconnected from the dune field and requiring artificial nourishment due to the absence of sediments- are therefore more vulnerable to sea level rise and beach erosion processes. According to the European Commission, the Balearic Islands have 'high exposure' to coastal erosion, including the effect of sea level rise (EC, 2004).

\footnotetext{
${ }^{1}$ This analysis is elaborated for illustration purposes and is not derived from stakeholder consultation.

${ }^{2}$ Although the results from this thesis (see Chapter 7) and other recent studies (e.g. Rutty \& Scott, 2009) show that this is not likely to occur, this climate change impact is recurrent in the literature and is also mentioned in the European Commission PESETA project. For this reason it is included here with the only aim of illustrating the application of the methodology.
} 
The operationalization of the tourists' comfort-temperature changes sub-system is represented in Figure 9.5 as an example. The exposure of the system to this hazard includes components such as 'temperature changes' or the changes in the 'climate suitability' for tourism. Temperature changes could be measured by monitoring the 'temperature variation' for the different seasons and the 'number of days in the year with maximum temperatures above $\mathrm{x}$ degrees', with $\mathrm{x}$ representing a certain threshold found to cause heat stress for beach tourism. Climate suitability is measured by 'changes in tourists' comfort' as measured by some indicator like the Beach Climate Index $(\mathrm{BCl})$ presented in Chapter 7 . Sensitivity can be described through the characteristics of the 'infrastructures' and the 'tourists' perceptions'. The sensitivity of the infrastructures is measured by the 'number of hotels which are air-conditioned', and 'tourists' climatic preferences' and 'country of origin' function as indicators of the sensitivity of tourists. Finally, adaptive capacity is determined by the 'institutional', 'financial' and 'managerial' components. Institutional support is reflected on the existence of 'early warning systems' in case of heat wave periods and by 'monitoring \& enforcing' construction standards that deal better with new climate conditions. The 'investment into adaptation' is used as indicator of the financial support. Finally, management strategies is monitored by the 'diversification' and 'marketing' programs and the implementation of 'building standards' on all new tourism developments. 


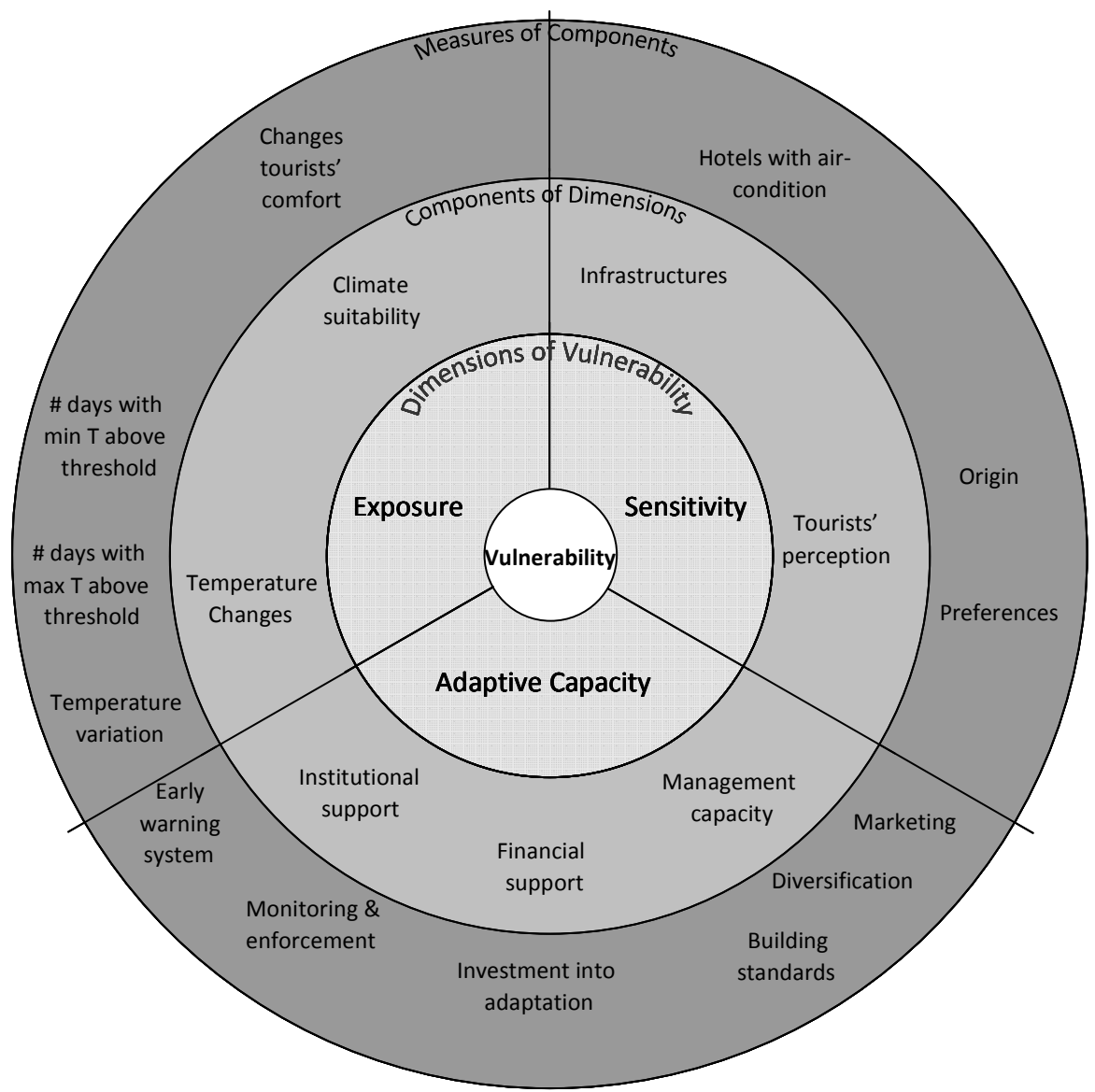

Figure 9.5 Hypothetical operationalization of the tourists' comfort-temperatures changes sub-system (adapted from Moreno \& Becken, 2009)

\subsection{Overview of Current Management and Policy Strategies}

Through its long tradition of tourism expansion, the Balearic Islands have developed an elaborate set of norms and laws to control and regulate the growth of tourist offer. It has been acknowledged many times that the continuous development of new tourist infrastructures generates a negative image of overdevelopment of the islands. In practice, however, tourism laws have not only been unable to stop growth, they have stimulated it in many cases. 
Clearly, tourism is not only regulated by tourism plans and the Balearic Tourism Ministry; it is also affected by general spatial planning and coastal management plans among others. In other words, the division by sector or areas within the regional government has an effect on the high fragmentation of information, where for example tourism management and climate change plans affecting tourism are coordinated by different governmental divisions and not integrated. Legislation at different levels from local to international- often has as well an effect on regional destination management.

To illustrate this data fragmentation and regulation overlap, three documents are briefly described: the first two set the basic regulatory framework of tourism management and the third one shows the initiatives the Balearic Islands are taking in the field of climate change. The first of these documents is the sectorial plan regulating tourism offer (Plan de Ordenación de la Oferta Turística (POOT), Consell de Mallorca, 1995), which identifies tourism as the main economic driver of the island of Mallorca and includes among its objectives the improvement of tourism offer, the determination of the carrying capacity, the promotion of measures to control excessive urban development of the coast and the renovation of obsolete tourism accommodation. The second legal text relevant to tourism management is the territorial plan of Mallorca (Plan Territorial de Mallorca (PTM), Consell de Mallorca, 2004), which analyzes the current situation of aspects as diverse as education centers or energy resources and proposes guiding principles for their management and future development. In terms of tourism, this plan aims at adapting tourism offer to the new motivations of demand, valuing the environmental aspects of tourist destinations and fostering the quality of the products. It is remarkable that despite the recognition of controlling excessive development in urban and coastal areas and the associated environmental degradation, the goals marked by the plan are to be achieved by making terrain available for the construction of 183,000 houses, which will increase substantially the pressures on the territory and its resources (Exceltur, 2007). These two documents (POOP and PTM) are specific for the island of Mallorca, although similar documents exist for the other islands. Despite the recognition of tourism as the main driver of the economy on the islands, none of the reports makes any reference or proposes any policy or management plan in relation to climate change and therefore to the vulnerability of the sector to its impacts. Some local governments are taking initiatives to compensate for the absence of a common strategy for the whole autonomous community. Ibiza is probably one of the most active ones at addressing the issue of climate change and tourism. It has taken several initiatives like the organization of the International conference 'World Heritage, Tourism and Climate Change - Sharing knowledge \& good practices' in May 2008, or a research currently under development on the perceptions of stakeholders on the vulnerability of the sector. 
The lack of a common climate change and tourism strategy does not mean climate change is not seen as an important issue by the regional government. In 2005, the Government of the Balearic Islands created the general climate change office (Direcció General de l'Oficina del Canvi Climàtic) with the role of coordinating the measures of the region on climate change and which belongs to the Balearics' Environmental Ministry. In the same year, the first Balearic strategy against climate change was approved, and in 2008 the action plan (Pla d'Acció) was presented, including the mitigation measures the Balearic Islands will implement in the period 2008-2012. This action plan is structured around 6 sectors, including tourism and commerce, and provides specific measures to reduce greenhouse gases emission and indicators to monitor their development over time. It also includes a number of generic measures which are not specific for any sector and that aim at changing the frame of reference in which the policies and sector programs are developed (e.g. education). The mitigation measures specific for the tourism sector are included in Table 9.1. Adaptation to climate change is an issue which still has not been addressed by the regional authorities.

Table 9.1 Mitigation measures for tourism \& commerce included in the Balearic action plan to fight climate change (Conselleria de Medi Ambient, 2008)

\begin{tabular}{|c|c|c|}
\hline Component & Measure & Indicator \\
\hline \multirow[t]{2}{*}{$\begin{array}{l}\text { Energy efficiency } \\
\text { and saving }\end{array}$} & $\begin{array}{l}\text { Development of entrepreneurial policies } \\
\text { of efficient use of the energy (e.g. light- } \\
\text { ing, air conditioning, heating, etc) }\end{array}$ & - Number and cost of grants \\
\hline & $\begin{array}{l}\text { Incorporate an assessment of GHGs } \\
\text { emissions and corrective measures on } \\
\text { the applications for new licenses for } \\
\text { tourism activities }\end{array}$ & $\begin{array}{l}\text { - Number of projects that include } \\
\text { the assessment of GHGs emissions } \\
\text { - Number of correcting measures } \\
\text { per project }\end{array}$ \\
\hline \multirow[t]{4}{*}{$\begin{array}{l}\text { Good practices } \\
\text { and technological } \\
\text { improvements }\end{array}$} & $\begin{array}{l}\text { Promotion of the use of more energy } \\
\text { efficient technologies and their monitor- } \\
\text { ing on tourism accommodation }\end{array}$ & $\begin{array}{l}\text { - Number of accommodations that } \\
\text { installed these mechanisms } \\
\text { - Energy consumption of the sector }\end{array}$ \\
\hline & $\begin{array}{l}\text { Promotion of good practices by medium } \\
\text { and small businesses and certificate of } \\
\text { best practices }\end{array}$ & $\begin{array}{l}\text { - Number of businesses with qual- } \\
\text { ity certificate }\end{array}$ \\
\hline & $\begin{array}{l}\text { Advice to the Balearic Islands and cham- } \\
\text { ber of commerce for a sustainable entre- } \\
\text { preneurial activity }\end{array}$ & $\begin{array}{l}\text { - Consumption of companies } \\
\text { - Number of companies with cer- } \\
\text { tificate of environmental manage- } \\
\text { ment } \\
\text { - Number of environmental audits } \\
\text { carried out }\end{array}$ \\
\hline & $\begin{array}{l}\text { Promotion of good practices in the field } \\
\text { of environment by the tourist sector }\end{array}$ & $\begin{array}{l}\text { - Number of establishments with } \\
\text { Environmental Management Systems } \\
\text { (e.g. Ecolabel) }\end{array}$ \\
\hline $\begin{array}{l}\text { Development of } \\
\text { regulations }\end{array}$ & $\begin{array}{l}\text { Creation of a law to promote energy } \\
\text { savings on tourism establishments }\end{array}$ & $\begin{array}{l}\text { - Energy consumption by the } \\
\text { tourism sector }\end{array}$ \\
\hline
\end{tabular}




\subsection{Summary and Conclusion of Critical Issues}

The Balearic Islands is one of the oldest and most important tourism destinations in the Mediterranean. Its success is based on a model of package holidays with highly competitive prices and rooted in the intrinsic beauty of the islands combined with the pleasant weather. Tourism is now the main economic activity, and therefore the islands rely heavily on tourists' flows, mainly linked to beach tourism. The geographical location of the Balearic Islands (west Mediterranean) and the high dependency on weather conditions of beach tourism, make the destination highly vulnerable to climate change. Increasing temperatures might lead to heat stress during the summer months, whereas changes in precipitation patterns might reduce the availability of water for tourism and other activities. Sea level rise might have severe implications for the tourism activity, exacerbating current issues such as salt-water intrusion in aquifers and important problems of beach erosion and degradation due to the high degree of anthropogenization of the coast.

Past efforts to revitalize the tourism sector in this mature destination have focused on product diversification and environmental protection; climate change has been neglected so far. Despite the interest the regional government shows for the issue (e.g. with the creation of a specialized office within the regional environmental department), this interest has not been reflected yet in any legal document on tourism management; future tourism planning is still completely unconnected to climate change from a legal point of view, particularly regarding adaptation. In this sense, authorities and businesses should realize that current tourism management strategies will be insufficient to deal effectively with future climate change.

The lack of understanding of how tourism is affected by climate change is a major source of uncertainty that needs to be tackled. To further develop the knowledge base on climate change impacts on the islands, a vulnerability methodology has been proposed. This methodology should provide a framework for the systematic assessment of major hazards and possibilities for adaptation in the tourism sector. However, to gain an integrated view guiding adequate management of the destination, climate change knowledge must be combined with other components including the sensitivity to the costs of transport and oil prices, weather anomalies, change in tourists' preferences and market trends and the appearance of new competitors. The combination of these elements in tourism management plans is likely to improve the sector's awareness and its resilience to climate change and other shocks. 

Chapter 10

DISCUSSION AND CONCLUSION 



\section{Discussion AND CONCLUSION}

The right to leisure was recognized by the Universal Declaration of Human Rights (art. $24, \mathrm{UN}, 1948$ ). As a result of this, the right to tourism was proclaimed universal in the Global Code of Ethics for Tourism of the UNWTO (1999). Although there are very important disparities worldwide in the access and use of these rights, it is unquestionable that recreation and tourism are key phenomena of our society and that they have global effects. The tourism sector contribution to global GDP and employment is estimated to be around $10 \%$, although large uncertainties exist about the exact number. This figure also applies to the GDP and employment in the European Union; between 7.3 and 20.6 million jobs are directly and indirectly related to tourism (Leidner, 2004). Despite the growth of cultural and rural tourism in recent years, coastal areas remain the preferred space for recreation in Europe. To a certain extent all types of leisure activities depend on weather and climate conditions but coastal and marine recreation in general, and sun, sea and sand tourism in particular, are especially exposed and highly sensitive to weather.

Our understanding of the relationships between climate and coastal tourism is still limited. The need to improve our knowledge about this link is strongly intensified by the increasing evidence that the climate is changing. With a potential impact on all the actors directly and indirectly involved in or related to tourism (from demand to offer, from tourism providers to other sectors such as agriculture), climate change is seen as one of the major challenges the industry will have to face in the coming years. The central aim of this thesis was to address these issues and explore the vulnerability of the sector by focusing on the following core research question:

In what different ways might climate change affect Europe's tourism in coastal \& marine environments and how can we assess the vulnerability of the sector?

This central research question was split up in four main sub-questions:

1. What is the state-of-the-art knowledge on climate (change) and tourism, and what are the main knowledge gaps in relation to coastal and marine recreation?

2. What are the weather determinants of 35 tourism?

3. What consequences will have climate change on the destinations' climate suitability for $3 \mathrm{~S}$ tourism as compared to current conditions?

4. How can the vulnerability of destinations be assessed? 
This chapter revisits these questions based on the findings and main conclusions drawn in this PhD. The chapter closes with some concluding remarks to guide future research.

\subsection{Climate Change \& Tourism: Knowledge and Implications for Coastal \& Marine Environments}

Our knowledge and understanding of the ways by which climate change is manifesting itself and will affect the environment and society have improved substantially in recent years. As it is evident from the Fourth Assessment Report (AR4) published by the IPCC -the most authoritative source of information on the science, impacts, adaptation and mitigation of climate change- there is an increasing attention paid to the relationship between climate change and tourism. Compared to the earlier reports the AR4 pays much more attention to the impacts of climate change on environments like coastal and mountain areas, which are at the center of many tourism activities and likely to be highly affected by climate change. Geographically, the published research is highly unbalanced: Europe, North America, Australia \& New Zealand and Small Island States dominate the tourism impact assessments literature. On the other side of the spectrum, Africa, Latin America, Asia and Polar regions are virtually unexplored suggesting that these are priority areas for future research. The projected increase of tourism in many of these regions (e.g. Polar Regions) adds to the urgency. Adaptation strategies for destinations and tourists are poorly accounted for in the AR4.

Coastal areas have been identified as being highly vulnerable to climate change impacts. In addition to the changes in temperature and precipitation patterns experienced by all regions, coastal areas face specific impacts such as acidification (severely threatening coral reefs), sea level rise and coastal erosion. These regions are also more exposed to extreme events such as hurricanes and storm surges. The high exposure of coastal environments to these impacts combined with the importance of these environments for recreation makes coastal tourism one of the most vulnerable tourism segments. Given this vulnerability there is surprisingly little known about the weather requirements of coastal and marine tourism activities. One of the findings of this thesis is that the knowledge about impacts of climate change on recreation in these environments is very limited. Beach tourism has received most of the attention due to its high dependency on weather conditions and its popularity. However, even for this segment, a lot of uncertainties about weather requirements for $3 \mathrm{~S}$ activities still exist. As for the rest of coastal leisure activities, they have been virtually unexplored so far. As the knowledge about physical impacts of climate change on certain marine ecosystems and species improves, it is expected that more attention will be paid to how 
these impacts will affect the tourism industry which makes use of those resources. For example, knowledge on the impacts of climate change on coral reefs has increased significantly over the years and now some studies are available that translate those ecosystem impacts into impacts on the diving tourism industry. Studies addressing greenhouse gas emissions from coastal and marine activities are almost non-existent. Compared to other natural and social systems, tourism has received much less attention in relation to its links with climate change.

The lack of tourism data with the required resolution (e.g. activity specific data) is a major factor hindering the assessment of emissions from tourism in general and from coastal activities specifically. This lack of information influences the way the IPCC Working Group III approaches the mitigation and tourism link, which is seen as a oneway relationship (effect of climate change mitigation on tourism). This is surprising as the important role of tourism as a source of greenhouse gases has been acknowledged by the UN World Tourism Organization (UNWTO et al., 2008), the tourism industry (WTTC, 2009) and the overall scientific community. Tourism is seen either as a victim of climate change mitigation policies, mainly due to the potential effect of taxation on air transport, or as a beneficiary of mitigation strategies due to for example the protection of forests and their use for recreation. This is a very incomplete, one-sided view that does not reflect the scientific, political and social consensus about the role of tourism -and more specifically aviation- as a source of greenhouse gases. Clearly, emissions and mitigation are issues that need to be addressed in the next IPCC report.

\subsection{Weather, Climate and 3S Tourism}

Detailed statistics on its magnitude are lacking, but 35 tourism is unquestionable one of the most important forms of recreation in Europe, and it is likely to retain this position in the future. Due to its magnitude and its high sensitivity to weather conditions, it is also projected to be one of the tourism segments most affected by climate change impacts. In order to assess these impacts, baseline information is required about the role of the different weather attributes in beach tourism. Existing studies have commonly emphasized the role of temperature as a key determinant (and limiting factor) of beach tourism. In this thesis the validity of this and similar assumptions has been assessed.

Two techniques have been used to investigate the weather requirements of beach tourism: questionnaires and observation. Questionnaires can elucidate weather preferences and the relative importance of certain parameters over other using for example rankings. They allow also to explore tourists stated behavior and sensitivity to future climate change impacts. Some of the drawbacks of questionnaires (e.g. the lack of empirical validation and the difference between stated vs. real behavior) have been 
balanced by using observation. Simultaneous observation of visitation (using webcams) and on-site weather has demonstrated to be a highly promising technique for the tourism and climate field, allowing for cheap, large-scale and relatively easy data gathering.

The results from both the questionnaires and the observation complement each other. Responses to the questionnaires highlighted the indisputable importance of climate as a key attribute of Mediterranean destinations. This is the case even for people that do not travel with beach recreation as the main activity during their holiday period. Overall, the absence of precipitation is the most important factor for beach recreation, followed by comfortable temperatures. When looking into the weather conditions that hinder beach recreation, precipitation appears as the number one factor, which is consistent with previous studies. Temperature, however, is less important when it comes to making a day unfavorable, especially when high temperature is considered. Overall, the ideal weather conditions respondents associated to beach tourism are a mean temperature of $28.3^{\circ} \mathrm{C}$, a light breeze, between 6 and 10 hours of sun and no clouds. The observation study reinforced the findings of the questionnaires. Precipitation, even in small quantities or for short periods of time, had a clear effect on participation, overriding other favorable weather conditions. Contrary to what existing literature suggests high temperatures seemed to stimulate rather than deter participation in beach activities. These findings provide new insights about the role of weather for 35 recreation (discussed in Chapters 5 and 6). The results also have important implications for the tourism and climate change literature, urging for a reassessment of the impacts that reflects the specific weather requirements of beach tourism.

\subsection{Climate Change and 35 Tourism in Europe}

With climate change shifting the main weather parameters relevant to tourism and putting pressure on the environments where tourism activities take place, the assessment of climate change impacts on tourism has become a major necessity. Existing studies on climate change impacts on Europe's tourism have commonly used composite indices such as the Tourism Climate Index ( $\mathrm{TCl}$, Mieczkowski, 1985) to assess destinations' climate suitability for recreation. This type of studies, however, was not specifically designed for beach tourism and therefore overemphasized the negative role of high temperature as compared to other weather aspects. The findings presented in this thesis confirm the importance of climate for beach tourism, but reveal that the role of high temperature is less important than for other forms of tourism. Another limitation of the $\mathrm{TCl}$ is that the weighting of the weather parameters is rooted in theoretical knowledge rather than empirical evidences. 
This thesis has reassessed the impacts of climate change on beach tourism using an adapted index (Beach Climate Index) that addresses both limitations of the TCl. The index is rooted in research carried out by Morgan et al. (2000) with a broad sample of north European beach users. Using baseline climate data and future projections of the main climate variables, the resulting index offered a view of the main changes in beach tourism climate comfort in Europe during the summer season. Conditions during the baseline period (1961-1990) depicted a Mediterranean with very good and excellent climate for beach tourism; the lack of precipitation, abundant sunshine, moderate wind breeze and comfortable temperature contribute to this high climatic comfort.

Index values were subsequently calculated for two models of climate change in the period 2051-2080 (2060s): the more extreme HadCM3 and the moderate CSIRO2 General Circulation Models (GCMs). The selected scenario for both models was the A1FI scenario, a high emissions scenario presenting the fastest emission growth and the greatest potential change for tourism in Europe of all IPCC SRES scenarios. This is also the scenario that recent studies identify as the path current emissions are following. The results of this analysis indicated a similar trend as the previous studies, although the magnitude and speed of change is significantly different. Future conditions reflected by both models show deteriorating comfort in some areas of the Mediterranean, mainly in the South of Spain in the HadCM3 model. Climatic comfort extends towards northern latitudes and the value of the beach climate index improves in the North of Spain and southwest France. But the similarities with previous assessments end here. The majority of the Mediterranean retains very good or excellent climatic comfort, something that contrasts with existing studies. This is especially the case for most of the east coast of Spain, the South of Italy, the coasts around the Aegean sea and all the islands, where even the extreme HadCM3 model does not bring the beach climate index to values under 70 (very good). Absolute 'winners', i.e. the regions that will benefit by even a moderate climate change scenario (CSIRO2 model), are mainly the eastern coast of the Adriatic Sea, areas in the Northwest of the Iberian Peninsula and the French regions of Poitou-Charentes and Aquitaine (southwest France). Areas that currently enjoy very good or better conditions but that will see their climate resources deteriorate to levels under 70 even if the moderate CSIRO2-A1FI scenario materializes ('losers') include various regions in the South of the Iberian Peninsula (Algarve, Andalucía, Valencia) and a few other areas in the Mediterranean. A remark regarding these areas with decreasing conditions is necessary, as the scenario that was used $(\mathrm{A} 1 \mathrm{Fl})$ represents the highest emissions growth of all the scenario families developed by the IPCC and is therefore associated with the high end of potential change.

The findings in this thesis confirm the importance of climate as a destination attribute, but they challenge some of the major statements about climate change impacts on European tourism and more specifically in the Mediterranean. Climatic comfort for 
beach recreation may shift to northern latitudes and the Mediterranean may decrease its suitability, but these changes are not likely to be significant at least in the coming $\mathbf{5 0}$ years and most likely not before the end of the century according to existing projections.

The existing projections of climate change impacts on Europe's tourism industry have typically focused on high temperatures as the main driver of change. An increased frequency and intensity of heat waves have therefore received most of the attention of all climate change impacts. The findings presented above, however, show that high temperature does not deter beach recreation, suggesting that the effect of heat waves may have been overestimated. To test this hypothesis, the questionnaires that were discussed before included a question about the importance of five projected impacts of climate change in the Mediterranean: risk of diseases, forest fires, water restrictions in hotels, reduced beach extension and heat waves. The results confirmed the hypothesis: of the five impacts, heat waves were seen as the least negative of all. This finding indicates that together with studies looking into tourists' comfort, there is a pressing need to assess the importance of other climate change impacts such as the risk of diseases or water availability.

\subsection{Tourism Vulnerability to Climate Change: A Framework}

Coastal destinations are highly vulnerable to climate change. This is exacerbated by existing pressures on these, often highly populated, areas. Coastal areas are not only exposed and sensitive to climate change, but in many cases their adaptive capacity is low. This threatens the sustainability of tourism activities not only from an economic point of view, but also socially and environmentally.

The analysis of vulnerability to climate change is a key element in the development of current and future management strategies for tourism destinations. It requires consistent and structured methodologies. The five-step methodology developed in this thesis provides a systematic framework for assessing coastal tourism's vulnerability to climate change. The assessment starts with a thorough analysis of the destination, both in terms of its tourism activities and relevant socio-economic parameters (Step 1). Step 2 involves an analysis of potential climate change impacts, and identifies and prioritizes relevant activity-hazard sub-systems. The analysis of vulnerability of each sub-system, based on the three dimensions of exposure, sensitivity and adaptive capacity, takes place in Step 3. Polsky et al.'s (2007) Vulnerability Scoping Diagram (VSD) is used in this step to provide a structure for working with stakeholders. Identification of feasible adaptation measures based on principles of sustainable development increases the resilience and preparedness of the system. Step 4 assesses the overall vulnerability of the destination by integrating the various individual analyses. Scenarios 
can assist in the exploration of future developments. Communication of results is key to enhancing the knowledge about tourism vulnerability (Step 5). Hence, a wide application of the proposed framework would generate knowledge and facilitate climate change adaptation in other coastal destinations.

The proposed vulnerability assessment methodology for coastal tourism has several advantages. As the case studies in Fiji and the Balearic Islands showed, the approach is able to cover all the tourism activities of interest and relate them to the various dimensions of vulnerability in a structured way. The disaggregation of a destination into multiple activity-hazard sub-systems reduces complexity and thereby allows for an assessment in manageable steps. This is a novel approach that improves on previous attempts to assess tourism vulnerability to climate change. The introduction of disaggregation is of high relevance, as climate change vulnerability (including key agents involved) is likely to differ substantially for the different sub-systems and destinations.

The proposed five-step framework reflects the dynamic nature of the tourism system by addressing the vulnerability of current activities as well as those planned for the future. Thus, it also lends itself to scenario analysis and vulnerability assessment of specific future states (in the climate or other factors). Moreover, both internal and external factors can be considered in the analysis of vulnerability components. Internal factors relate to the destination itself (e.g. whether it is located within a hurricane zone or not), whereas external factors relate to pressures that occur outside the system (e.g. the activities of competing destinations).

The methodology explicitly integrates stakeholders into the process in each step and recognizes that the ultimate outcome of the assessment (including adaptation measures put in place) is the result of stakeholder decision-making. This is subjective in nature and the result will reflect the priorities and expectations that stakeholders attach to tourism. As a result, the framework is more likely to lead to a successful implementation of adaptation measures. Moreover, this stakeholder dialogue adds credibility to and improves the social relevance of the assessment (Brooks et al., 2005; de la Vega-Leinert et al., 2008). The presented framework can also be easily applied in a wide range of settings, even beyond coastal tourism, and has the potential to play an important role in raising awareness in other destinations.

Finally, the validity of the methodology will ultimately be determined by its capacity to improve the understanding of vulnerability of the particular destination (short term), and, to the extent that adaptation measures are put in place, to reduce climate change vulnerability (long term). The short term validity and usefulness of the framework is given by an evaluation of stakeholders' understanding of vulnerability and their satisfaction with the process and the outcome of the assessment. If, as a result of the 
vulnerability assessment, adaptation measures are implemented (e.g. "beach nourishment", "elevating structures", "cyclone proof buildings", "early warning systems" etc.), it might be possible to assess the validity by monitoring vulnerability indicators over time and to identify reductions in vulnerability. The implementation of these adaptation measures should be based on stakeholders' dialogue assisted by technical and scientific knowledge (e.g. cost-benefit analysis; sustainability assessments). Destinations that have used the proposed methodology to reduce vulnerability could be compared with similar destinations that have not assessed their vulnerability and have not implemented adaptation measures.

\subsection{Climate Change and Coastal \& Marine Tourism: Guidelines for Future Research}

This thesis demonstrates the importance of weather and climate for coastal and marine recreation in Europe and explores how climate change may affect tourism in the coastal zone. In addition to the guidelines for future research given in each of the chapters, a number of recommendations can be put forward to improve and expand the existing knowledge on the coastal tourism and climate change relationship. As a fundamental step more information is needed on the weather requirements of different activities, as well as data on number of users and temporal and spatial distribution of activities. This is a necessary step before any attempt is done to assess the vulnerability of a destination. In terms of impacts, current experiences with extreme events could be used as analogues for tourist responses to future climate conditions, a technique applied already to ski tourism but which has been scarcely used with other tourism segments. Innovative approaches to exploring tourism vulnerability may be inspired by progress in other disciplines such as ecology that have a longer tradition in climate change impact research. Direct collaboration with other disciplines such as psychology, sociology and marketing would also contribute greatly to the study of the climate change-tourism relationship, as they can assist in building knowledge in aspects such as the decision making process by tourists. Stakeholders in general, and local businesses and tourism planners in particular, need to be more aware of the vulnerability of their destinations and the potential adaptation measures to be implemented if the impacts of climate change are to be minimized.

Sun, sea and sand activities are especially vulnerable to climate change due to their high sensitivity to weather parameters. Although the results from this research for beach tourism in the Mediterranean are promising in terms of tourism comfort, there are important caveats in knowledge that could be addressed by future research. This thesis explored tourists' comfort, which does not necessarily determine the success of a destination on its own as other characteristics may, in the future, override climate as 
the key attribute. In this sense, an increase in air transport taxation may play a critical role, especially for islands and long-haul destinations, and therefore needs further attention. Apart from the uncertainties intrinsic to any social system like tourism, the magnitude of climate change impacts themselves are also uncertain. The A1FI scenario applied in this thesis is the highest impact scenario of the ones existing at the moment, but this does not mean that more dramatic and unexpected changes could not occur. The exploration of these scenarios may provide useful information about highly vulnerable tourism hotspots and therefore requires more research. Finally, to the already mentioned need to pay attention to tourists' preferences and market trends, other climate change impacts such as coastal erosion, water availability or health related impacts are also important issues that require consideration as they may become critical in many coastal destinations. 



\section{EPILOGUE}

Climate change has the potential to alter in a fundamental way and on a global scale not only tourism, but all aspects of our society and the Earth's environments. From a geological perspective climate change is an inherent characteristic of Planet Earth; climate has always changed during the past billions of years of the Earth history. During the last two million years climate on Earth has varied periodically, with ice ages (glaciations) in which large parts of the Northern Hemisphere were covered by ice sheets, followed by relatively warmer phases. However, there are a number of fundamental differences with the projected changes in climate. In the first place, the scale and rate at which changes are occurring since the industrial revolution are occurring much faster now than at any other moment in time, and certainly too fast to allow certain ecosystems and species to adapt to the new conditions. This last point is intimately related to the human intervention in many ecosystems, which has dramatically reduced their capacity to adapt to new conditions due to a combination of habitat destruction, creation of artificial boundaries that do not allow the ecosystem to migrate in order to adapt, and deterioration of resources. This human interference is so profound and unprecedented that there is the risk that even the smallest disturbances or shocks caused by climate change may have catastrophic impacts on some ecosystems. Finally, a major difference between current and historical changes in the climate system is that it is not occurring due to natural causes but driven by human activities. As a result of all these elements, there is a tremendous necessity to start acting to combat climate change in order to avoid the unmanageable and to manage the unavoidable (SEG, 2007).

One could argue that we are better prepared now than ever before in history to deal with these changes due to our capacity to study and to a certain extent predict the climate system, to think in the long term and to make use of the technology available to protect us against the impacts. However, only a small part of the world population has access to the economic means and technology necessary to adapt and reduce the threats of climate change. Even those countries with sufficient economic resources to recover from specific climate change events have a limit to protect themselves, especially when climate change impacts become more frequent and more severe. Moreover, and ironically, this small percentage of the population that has sufficient means to adapt to these changes has contributed the most to the creation of the problem. Therefore it is not possible to find a justification for inaction as the magnitude of impacts will depend, to a great extent, on the capacity and speed at which humans are able to respond to the ever-increasing emissions of greenhouse gases and bring them under control. 
Tourism is the main economic engine in many countries. This is especially relevant for less developed countries, and vital for small island states. This element has to a certain extent shaped the arguments and position of some stakeholders in the tourism sector. Although acknowledging the role of tourism as a source of greenhouse gases, these actors commonly use the role of tourism in developing countries as an argument to respond to the critics that tourism as a sector should do more to combat climate change, i.e. reduce its emissions. Ironically, by pointing at others sectors and doing nothing to reduce emissions, in the long run climate change impacts may be a greater threat than any reduction in arrivals for these very same developing countries and islands that these stakeholders are trying to protect. Even though the tourism sector is setting initiatives and specific goals to limit their emissions (WTTC, 2009), it is questionable whether this is done in order to avoid binding targets in international agreements or as a real commitment to emissions reduction. It is in the coming years when tourism has to choose between lagging behind other economic sectors in terms of emissions reductions and positioning itself as a pioneer, leading the path towards sustainability.

The tourism sector, and particularly the coastal and marine segment analyzed in this research, is showing the first signs of awareness and concern about the possible impacts of climate change on the sector's activities. However, the full recognition of the magnitude of the problem still needs to be acknowledged. Reduced numbers of visitors is only part of the more fundamental, and often irreversible, problems we are facing such as sea level rise and associated flooding and loss of shoreline and coral reef ecosystems extinction. Two reasons seem to contribute to this limited awareness. In the first place, the level of understanding about climate change impacts on coastal tourism is limited and there are important knowledge gaps that require more attention. The second reason relates to the science-practitioners divide; even though the industry is becoming aware of what is at stake, short-term benefit still dominates over long-term planning. In this sense, science needs to play a more dominant role and provide the tools to facilitate the sector's risk assessment and adaptation options. Tourism efforts to adapt to a changing climate are only likely to be long-lasting if a deep knowledge of the tourism-climate change interactions exists to allow adaptive management strategies to be put in place. If this is not done, any attempt to maintain the status quo in tourism in an environment of continuous change may be successful temporarily, but it is likely to fail in the long-term. Against this background, I hope this research will contribute to gain a better understanding of the climate change impacts on coastal and marine tourism and to provide stakeholders with the tools to assess and reduce the vulnerability of the sector. 


\section{REFERENCES}

ABEGG, B., KÖNIG, U., BÜRKI, R., \& ElSASSER, H. (1997). Climate impact assessment im Tourismus. Die Erde, 128(2), 105-116.

ADGER, W.N. (1999). Social vulnerability to climate change and extremes in coastal Vietnam. World Development, 27(2), 249-269.

AdGER, W.N. (2006). Vulnerability. Global Environmental Change, 16(3), 268-281.

AGNEW, M.D., \& VINER, D. (2001). Potential impacts of climate change on international tourism. International journal of Tourism and Hospitatility Research, 3(1), 37-60.

Aguiló, E., Alegre, J., \& SARD, M. (2005). The persistence of the sun and sand tourism model. Tourism Management, 26(2), 219-231.

AgUIRRE, B.E. (1991). Evacuation in Cancun during hurricane Gilbert. International Journal of Mass Emergencies and Disasters, 9(1), 31-45.

Alcamo, J., Moreno, J.M., Nováky, B., Bindi, M., Corobov, R., Devoy, R.J.N., et al. (Eds.). (2007). Europe. Climate Change 2007: Impacts, Adaptation and Vulnerability. Cambridge, UK: Cambridge University Press.

AMELUNG, B. (2006). Global (environmental) change and tourism - Issues of scale and distribution. Maastricht University, Maastricht.

Amelung, B., \& LAMERS, M. (2007). Estimating the greenhouse gas emissions from Antarctic tourism. Tourism in Marine Environments, 4(2-3), 121-133.

Amelung, B., Moreno, A., \& SCOTT, D. (2008). The place of tourism in the IPCC Fourth Assessment Report: A review. Tourism Review International, 12, 5-12.

AMELUNG, B., NiCHOLLS, S., \& VINER, D. (2007). Implications of global climate change for tourism flows and seasonality. Journal of Travel Research, 45, 285-296.

AMELUNG, B., \& SCOTT, D. (2007). Tourist climate requirements. Paper presented the E-Clat Technical Seminar: Policy Dialogue on Tourism Transport and Climate Change - Stakeholders Meet Researchers, Paris.

AMELUNG, B., \& VINER, D. (2006). Mediterranean tourism: exploring the future with the Tourism Climate Index. Journal of Sustainable Tourism, 14, 349-366.

ANDERSSON, J.E.C. (2007). The recreational cost of coral bleaching - A stated revealed preference study of international tourists. Ecological Economics, 62, 704-715.

Balafoutis, C., IVANOVA, D., \& MAKRogianNIS, T. (2004). Estimation and comparison of hourly thermal discomfort along the Mediterranean basin for tourism planning. In Matzarakis, A., de Freitas, C.R. \& Scott, D. (Eds.), Advances in Tourism Climatology (Vol. 12). Freiburg: Berichte des Meteorologischen Institutes der Universität Freiburg.

BATES, B.C., KUnDZEWICZ, Z.W., Wu, S., \& PALUTIKOF, J.P. (2008). Climate change and water. Technical paper of the Intergovernmental Panel on Climate Change, IPCC Secretariat. Geneva. 
Bayón Marine, F., Gonzalez de Souza, M.A., Marcos Valdueza, H., Alonso Sutil, M.C., Vogeler Ruiz, C., \& Gomez-Luengo SAN Roman, E. (1999). 50 años del turismo español: Un análisis histórico y estructural. Madrid: Editorial Ramon Areces.

BECKEN, S. (2002). Analyzing international tourist flows to estimate energy use associated with air travel. Journal of Sustainable Tourism, 10(2), 114-131.

BECKEN, S. (2004). Climate change and tourism in Fiji. Vulnerability, adaptation and mitigation: University of the South Pacific.

BECKEN, S. (2005). Harmonizing climate change adaptation and mitigation. The case of tourist resorts in Fiji. Global Environmental Change, 15(4), 381-393.

BECKEN, S., \& HAY, J.E. (2007). Tourism and climate change - Risks and opportunities. Cleveland: Channel View Publications.

BECKEN, S., \& SIMMONS, D.G. (2002). Understanding energy consumption patterns of tourist attractions and activities in New Zealand. Tourism Management, 23(4), 343354.

BECKER, S. (1998). Beach Comfort Index - a new approach to evaluate the thermal conditions of beach holiday resorts using a South African example. GeoJournal, 44(4), 297-307.

Belle, N., \& BRAmwell, B. (2005). Climate change and small island tourism: policy maker and industry perspectives in Barbados. Journal of Travel Research, 44(1), 32-41.

Besancenot, J., Mouiner, J., \& De LAVEnNe, F. (1978). Les conditions climatiques du tourisme littoral: un méthode de recherche compréhensive. Norois, 99, 357-382.

BESANCENOT, J.P. (1990). Climat et tourisme. Dijon: Masson.

BLoutsos, A.A. (1976). The climate in the upper atmosphere over Athens. PhD thesis.

BRAMWELL, B. (Ed.). (2004). Coastal mass tourism. Diversification and sustainable development in southern Europe. Clevedon: Channel View Publications.

Braun, O.L., Lohmann, M., Maksimovic, O., Meyer, M., Merkovic, A., Messerschmidt, E., et al. (1999). Potential impact of climate change effects on preferences for tourism destinations. A psychological pilot study. Climate Research, 11, 247-254.

BRooks, N., Adger, W.N., \& Kelly, P.M. (2005). The determinants of vulnerability and adaptive capacity at the national level and the implications for adaptation. Global Environmental Change, 15, 151-163.

Brown, K., Adger, W.N., ToMPkINS, E., BACON, P., SHIM, D., \& Young, K. (2001). Trade-off analysis for marine protected area management. Ecological Economics, 37(3), 417434.

BUTLER, R. (1980). The concept of a tourist area cycle of evolution: Implications for the management of resources. Canadian Geographer, 24(1), 5-12.

BYRNES, T.A., \& WARNKEN, J. (2004). Boat tourism and greenhouse gas emissions: contributions from downunder. In Matzarakis, A., De Freitas, C.R. \& Scott, D. (Eds.), Advances in tourism climatology (pp. 223-235). Freiburg: Universität Freiburg. 
CARTeR, T.R., PARRY, M.L., Nishioka, S., \& HARASAWA, H. (1994). Technical guidelines for assessing climate change impacts and adaptations. London and Tsukuba: Report of the Working Group II of the Intergovernmental Panel on Climate Change. University College London and Centre for Global Environmental Research.

Cegnar, T., \& Matzarakis, A. (2004). Trends of thermal bioclimate and their application for tourism in Slovenia. In Advances in tourism climatology (pp. 66-73): Ber. Meteor. Inst. Univ. Freiburg.

CERON, J.P., \& SCOTT, D. (2007). Overview of issues regarding impacts of, and adaptation to climate change. Paper presented at the E-Clat Technical Seminar: Policy Dialogue on Tourism Transport and Climate Change - Stakeholders Meet Researchers, Paris.

CESAR, H. (2000). Impacts of the 1998 coral bleaching event on tourism in El Nido, Philippines: Coastal Resource Center - Coral Bleaching Initiative.

CLIA. (2008). CLIA cruise market overview - Statistical cruise industry data through 2007. Retrieved 29-07-2008

Coghlan, A., \& PrideauX, B. (2007). Keeping an I (and 1.9 million others) on the reef: the sustainability of tourism on the Great Barrier Reef. Paper presented at the 5th International Coastal \& Marine Tourism Congress, Auckland, New Zealand.

Consell de Mallorca. (1995). Pla d'ordenació de l'oferta turística (POOT). Palma. Available http://www.conselldemallorca.net/?id section=1518\&id son=1519\&id parent $=49$ 3. Retrieved on 27-02-2009.

Consell de Mallorca. (2004). Plan territorial de Mallorca. Palma. Available at http://www.conselldemallorca.cat/platerritorial. Retrieved on 27-02-2009.

Conselleria de Medi Ambient. (2008). Pla d'acció per la lluita contra el canvi climatic. Palma. Available at http://www.caib.es/sacmicrofront/archivopub.do?ctrl=MCRST297Z141685\&id=416 $\underline{85}$.

COnSelleria de TURISMe. (2008). Principales conclusiones del informe IMPACTUR Illes Balears 2007. Palma. Available at http://exceltur.org/excel01/contenido/portal/files/Resumen\%20IMPACTUR\%20Ille s\%20Baleares\%202007.pdf. Retrieved on 28-02-2009.

ConselleRIA De TURISMe. (2009). El turismo a les Illes Balears. Dades informatives 2008. Palma.

CORMIER, B. (2007). Iceberg sinks cruise ship off Antarctica. National Geographic News. Available at http://news.nationalgeographic.com/news/2007/11/071124-APcruise-ship.html. Accessed on 30-07-2008.

Cumming, R., Toscano, M., lovell, E., Carlson, B., Dulvy, N., Hughes, A., et al. (2002). Mass coral bleaching in the Fiji Islands, 2000. Paper presented at the Ninth International Coral Reef Symposium, Bali. 
CURTIN, S. (2003). Whale-watching in Kaikoura: sustainable destination development? Journal of Ecotourism, 2(3), 173-195.

CUTTER, S.L. (1996). Vulnerability to environmental hazards. Progress in Human Geography, 20, 529-539.

DAVENPORT, J., \& DAVENPORT, J.L. (2006). The impact of tourism and personal leisure transport on coastal environments: A review. Estuarine, Coastal and Shelf Science, 67(1-2), 280-292.

DAWSON, J., StEWART, E., \& SCOT, D. (2007). Climate change vulnerability of the polar bear viewing industry in Churchill, Manitoba. Paper presented at the Tourism and global change in polar regions. An international conference, Oulu, Finland.

DE FREITAS, C.R. (1990). Recreation climate assessment. International Journal of Climatology, 10, 89-103.

DE FreitAS, C.R., SCOTt, D., \& McBoyle, G. (2004). A new generation climate index for tourism and recreation. Paper presented at the International Society of Biometeorology Commission on Climate, Tourism and Recreation. 9-12 June, Kolimbari, Creete.

DE FreitAS, C.R., SCOTt, D., \& MCBoyle, G. (2008). A second generation climate index for tourism (CIT): specification and verification. International Journal of Biometeorology, 52, 399-407.

de la Vega-Leinert, A.C., Schröter, D., Leemans, R., Frisch, U., \& Pluimers, J. (2008). A stakeholder dialogue on European vulnerability. Regional Environmental Change, 8(3), 109-124.

DE SAUSMAREZ, N. (2007). Crisis management, tourism and sustainability: the role of indicators. Journal of Sustainable Tourism, 15(6), 700-715.

DeROCHER, A.E., LUNN, N.J., \& STIRLING, I. (2004). Polar bears in warming climate. Integrative and Comparative Biology, 44, 163-176.

DONner, S.D., SkIRVIng, W.J., LitTle, C.M., OpPenheimer, M., \& Hoegh-Guldberg, O. (2005). Global assessment of coral bleaching and required rates of adaptation under climate change. Global Change Biology, 11, 2251-2265.

DowlatABADI, H., \& MoRgan, M.G. (1993). Integrated assessment of climate change. Science, 253, 1813.

DYCK, M.G., \& BAYDACK, R.K. (2004). Vigilance behaviour of polar bears (Ursus maritimus) in the context of wildlife-viewing activities at Churchill, Manitoba, Canada. Biological Conservation, 116(3), 343-350.

EC. (2000). Towards quality coastal tourism. Brussels: European Commission.

EC. (2004). Living with coastal erosion in Europe - Sediment and space for sustainability. Luxemburg: European Commission.

EC. (2009). Survey on the attitudes of Europeans towards tourism. Brussels: European Commission. 
EL-RAEY, M. (1998). Vulnerability assessment of the coastal zone of the Nile delta of Egypt, to the impacts of sea level rise. Ocean \& Coastal Management, 37(1), 29-40.

ElSASSER, H., \& BÜRKI, R. (2002). Climate Change as a Threat to Tourism in the Alps. Climate Research, 20(3), 253-257.

EmANUEL, K. (2005). Increasing destructiveness of tropical cyclones over the past 30 years. Nature, 436, 686-688.

ESSEX, S., KeNT, M., \& NeWNHAM, R. (2004). Tourism development in Mallorca: is water supply a constraint? Journal of Sustainable Tourism, 12(1), 4-25.

EXCELTUR. (2007). Estrategias turisticas integradas en los vigentes planes de ordenacion del territorio, en zonas del litoral mediterraneo, Baleares y Canarias: Exceltur.

FARRELL, B.H., \& TWINING-WARD, L. (2004). Reconceptualizing tourism. Annals of Tourism Research, 31(2), 274-295.

FARRELL, B.H., \& TWINING-WARD, L. (2005). Seven steps towards sustainability: tourism in the context of new knowledge. Journal of Sustainable Tourism, 13(2), 109-122.

FeEnStRA, J.F., BURTON, I., SMITH, J.B., \& Tol, R.S.J. (1998). Handbook on methods for climate change impacts assessment and adaptation strategies. In: United Nations Environmental Programme and Institute for Environmental Studies, Vrije Universiteit, Nairobi and Amsterdam.

Fij Meteorological Service. (2006). Meteorological Data and Risk Profile. Presented at the Initial Stakeholder Workshop, 2 May 2006, convened by the Fiji Ministry of Tourism with the United Nations World Tourism Organisation and the United Nations Environment Programme, Suva, Fiji.

FIJI MINISTRY OF TOURISM. (2006). Summary report of the initial stakeholder workshop 2 May 2006, convened by the Fiji Ministry of Tourism with the United nations World Tourism Organisation and the United Nations Environment Programme. Suva, Fiji. http://www.tourism.gov.fj/downloads/mswfiles/climate change workshop report.pdf. Accessed12.01.08.

FIJI VISITOR BUREAU. (2004). Explore Fiji. Suva.

FüSSEL, H.M. (2007). Vulnerability: a generally applicable conceptual framework for climate change research. Global Environmental Change, 17, 155-167.

FüSSEL, H.M., \& KLEIN, R.J.T. (2006). Climate change vulnerability assessments: an evolution of conceptual thinking. Climatic Change, 75(3), 301-329.

GARCIA, C., \& SeRVERA, J. (2003). Impacts of tourism development on water demand and beach degradation on the island of Mallorca (Spain). Geografiska Annaler, 85A, 287-300.

Gómez MARTín, M.B. (2004). An evaluation of the tourist potential of the climate in Catalonia (Spain): a regional study. Geografiska Annaler, 86(3), 249-264.

Gómez MARTín, M.B. (2005). Weather, climate and tourism - A geographical perspective. Annals of Tourism Research, 32(3), 571-591. 
Gómez MARTín, M.B. (2006). Climate potential and tourist demand in Catalonia (Spain) during the summer season. Climate Research, 32, 75-87.

GössLING, S. (2002). Global environmental consequences. Global Environmental Change, 12(4), 283-302.

GöSSLING, S., \& HALL, C.M. (2006). An introduction to tourism and global environmental change. In Gössling, S. \& Hall, C.M. (Eds.), Tourism \& global environmental change Ecological, social, economic and political interrelationships. New York: Rutledge.

Gough, C., CASTELLS, N., \& Funtowicz, S. (1998). Integrated Assessment: an emerging methodology for complex issues. Environmental Modeling and Assessment, 3, 1929.

GREEN, J.S.A. (1967). Holiday meteorology: reflections on weather and outdoor comfort. Weather, 22, 128-131.

GRM InTERnATIONAL. (2007). Tourism Development Plan 2007-2016. Draft to stakeholder comment. Suva. Fiji.

HALL, C.M. (2001). Trends in ocean and coastal tourism: the end of the last frontier? Ocean \& Coastal Management, 44, 601-618.

Hamilton, J.M. (2003). Climate and the destination choice of German tourists. Hamburg: Research Unit Sustainability and Global Change Working Paper FNU-15, Centre for Marine and Climate Research, University of Hamburg.

HAMILTON, J.M., \& LAU, M.A. (2005). The role of climate information in tourist destination choice decision making. In Gössling, S. \& Hall, C.M. (Eds.), Tourism and global environmental change. London: Routledge.

HAMILTON, J.M., MADDISON, D.J., \& TOL, R.S.J. (2005). Climate change and international tourism: A simulation study. Global Environmental Change, 15, 253-266.

HARRIS, G. (2002). Integrated assessment and modelling: an essential way of doing science. Environmental Modelling \& Software, 17, 201-207.

HATCH, D. (1988). The distribution of world climate conditions. Journal of Meteorology, 13(133), 344-349.

HaY, J.E., Mimura, N., Campbell, J., Fifita, S., Koshy, K., McLean, R.F., et al. (2003). A resource book for policy and decision makers, educators and other stakeholders. In: South Pacific Regional Environment Programme. Ministry of the Environment, Japan.

HIGHAM, J., \& HALL, C.M. (2005). Making tourism sustainable: the real challenge of climate change? In Hall, C.M. \& Higham, J. (Eds.), Tourism, recreation and climate change (pp. 301-307). Clevedon: Channel View Publications.

HOLDEN, A. (2000). Environment and tourism. London: Routledge.

HoYT, E. (1996). Whale watching: a global overview of the industry's rapid growth and some recent implications and suggestions for Australia. Paper presented at the Encounters with whales 1995, Canberra. 
HUBERTY, C.J., \& HUSSEIN, M.H. (2003). Some problems in reporting use of discriminant analyses. The Journal of Experimental Education, 71(2), 177-191.

HUberTy, C.J., \& Olejnik, S. (2006). Applied MANOVA and Discriminant Analysis (Second ed.). Hoboken, New Jersey: Wiley.

IFRC. (2007). VCA toolbox with reference sheets. Geneva: International Federation of Red Cross and Red Crescent Societies.

IPCC-TGICA. (2007). General Guidelines on the use of scenario data for climate impact and adaptation assessment, version 2. Report by the Intergovernmental Panel on Climate Change (IPCC) Task Group on Data and Scenario Support for Impact and Climate Assessment (TCICA). Available from: http://www.ipccdata.org/guidelines/TGICA guidance sdciaa v2 final.pdf.

IPCC. (2007a). Climate change 2007: Impacts, adaptation and vulnerability. Geneva: Intergovernmental Panel on Climate Change.

IPCC. (2007b). Climate change 2007: Mitigation of climate change. Geneva: Intergovernmental Panel on Climate Change.

IPCC. (2007c). Climate change 2007: Synthesis Report. Geneva: Intergovernmental Panel on Climate Change.

IPCC. (2007d). Climate change 2007: The physical science basis. Geneva: Intergovernmental Panel on Climate Change.

JAKEMAN, A.J., \& LETCHER, R.A. (2003). Integrated assessment and modelling: features, principles and examples for catchment management. Environmental Modelling \& Software, 18, 491-501.

JeHN, K.H., \& JeHN, M.S. (1979). Beach atmosphere. Weather, XXXIV(6), 223-232.

Jiménez, J.A., Osorio, A., Marino-TAPiA, I., Davidson, M., Medina, R., Kroon, A., et al. (2007). Beach recreation planning using video-derived coastal state indicators. Coastal Engineering, 54, 507-521.

JONES, B., \& SCOTT, D. (2006a). Climate change, seasonality and visitation to Canada's National Parks. Journal of Parks and Recreation Administration, 24, 42-62.

JONES, B., \& SCOTT, D. (2006b). Implications of climate change for visitation to Ontario's Provincial Parks. Leisure, 30, 233-261.

KAMMLER, M., \& SCHERNEWSKI, G. (2004). Spatial and temporal analysis of beach tourism using webcam and aerial photographs. Paper presented at the BaltCoast 2004 Managing the Baltic Sea, Warnemünde, Germany.

Kasperson, J.X., Kasperson, R.E., TURner, B.L., HSieh, W.-H., \& SCHiller, A. (2003). Vulnerability to global environmental change. In Diekman, A., Dietz, T., Jaeger, C. \& Rosa, E.A. (Eds.), The Human Dimensions of Global Environmental Change. MIT, Cambridge.

KENCHINGTON, R. (1993). Tourism in coastal and marine environments - A recreational perspective. Ocean \& Coastal Management, 19, 1-16. 
KENT, M., NeWNHAM, R., \& ESSEX, S. (2002). Tourism and sustainable water supply in Mallorca: a geographical analysis. Applied Geography, 22, 351-374.

KNMI. (2006a). Augustus 2006:Record nat, somber en koel [Electronic Version]. http://www.knmi.nl/kd/maand en seizoensoverzichten/maand/aug06.html. Retrieved 30-05-2007.

KNMI. (2006b). Juli 2006 warmste maand in zeker 300 jaar [Electronic Version]. http://www.knmi.nl/VinkCMS/news detail.jsp?id=33586. Retrieved 23-05-2007.

KNOWLES, T., \& CURTIS, S. (1999). The market viability of European mass tourist destinations. A post-stagnation life-cycle analysis. International Journal of Tourism Research, 1(2), 87-96.

KozAK, M. (2002). Comparative analysis of tourist motivations by nationality and destinations. Tourism Management, 23, 221-232.

Learmonth, J.A., Macleod, C.D., Santos, M.B., Pierce, G.J., Crick, H.Q.P., \& Robinson, R.A. (2006). Potential effects of climate change on marine mammals. In Gibson, R.N., Atkinson, R.J.A. \& Gordon, J.D.M. (Eds.), Oceanography and Marine Biology: An Annual Review, 2006 (Vol. 44, pp. 431-464): Taylor \& Francis.

LEEWORTHY, V.R., \& WILEY, P.C. (2001). Current participation patterns in marine recreation. National survey on recreation and the environment 2000. Silver Spring (Maryland): U.S. National Oceanic and Atmospheric Administration (U.S. Department of Commerce).

LEIDNER, R. (2004). The European tourism industry - A multi-sector with dynamic markets. Luxemburg: European Commission.

LISE, W., \& TOL, R.S.J. (2002). Impact of climate on tourist demand. Climatic Change, 55(4), 429-449.

LOHMANN, M., \& KAIM, E. (1999). Weather and holiday destination preferences: image, attitude and experience. The Tourist Review, 2, 54-63.

LUeRS, A.L., LobelL, D.B., SkLAR, L.A., AdDAMS, C.L., \& MATSON, P.A. (2003). A method for quantifying vulnerability, applied to the agricultural system of the Yaqui Valley, Mexico. Global Environmental Change, 13, 255-267.

MADDISON, D. (2001). In search of warmer climates? The impact of climate change on flows of British tourists. Climatic Change, 49(1/2), 193-208.

MARTínez IBARRA, E. (2006). Consideraciones geográficas en torno al binomio climaturismo: aplicación al litoral alicantino. Universidad de Alicante, Alicante.

MATHER, S., VINER, D., \& TODD, G. (2005). Climate and policy changes: their implications for international tourism flows. In Hall, C.M. \& Higham, J. (Eds.), Tourism, recreation and climate change (pp. 63-85). New York: Channel View Publications.

MATZARAKIS, A., DE FreitAS, C.R., \& SCOTt, D. (2004). Tourism and recreation climatology. In Matzarakis, A., de Freitas, C.R. \& Scott, D. (Eds.), Advances in Tourism Climatology (pp. 6-9). Freiburg: Universität Freiburg. 
Matzarakis, A., Mayer, H., \& IzIOMON, M.G. (1999). Applications of a universal thermal index: physiological equivalent temperature. International Journal of Biometeorology, 43(2), 76-84.

McCarthy, J.J., CANZIANI, O.F., LeARY, N.A., DokKEN, D.J., \& White, K.S.E. (2001). Climate Change 2001: Impacts, Adaptation and Vulnerability. Cambridge: Cambridge University Press.

MCKeRCHER, B. (1999). A chaos approach to tourism. Tourism Management, 20, 425434.

MeHEUX, K., \& PARKER, E. (2006). Tourist sector perceptions of natural hazards in Vanuatu and the implications for a small island developing state. Tourism Management, $27,69-85$.

Meze-Hausken, E. (2008). On the (im-)possibilities of defining human climate thresholds. Climatic Change, 89(3-4), 299-324.

MIECZKOWSKI, Z. (1985). The Tourism Climate Index: a method of evaluating world climates for tourism. The Canadian Geographer, 29(3), 220-233.

MILleR, G.A., \& TWINING-WARD, L. (2005). Monitoring for a sustainable tourism transition: The challenge of developing and using indicators. Wallingford: CABI Publishing.

MilleR, M.L. (1993). The rise of coastal and marine tourism. Ocean \& Coastal Management, 20, 181-199.

MimuRA, N., \& NUNN, P. (1997). Trends of beach erosion and shoreline protection in rural Fiji. Journal of Coastal Research, 14(1), 37-46.

MitChell, T.D., CARTER, T.R., Jones, P.D., Hulme, M., \& NeW, M. (2004). A comprehensive set of high resolution grids of monthly climate for Europe and the globe: the observed record (1901-2000) and 16 scenarios (2001-2100). Norwich: Tyndall Centre for Climate Change Research, University of East Anglia.

Morabito, M., CecCHI, L., Modesti, P., Cricl, A., Orlandi, G., Maracchi, G., et al. (2004). The impact of hot weather conditionss on tourism in Florence, Italy: the summer of 2002-2003 experience. In Advances in tourism climatology (pp. 158-165): Ber. Meteor. Inst. Univ. Freiburg.

MoReno, A. (2007). The role of weather in beach recreation - a case study using webcam images. In Matzarakis, A., De Freitas, C.R. \& Scott, D. (Eds.), Developments in tourism climatology. Freiburg: Commission on climate, tourism and recreation - International Society of Biometeorology.

MoReno, A. (2009). Mediterranean tourism and climate (change): a survey-based study. Paper presented at the 7th International Symposium on Tourism and Sustainability, Eastbourne.

Moreno, A. (in press). Impact of climate change on island tourism - The Balearic Islands: impacts, vulnerability and crititical management issues. In Jones, A. \& Phillips, M. (Eds.), Disappearing Destinations: CABI. 
Moreno, A., \& Amelung, B. (2009a). Climate change and coastal \& marine tourism: review and analysis. Journal of Coastal Research, SI 56, 1140-1144.

Moreno, A., \& AMELUnG, B. (2009b). Climate change and tourist comfort on Europe's beaches in summer: a reassessment. Coastal Management, 37(6), 550-568.

Moreno, A., Amelung, B., \& SANTAMARTA, L. (2008). Linking beach recreation to weather conditions. A case study in Zandvoort, Netherlands. Tourism in Marine Environments, 5(2-3), 111-119.

MoReno, A., \& BECKEN, S. (2009). A climate change vulnerability assessment methodology for coastal tourism. Journal of Sustainable Tourism, 17(4), 473-488.

Moreno, J.M., Aguiló, E., Alonso, S., Cobelas, M.Á., Anadón, R., Ballester, F., et al. (2005). A premilinary assessment of the impacts in Spain due to the effects of climate change. Madrid, Spain: Ministry of Environment.

MoRgan, M.G., \& DowlatabadI, H. (1996). Learning from Integrated Assessment of climate change. Climatic Change, 34, 337-368.

Morgan, R., Gatell, E., Junyent, R., Micallef, A., Ozhan, E., \& Williams, A.T. (2000). An improved user-based beach climate index. Journal of Coastal Conservation, 6, 4150 .

Nakicenovic, N., Alcamo, J., Davis, G., de Vries, B., Fenhann, J., Gaffin, S., et al. (2000). Special Report on Emissions Scenarios. Cambridge, United Kingdom: Intergovernmental Panel on Climate Change.

NeW, M., LISTER, D., HULME, M., \& MAKEN, I. (2002). A high-resolution dataset of surface climate over global land areas. Climate Research, 21, 1-25.

NGAZY, Z., JIDDAWI, N., \& CESAR, H. (2001). Coral bleaching and the demand for coral reefs: a marine recreation case in Zanzibar. Paper presented at the Economic valuation and policy priorities for sustainable management of coral reefs, Penang, Malaysia.

NiCHOLLS, R.J. (1995). Synthesis of vulnerability analysis studies. Paper presented the Proceedings World Coast '93, The Netherlands.

NiCHOlls, R.J., HoOzemANS, F.M.J., \& MARCHAND, M. (1999). Increasing flood risk and wetland losses due to global sea-level rise: regional and global analyses. Global Environmental Change, 9, S69-587.

Nicholls, R.J., Wong, P.P., Burkett, J.O., Codignotto, J.E., HAY, J.E., Mclean, R.F., et al. (2007). Coastal systems and low-lying areas. In Parry, M.L., Canziani, O.F., Palutikof, J.P., van der Linden, P.J. \& Handson, C.E. (Eds.), Climate Change 2007: Impacts, Adaptation and Vulnerability. Contribution of Working Group II to the Fourth Assessment Report of the Intergovernmental Panel on Climate Change (pp. 982pp). Cambridge, UK: Cambridge University Press.

NiCHOLLS, S. (2006). Climate change, tourism and outdoor recreation in Europe. Managing Leisure, 11, 151-163. 
NiCholls, S., \& AMELUNG, B. (2008). Climate change and tourism in northwestern Europe: impacts and adaptation. Tourism Analysis, 13, 21-31.

O'BRIEN, K., ERIKSEN, S., SCHJOlden, A., \& NYGAARD, L. (2004). What's in a word? Conflicting interpretations of vulnerability in climate change research: CICERO Working Paper 2004:04.

OECD. (2008). Tourism in OECD countries 2008: trends and policies. Paris: Organisation for Economic Co-operation and Development.

ORAMS, M.B. (1999). Marine tourism: development, impacts and management. London: Routledge.

ORAMS, M.B. (2000). Tourists getting close to whales, is it what whale-watching is all about? Tourism Management, 21(6), 561-569.

ORAMS, M.B. (2007). Extreme marines: the rise of high risk marine tourism. Paper presented at the 5th International Coastal \& Marine Tourism Congress, Auckland, New Zealand.

Pacific islands Climate Change Assistance Programme. (2005). Climate change. The Fiji Islands response: PICCAP.

PALmer, T., \& RIERA, A. (2003). Tourism and environmental taxes. With special reference to the "Balearic ecotax". Tourism Management, 24, 665-674.

PATterson, T., BASTIANONI, S., \& SIMPSON, M.C. (2006). Tourism and climate change: twoway street, or vicious/virtuous circle? Journal of Sustainable Tourism, 14(4), 339348.

PeETERS, P., Gössling, S., \& BECKEN, S. (2006). Innovation towards tourism sustainability: climate change and aviation. International Journal of Innovation and Sustainable Development, 1(3), 184-200.

Peeters, P., SzimbA, E., \& DuIJnisVeld, M. (2007). Major environmental impacts of European tourist transport. Journal of Transport Geography, 15(83-93).

Peñuelas, J., \& Filella, I. (2001). Phenology: Responses to a warming world. Science, 294(5543), 793-795.

PERRY, A. (2005). The Mediterranean: how can the world's most popular and successful tourist destination adapt to a chaning climate? In Hall, M. \& Higham, J. (Eds.), Tourism, recreation and climate change (pp. 86-97). Clevedon: Channel View Press.

PERRY, A. (2006). Will predicted climate change compromise the sustainability of Mediterranean tourism? Journal of Sustainable Tourism, 14(4), 367-375.

Polsky, C., NeFF, R., \& YARNAL, B. (2007). Building comparable global change vulnerability assessments: the vulnerability scoping diagram. Global Environmental Change, 17(3-4), 472-485.

RAKSAKULTHAI, V. (2003). Climate change impacts and adaptation for tourism in Phuket, Thailand. Pathumthani, Thailand: Asian Disaster Preparedness Centre. 
Ramjeawon, T., \& Beedassy, R. (2004). Evaluation of the ElA system on the Island of Mauritius and development of an environmental monitoring plan framework. Environmental Impact Assessment Review, 24(5), 537-549.

Raupach, M.R., Marland, G., Cials, P., Le Quere, C., Canadell, J.G., Klepper, G., et al. (2007). Global and regional drivers of accelerating CO2 emisssions. PNAS, 104(24), 10288-10293.

RIBOT, J.C. (1995). The causal structure of vulnerability: its application to climate impacts analysis. GeoJournal, 35, 119-122.

RIND, D. (1999). Complexity and climate. Science, 284, 105-107.

ROBLEDO, M.A., \& BATLE, J. (2002). Re-planning for tourism in a mature destination: a note on Mallorca. In Voase, R.N. (Ed.), Tourism in Western Europe: a collection of case histories (Vol. Wallingford, Oxon, pp. 85-94): CABI Publishing.

RotMANS, J. (1998). Methods for IA: The challenges and opportunities ahead. Environmental Modeling and Assessment, 3, 155-179.

RUSSELL, R., \& FAULKNER, B. (1999). Movers and shakers: chaos makers in tourism development. Tourism Management, 20, 411-423.

RUTTY, M., \& SCOTT, D. (2009). Will the Mediterranean become "too hot" for tourism? A reassessment. Paper presented at the 7 th International Symposium on Tourism and Sustainability, Eastbourne.

SCHRÖTER, D., POLSKY, C., \& PATT, A.G. (2005). Assessing vulnerabilities to the effects of global environmental change: an eight step approach. Mitigation and Adaptation Strategies for Global Change, 10(4), 573-596.

Scott, D., Gossling, S., \& De Freitas, C.R. (2008). Preferred climates for tourism: case studies from Canada, New Zealand and Sweden. Climate Research, 38(1), 61-73.

SCOTt, D., JONES, B., \& MCBOyLE, G. (2006). Climate, tourism \& recreation. A bibligraphy 1936 to 2006. Waterloo: University of Waterloo.

SCOTT, D., \& McBoyle, G. (2007). Climate change adaptations in the ski industry. Mitigation and Adaptation Strategies for Global Change, 12(8), 1411-1431.

SCOTt, D., MCBoyle, G., \& Mills, B. (2003). Climate change and the skiing industry in Southern Ontario (Canada): exploring the importance of snowmaking as a technical adaptation. Climate Research, 23, 171-181.

SCOTT, D., McBoyle, G., MilLS, B., \& WALL, G. (2001). Assessing the sensitivity of the alpine skiing industry in Ontario, Canada to climate variability and change. Paper presented at the First International Workshop on Climate, Tourism and Recreation, Halkidiki, Greece.

Scott, D., McBoyle, G., \& SChWARTZentruber, M. (2004). Climate change and the distribution of climatic resources for tourism in North America. Climate Research, 27, 105-117. 
SEG. (2007). Confronting climate change: avoiding the unmanageble and managing the unavoidable: Report prepared for the United Nations Commission on Sustainable Development. Sigma Xi, Research Triangle Park, NC and the United Nations Foundation, Washington, DC.

Simpson, M.C., Gössling, S., SCOTT, D., HALl, C.M., \& Gladin, E. (2008). Climate change adaptation and mitigation in the tourism sector: frameworks, tools and practices. Paris: UNEP, University of Oxford, UNWTO, WMO.

SINCLAIR-HANNOCKS, S. (1994). Sustainable ecological and recreational management of sandy beach systems. Unpublished PhD, University of technology, Sydney.

SMIT, B., \& WANDEL, J. (2006). Adaptation, adaptive capacity and vulnerability. Global Environmental Change, 16(3), 282-292.

SMITH, K. (1993). The influence of weather and climate on recreation and tourism. Weather, 48(12), 398-404.

SteadMAn, R.G. (1979). The assessment of sultriness. Part I: A temperature-humidity index based on human physiology and clothing science. Journal of Applied Meteorology, 18(7), 861-873.

STERN, N. (2006). The economics of climate change: The Stern review. London: Cabinet Office-HM Treasury.

Stirling, I., \& PARKInson, C.L. (2006). Possible effects of climate warming on selected populations of polar bears (Ursus maritimus) in the Canadian Arctic. Arctic, 59(3), 261-275.

SUCHMAN, L., \& JORDAN, B. (1990). Interactional troubles in face-to-face survey interviews. Journal of the American Statistical Association, 85(409), 232-241.

TIAS. (2009). Defining Integrated Assessment.

TIMOTHY, D., \& GRoves, D. (2001). Research Note: Webcam Images as Potential Data Sources for Tourism Research. Tourism Geographies, 3(4), 394-404.

Turner, B.L., Kasperson, R.E., Matson, P.A., McCarthy, J.J., Corell, R.W., Christensen, L., et al. (2003). Science and technology for sustainable development special feature: A framework for vulnerability analysis in sustainability science. Proceedings of the National Academy of Sciences, 100(14), 8074-8079.

TYNAN, C.T., \& DEMASTER, D.P. (1997). Observations and predictions of Arctic climatic change: potential effects on marine mammals. Arctic, 50(4), 308-322.

UN. (1948). The Universal Declaration of Human Rights. United Nations. Available at http://www.un.org/en/documents/udhr/index.shtml\#a13.

UNEP, \& UNWTO. (2005). Making tourism more sustainable - A guide for policy makers: United Nations Environmental Programme and World Tourism Organization.

UNESCO. (2007). Case studies on climate change and world heritage. Paris: United Nations Educational, Scientific and Cultural Organization. 
UNFCCC. (1992). United Nations Framework Convention on Climate Change: Retrieved from http://unfcc.int/resource/docs/convkp/conveng.pdf.

UNWTO. (1999). Global code of ethics for tourism. Madrid: United Nations World Tourism Organization.

UNWTO. (2001). Tourism 2020 vision - Global forecast and profiles of market segments. Madrid: United Nations World Tourism Organization.

UNWTO. (2004). Indicators of sustainable development for tourism destinations: a guidebook. Madrid: United Nations World Tourism Organization.

UNWTO. (2009). World Tourism Barometer. Volume 7, Number 2. Madrid: United Nations World Tourism Organization.

UNWTO, UNEP, \& WMO. (2008). Climate change and tourism - Responding to global challenges. Madrid: United Nations World Tourism Organization.

UyarRa, M.C., CôtÉ, I.M., GILl, J.A., TINCH, R.R.T., Viner, D., \& WATKInSON, A.R. (2005). Island-specific preferences of tourits for environmental features: implications of climate change for tourism-dependent states. Environmental Conservation, 32(1), 11-19.

VAN ASSELT, M.B.A., \& RIJKENS-KLOMP, N. (2002). A look in the mirror: reflection on participation in Integrated Assessment from a methodological perspective. Global Environmental Change, 12, 167-184.

van Herwerden, L., Griffiths, C.L., Bally, R., Blaine, M., \& du Plessis, C. (1989). Patterns of shore utilization in a metropolitan area: the Cape Peninsula, South Africa. Ocean \& Shoreline Management, 12, 331-346.

VINER, D. (2002). A qualitative assessment of the sources of uncertainty in climate change impacts assessment studies: a short discussion paper. Advances in Global Change Research, 10, 139-151.

Vogel, C., Moser, S.C., KASPeRson, R.E., \& DABelko, G.D. (2007). Linking vulnerability, adaptation, and resilience science to practice: Pathways, players, and partnerships. Global Environmental Change, 17(3-4), 349-364.

WALL, G. (1998). Climate change, tourism and the IPCC. Tourism Recreation Research, 23(2), 65-68.

Walther, G.-R., Post, E., Convey, P., Menzel, A., Parmesan, C., Beebee, T.J.C., et al. (2002). Ecological responses to recent climate change. Nature, 416(6879), 389-395.

Weyant, J., Davidson, O., Dowlatabadi, H., Edmonds, M., GrubB, M., Parson, E.A., et al. (1995). Integrated assessment of climate change: an overview and comparison of approaches and results. Geneva: IPCC, Working Group III.

WiLLIAMS, R. (2007). 17 British tourists injured as ice falls from Arctic glacier. The Guardian.

http://www.guardian.co.uk/travel/2007/aug/10/climatechange.uknews. Accessed 30-07-2008. 
WTTC. (2009). Leading the challenge on climate change. London: World Travel \& Tourism Council.

Yamada, K., NunN, P., Mimura, N., Machida, S., \& Yamamoto, M. (1995). Methodology for the assessment of vulnerability of South Pacific island countries to sea-level rise and climate change. Journal of Environment Engineering, 1, 101-125. 



\section{LIST OF ACRONYMS AND ABBREVIATIONS}

$3 S$

AR4

$\mathrm{BCl}$

CLIA

$\mathrm{CO}_{2}$-eq

CRC Reef

CSIRO

EC

FAR

GCM

GDP

GHG

IA

IFRC

IPCC

KNMI

NGOs

NOAA

OECD

PET

POOT

PTM

SAR

SEG

SOPAC
Sun, Sea and Sand

Fourth Assessment Report

Beach Climate Index

Cruise Lines International Association

Carbon Dioxide equivalent

Cooperative Research Centre

Australia's Commonwealth Scientific and Industrial Research Organisation

European Commission

First Assessment Report

General Circulation Model

Gross Domestic Product

Greenhouse Gases

Integrated Assessment

International Federation of Red Cross

Intergovernmental Panel of Climate Change

Koninklijk Nederlands Meteorologisch Instituut

Non-governmental Organization

National Oceanic and Atmospheric Administration

Organisation for Economic Co-operation and Development

Physiologically Equivalent Temperature

Plan de Ordenación de la Oferta Turística

Plan Territorial de Mallorca

Second Assessment Report

Scientific Expert Group on Climate Change and Sustainable Development

Pacific Islands Applied Geoscience Commission 
182 | List of Acronyms

SRES

Special Report on Emissions Scenarios

$\mathrm{TCl}$

Tourism Climatic Index

TIAS

The Integrated Assessment Society

UN

United Nations

UNEP

United Nations Environment Programme

UNESCO

Nations Educational, Scientific and Cultural Organization

UNFCCC

United Nations Framework Convention on Climate Change

UNWTO

United Nations World Tourism Organization

VSD

Vulnerability Scoping Diagram

WMO

World Meteorological Organization

WTTC

World Travel and Tourism Council

WWF

World Wildlife Fund 


\section{SUMMARY}

In light of the changes occurring in the climate system as a result of human activities, exploring the impacts of these changes on society and the environment has become a necessity. The tourism sector, and especially outdoor activities in coastal areas, is highly sensitive to climate and highly vulnerable to climate change. Despite this vulnerability and tourism's economic, social, environmental and -some would argueclimatic relevance, the sector is lagging behind other research fields in terms of impact assessment. The aim of this thesis is to enhance our understanding of climate change impacts on coastal and marine tourism in Europe and to assist in the vulnerability assessment of the sector.

\section{CHAPTER 1}

Coastal and marine environments are key areas for recreation and tourism in Europe. Since the development of the first coastal resorts, these areas have experienced an exponential growth both in volume of tourists and in diversity of activities. The dependency of these activities on climate is evident. Climate influences the spatial and temporal distribution of tourists, affecting the attractiveness of certain destinations. Weather determines levels of participation in different activities as many of these activities require a minimum value for certain weather parameters to be carried out with comfort and safety (e.g. warm and sunny weather for sunbathing). Climate change has the potential of altering the coastal and marine tourism segment as we know it today. In Chapter 1 it is argued that tourism in coastal zones is highly vulnerable to the impacts of climate change, and this is specially the case for sun, sea and sand (3S) recreation due to its high exposure and sensitivity to weather conditions and because it is one of the most relevant types of tourism in Europe. The objectives of this thesis are therefore to address the different ways by which climate change might affect Europe's tourism in coastal and marine environments and to propose a way of assessing the vulnerability of the sector. These objectives have been approached using four sub-questions:

- What is the state-of-the-art knowledge on climate (change) and tourism, and what are the main knowledge gaps in relation to coastal and marine recreation?

- What are the weather determinants of 35 tourism?

- What consequences will climate change have for the destinations' climate suitability for 35 tourism?

- How can the vulnerability of destinations be assessed? 


\section{CHAPTER 2}

Chapter 2 presents the theoretical and methodological frameworks of this thesis. Complexity theory is used to understand the nature of the climate change and tourism relationship. This relationship is characterized by the uncertainties in the tourism and climate systems and therefore it can not be understood following linear, reductionist approaches. The multiple stakeholders involved in the tourism sector, and the nature of the problem under consideration (climate change effects on tourism) require a transdisciplinary approach that integrates the input from different knowledge fields, from ecology to sociology. Integrated Assessment provides the necessary tools to analyze complex problems and therefore it has been used as an overarching frame for this research. This chapter presents the key principles of Integrated Assessment and finalizes with a short methodological discussion about the remaining chapters of this thesis.

\section{CHAPTER 3}

The Intergovernmental Panel on Climate Change (IPCC) is the most important source of information in the field of climate change. In 2007 the IPCC published in Fourth Assessment Report (AR4), which encompasses the main knowledge on the science, impacts and mitigation of climate change and on adaptation. Chapter 3 reports on they way tourism has been incorporated into the AR4. Based on the analysis it is argued that although tourism has received an increasing attention as compared to previous IPCC reports, many gaps still exist that will need to be incorporated in future publications, especially in relation to regional coverage disparities and the overlooked role of tourism as a driver of climate change.

\section{CHAPTER 4}

The knowledge about climate change impacts on coastal and marine tourism is explored in Chapter 4. Coastal and marine environments are among the most vulnerable to climate change. The chapter reviews the impacts climate change may have on these environments and the extent to which these effects may be translated into impacts on coastal and marine tourism activities. It is argued that while some activities have received most of the attention (mainly sun, sea and sand recreation), for other activities the knowledge about impacts is very scarce or even non-existent. Studies analyzing the greenhouse gas emissions associated with coastal and marine activities are also scarce, a problem linked to the lack of tourism data at the necessary spatial and temporal resolution. Based on this information, a number of recommendations are put forward 
in order to improve and expand the knowledge on the climate change impacts on coastal and marine tourism.

\section{CHAPTER 5}

Chapter 5 explores the issue of weather preferences in sun, sea and sand tourism. Existing literature on weather and tourism highlights the unequal weight of different weather variables for beach tourism, but studies on the subject are still limited. Moreover, analyses of climate change impacts on the Mediterranean emphasize the role of increasing temperature to project a shift in tourism flows within Europe in the coming decades. Based on the information obtained from tourists' responses to a questionnaire, the chapter presents the respondents' views about the role of different weather parameters for beach tourism and about the potential behavioral responses to future climate change impacts. In the chapter it is suggested that the role of high temperature might not be as crucial for beach recreation as it is for other types of tourism and it is argued that some attention should be shifted from impacts on tourists' comfort to other kind of impacts such as the emergence of diseases, water availability and forest fires.

\section{CHAPTER 6}

In Chapter 6 observation techniques are applied to further analyze the behavior of beach users in relation to weather conditions. Using two case studies, one from the Netherlands and one from Spain, the chapter investigates the relation between the density of beach users and weather conditions at different hours of the day. Although in the two cases the temporal distribution of visitors along the day is different, the analysis of the response to weather variables is similar and supports the finding of Chapter 5 about the role of high temperature.

\section{CHAPTER 7}

Major impacts of climate change have been projected for tourism in Europe. Typically, these projections took general tourism activities such as sight-seeing and their climate requirements as their point of reference. The purpose of Chapter 7 is to reassess the impact of climate change by looking specifically at beach tourism in summer, a crucial market segment in Europe and more specifically in the Mediterranean. As beach tourism requires comparatively high temperatures, relatively modest shifts in attractiveness are found. With respect to climate, the Mediterranean is likely to remain Europe's prime region for summer-time beach tourism for at least the next 50 years. It is argued 
that more attention should be paid to other climate change impacts such as sea-level rise or water availability. Environmental quality and diversification of activities should be included in tourism planning deliberations. In non-Mediterranean regions, a strategy may be to focus on short- and medium-distance visitors who can take advantage of the new opportunities for beach tourism, and to explore the merits of seasonal climate forecasting.

\section{CHAPTER 8}

Coastal areas have been identified as belonging to the most vulnerable environments to climate change as a result of cumulative impacts (including temperature change, extreme events and sea-level rise) and high population density. It will be increasingly important for coastal tourism destination managers to understand their vulnerability to climatic changes and to devise appropriate adaptation. Chapter 8 presents a fivestep vulnerability assessment methodology for tourism in coastal areas. The five steps include (1) system analysis, (2) identification of activity and hazard sub-systems, (3) vulnerability assessments for the different sub-systems at risk, (4) integration for the destination as a whole and scenario analysis and (5) communication. The framework is illustrated by an example of how it might be applied to Fiji. It is argued that a consistent methodology, like the one proposed, facilitates vulnerability assessments in a range of coastal destinations, allows comparison to be made of vulnerabilities across different situations, provides a basis for more research into specific adaptation measures and assists destinations to develop a more sustainable tourism industry.

\section{CHAPTER 9}

The Balearic Islands, one of the most important destinations in Spain and in the whole of Europe, are the focus of Chapter 9. In this chapter, a review of the past, present and future of tourism in the Balearic Islands is presented. The islands are already experiencing some challenges in relation to tourism and the exploitation of resources, such as water. Unplanned tourism development is behind some of these water problems. In an era of climate change, however, these problems are likely to be amplified. Due to its location in the Mediterranean (which has been identified as an impact hotspot) and its high dependency in tourism, it is argued that tourism in the Balearic Islands is highly vulnerable to the impacts of climate change. This recognition, however, has not permeated the tourism management institutions. 


\section{CHAPTER 10}

The main results and conclusions from this thesis are summarized in Chapter 10. The main research question underlying this thesis asks in what different ways climate change might affect Europe's tourism in coastal \& marine environments and how the vulnerability of the sector can be assessed. This question is approached by a combination of methodologies and disciplines; integrated research and transdiciplinarity are key elements to this research. Tourism in coastal and marine environments has experienced a continuous growth that is likely to persist in the future. This form of tourism is also one of the most dependent on climate, and this is especially the case for sun, sea and sand tourism. Climate change threatens to shift European 35 tourism as we know it today. It is argued that regarding tourists' comfort the Mediterranean might retain its suitability in the coming 50 years. Improving conditions in source countries and other climate change related pressures in destinations such as water availability may, however, challenge this leading position of the Mediterranean. If coastal destinations want to remain at the forefront of European tourism, they will need to incorporate climate change into their development and management plans. In this respect, it is argued that the adaptation of a destination starts with the assessment of its vulnerability. This thesis is aimed, therefore, at enhancing our understanding of the relationship between climate and tourism and the impacts climate change might pose to the sector in order to facilitate vulnerability assessment and adaptation. 



\section{SAMENVATTING}

Veranderingen in het klimaatsysteem, de rol van de mens daarin en de gevolgen voor mens en milieu zetten aan tot verdere verkenningen. Toerisme, en dan met name activiteiten in de kustgebieden, is zeer klimaatgevoelig en kwetsbaar voor klimaatverandering. Ondanks deze kwetsbaarheid en de grote invloed van het toerisme op economie, maatschappij, milieu en - volgens sommigen - klimaat, loopt de sector achter op het gebied van impact studies. Het doel van dit proefschrift is tweeledig: enerzijds het versterken van ons begrip omtrent de gevolgen van klimaatverandering op het kusttoerisme in Europa, en anderzijds het ondersteunen van de beoordeling van de kwetsbaarheid van de sector.

\section{HOOFDSTUK 1}

Kustgebieden zijn belangrijk voor recreatie en toerisme in Europa. Sinds de ontwikkeling van de eerste badplaatsen hebben deze gebieden een exponentiële groei gerealiseerd, zowel in termen van aantallen toeristen als in termen van diversiteit van activiteiten. Dat deze activiteiten afhankelijk zijn van het klimaat is duidelijk. Klimaat beïnvloedt de aantrekkelijkheid van bestemmingen en daarmee de ruimtelijke en temporele verdeling van toeristen. Het weer bepaalt mede wat toeristen op hun bestemming doen en hoe veel toeristen hieraan deelnemen, omdat veel activiteiten vanwege comfort en veiligheid minimale eisen stellen aan de weersomstandigheden (bijv. warm en zonnig weer om te zonnebaden). Klimaatverandering kan een verandering teweeg brengen in het kusttoerisme zoals we dat vandaag de dag kennen. In hoofdstuk 1 wordt betoogd dat toerisme in kustgebieden kwetsbaar is voor de gevolgen van klimaatverandering. Dit geldt met name voor zee, zon en zand recreatie ( $3 Z$ of strandrecreatie) vanwege de blootstelling aan en kwetsbaarheid voor bepaalde weersomstandigheden, en het feit dit behoort tot de belangrijkste vormen van toerisme in Europa. De doelstellingen van dit proefschrift zijn het belichten van verschillende manieren waarop klimaatverandering effect kan hebben op het toerisme in de Europese kustgebieden, en een voorstel te doen tot een methode om de kwetsbaarheid van de toeristen sector te beoordelen. Deze doelstellingen zijn geoperationaliseerd in vier deelvragen:

- Wat is de meest recente kennis op het gebied van klimaat (verandering) en toerisme, en wat zijn de belangrijkste lacunes in die kennis met betrekking tot het kusttoerisme?

- Welke weersfactoren beïnvloeden het strandtoerisme, en in welke mate? 
- Welke gevolgen zal klimaatverandering hebben voor de klimatologische geschiktheid van bestemmingen voor het strandtoerisme?

- Op welke wijze kan de kwetsbaarheid van bestemmingen worden beoordeeld?

\section{HOOFDSTUK 2}

Hoofdstuk 2 zet de theoretische en methodologische kaders van dit proefschrift uiteen. Met behulp van complexiteitstheorie wordt de relatie tussen klimaatverandering en toerisme geduid. Deze relatie wordt gekenmerkt door grote onzekerheden in de toerisme- en klimaat systemen en kan daarom niet met lineaire, reductionistische benaderingen worden begrepen. De verscheidenheid aan belanghebbenden in de toeristische sector en de aard van het probleem (de gevolgen van klimaatverandering voor het toerisme) vereisen een transdisciplinaire aanpak waarin bijdragen vanuit verschillende kennisvelden worden verenigd. Integrated Assessment biedt het benodigde gereedschap om complexe problemen te analyseren en is daarom gebruikt als overkoepelend kader voor dit onderzoek. Dit hoofdstuk belicht de belangrijkste beginselen van Integrated Assessment en bevat een korte methodologische discussie over het navolgende deel van het proefschrift.

\section{HOOFDSTUK 3}

De intergouvernementele werkgroep inzake klimaatverandering (IPCC) is de belangrijkste bron van informatie op het gebied van klimaatverandering. In 2007 verscheen het vierde rapport van de werkgroep (AR4), met daarin een rapportage over de voornaamste inzichten omtrent het klimaatsysteem, de gevolgen van klimaatverandering, de vermindering van de uitstoot van broeikasgassen, en de aanpassing aan klimaatverandering. Hoofdstuk 3 analyseert de manier waarop het toerisme is opgenomen in het AR4 rapport. De belangrijkste conclusie is dat er duidelijk meer aandacht voor toerisme is ten opzichte van eerdere rapporten, maar dat er nog steeds grote kennislacunes bestaan, waaraan in toekomstige publicaties aandacht zou moeten worden besteed. Zo is er over de gevolgen van klimaatverandering voor toerisme en regionale verschillen die hierin bestaan vrijwel geen kennis beschikbaar, en wordt de bijdrage van het toerisme aan klimaatverandering vrijwel geheel over het hoofd gezien.

\section{HOOFDSTUK 4}

Hoofdstuk 4 geeft een overzicht van de beschikbare kennis over de gevolgen van klimaatverandering voor maritiem- en kusttoerisme. Maritieme - en kustgebieden behoren tot de streken die het meest kwetsbaar zijn voor klimaatverandering. Het hoofd- 
stuk bespreekt de gevolgen die klimaatverandering kan hebben voor de bovengenoemde gebieden, en welke effecten dit vervolgens op het toerisme kan hebben. Een belangrijke conclusie is dat tot op heden vooral aandacht is besteed aan strandtoerisme (3Z), terwijl de gevolgen voor andere activiteiten onderbelicht zijn gebleven of zelfs onbekend zijn. Er zijn ook zeer weinig studies verricht naar de bijdragen van strand- en maritieme activiteiten aan de uitstoot van broeikasgassen, hetgeen samenhangt met een gebrek aan toerismestatistieken met voldoende detail in ruimte en tijd. Deze uitkomsten leiden tot een aantal aanbevelingen om de kennis over de gevolgen van klimaatverandering voor kust- en maritiem toerisme te vergroten en te verbeteren.

\section{HOOFDSTUK 5}

Hoofdstuk 5 bestudeert de weersvoorkeuren van strandtoeristen. Bestaande literatuur, die nog zeer beperkt is, wijst op het grote belang van verschillende weersfactoren voor strandtoerisme. Daarnaast zijn er studies naar de gevolgen van klimaatverandering in Mediterrane gebieden waarin aangeven wordt dat hogere temperaturen kunnen resulteren in een verschuiving van toeristische stromen binnen Europa in de komende decennia. Het hoofdstuk presenteert de resultaten van een empirisch onderzoek onder toeristen. De antwoorden van de respondenten geven een beeld over het belang dat zij hechten aan weersfactoren in het strandtoerisme, en de manier waarop toeristen op klimaatverandering kunnen reageren. De uitkomsten suggereren dat hoge temperaturen minder belangrijk zijn voor strandrecreatie dan voor andere vormen van recreatie. Een implicatie hiervan is dat een deel van de aandacht wellicht moet worden verschoven van gevolgen voor het comfort van toeristen naar andere soorten effecten zoals het ontstaan van ziekten, de beschikbaarheid van water of bosbranden.

\section{HOOFDSTUK 6}

Het gedrag van strandgebruikers onder verschillende weersomstandigheden wordt in hoofdstuk 6 verder geanalyseerd, maar nu met observatietechnieken. Aan de hand van twee case studies, één in Nederland en één in Spanje, belicht het hoofdstuk de relatie tussen de weersomstandigheden en de drukte op het strand op verschillende uren van de dag. De drukte op het strand is gedurende de dag verschillend verdeeld in de twee case studie gebieden, maar de reactie op de verschillende weersfactoren is vergelijkbaar. De uitkomsten ondersteunen de conclusie uit hoofdstuk 5 dat (zeer) hoge temperaturen geen duidelijk negatief effect hebben op het strandbezoek. 


\section{HOOFDSTUK 7}

Projecties van de effecten van klimaatverandering op toerisme in Europa wijzen op grote gevolgen. Doorgaans echter namen deze projecties algemene toeristische activiteiten (zoals sightseeing) en hun klimaateisen als uitgangspunt. Het doel van hoofdstuk 7 is het herbeoordelen van de gevolgen van klimaatverandering voor het strandtoerisme in de zomer, hetgeen een cruciaal marktsegment in Europa en zeker in het Middellandse Zeegebied vormt. Omdat het strandtoerisme relatief hoge temperaturen vereist, worden er bescheiden verschuivingen rondom aantrekkelijkheid gevonden. Voor wat betreft de eisen die toeristen aan het weer stellen, zal het Middellandse Zeegebied Europa's voornaamste regio voor strandtoerisme blijven, in ieder geval voor de komende 50 jaar. Belangrijk is echter om daarnaast meer aandacht te besteden aan andere effecten van klimaatverandering, zoals zeespiegelstijging en de beschikbaarheid van water. Milieukwaliteit en de diversificatie van het aanbod aan toeristische activiteiten moeten worden meegenomen in beleidsplannen omtrent toeristische bestemmingen. Niet-Mediterrane regio's kunnen zich meer richten op bezoekers die op korte- of middellange afstand van de bestemming wonen en dus snel kunnen inspelen op weersomstandigheden voor hun strandbezoek. Ook kunnen deze regio's wellicht hun voordeel doen met weersvoorspellingen op de langere termijn (seizoensvoorspellingen).

\section{HOOFDSTUK 8}

Kustgebieden zijn zeer kwetsbaar voor klimaatverandering, omdat verschillende facetten van klimaatverandering er samenkomen (zoals extreme weersomstandigheden en zeespiegelstijging). Tevens worden deze gebieden vaak gekenmerkt door een hoge bevolkingsdichtheid. Met name voor managers van toeristische bestemmingen aan de kust wordt het steeds belangrijker om de kwetsbaarheid voor klimaatverandering te begrijpen en hiervoor passende aanpassingen te beramen. Hoofdstuk 8 presenteert in vijf stappen een methodologie om de kwetsbaarheid voor klimaatverandering van het kusttoerisme in kaart te brengen. De vijf stappen betreffen (1) systeem analyse, (2) identificatie van activiteit- risico combinaties, (3) het beoordelen van de kwetsbaarheid van verschillende activiteit- risico combinaties, (4) beoordeling van de kwetsbaarheid van de bestemming als geheel, en scenario-analyse en (5) communicatie. Als voorbeeld is de methodologie toegepast op Fiji. Betoogd wordt dat een coherente methode, zoals de voorgestelde, de beoordeling van kwetsbaarheden zal vergemakkelijken en het vergelijken van verschillende bestemmingen rondom kwetsbaarheid mogelijk maakt. Tevens biedt deze methodologie aanknopingspunten voor de ontwikkeling van aanpassingsmaatregelen, en kan zij helpen om binnen bepaalde bestemmingen een duurzamere toeristische bedrijfstak tot stand te brengen. 


\section{HOOFDSTUK 9}

De Balearen, één van de belangrijkste toeristische bestemmingen in Spanje en zelfs Europa, zijn het onderwerp van hoofdstuk 9. Dit hoofdstuk geeft een overzicht van verleden, heden en toekomst van het toerisme in de Balearen. Mede door ongeplande toeristische ontwikkelingen staan de eilanden nu al voor een aantal uitdagingen met betrekking tot het toerisme en het gebruik van hulpbronnen, zoals water. Naar het zich laat aanzien, zal klimaatverandering deze problemen versterken. De Balearen liggen in de Middellandse Zee (die is geïdentificeerd als een hotspot van klimaateffecten) en zijn in hoge mate afhankelijk van het toerisme, wat de toeristische sector op de eilanden zeer kwetsbaar maakt voor de gevolgen van klimaatverandering. Dit wordt echter nog niet door de toeristische managers onderkend.

\section{HOOFDSTUK 10}

De belangrijkste resultaten en conclusies van dit proefschrift zijn samengevat in hoofdstuk 10. De belangrijkste onderzoeksvraag die ten grondslag ligt aan dit proefschrift is op welke verschillende manieren klimaatverandering van invloed kan zijn op het toerisme in de Europese kustgebieden, en hoe de kwetsbaarheid van de sector kan worden beoordeeld. Deze vraag is benaderd vanuit een combinatie van methodieken en disciplines; geïntegreerd onderzoek en transdisciplinariteit zijn belangrijke uitgangspunten voor dit onderzoek. Toerisme in kustgebieden is gestaag gegroeid, een trend die zich in de toekomst waarschijnlijk zal doorzetten. Strand- en maritiem toerisme zijn zeer afhankelijk van het klimaat, met name het strandtoerisme, en dreigt daarom grote gevolgen te ondervinden van klimaatverandering. In dit proefschrift wordt geconcludeerd dat het Middellandse Zeegebied de komende 50 jaar waarschijnlijk aan de klimaateisen van de strandtoerist zal kunnen blijven voldoen. Klimaatverandering kan de leidende positie van het Middellandse Zeegebied echter wel degelijk onder druk zetten, door de negatieve gevolgen voor onder meer de waterbeschikbaarheid en de volksgezondheid in de regio, en door de verbeterende omstandigheden in de meer noordelijk gelegen landen waar de toeristen zelf vandaan komen. Als kustbestemmingen in de voorhoede van het Europese toerisme willen blijven opereren, zullen zal klimaatverandering geïntegreerd moeten worden in ontwikkelings- en beheerplannen. In dit proefschrift wordt aangevoerd dat de aanpassing van toeristische bestemmingen begint met een beoordeling van de kwetsbaarheid. De in dit proefschrift ontwikkelde methode draagt bij aan het beoordelen van deze kwetsbaarheid en het nadenken over aanpassingsmogelijkheden. 



\section{RESUMEN}

A la luz de los cambios que están ocurriendo en el sistema climático como resultado de las actividades humanas, la investigación de los impactos de estos cambios en la sociedad y el medio ambiente se ha convertido en una necesidad. El sector turístico y las actividades al aire libre, especialmente en las zonas costeras, son altamente sensibles al clima y muy vulnerables al cambio climático. A pesar de esta vulnerabilidad y la gran relevancia económica, social, ambiental y -según algunos autores-climática del turismo, el sector se encuentra muy por detrás de otros campos de investigación en relación a la evaluación de impactos. El objetivo de esta tesis es mejorar nuestra comprensión sobre los impactos del cambio climático en el turismo costero y marino en Europa y contribuir en la evaluación de la vulnerabilidad del sector.

\section{CAPÍtULO 1}

Los ecosistemas costeros y marinos son áreas clave para las actividades de recreo y el turismo en Europa. Desde la creación de los primeros hoteles y centros turísticos en zonas costeras, tanto el volumen de turistas como la diversidad de actividades en estas áreas han experimentado un crecimiento exponencial. La dependencia de estas actividades en el clima es evidente. El clima influye en la distribución espacial y temporal de los turistas, afectando al atractivo de determinados destinos. El tiempo condiciona los niveles de participación en diferentes actividades ya que muchas de ellas requieren un valor mínimo en determinadas variables meteorológicas para poder desarrollarse en condiciones de confort y seguridad (por ejemplo, clima cálido y soleado para tomar el sol). El cambio climático tiene el potencial de alterar el turismo en zonas costeras tal y como lo conocemos hoy. En el capítulo 1 se afirma que el turismo en zonas costeras es altamente vulnerable a los impactos del cambio climático, especialmente en el caso del turismo de sol y playa debido a su alta exposición y sensibilidad a las condiciones climáticas y porque es uno de los tipos de turismo más importante en Europa. Los objetivos de esta tesis son, por lo tanto, analizar las diferentes formas en que el cambio climático podría afectar al turismo en Europa en los ambientes costeros y marinos y proponer una forma de evaluar la vulnerabilidad del sector. Estos objetivos han sido abordados mediante las siguientes preguntas:

- ¿Cuál es el estado del arte sobre la relación entre el clima (y el cambio climático) y el turismo, y cuáles son las principales lagunas de conocimiento en relación al turismo en el medio costero y marino?

- ¿Cuáles son los factores climáticos que determinan el turismo sol y playa? 
- ¿Qué consecuencias tendrá el cambio climático para la aptitud de los destinos para la práctica del turismo de sol y playa?

- ¿Cómo se puede evaluar la vulnerabilidad de los destinos frente al cambio climático?

\section{CAPÍtULO 2}

En el capítulo 2 se presenta el marco teórico y metodológico de esta tesis. La Teoría de la Complejidad se utiliza para comprender la naturaleza de la relación entre cambio climático y turismo. Esta relación no puede ser entendida siguiendo modelos lineales y reduccionistas ya que se caracteriza por la incertidumbre a cerca del sistema turístico y el sistema climático. Los múltiples actores involucrados en el sector del turismo y la naturaleza del problema en cuestión (los efectos del cambio climático en el turismo) requieren un enfoque multidisciplinario que integre las aportaciones de diferentes áreas de conocimiento, desde la ecología hasta la sociología. Integrated Assessment (Evaluación Integral) proporciona las herramientas necesarias para analizar problemas complejos y por lo tanto se ha utilizado como un marco general para esta investigación. Este capítulo presenta los principios fundamentales de la Evaluación Integral y finaliza con una breve discusión metodológica sobre el resto de los capítulos que integran esta tesis.

\section{CAPÍTULO 3}

El Grupo Intergubernamental de Expertos sobre el Cambio Climático (IPCC en sus siglas en inglés) es la fuente principal de información en el ámbito del cambio climático. En 2007, el IPCC publicó el Cuarto Informe de Evaluación (AR4), que incorpora los principales conocimientos sobre la ciencia, los impactos y mitigación del cambio climático y la adaptación al mismo. En el capítulo 3 se presenta la forma en que el turismo se ha incorporado en el AR4. Basándose en el análisis realizado del informe se sostiene que, aunque el turismo ha recibido una mayor atención en comparación con informes anteriores del IPCC, aún existen muchos aspectos que deben ser incorporados en futuras publicaciones, especialmente en relación con la cobertura de distintas regiones y el papel del turismo como causante del cambio climático.

\section{CAPÍtULO 4}

El conocimiento sobre los impactos del cambio climático en el turismo en ámbitos costeros y marinos se explora en el capítulo 4 . Los ambientes costeros y marinos se encuentran entre los espacios más vulnerables al cambio climático. El capítulo revisa 
los efectos que el cambio climático puede tener sobre estos ambientes y en qué medida estos efectos se han traducido o se traducirán en impactos sobre las actividades de recreo. En el capítulo se indica que mientras que algunas actividades han recibido la mayor parte de la atención (principalmente el turismo costero de sol y playa), para otras actividades los conocimientos acerca de los impactos es muy escasa o incluso inexistente. Los estudios que analizan las emisiones de gases de efecto invernadero asociadas con el turismo costero y marino también son escasos, un problema vinculado a la falta de datos sobre el turismo con la resolución espacial y temporal necesaria. Basándose en esta información, en el capítulo se presentan una serie de recomendaciones con el fin de mejorar y ampliar los conocimientos sobre los impactos del cambio climático en el turismo costero y marino.

\section{CAPÍtULO 5}

El capítulo 5 analiza las preferencias climáticas para el turismo de sol y playa. Las publicaciones existentes que investigan la relación entre el clima y el turismo ponen de relieve la diferente importancia de las distintas variables meteorológicas para el turismo de sol y playa, pero este tipo de estudios son todavía limitados. Por otra parte, los análisis de los impactos del cambio climático en el Mediterráneo destacan el papel del aumento de la temperatura como causante de un cambio en los flujos de turistas en Europa en las próximas décadas. Basándose en la información obtenida de un cuestionario realizado a un grupo de turistas, el capítulo presenta los puntos de vista de los encuestados sobre el papel que desempeñan las distintas variables climáticas para el disfrute de actividades de sol y playa y los posibles cambios de comportamiento de dichos turistas frente a algunos de los impactos del cambio climático. En el capítulo se indica que el papel de las temperaturas altas podría no ser tan crucial para las actividades de recreo de sol y playa como lo es para otros tipos de turismo y se argumenta que, a parte de analizar los impactos relacionados con los aspectos de confort de los turistas, en el futuro se debe prestar mas atención a otro tipo de impactos como la aparición de enfermedades, la disponibilidad de agua y los incendios forestales.

\section{CAPÍtULO 6}

En el capítulo 6 se aplican técnicas de observación para analizar más en profundidad el comportamiento de los usuarios de la playa en relación a las condiciones climáticas. Por medio del análisis de dos destinos costeros, uno en los Países Bajos y otro en España, en el capítulo se investiga la relación entre la densidad de usuarios de la playa y las condiciones meteorológicas. Aunque la distribución temporal de los visitantes a lo largo del día es diferente para cada uno de los casos, el análisis de la respuesta de los 
visitantes a los factores meteorológicos es similar y apoya la conclusión del capítulo 5 sobre el papel de las altas temperaturas.

\section{CAPÍtULO 7}

Los estudios existentes que investigan los impactos del cambio climático en el turismo en Europa indican que la magnitud de estos impactos puede ser muy importante. Normalmente, estas proyecciones han estado basadas en los requerimientos climáticos de actividades turísticas genéricas tales como la visita a monumentos. El propósito del capítulo 7 es reevaluar el impacto del cambio climático centrándose específicamente en el turismo de sol y playa en verano, un segmento de mercado crucial en Europa y más concretamente en el Mediterráneo. Debido a que el turismo de sol y playa requiere temperaturas relativamente altas, los cambios en el atractivo turístico provocados por el aumento de temperaturas se espera que sean moderados. Con respecto al clima, es probable que el Mediterráneo siga siendo durante el verano la principal región de Europa para el turismo de sol y playa al menos durante los próximos 50 años. Aunque estos resultados reducen la magnitud de los impactos del cambio climático en el turismo de sol y playa proyectados por otros estudios, se afirma que se debe prestar más atención a otros efectos del cambio climático, como la elevación del nivel del mar o la disponibilidad de agua. La calidad en los recursos medioambientales y la diversificación de las actividades deben ser incluidas en la planificación turística. En las regiones Europeas que no pertenecen a la zona Mediterránea, estrategias para maximizar cualquier posible beneficio derivado del cambio climático pueden consistir en medidas centradas en atraer visitantes de distancias cortas y medias y explorar las posibilidades de los pronósticos climáticos estacionales, todo ello con el objetivo de aprovechar las nuevas oportunidades para el turismo de sol y playa.

\section{CAPÍtulo 8}

Las zonas costeras han sido identificadas como uno de los entornos más vulnerables al cambio climático como resultado de la elevada densidad de población así como de múltiples impactos (incluido el cambio de temperatura, los fenómenos extremos y la elevación del nivel del mar). Por lo tanto para los gerentes de los destinos turísticos costeros será cada vez más importante entender su vulnerabilidad al cambio climático y diseñar las medidas de adaptación necesarias. El capítulo 8 presenta una metodología de evaluación de la vulnerabilidad del turismo costero frente al cambio climático basada en cinco pasos. Los cinco pasos incluyen (1) análisis sistémico del destino, (2) identificación de los sub-sistemas 'actividad-riesgo', (3) evaluación de la vulnerabilidad de los diferentes sub-sistemas en situación de riesgo, (4) integración de los análisis 
individuales para el destino en su conjunto y análisis de escenarios y (5) comunicación de resultados. La metodología se ilustra con un ejemplo de cómo podría aplicarse a Fiji. Se afirma que una metodología coherente como la propuesta, facilita la evaluación de la vulnerabilidad en una variedad de destinos costeros, permite la comparación de vulnerabilidades en diferentes contextos, proporciona una base sólida para el desarrollo de nuevas investigaciones sobre medidas específicas de adaptación y ayuda a los destinos a desarrollar una industria turística más sostenible.

\section{CAPÍtULO 9}

El capítulo 9 se centra en las Islas Baleares, uno de los destinos más importantes en España y en el conjunto de Europa. En este capítulo se ofrece una revisión del pasado, presente y futuro del turismo en las Islas Baleares, prestando una atención especial a las implicaciones sobre el destino de algunos de los temas discutidos en esta tesis. Las Islas Baleares ya están experimentando algunos desafíos en relación al turismo y la explotación de los recursos, como el agua. El desarrollo del turismo no planificado está detrás de algunos de estos problemas. Sin embargo, y como consecuencia del cambio climático, se espera que estos problemas se acentúen. Debido a su ubicación en el Mediterráneo (que ha sido identificado como un área de gran impacto) y su alta dependencia en el turismo, en el capítulo se argumenta que el turismo en las Islas Baleares es muy vulnerable a los impactos del cambio climático. Este reconocimiento, sin embargo, aun no ha permeado lo suficiente en las instituciones de gestión turística.

\section{CAPÍTULO 10}

Los principales resultados y conclusiones de esta tesis se resumen en el capítulo 10. El objetivo principal que subyace a esta tesis es el de investigar las diferentes formas en que el cambio climático podría afectar al turismo en Europa en los ambientes costeros y marinos y proponer una forma de evaluar la vulnerabilidad del sector. Este objetivo es abordado usando una combinación de metodologías y disciplinas; la investigación integral y transdisciplinar es clave en esta tesis. El turismo en los ambientes costeros y marinos ha experimentado un crecimiento continuo que es probable que persista en el futuro. Las actividades turísticas en estos ambientes son también unas de las más dependientes del clima, y esto es especialmente el caso del turismo de sol y playa. El cambio climático amenaza con cambiar el turismo de sol y playa en Europea tal y como lo conocemos hoy en día. Se argumenta que en lo que se refiere al confort de los turistas el Mediterráneo podría mantener su idoneidad climática durante la menos los próximos 50 años. La mejora de las condiciones en los países de origen y otros efectos en los destinos relacionados con el cambio climático tales como la disponibilidad de 
200 | Resumen

agua podrían, sin embargo, desafiar esta posición de liderazgo de los países del Mediterráneo. Si los destinos costeros quieren permanecer en la vanguardia del turismo Europeo, será necesario que incorporen el cambio climático a sus planes de gestión y desarrollo. En este sentido, se sostiene que la adaptación de los destinos se inicia con la evaluación de su vulnerabilidad. Esta tesis tiene como objetivo, por lo tanto, mejorar nuestra comprensión de la relación entre el clima y el turismo y de los impactos que el cambio climático puede generar en el sector a fin de facilitar la evaluación de la vulnerabilidad y la adaptación. 


\section{ACKNOWLEDgements / Agradecimientos}

Completing this thesis has been a very rewarding work no absent of challenges. Many people has contributed to overcome those challenges during the four years that this adventure has lasted, and many more played a role, in one way or another, in the years before I arrived to Maastricht. Therefore, I would like to thank all of them, including those not mentioned here by name.

I am deeply indebted to my promotors Prof. Dr. Pim Martens and Dr. Bas Amelung. They are the ones who believed I could do this thesis in the first place and provided their support through the whole process. Having Bas as daily supervisor has been a great experience; near him I have learnt about climate change and tourism, I have been involved in exciting and challenging projects and I have met the rest of the scientists in the field. I would also like to thank the rest of the ICIS team for the interesting discussions and support; I can say with confidence that I have learnt something from each of you. Thanks specially to Anja and Annet for helping with the logistics of the project and keeping ICIS up and running as smoothly as it does. And these acknowledgements would not be complete without thanking Astrid. Together we have worked and laughed, and shared many moments of happiness (and some of frustration) both at the personal and at the professional level, so I would like to thank her for the great time spent together.

I would like to take this chance to thank other people who have contributed to my development as a researcher. First of all, I would like to thank Rik Leemans for giving me an opportunity to develop my interest on climate change and tourism in a rewarding and challenging environment while I was studying at Wageningen University. During the last years I have been able to collaborate, and in some cases visit at their institutions, a number of excellent researchers. I am indebted to Susanne Becken, Belén Gómez Martín, Darryn McEvoy and Daniel Scott for their time spent sharing with me their knowledge and experience. Also, I would like to thank sincerely all the members of the promotion committee for their critical review on my work. To NWO and the Vulnerability, Adaptation and Mitigation (VAM) programme I would like to thank the financial support to this project.

My time in Maastricht would not have been the same without the friends I have met here. With Anna, Nieves and Lorena I spent much time discovering Maastricht. Lorena also contributed to different parts of this thesis, which without her I would have never been able to carry out. With Cinzia I have shared 'the Maastricht PhD experience'; thank you for the uncountable hours spent together. In Diana I found a refreshing breeze of 'aire Canario'; I thank her for the 'table for two' sessions which offered loads of good moments and an alternative to the sandwich in front of the computer. 
I lived in Sterreplein since I arrived to Maastricht and the 'sterres' have become my family and friends through this years. Bart, Dienne, Marjolein, Theun, Tia, Sammie and previous sterres, thank you for the moments spent together and for the moments still to come. Thanks to you Sterreplein does not feel as a place to live, but as my home.

Esta tesis cierra un capítulo que comenzó hace cuatro años cuando vine a Maastricht a realizar este proyecto de investigación. Sin embargo, y como en cualquier libro, este capítulo es la continuación de una historia que se ha escrito en su mayoría en Madrid, con algunas secciones en diversas partes del mundo. Son muchas las personas que han contribuido ha escribir esta historia. Mencionarlos a todos seria casi imposible, aunque seguramente todos y cada uno de ellos lo merecen. Un capítulo importante lo compone mí tiempo en Forestales y las muchas horas compartidas con Bárbara, Camino, Edu, Guille, Nacho, Patricia B., Patricia P., Rubén, y muchos más. Esta tesis se la dedico con mucho cariño a Javi, un buen amigo al que siempre recordaré. A Leticia le agradezco su paciencia y su ayuda con los programas de GIS y a Valle sus sabios consejos. También agradezco a Fernando su inagotable interés en descubrir y compartir y seguir a mi lado después de todo este tiempo, y a Jorge, Juan, Mario, Olga, Pablo y resto del equipo por el tiempo dedicado juntos a descubrir rincones de Madrid y de España. Con Mónica casi se pude decir que crecí y a nadie que la conozca le sorprenderá leer que me siento extremadamente afortunado por tenerla a mi lado aunque estemos en países distintos.

Un periodo que definió de manera definitiva mi camino hasta el día de hoy es el tiempo que pasé en Wageningen. Bárbara, Gonzalo, Inma, Jara, Lourdes, Marta, Noe, Paloma... gracias por hacer de Wageningen un lugar donde es posible pasar dos años, compartiendo momentos en la cocina de alguno de los quintos. Gracias también por ser la mejor compañía imaginable en los viajes fuera de Wageningen: Islandia, Polandia, Dinamarca, etc. Con Lucia he tenido la suerte de compartir viajes y muchos buenos momentos y espero poder seguir haciéndolo en el futuro.

Benoît ça fait déjà cinq ans que nous avons commencé à écrire un chapitre ensemble et j'attends avec impatience les prochaines pages qui nous restent à écrire. Merci d'être venu aux Pays bas et pour être à mes côtés tout ce temps.

Finalmente me gustaría agradecer el apoyo de toda mi familia: abuelos, tíos, primos, etc. Cuando era niño jugaba con mi abuela a imaginar que sería de mayor; aunque nada de lo que imaginamos se ha cumplido de momento, estoy seguro que estaría muy orgullosa del resultado... esta tesis también está dedicada a ella. Por último, ya solo me queda mencionar a mis cuñados, Álvaro y Angélica, mis hermanos Ana y Jorge, mis sobrinos Lucas y Lucia y por supuesto a mis padres, Angel y Victoria, a quienes les debo el haber llegado donde estoy. A ellos les agradezco su apoyo, su fuerza y su amor. Ellos han luchado y siguen luchando cada día por mí y por el resto de la familia; ellos son mi punto de referencia y mi modelo a seguir. Por todo esto, esta tesis está, por encima de todo, dedicada a mis padres. 


\section{CURRICULUM VITAE}

Alvaro Moreno was born in Madrid on December $20^{\text {th }} 1979$. He studied Forest Engineering at Universidad Politécnica de Madrid (Spain). During the years he spent studying Forestry, he traveled and volunteered for different NGOs and other organizations in USA and Venezuela. His end-of-studies project fo-

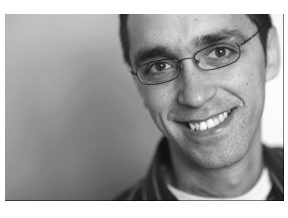
cused on the restoration of a hiking trail to improve its accessibility and education in the North of Spain and this was his first contact with the tourism field. After concluding his studies in Madrid, Alvaro enrolled as a student in Environmental Sciences at Wageningen University (The Netherlands) in 2003. His multiple interests, following courses on tourism, remote sensing and GIS, water management developing countries and, of course, environmental sciences, led him in 2005 to write his Master thesis on an exploration of the impacts of climate change on tourism in Europe.

In September 2005 Alvaro started his PhD at the International Centre for Integrated assessment and Sustainable development (ICIS, Maastricht University). Funded by the Nederlandse Organisatie voor Wetenschappelijk Onderzoek (NWO), his project explored the vulnerability to climate change of the tourism sector in coastal areas of Europe. This thesis is the result of this research project.

Next to his PhD, Alvaro has been actively involved in several other research projects, including the European funded PESETA project on the economic impacts of climate change in different European sectors or the CLIMAS project on the assessment of impacts in Asturias (Spain).

In the field of education, Alvaro has worked as lecturer for the United Nations World Tourism Organization (UNWTO) capacity building program in Mexico and in different universities and international congresses (both in Spanish and English). Alvaro also teaches in several courses at the University College Maastricht on topics related to sustainable development, globalization and global environmental change. 



\section{SENSE CERTIFICATE}

\section{SENSE}

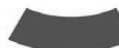

Netherlands Research School for the

Socio-Economic and Natural Sciences of the Environment

\section{CERTIFICATE}

The Netherlands Research School for the Socio-Economic and Natural Sciences of the Environment

(SENSE), declares that

\section{Alvaro Moreno Sanchez}

Born on: 20 December 1979 at: Madrid, Spain

has successfully fulfilled all requirements of the Educational Programme of SENSE.

\section{Place: Maastricht Date: 19 March 2010}

the Chairman of the

SENSE board

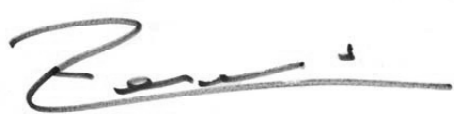

Prof. dr. R. Leemans the SENSE Director

of Education

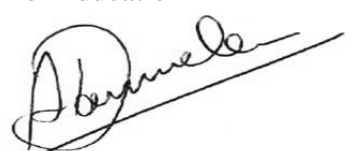

Dr. A. van Dommelen 


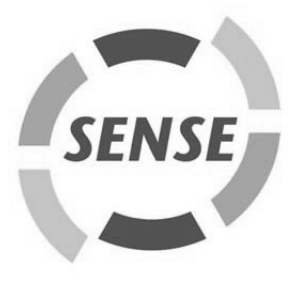

The SENSE Research School declares that Mr. Alvaro Moreno Sanchez has successfully fulfilled all requirements of the Educational PhD Programme of SENSE with a work load of 45 ECTS, including the following activities:

\section{SENSE PhD courses:}

- Environmental Research in Context

- Research Context Activity: "Revitalizing and developing dedicated website www.e-CLAT.org, for Experts in Climate Change and Tourism"

- Integrated Assessment of Global Environmental Change: Causes and Responses

\section{Other Phd courses:}

GIS Techniques in Environmental Sciences, Roskilde University, Denmark A Guided Tour of Essential Statistical Methods for Environmental Scientists, Roskilde University, Denmark

Writing Scientific English

Tourism and International Cooperation for Development, Organized by UNWTO and University of Brighton, UK

Research and Management Skills:

- Training period and research collaboration, Lincoln University, New Zealand

\section{Oral Presentations:}

12th International Symposium on Society and Resource Management (ISSRM), 6 June 2006, Vancouver, Canada 5th International Coastal and Marine Tourism Congress, 19 September 2007, Auckland, New Zeeland

- SENSE / EPCEM Symposium, 10 October 2008, Wageningen, The Netherlands

- $10^{\text {th }}$ International Coastal Symposium, 17 April 2009, Lisbon, Portugal

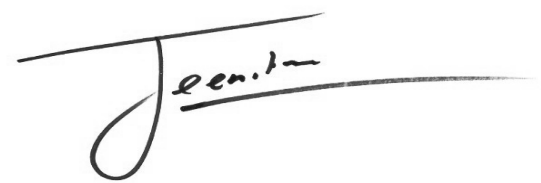

Mr. J. Feenstra

SENSE Coordinator PhD Education and Research 